\title{
Transformation und Pilusbiogenese: zwei voneinander unabhängige Systeme in Acinetobacter sp. BD413
}

\author{
Dissertation \\ zur Erlangung des Doktorgrades \\ der Mathematisch-Naturwissenschaftlichen Fakultäten \\ der Georg-August-Universität zu Göttingen
}

\author{
vorgelegt von \\ Olivia Gohl \\ aus Goslar
}

Göttingen 2002 
Die vorliegende Arbeit wurde am I nstitut für Mikrobiol ogie und Genetik der GeorgAugust-Universität zu Göttingen angefertigt.

D7

Referentin: Priv. Doz. Dr. B. Averhoff

Korreferent: Prof. Dr. G. Gottschalk

Tag der mündl ichen Prüfung: 01.11.2002 


\section{Inhaltsverzeichnis}

$\begin{array}{ll}\text { 1. EINLEITUNG } & 1\end{array}$

2. Material Und Methoden

2.1 Organismen und Plasmide $\quad 8$

2.2 Zellanzucht $\quad 14$

2.2.1 Nährmedien 14

2.2.1.1 Mineral medium 14

2.2.1.2. Komplexmedien 15

2.2.2. Antibiotika 15

2.2.3 Zellanzucht 16

2.2.4 Messung der optischen Dichte 16

2.2.5 Reinheitskontrolle und Stammaltung 16

2.3 Standardtechniken für das Arbeiten mit DNA 17

2.3.1 Isolierung von Plasmiden 17

2.3.2 Isolierung chromosomal er DNA mittels DNA-Extraktionskit 18

2.3.3 Präparative I solierung chromosomaler DNA aus Acinetobacter sp. $\quad 19$

2.3.4 Lagerung von DNA 19

2.3.5 Schnel le Isolierung von Plasmiden aus E. coli ('Cracking') 20

2.3.6 Gelelektrophorese von DNA imAgarosegel 20

2.3.7 Färbung und Fotografie von DNA in Agarose oder Polyacrylamidgelen 21

2.3.8 Isolierung von DNA aus Agarosegelen 21

2.4 Enzymatische M odifikationen von DNA 22

2.4.1 Restriktionsverdau von DNA 22

2.4.2 Herstel lung von stumpfen DNA-Enden 22

2.4.3 Dephosphorylienung von DNA 22

2.4.4 Ligation von DNA-Fragmenten 23

2.4.5 N-terminale Sequenzierung von Proteinen 23

2.4.5.1 Enzymatische Spaltungen von Proteinen im Polyacrylamidge 23

2.4.5.2 "in situ"-Verdau membrangebundener Proteine (PATTERSON 1994) 24

2.5 DNA-A mplifikation durch die Polymerase-Kettenreaktion 25

2.6 SOUTHERN-H ybridisierung $\quad 26$

2.6.1 Markierung von DNA mit Digoxigenin-11-dUTP 26 
2.6.2 Übertragung von DNA auf Nylonmembranen durch Vakuumblot 27

2.6.3 Hybridisierung und Detektion 28

2.7 Transfer von DNA in E. coli und Acinetabacter sp.

2.7.1 DNA-Übertragung durch Konjugation ('spot mating') 30

2.7.2 DNA-Übertragung durch Transformation 30

2.7.2.1 Herstellung kompetenter $E$. coli-Zellen (INOUE et al. 1990) 30

2.7.2.2 Transformation von $E$. coli und Blau-Weiß-Selektion 31

2.7.2.3 Transformation von Acinetobacter $\mathrm{sp}$. 32

2.8 Standardtechniken für das A rbeiten mit Proteinen 33

2.8.1 Proteinbestimmung nach BRADFORD (1976; modifiziert) 33

2.8.2 Auftrennung von Proteinen über SDS-Polyacrylamidgel el ektrophorese 33

2.8.3 Native Gradienten-PAGE (SCHÄGGER \& VoN J AGOW 1991; mod.) 35

2.8.4 Zweidimensionale Auftrennung von Proteinen 36

2.8.5 Größenbestimmung von Proteinen 37

2.8.6 Färbung von Proteinen mit Coomassie (WEBER \& OSBORN 1969) 37

2.8.7 Silber-Färbung (BLUM et al. 1987; modifiziert) 38

2.8.8 Konzentrierung von Proteinen $\quad 39$

2.8.9 Dialyse von Proteinlösungen 39

2.9 WESTERN-Blotting $\quad 40$

2.9.1 Elektrophoretischer Transfer von Proteinen denaturierender Gele $\quad 40$

2.9.2 Elektrophoretischer Transfer von Proteinen nativere Gele 41

2.10 Ü berexpression und Anreicherung von Fusionsproteinen 41

2.10.1 Überexpression von MalE-Fusionsproteinen $\quad 41$

2.10.2 Aufreinigung von MalE-Fusionsprotein über Affinitätschromatographie 42

2.10.3 Aufreinigung von His-Tag-Fusionspoteinen 43

2.10.4 Denaturierung von Einschl ußkörpern und Renaturierung 44

2.10.5 Spaltung von Fusionsproteinen mit demFaktor $\mathrm{Xa}$

2.11 Immunologische M ethode $\quad 45$

2.11.1 Herstellung polyklonaler Antiseren 45

2.11.2 Immunodetektion von Proteinen mittels Chemilumineszenz 45

2.12 Enzymaktivitätstests $\quad 46$

2.12.1 Bestimmung der $\square$-Galaktosi daseaktivität 46

2.12.2 Bestimmung der NADH-Dehydrogenase-Aktivität 47

2.13 Isolierung von M embranen und Proteinen $\quad 48$

2.13.1 I solierung der dicken und dünnen Pili 48

2.13.2 Präparation von Gesamt-Membranen 49 
2.13.3 I sol ierung von cytoplasmatischer und äußerer Membran

2.13.4 Solubilisierung der gewaschenen Membranen

2.13.5 Chromatographische Methoden

51

2.13.5.1 Anionenaustausch-Chromatographie an Q-Sepharose

52

2.13.5.2 Gelfiltration mit Sephadex S-300

53

2.14 R einigung humaner E rythrocyten

54

2.15 E lektronenmikroskopische Untersuchungen

54

2.15.1 Herstellung von Kohle-Trägerfolien

54

2.15.2 Negativkontrastierung

55

2.15.3 Elektronemikroskopische Abbildung

55

2.15.4 Einbettung von Zellen

55

2.15.5 Ultramikrotomie

2.17 Bezugsquellen für Chemikalien, B iochemikalien und E nzyme

3. EXPERIMENTE UND ERGEBNISSE

3.1 Untersuchung der Beteiligung von c-PH B an der Transformation

3.1.1 Unterbrechung der PHB-Synthase in Acinetobacter sp. ADP23

3.1.2 Untersuchung der phaC-Mutante B100 auf Speicherstoff-Synthese

61

3.1.3 Transformationstest der phaC-Mutante B100

3.2 Ü berexpression und R einigung von Proteinen

3.2.1 Überexpression und Reinigung des Kompetenzproteins ComC

3.2.2 Untersuchungen zur spezifischen Bindung der Anti-ComC-Antikörper

3.2.3 Überexpression und Reinigung des Kompetenzproteins ComA

3.2.4 Untersuchungen zur spezifischen Bindung der Anti-ComA-Antikörper

3.3.1 I dentifizierung des comEA-Gens in Acinetobacter sp. BD413

3.3.2 Unterbrechung des Kompetenzgens comEA aus Acinetobacter sp. BD413 72

3.3.3 Transformationstest der comEA-M utanteT100 74

3.3.4 Transkriptionale Regulation von comEA 76

3.4 Untersuchungen zur L okalisation und F unktion von C omE A 79

3.4.1 Überexpression und Aufreinigung von ComEA 79

3.4.2 Untersuchungen zur spezifischen Bindung der Anti-ComEA-Antikörper 81

3.4.3Steigerung der Expressionsratevon comEA 82

3.4.4 Detektion von ComEA in Zelllysaten 84

3.4.5 Lokalisation von ComEA 85 
3.4.6 DNA-Bindestudien mit ComEA 88

3.5 Identifizierung von Protein/Protein-Interaktionen $\quad 90$

3.5.1 Solubilisierung von Zellmembranen $\quad 91$

3.5.2 Reinigung des gelösten ComP-Komplexes 94

3.5.3 Auftrennung des ComP-Komplexes in einer 2D-Gelelektrophorese $\quad 97$

3.5.4 Elektronenmikroskopische Darstellung des ComP- Komplexes 98

3.5.5 Vergleich der ComP-Komplexgröße nach Behandlung mit Triton-X 100100

3.6 Charakterisierung der Pili von Acinetobacter sp. BD413 103

3.6.1 Reinigung der Pilusstrukturen und N-terminal e Sequenzierung 103

3.6.2 Klonierung der Pilusstrukturgene 105

3.6.3 Unterbrechung der Pilusgene von Acinetobacter sp. ADP239 107

3.6.4 Generierung einer Doppel mutante 109

3.6.5 Untersuchung der Zel loberfläche nach Unterbrechung der Pilusgene $\quad 113$

3.6.6 Physiologische Untersuchung der Pilus-Mutanten 115

3.6.6.1 Transformationstest der Pilus-Mutanten 116

3.6.6.2 Test auf gleitende Bewegung der Pilus-Mutanten 117

3.6.7 Molekulare Charakterisierung des dicken Pilus $\quad 120$

3.6.7.1 Untersuchung der A minosäuresequenz der $28 \mathrm{kDa}$-Untereinheit $\quad 120$

3.6.7.2 Analyse des filA-Lokus $\quad 124$

3.6.7.3 Unterbrechung und Deletionen der ORFs imfil-Cluster 125

3.6.7.4 Untersuchung auf Pilusbiogenese der Mutantenstämme 130

3.6.7.5 Komplementation der Mutantenstämme K101 und K102 132

3.6.8 Charakterisienung des dünnen Pilus 135

3.6.8.1 Untersuchung der Untereinheit des dünnen Pilus 135

3.6.8.2 Untersuchung der genomischen Lokalisation von fimA 137

3.6.8.3 Elektronenmikroskopische Darstellung der dünnen Pili 139

3.6.9 Regulation der Expression der Pilusgene filA und fimA 140

4. DISKUSSION 152

4.1 Struktur und F unktion der Pili von Adinetobacter sp. BD413 152

4.1.1 Die Pilusstrukturen sich nicht an der natürlichen Transformation beteiligt 152

4.1.2 DiePilusstrukturen von Acinetobacter sp. BD413 sind nicht an der gleitenden Fortbewegung beteiligt 153

4.1.3 Acinetobacter sp. BD413 bildet Biofilme 157

4.2 Das Transformationssystem von Acinetobacter sp. B D413 161

4.2.1 Das Polymer PHB ist nicht amTransport der DNA durch die 
Zellmembranen beteiligt

161

4.2.2 Struktur und Funktion der Pilin-ähnlichen Kompetenzfaktoren

163

4.2.3 Assemblierung des Pilin-ähnlichen Kompetenzproteins ComP in Acinetobacter sp. BD413

169

4.2.4 ComEA vermittelt die Bindung der DNA auf der Zelloberfläche

172

4.2.5 Das DNA-Aufnahmesystem in Acinetobacter sp. BD413

174

5. ZUSAMMENFASSUNG

179

6. LITERATUR

181 


\section{Abkürzungen}

$\begin{array}{ll}\text { Abb. } & \text { Abbildung } \\ \text { Amp }^{r} & \text { Ampicilinresistenz } \\ \text { APS } & \text { Ammoniumpersulfat } \\ \text { ATP } & \text { Adenosintriphosphat } \\ \text { ATPase } & \text { ATP-Synthase } \\ \text { Bis-Tris } & \text { Bis(2-Hydroxyethyl)-Amino-Tris(Hydroxymethyl)Methan } \\ \text { bp } & \text { Basenpaare } \\ \text { BSA } & \text { Rinderserumal bumin } \\ \text { C- } & \text { Carboxy- } \\ { }^{\circ} \mathrm{C} & \text { Grad Celsius } \\ \text { ca. } & \text { circa } \\ \text { CHAPS } & \text { 3-[(3-Cholamidopropyl)Dimethylamino]1-Propansulfonsäure } \\ \text { cm } & \text { Zentimeter } \\ \text { CTAB } & \text { Hexadecyltrimethylammoniumbromid } \\ \text { Da } & \text { Dalton } \\ \text { d.h. } & \text { das heißst } \\ \text { DMSO } & \text { Dimethylsulfoxid } \\ \text { DNA } & \text { Desoxyribonukleinsäure } \\ \text { DNase } & \text { Desoxyribonuklease } \\ \text { ds } & \text { doppelsträngig } \\ \text { DTE } & \text { Dithioerythreitol } \\ \text { E } & \text { Extinktion } \\ \text { E. } & \text { Escherichia } \\ \text { eds. } & \text { editor: Herausgeber } \\ \text { EDTA } & \text { Ethyldiamintetraessigsäure } \\ \text { etal. } & \text { et alteri: und andere } \\ \text { Fa. } & \text { Firma } \\ \text { g } & \text { Gramm } \\ \text { Gal } & \text { Galaktosyl-, Galaktose } \\ \text { h } & \text { Stunde } \\ \mathrm{H}_{2} \mathrm{O}_{\text {dest }} & \text { destilliertes Wasser } \\ \mathrm{H}_{2} \mathrm{O}_{\text {denin. }} & \text { demineralisiertes Wasser } \\ & \end{array}$




\begin{tabular}{|c|c|}
\hline i.d.R. & in der Regel \\
\hline IPTG & Isopropyl-[-D-Thiogal actopyranosid \\
\hline k- & $\operatorname{Kilo}\left(10^{3}\right)$ \\
\hline $\mathrm{kb}$ & Kilobasen \\
\hline Km' & Kanamycinresistenz \\
\hline konz. & konzentriert \\
\hline । & Liter \\
\hline$\square$ & Wellenlänge \\
\hline $\log$ & Logarithmus \\
\hline M & molar \\
\hline $\mathrm{m}$ & milli $\left(10^{-3}\right)$ \\
\hline mRNA & Boten-Ribonukleinsäure \\
\hline$\square-$ & micro $\left(10^{-6}\right)$ \\
\hline $\min$ & Minute \\
\hline $\mathrm{Mr}$ & Molekulargewicht \\
\hline N- & Amino- \\
\hline$n$ & nano $\left(10^{-9}\right)$ \\
\hline$N A D(P)$ & Nicotinamidadeni ndinukleotid-(phosphat) \\
\hline OD & optische Dichte \\
\hline PAGE & Polyacrylamid Gelelektrophorese \\
\hline PBS & Phosphat-gepufferte Saline \\
\hline PEG & Polyethylenglycol \\
\hline PSI & Druckeinheit \\
\hline RNA & Ribonukleinsäure \\
\hline RNase & Ribonuklease \\
\hline rRNA & Ribosomale Ribonukleinsäure \\
\hline s & Sekunde \\
\hline SDS & Natriumdodecylsulfat \\
\hline SL & Spurenelementlösung \\
\hline Smr & Streptomycinresistenz \\
\hline sp. & Spezies \\
\hline$S p^{r}$ & Spectomycinreststenz \\
\hline Tab. & Tabelle \\
\hline TAE & Tris-A cetat-EDTA \\
\hline TE & Tris-EDTA \\
\hline TEMED & $\mathrm{N}, \mathrm{N}, \mathrm{N}, \mathrm{N}$-Tetramethyldiamin \\
\hline
\end{tabular}




$\begin{array}{ll}\text { Tet } & \text { Tetracyclinresistenz } \\ \text { Tris } & \text { Tris-Hydroxymethylaminomethan } \\ \text { U } & \text { Unit, Enzymeinheit (1 U = 1 mmol Substrat/min) } \\ \text { u.a. } & \text { unter anderem } \\ \text { Upm } & \text { Umdrehungen pro Minute } \\ \text { UV } & \text { Ultraviolett } \\ \text { V } & \text { Volt } \\ \text { v/v } & \text { Volumen pro Volumen } \\ \text { w/v } & \text { Gewicht pro Volumen } \\ \text { xg } & \text {-facheErdbeschleunigung } \\ \text { X-Gal } & \text { 5-Brom-4-Chlor-3-Indolyl-G-D-Gal actopyranosid } \\ \text { z.B. } & \text { zumBeispiel } \\ \text { z.T. } & \text { zumTeil }\end{array}$

Nukleotidbase
A Purinbase Adenin
G Purinbase Guanin
C Pyrimidinbase Cytosin
$\mathrm{T}$ Pyrimidinbase Thymidin

\section{Aminosäuren}

$\begin{array}{llll}\text { A } & \text { Alanin } & \text { M } & \text { Methionin } \\ \text { C } & \text { Cystein } & \text { N } & \text { Asparagin } \\ \text { D } & \text { Aspartat } & \text { P } & \text { Prolin } \\ \text { E } & \text { Glutamat } & \text { Q } & \text { Glutamin } \\ \text { F } & \text { Phenylalanin } & \text { R } & \text { Arginin } \\ \text { G } & \text { Glycin } & \text { S } & \text { Serin } \\ \text { H } & \text { Histidin } & \text { T } & \text { Threonin } \\ \text { I } & \text { Isoleucin } & \text { V } & \text { Valin } \\ \text { K } & \text { Lysin } & \text { W } & \text { Tryptophan } \\ \text { L } & \text { Leucin } & \text { Y } & \text { Tyrosin }\end{array}$




\section{E inleitung}

Die Sekretion von Proteinen in das extracytoplasmatische Kompartiment und der Import von Makromolekülen aus dem extrazellulären Milieu stellen einen grundl egenden Aspekt in der Physiologie der Bakterien dar. Transportprozesse vermitteln neben der Substratversorgung wichtige biologische Eigenschaften, wie die Bindung und Invasion von Wirtszellen, den Transfer genetischer Informationen über Konjugation und Transformation, sowie Zellkommunikation ('Quorum Sensing') und Mobilität der Bakterien. Extrazelluläre Enzyme, Exotoxine und Untereinheiten von Flagellen oder Pili (Fimbrien) müssen hierfür sowohl die innere als auch die äußere Zellmembran sowie die Mureinschicht passieren, um den Bestimmungsort zu erreichen. Darüber hinaus sezzen die Synthese von Oberflächenstrukturen und der Transport von Proteinen aufgrund ihrer regulatorischen und strukturellen Komplexität eine koordinierte Biogenese und Assoziation von Struktur- und Assemblierungsproteinen voraus.

Die Untersuchungen der letzten Jahre haben gezeigt, daß die in den verschiedenen Prozessen involvierten Proteine hohe Homologien aufweisen, was für einen gemeinsamen evolutiven Ursprung spricht Proteine, dieÄhnlichkeiten aufweisen, finden sich z.B. in den Typ-IV-Sekretionswegen, bei Konjugationssystemen sowie im DNA-A ufnahmeapparat des natürlich kompetenten Bakteriums Helicobacter pylori (HOFREUTER et al. 2001). Hierzu zählt auch das System für den Transfer des T-Plasmids von Agrobacterium tumefaciens in Pflanzenzellen (LAI \& KADO 2000). Die ähnlichen Proteine der genannten Transportsysteme bilden Kanalstrukturen in den Zellmembranen, weisen ATPasenAktivität auf oder dienen der Bindung an Wirtszellen oder an andere Bakterien. Das TypIII-Sekretionssystem, welches als nadelförmiger Komplex Toxine direkt in die Wirtszelle injiziert, weist Homologien zu Basalkörpern der Flagellen auf. Dieser basale Membrananker besteht aus einem oberen in der Peptidoglycan-Schicht lokalisierten Ring und einem unteren Doppelring, der die innere Membran durchspannt und ins Cytoplasma ragt (TAMANO et al. 2000, SEKIYA et al.2001). Bisher wurden acht konservierte Proteine des Typ-III-Sekretionssystems identifiziert, dessen homologe Komponenten an der Flagel len-Synthese beteiligt sind (HücK 1998). Den Durchtritt durch die äußere Membran vermittelt im Typ-III-Sekretionssystem eine Pore, deren Untereinheiten Ä hnlichkeiten zu der Proteinfamilie der Sekretine aufweisen (HOBBS \& MATTICK 1993). Während die Flagelline in helikaler Anordnung ein Filament von ca. 20 nm Durchmesser und einer Länge von 5-10 $7 \mathrm{~m}$ bilden, weist dagegen der nadelförmige Sekretionskomplex beispielsweise bei Salmonella oder Shigella eine Länge von $45 \mathrm{~nm}$ und eine Breite von $8 \mathrm{~nm}$ auf (KUBORI et al. 1998, TAMANO et al. 2000), wodurch der funktionale Unterschied 
- zum einen als Mittel der Fortbewegung und zum anderen als röhrenförmige Struktur für Export und Injektion der Proteine in dieZielzelle- zum Ausdruck kommt.

Ein weiterer prinzipiell ähnlicher Transportmechanismus muß der Typ-II-Sekretion, der natürlichen Transformation und Typ-IV-Pilusbiogenese zugrunde liegen. Die Komponenten der Typ-IV-Pilusbiogenese natürlich transformierbarer Bakterien sind am DNA-Import durch die äußere Membran und die Peptidoglykanschicht beteiligt. Doch weisen nicht alle Organismen, die Typ-IV-Pili synthetisieren die Fähigkeit zur natürlichen Transformation auf, da transformationsspezifische Proteine, die nicht in die Pilusbiogenese involviert sind, für die Bindung und Aufnahme der DNA erforderlich sind. Hierzu zählen z.B. Proteine, die nukleolytische oder DNA-bindende Eigenschaften aufweisen und Faktoren, die am Transport der DNA durch die inneren Membran beteiligt sind (PROVVEDI \& DUBNAU 1999, PROVVEDI et al. 2001). Andererseits weisen nicht al le transformierbaren Bakterien Typ-IV-Pili auf, welches zu dem Schluß führt, daß die Pilusstrukturen keine Voraussetzung für die DNA-A ufnahme darstellen. Zu dieser Gruppe von transformierbaren Bakterien zählen der gut untersuchte Gram-negative Organismus Haemophilus influenzae und natürlich kompetenten Gram-positiven Bakterien, wie z.B. Bacillus subtilis und Streptococcus pneumoniae (CHUNG \& DUBNAU 1998, DOUGHERTY \& SMITH 1999). Hier sind die Pilin-ähnlichen Proteine in der Cytoplasmamembran, im Periplasma und (bei Gram-negativen Bakterien) in der äußeren Membran lokal isiert (CHUNG et al. 1998).

Bei der Typ-II-Sekretion übernehmen die Komponenten, die Ähnlichkeiten zu den Struktur- und Assemblierungsproteinen der Typ-IV-Pili zeigen, den Transport von Exoenzymen durch den periplasmatischen Raum und die äußere Membran. Zuvor gelangen die zu exportierenden Proteine durch einen Sec- oder Tat-abhängigen Transport durch die Cytoplasmamembran ins Periplasma. Während Typ-IV-Piline zu einem mehrere Micrometer langen Filament assembliert werden, wurden dagegen für die Pilin-ähnlichen Komponenten des DNA-Aufnahme- und des Typ-II-Sekretionssystems eine Pseudopilusstruktur postuliert, welche verankert in der Cytoplasmamembran den periplasmatischen Raum und die äußere Membran durchspannt. Diese Struktur könnte zum einen im Falle des Transformationssystems DNA-bi ndende Proteine exponieren oder eine Aussparung für den I mport des DNA-Stranges bilden, oder zum anderen im Falle des TypII-Sekretionssystems durch die Assemblierung Exoenzyme durch die Pore (Sekretin) in der äußeren Membran in den extrazellulären Raum schleusen.

Die Klasse der Typ-IV-Pili wurde bereits ausgiebig untersucht, da diese Strukturen die Adhäsion pathogener Organismen an Wirtszellen vermitteln. Zu diesen zählen u.a. Vibrio cholerae, Pseudomonas aeruginosa, enteropathogene und enterotoxische E. coliStämme (EPEC und ETEC), Neisseria gonorrhoeae, Neisseria meningitidis und Moraxella 
bovis (STROM \& LORY 1993). Weiterhin vermittelt der Typ-IV-Pilus eine spezielle Art der gleitenden Fortbewegung auf festen Oberflächen, die 'Twitching Motility' genannt wird. Dieses Gleiten beruht auf Synthese und Retraktion der Pilusstruktur unter Vorschub der Zelle (WALL \& KAISER 1999). Die Assemblierung der Piline erfolgt nach deren Prozessierung durch eine Präpilinpeptidase an der Cytoplasmamembran (STROM \& LORY 1992, Strom et al. 1993). Vermutlich bildet die Peptidase einen Komplex mit ca. zehn unterschiedlichen Proteinen, die an der inneren Zellmembran oder im Periplasma lokalisiert sind. Einige dieser Komponenten sind Pilin-ähnliche Proteine, die verglichen mit der Hauptstrukturkomponente nur in sehr geringen Mengen exprimiert werden, oder ATP-bindende Proteine (TURNER et al. 1993, SANDKVIST et al. 1995, LORY 1998). Das Sekretin in der äußeren Membran, welches durch Lipoproteine stabilisiert wird, bi ldet eine Pore, durch die die Sekretion des Pilus erfolgt (DRAKE et al. 1997, BITTER et al. 1998). Während der ersten Schritte der Synthese des Pilus wird ein Assemblierungfaktor, der gleichzeitig als Adhäsin fungiert, an seiner Spitze inkorpuriert, welcher ebenso in der äußeren Membran lokalisiert ist (J ONSSON et al. 1991, RUDEL et al. 1995, 1995a, 1995b, ALM etal. 1996, RYLL et al. 1997).

Aufgrund der zahl reich ähnlichen Komponenten von Transformations- und Typ-IVPilusbiogenessystem wird für den DNA-Aufnahmeapparat natürlich kompetenter Bakterien eine ähnliche Biogenese angenommen. Die Synthese des DNAA ufnahmeapparats unterliegt dabei einer Regulation, d.h. sie werden in der physioloischen Phase der Kompetenzinduktion gebildet. Dabei entscheiden definierte Umweltbedingungen, intra- und extrazelluläre Signalstoffe, die mittels Rezeptoren wahrgenommen werden, über die Induktion der Genexpression, wobei die Dauer, Rate und Effizienz der DNA-A ufnahme von Spezies zu Spezies variiert. DieAnforderungen, welche die verschiedenen Organismen zur Induktion der Kompetenz an ihre Umwelt stellen reichen von optimalen Wachstumsbedingungen bis hin zu wachstumslimitierenden Mangel bedingungen oder basieren auf bestimmte Medium-Zusammensetzungen. Bei Bacillus subtilis z.B. ist die Entwicklung der Kompetenz von Pheromonen abhängig, die sich mit steigender Zelldichte im Medium akkumulieren (DUBNAU 1991, HAHN et al. 1994; MAGNUSON 1994) und als Initiatoren einer komplexen Phosphorylierungskaskade fungieren, so daß schließlich beim Eintritt in die stationäre Wachstumsphase die Kompetenzgene exprimiert werden und daraufhin die Aufnahme der DNA für einen kurzen Zeitraumermöglicht wird.

Das zweite sehr gut untersuchte Transformationssystem Gram-positiver Bakterien ist das von Streptococcus pneumoniae. Dieser Stamm entwickelt die höchste Kompetenz bereits im Verlauf des exponentiellen Wachstums für eine kurze Zeit bei einer bestimmten Zelldichte (TomASz 1966, TROMBE et al. 1992), wobei an der Induktion ein extrazelluläres 
Aktivatorpeptid beteiligt ist (Havarstein 1995, Pestova et al. 1996, Alloing et al. 1998). Neben dieser Kompetenzstimulation über 'Quorum Sensing' sind weitere Faktoren wie dival ente Kationen (GIAMMARINARO et al. 1999), der pH-Wert ( TROMBE et al. 1992, TROMBe 1993) und die $\mathrm{O}_{2}$-Konzentration von Bedeutung (ECHENIQUE et al. 2000). Wie Bacillus subtilis zeigen Azotobacter vinelandii (PAGE \& V on TIGERSTROM 1978) und Haemophilus influenzae (GoOdGAL 1982) die höchste Transformationsfrequenz am Anfang des stationären Wachstums, wobei bei Haemophilus influenzae der CAMP-Spiegel von Bedeutung ist (CHANDLER 1992, MACFADYEN et al. 1998). Die Überführung der Zellen in ein Medium, das keine ausreichende Substrat oder $\mathrm{O}_{2}$-Versorgung liefert, wirkt dabei zusätzlich stimulierend auf die DNA-Aufnahme (WISE et al. 1973). Nersseria gonorrhoeae exprimiert im Gegensatz zu allen anderen untersuchten Organismen die Kompetenzgene in einer nahezu konstitutiven Weise (BISWAS et al. 1977).

Nach der Synthese des DNA-A ufnahmeapparats erfolgt die Anlagerung der freien DNA über Bindeproteine an der Zelloberfläche. Dabei geht die DNA in einen waschfesten, jedoch weiterhin DNase-sensitiven Zustand über. Bei Bacillus subtilis und Streptococcus pneumoniae konnten 30 bis 80 Bindestellen pro kompetenter Zelle nachgewiesen werden, was auf die Synthese eines DNA-bindenden Proteins zurückzuführen ist (LORENZ \& Wackernagel 1994, Pestova \& Morrison 1998, Provvedi \& Dubnau 1999); bei Haemophilus influenzae wurden dagegen nur maximal 8 Bindestellen kalkuliert (DEICH \& SMITH 1980). Auf der Zelloberfläche von Bacillus subtilis konnte eine Endonuklease identifiziert werden, die spezifisch doppelsträngige DNA schneidet und an der Fragmentierung der gebundenen DNA beteiligt ist (PROVVEDI et al. 2001). Während bei der größten Zahl der bisher charakterisierten Organismen sowohl homologe als auch heterologe DNA gebunden und aufgenommen wird, zeigen Haemophilus influenzae und Neisseria gonorrhoeae Affinitäten zu kurzen, im eigenen Chromosom zahlreich vertretenen Erkennungssequenzen und somit eine Diskriminierung heterologer DNA (GoodGaL 1982). Bei Neisseria wird die Selektivität für homologe DNA erst im eigentlichen Aufnahmeprozeß wirksam (Goodman \& SCOCCA 1988; CHEN \& GOTSCHLICH 2001).

Nach der Bindung folgt die DNA-Aufnahme durch die Zellhülle durch einen energieabhängigen Mechanismus. DieCharakterisierung von bereits identifizierten, für die natürliche Transformation essentiellen Genen in Gram-positiven und Gram-negativen Organismen ergab, daß zahlreiche DNA-A ufnahmeproteine signifikante Ähnlichkeiten aufweisen, so daß bei den verschiedenen Organismen von einem grundsätzlich ähnlichen Aufnahmemechanismus ausgegangen werden kann, wobei sich die Struktur dieser Apparate aufgrund des unterschiedlichen Aufbaus der Zellhülle unterscheiden muß.. Die 
DNA wird als Doppelstrang durch die äußere Membran (bei Gram-negativen Bakterien), durch die Peptidoglycanschicht und als Einzel strang unter Hydrolyse des komplementären Stranges durch die Cytoplasmamembran in das Cytoplasma aufgenommen, wobei Energie in Form von ATP oder proton-motorischer Kraft erforderlich ist (GRINIUS 1980, PALMEN \& HeLLINGWERF 1997). Die freien Nukleotide außerhalb der Zelle und die A bhängigkeit der DNA-Aufnahme von zweiwertigen Kationen lassen auf eine beteiligte Nuklease schließen, die bei Streptococcus pneumnniae bereits nachgewiesen wurde (PUYET et al. 1990). Der letzte Transformationsschritt beinhaltet die genetische Etablierung der aufgenommenen DNA. Die Voraussetzung dafür sind homologe Bereiche, die den entsprechenden Bereich des Chromosom in einem RecA-abhängigen Rekombinationsereignis ersetzen können (DUBNAU \& CIRIGLIANo 1973, 1973a, DUBNAU et al. 1973; Vosman \& HelLINGWERF 1991, GREGG-J OLLY \& ORNSTON 1994). Alternativ kann bei Aufnahme geeigneter Replikons die Rekonstitution der DNA zu sich unabhängig replizierenden Plasmiden erfolgen.

Eine relativ hohe Transformationsfrequenz zeigt ein Stamm des Gram-negativen Bodenbakteriums Acinetobacter (JUNI \& J ANIK 1969). Hierbei handelt es sich um ein im Boden lebendes, strikt aerobes, zur [-Gruppe der Proteobakterien zugeordnetes Bakterium, welches sich durch eine hohe metabolische Diversität auszeichnet (JUNI 1978). Die Physiologie der natürlichen Transformation von Acinetobacter sp. BD4 bzw. seiner kapsel losen Mutante sp. BD413 wurde in zahl reichen Untersuchungen analysiert (PALMEN et al. 1993). Dabei konnte gezeigt werden, daß Acinetobacter sp. BD413 unmittelbar nach dem Überimpfen in frisches Medium eine hohe Kompetenz für natürliche Transformation entwickelt und diese im Verlauf des exponentiellen Wachstums auf ein niedriges Grundnivea reguliert (PALMEN et al. 1993). Die DNA-Aufnahme ist nicht sequenzspezifisch und ist abhängig von zweiwertigen $\mathrm{Kationen}$ wie $\mathrm{Mg}^{2+}, \mathrm{Mn}^{2+}$ oder $\mathrm{Ca}^{2+}$ (LoRENZ et al. 1992), was auf die Beteiligung einer Nuklease schließen läßst. Die auf der Zell oberfläche gebundene doppel strängige DNA wird dabei als Einzelstrang durch einen energieabhängigen Prozeß in die Zelle aufgenommen und durch ein RecA-abhängiges Rekombinationsereignis ins Chromosom integriert (PALMEN et al. 1993, PALMEN \& HELLINGWERF 1997). Ungeachtet der zahl reichen Informationen von der Physiologie der Transformation in Acinetobacter sp.BD413 sind für Untersuchungen der molekularen Grundl age und für das Verständnis von Struktur und Funktion des Transformationssystems die Identifizierung und Charakterisierung der Komponenten essentiel.

Zur Charakterisierung des Transformationsapparates bei Acinetobacter sp. BD413 sind durch die Insertion eines Kanamycinmarkers transformationsdefekte Mutanten erzeugt 
worden, die in den letzten J ahren zur Identifizierung einer Vielzahl von Kompetenzgenen geführt hatte. So konnte z.B. ein mit comA bezeichnetes Kompetenzgen identifiziert werden (FRIEDRICH et al. 2001), dessen Genprodukt Ähnlichkeiten zu ComA aus Nersseria gonorrhoeae und ComEC aus Bacillus subtilis aufweist (FACIUS \& MEYER 1993, HAHN et al. 1993). ComA bzw. ComEC sind vermutlich an dem Transport der DNA durch die Cytoplasmamembran beteiligt. Weiterhin wurde durch Transposonmutagenese das Gencluster bestehend aus comM, -N, -O, -L und comQ identifiziert, welche Homologien zu den Genen aufweisen, die für das Sekretin des Typ-II-Sekretionssystems, der Typ-IVPilusbiogenese und dessen Assemblierungsfaktoren codieren (ROSENPLÄNTER pers. Mitteilung). Datenbankabgleiche des Genprodukts eines weiteren BD413-Kompetenzgens comC aus BD413 ergaben Ähnlichkeiten zu den gut untersuchten Proteinen PilC1 Und PilC2 aus Neisseria gonorrhoeae (JONSSON et al. 1991) und Neisseria meningitidis (NASSIF et al. 1994) sowie PilY 1 aus Pseudomonas aeruginosa (ALM et al. 1996), die an der Biosynthese von Typ-IV-Pili und der gleitenden Fortbewegung 'Twitching Motility' beteiligt sind. Immunologische Studien bei Neisseria gonorrhoeae demonstrierten, daßs ComC in der äußeren Membran lokalisiert ist aber ebenso an der Spize des Typ-IV-Pilus zu finden ist (MORAND et al. 2001, Scheuerpflug et al. 1999, RAHMAn et al. 1997). Bei den Kompetenzfaktoren ComP, ComB, ComE und ComF handelt es sich um Proteine mit signifikanten Ähnlichkeiten zu Typ-IV-Pilinen (PORSTENDÖRFER \&t al. 1997, BusCH \&t al. 1998, Herzberg et al. 1999). Das sehr gut untersuchte Protein ComP ist in den Zellmembranen lokalisiert, an der Bindung der DNA auf der Zelloberfläche beteiligt und wird posttranlational glykosyliert, was für die Untereinheiten der Typ-IV-Pili ein charakteristisches Merkmal darstellt. Verglichen zu den Strukturproteinen ComB, ComE und ComF wird ComP relativ stark exprimiert (PORSTENDÖRFER et al. 2000), welches zu der Vermutung führte, daß ComP die Hauptstrukturuntereinheit darstelt.

Während die Typ-IV-Piline zu einem mehrere Micrometer langen Pilus assembliert werden, ist eine Assemblierung der Hauptstrukturkomponenten des Typ-IISekretionssystems sowie des DNA-Aufnahmesystems nicht untersucht. Aufgrund des homologen Biosyntheseapparates kann die Synthese eines Pseudopilus postuliert werden, der den periplasmatischen Raum durchspannt. Eine solche Pseudopilusstruktur ist allerdings noch in keinem Fall identifiziert worden. Vor dem Hintergrund, daß zum einen die Untereinheiten des Typ-IV-Pilus eine essentielle Funktion bei der DNA-Bindung und -Aufnahme ausüben und zum anderen eine Pilusstruktur aber kein notwendiges Strukturmerkmal für die natürliche Transformation darstellt, bleibt die Frage offen, inwiefern der Typ-IV-Pilus die DNA-A ufnahme vermittelt bzw. ob die Piline in einem separaten Transformationssystem, der zu keiner filamentösen Struktur assembliert, diese Funktion ausüben. 
Obwohl bei bisher untersuchten transformierbaren Organismen die Komponenten der Typ-IV-Pilusbiogenese an der gleitenden Fortbewegung 'Twitching Motility' und DNAA ufnahme beteiligt sind, führten dagegen Unterbrechungen in den Kompetenzgenen von Acinetobacter sp. BD413 nicht zu einer Beeinträchtigung der gleitenden Fortbewegung und der Pilusbiogenese, was einer direkten Involvierung der Pilusstrukturen in die DNAAufnahme widerspricht (PORSTENDÖRFER et al. 1997, LINK et al. 1998, BuSCH et al. 1998, HerzBerg et al. 1999). Be den zwei Pilustypen von BD413 handelt es sich zum einen um flexible Strukturen mit einem Durchmesser von ca. $6 \mathrm{~nm}$ und zum anderen um starre, bündel bildende Filamente, die einen Durchmesser von 2-3 nmaufweisen (PORSTENDÖRFER et al. 1997, 2000). Die Charakterisierung dieser Pilusstrukturen ermöglicht die Klassifizierung der Pilustypen von BD413. Mit Hilfe der gereinigten Pili sollen die strukturellen Untereinheiten identifiziert, charakterisiert und ihre Gene anschließend mutagenisiert werden. Sich anschließende Mutantenstudien werden dann den eindeutigen Schluß zulassen, ob die Pili von Acinetobacter sp. BD413 an der Transformation beteiligt sind. Parallel zu diesen Untersuchungen sollen periplasmatische und Membrandurchspannende Subkomplexe des Transformatinsapparats isoliert und strukturell analysiert werden, um Hinweise auf den Aufbau des Transformationssystems zu erhalten. Bei der Detektion und Isolierung dieser Subkomplexe wird von den bereits vorliegenden Antikörpern gegen das Pilin-ähnliche Protein ComP ausgegangen.

Weiters Ziel dieser Arbeit ist die Identifizierung von am DNA-Transport beteiligten Komponenten. Hierfür soll die uns vorliegende genomische Sequenz von Acinetobacter sp. BD413 genutzt werden, was eine Identifizierung von Kompetenzgenen durch Sequenzabgleiche erlaubt. Die sich anschließenden strukturellen und funktionellen Charakterisierungen sollen daraufhin weitere Hinweise auf den Mechanismus des DNATransports durch die Zellmembranen liefern. 


\section{M aterial und M ethoden}

\subsection{Organismen und Plasmide}

In Tabelle 2.1 sind die in dieser Arbeit verwendeten Acinetobacter sp.- und E. coliStämme zusammemgefaßst. In Tabelle 2.2 und 2.3 sind die verwendeten Vektoren und rekombinanten Plasmide aufgeführt

Tab. 2.1: Acinetobacter sp.-/E. coli-Stämme

\begin{tabular}{|c|c|c|}
\hline Stamm & $\begin{array}{l}\text { Relevanter Geno- oder } \\
\text { Phänotyp }\end{array}$ & Referenz/Herkunft \\
\hline Acinetobacter sp. ${ }^{b}$ BD413 & $\begin{array}{l}\text { kapsellose Variante des } \\
\text { Wildtyps BD4 }\end{array}$ & JUNI, 1972 \\
\hline Acinetobacter sp. ${ }^{b}$ ADP239 & $\begin{array}{l}\text { spontane pobA-Mutante } \\
\text { von BD } 413^{c}\end{array}$ & HARTNETT et al., 1990 \\
\hline Acinetobacter sp. ${ }^{b}$ T205 & 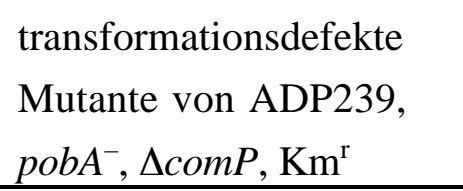 & PORSTENDÖRFER \& al., 1997 \\
\hline Acinetobacter sp. ${ }^{\mathrm{b}}$ T206 & $\begin{array}{l}\text { transformationsdefekte } \\
\text { Mutante von ADP239, } \\
\text { pobA- , comP::nptl, Km' }\end{array}$ & PORSTENDÖRFER et al., 1997 \\
\hline Acinetobacter sp. ${ }^{\mathrm{b}}$ T308 & $\begin{array}{l}\text { transformationsdefekte } \\
\text { Mutante von ADP239, } \\
\text { pobA-', comC::nptl , Km' }\end{array}$ & LINK etal., 1998 \\
\hline Acinetobacter sp. ${ }^{\text {b }}$ T401 & $\begin{array}{l}\text { transformationsdefekte } \\
\text { Mutante von ADP239, } \\
\text { pobA- , comB::nptl, Km' }\end{array}$ & HERZBERg et al. 2000 \\
\hline Acinetobacter sp. ${ }^{\mathrm{b}}$ T701 & 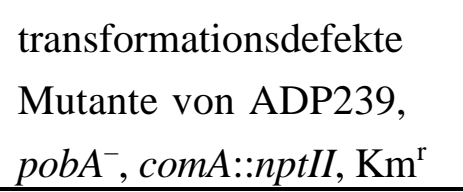 & FRIEDRICH et al., 2001 \\
\hline Acinetobacter sp. ${ }^{\mathrm{b}}$ T100 & $\begin{array}{l}\text { transformationsdefekte } \\
\text { Mutante von ADP239, } \\
\text { pobA' , comEA::nptll, Km' }\end{array}$ & dieseArbeit \\
\hline
\end{tabular}




\begin{tabular}{|c|c|c|}
\hline Acinetobacter sp. ${ }^{\mathrm{b}}$ B100 & $\begin{array}{l}\text { PHB-Synthese defekte } \\
\text { Mutante von ADP239, } \\
\text { phaC::nptII, Km }\end{array}$ & dieseArbeit \\
\hline Acinetobacter sp. ${ }^{\mathrm{b}} \mathrm{K} 101$ & $\begin{array}{l}\text { Fil-Pilus-Synthese defekte } \\
\text { Mutante von ADP239, } \\
\text { filA::nptI, Kr' }\end{array}$ & dieseArbeit \\
\hline Acinetobacter sp. ${ }^{\text {b } ~ K 102}$ & $\begin{array}{l}\text { Fil-Pilus-Synthese defekte } \\
\text { Mutante von ADP239, } \\
\text { orfB::nptI, Km' }\end{array}$ & dieseArbeit \\
\hline Acinetobacter sp. ${ }^{\mathrm{b}} \mathrm{K} 103$ & $\begin{array}{l}\text { Fil-Pilus-Synthese defekte } \\
\text { Mutante von ADP239, } \\
\text { DorfC::nptII, Km' }\end{array}$ & diese Arbeit \\
\hline Acinetobacter sp. ${ }^{\mathrm{b}} \mathrm{K} 104$ & $\begin{array}{l}\text { Fil-Pilus-Synthese defekte } \\
\text { Mutante von ADP239, } \\
\text { DorfD/\orfE::nptII, Km' }\end{array}$ & dieseArbeit \\
\hline Acinetobacter sp. ${ }^{\mathrm{b}} \mathrm{N} 100$ & $\begin{array}{l}\text { Fim-Pilus-Synthese defekte } \\
\text { Mutante von ADP239, } \\
\text { fimA::nptI, } \mathrm{Km}\end{array}$ & diese Arbeit \\
\hline Acinetobacter sp. ${ }^{b}$ KN100 & $\begin{array}{l}\text { Fil/Fim-Pilus-Synthese } \\
\text { defekte Mutante von } \\
\text { ADP239, fimA::nptl, } \\
\square \text { filA:: } \Omega, \text { Km Smr }\end{array}$ & dieseArbeit \\
\hline Escherichia coli DH5] & $\begin{array}{l}\mathrm{F}^{-}, \text {lacZ } \square \mathrm{M} 15, \text { recA1, } \square, \\
\text { hsdR17, supE44, } \square(\text { lacZYA, } \\
\text { argF ) }\end{array}$ & HANAHAN 1983 \\
\hline Escherichia coli BL21 (DE3) & $\begin{array}{l}\text { hsdF, gal ( } \square \text { cl ts857 ind1 } \\
\text { Sam7 nin5 lacUV5-T7 } \\
\text { genel) }\end{array}$ & Studier \& MOFfat 1986 \\
\hline
\end{tabular}


Tab. 2.2: Vektoren

\begin{tabular}{|c|c|c|c|}
\hline Pasmid & Relevanter Geno- oder Phänotypa & Größe (kb) & Referenz/Herkunft \\
\hline pUC18 & Amp', lacPOZ', ColE1, ori R & 2,68 & $\begin{array}{l}\text { MESSING \& VIEIRA } \\
1992\end{array}$ \\
\hline pGEM-7Zf+ & Amp', lacPOZ' & 3,0 & $\begin{array}{l}\text { Pomega Serva } \\
\text { GmbH, } \\
\text { Heidelberg }\end{array}$ \\
\hline $\begin{array}{l}\text { pBluescriptll } \\
\mathrm{KS} / \mathrm{SK}+\text { - }\end{array}$ & Amp', lacPOZ', ColE1, ori R, F1 ori & 2,96 & Stratagene \\
\hline pRK415 & $\begin{array}{l}\text { Tet', lacPOZ', ori R, breites } \\
\text { Wirtsspektrum, geringe Kopienzahl }\end{array}$ & 10,5 & KeEn et al. 1988 \\
\hline $\mathrm{pBK}$ & $\begin{array}{l}\text { Tet', mob+, tra-, promotorlose lacZ- } \\
\text { und gusA-Reportergene }\end{array}$ & 12,4 & KUSIAN 1994 \\
\hline pMal-c2 & $\begin{array}{l}\text { Amp', lacPOZ', ori R, malE-lacZ } \square- \\
\text { Fusionsgen, rrB-Terminator, laclq- } \\
\text { Repressor }\end{array}$ & 6,6 & $\begin{array}{l}\text { New England } \\
\text { Biolabs, } \\
\text { Schwalbach }\end{array}$ \\
\hline pRK2013 & $\mathrm{Km}^{r}, \mathrm{mob}^{+}$, tra ${ }^{+}$, ColE1, ori $\mathrm{R}$ & 48 & $\begin{array}{l}\text { FIGURSKI \& HELINSKI } \\
1979\end{array}$ \\
\hline pJ C40 & $\begin{array}{l}\text { Ampr, T7-Promotor, } 010-T e r m i n a t o r, \\
\text { codiert für } 10 \text { Histidin-Reste und eine } \\
\text { Faktor Xa-Schnittstelle }\end{array}$ & 2,4 & $\begin{array}{l}\text { CLOS \& BRANDAU } \\
1994\end{array}$ \\
\hline
\end{tabular}

Tab. 2.3: rekombinante Plasmide

\begin{tabular}{|c|c|c|c|}
\hline $\begin{array}{l}\text { Plasmid } \\
\text { (Vektor) }\end{array}$ & Relevanter Geno- oder Phänotypa & Größe (kb) & Referenz/Herkunft \\
\hline $\begin{array}{l}\text { pCC01 } \\
(p \mathrm{p} C 40)\end{array}$ & $\begin{array}{l}\text { Amp }{ }^{r} ; 1,3 \text { kb-Hindl II/BamHl- } \\
\text { Fragment aus pRK } 9\end{array}$ & 3,7 & diese Arbeit \\
\hline $\begin{array}{l}\text { pRK9 } \\
(\text { pRK 415) }\end{array}$ & $\begin{array}{l}\text { Tet'; enthält 4,6 kb-Clal/Xbal- } \\
\text { Fragment aus Acinetobacter sp. } \\
\text { T308 (enthält comC) }\end{array}$ & 15,1 & LINK 1998 \\
\hline $\begin{array}{l}\text { pRP1 } \\
\text { (pRK415) }\end{array}$ & $\begin{array}{l}\text { Tetr; } 1,4 \text { kb-BgllI/Sacl-Insert, } \\
\text { enthält comP und orfC }\end{array}$ & 11,9 & $\begin{array}{l}\text { PORSTENDÖRFER } \\
1997\end{array}$ \\
\hline
\end{tabular}




\begin{tabular}{|c|c|c|c|}
\hline $\begin{array}{l}\text { pUI1638 } \\
(p B I I K S+)\end{array}$ & $\begin{array}{l}\text { Amp', Smr; enthält 2,0 kb-BamHI- } \\
\text { Sm/Sp-Kassettein mittlerer Kpnl- } \\
\text { Schnittstelle (stumpfe Enden) von } \\
\text { pUI } 1188\end{array}$ & 5,4 & $\begin{array}{l}\text { NEIDLE, pers. } \\
\text { Mitteilung }\end{array}$ \\
\hline $\begin{array}{l}\text { pUI1188 } \\
(p B I I K S+)\end{array}$ & $\begin{array}{l}\text { Ampri enthält doppelte MCS (von } \\
\text { Sst bis Apal) }\end{array}$ & 3,4 & $\begin{array}{l}\text { NEIDLE, pers. } \\
\text { Mitteilung }\end{array}$ \\
\hline $\begin{array}{l}\text { pUS01 } \\
\text { (pUC18) }\end{array}$ & $\begin{array}{l}\text { Amp }{ }^{r}, \text { Smr; } 2,0 \text { kb-EcoRV/Hincll- } \\
\text { Sm/Sp-Kassette aus pBS01 in Sspl } \\
\text { von pUK18 }\end{array}$ & 4,7 & diese Arbeit \\
\hline $\begin{array}{l}\text { pBSO1 } \\
(\mathrm{pBIISK}+)\end{array}$ & 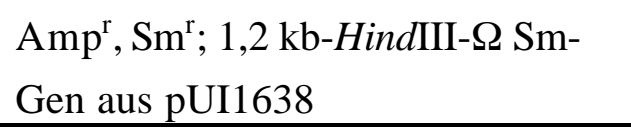 & 3,2 & diese Arbeit \\
\hline $\begin{array}{l}\text { pBK01 } \\
(\mathrm{pBIISK}+)\end{array}$ & $\begin{array}{l}\text { A mp }{ }^{\text {; }} \text { 0,68 kb-PCR-Fragment von } \\
\text { filA (stumpfe Enden in EcoRV) }\end{array}$ & 3,6 & diese Arbeit \\
\hline $\begin{array}{l}\text { pBK03 } \\
(\mathrm{pBIISK}+)\end{array}$ & $\begin{array}{l}\text { A mp }{ }^{r}, \mathrm{Km}^{r} ; \text { nptlI-Marker in EcoRV } \\
\text { von pBK01 (filA::nptlI) }\end{array}$ & 4,8 & diese Arbeit \\
\hline $\begin{array}{l}\text { pGK04 } \\
(\text { pGEM-7Zf+) }\end{array}$ & $\begin{array}{l}\text { Ampr, Kmr; enthält Mutationsort } \\
\text { der Pilus-Mutante K101 als } \\
\text { Sad/Xbal-Fragment (filA::nptl, } \\
\text { orfB) }\end{array}$ & 11,0 & diese Arbeit \\
\hline $\begin{array}{l}\text { pGK06 } \\
(\text { pGEM-7Zf }+)\end{array}$ & $\begin{array}{l}\text { A mp }{ }^{r} ; 1,0 \text { kb-SnaBI/Sacl-Fragment } \\
\text { aus pGK } 04 \text { (orfB) }\end{array}$ & 4,0 & diese Arbeit \\
\hline $\begin{array}{l}\text { pGK07 } \\
(\text { pGEM-7Zf }+)\end{array}$ & $\begin{array}{l}\text { A mpr; }{ }^{r} \mathrm{~m}^{r} ; \text { nptlI-Marker in Hincll } \\
\text { von pGK06 }\end{array}$ & 5,2 & diese Arbeit \\
\hline $\begin{array}{l}\text { pUK11 } \\
\text { (pUC18) }\end{array}$ & $\begin{array}{l}\text { A mp }{ }^{\text {r; }} 3,6 \text { kb-EcoRI/Sacl-Fragment } \\
\text { aus pGK04 (filA::nptI , orfB) }\end{array}$ & 6,3 & diese Arbeit \\
\hline $\begin{array}{l}\text { pUK } 12 \\
\text { (pUC18) }\end{array}$ & $\begin{array}{l}\text { A mpr; } 0,51 \mathrm{~kb}-\mathrm{EcoRI} / \mathrm{Xbal}-\mathrm{PCR}- \\
\text { Fragment stromaufwärts von filA }\end{array}$ & 3,2 & diese Arbeit \\
\hline $\begin{array}{l}\text { pUK } 13 \\
\text { (pUC18) }\end{array}$ & $\begin{array}{l}\text { A mpr; } 0,45 \text { kb-EcoRI/Xbal-PCR- } \\
\text { Fragment stromabwärts von filA }\end{array}$ & 3,1 & diese Arbeit \\
\hline $\begin{array}{l}\text { pGK } 16 \\
(\text { pGEM-7Zf }+)\end{array}$ & $\begin{array}{l}\text { A mpr; 0,79 kb-Sacl/BamHI-PCR- } \\
\text { Fragment stromaufwärts von orfC }\end{array}$ & 3,8 & diese Arbeit \\
\hline $\begin{array}{l}\text { pGK } 17 \\
(\text { pGEM-7Zf }+)\end{array}$ & $\begin{array}{l}\text { Ampr; 0,79 kb-EcoRI/Xbal-PCR- } \\
\text { Fragment stromabwärts von orfC }\end{array}$ & 3,8 & diese Arbeit \\
\hline $\begin{array}{l}\text { pGK } 18 \\
(\text { pGEM-7Zf }+)\end{array}$ & $\begin{array}{l}\text { A mpr; } 0,73 \text { kb-Sacl/BamHI-PCR- } \\
\text { Fragment stromaufwärts von orfD }\end{array}$ & 3,7 & diese Arbeit \\
\hline
\end{tabular}




\begin{tabular}{|c|c|c|c|}
\hline $\begin{array}{l}\text { pGK } 19 \\
(p G E M-7 Z f+)\end{array}$ & $\begin{array}{l}\text { A mpr; } 0,68 \text { kb-EcoRI/Xbal-PCR- } \\
\text { Fragment stromabwärts von orfE }\end{array}$ & 3,7 & diese Arbeit \\
\hline $\begin{array}{l}\text { pGK } 21 \\
(\text { pGEM-7Zf }+)\end{array}$ & $\begin{array}{l}\text { A mpr', Kmr; nptl-Marker in Smal } \\
\text { (MCS) von pBK16 }\end{array}$ & 5,0 & diese Arbeit \\
\hline $\begin{array}{l}\text { pGK22 } \\
(\text { pGEM-7Zf }+)\end{array}$ & $\begin{array}{l}\text { A mpr', Km; nptl-Marker in Smal } \\
\text { (MCS) von pBK18 }\end{array}$ & 4,9 & diese Arbeit \\
\hline $\begin{array}{l}\text { pGK23 } \\
(p G E M-7 Z f+)\end{array}$ & $\begin{array}{l}\text { Ampr', Kmr; 2,0 kb-BamHI/Xbal- } \\
\text { Fragment aus pGK21 } \\
\text { inpGK16( } \square \text { orfC:: nptII) }\end{array}$ & 5,8 & diese Arbeit \\
\hline $\begin{array}{l}\text { pGK } 24 \\
(p G E M-7 Z f+)\end{array}$ & 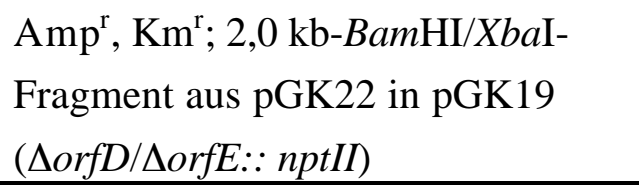 & 5,6 & diese Arbeit \\
\hline $\begin{array}{l}\text { pUK 25 } \\
\text { (pUC18) }\end{array}$ & $\begin{array}{l}\text { A mpr; } 0,4 \text { kb-BamHI/Xbal-PCR- } \\
\text { Fragment des Promotors von filA }\end{array}$ & 3,1 & diese Arbeit \\
\hline $\begin{array}{l}\mathrm{pBK} 27 \\
(\mathrm{pBK})\end{array}$ & $\begin{array}{l}\text { Tetr; 0,4 bp-EcoRI/Xbal-Insert aus } \\
\text { pUK25 (filA -Promotor lacZ- } \\
\text { fusioniert) }\end{array}$ & 10,9 & diese Arbeit \\
\hline $\begin{array}{l}\text { pUK29 } \\
\text { (pUC18) }\end{array}$ & $\begin{array}{l}\text { Ampr', Sm; ; -Marker aus pBS01 in } \\
\text { Hincll (MCS) von pUK13 }\end{array}$ & 5,1 & diese Arbeit \\
\hline $\begin{array}{l}\text { pUK } 30 \\
\text { (pUC18) }\end{array}$ & $\begin{array}{l}\text { Amp', Smr; } 2,0 \text { kb-Pstl/EcoRI- } \\
\text { Fragment aus pUK } 29 \text { mit stumpfen } \\
\text { Enden in pUK } 12 \text { ( } \square \text { filA:: } \square \text { ) }\end{array}$ & 5,5 & diese Arbeit \\
\hline $\begin{array}{l}\text { pKK } 32 \\
(p R K 415)\end{array}$ & $\begin{array}{l}\text { Tet', Km'; enthält Mutationsort der } \\
\text { Pilus-Mutante K } 102 \text { als 3,6- } \\
\text { EcoRI/Sacl-Fragment (filA, } \\
\text { orfB::nptI) }\end{array}$ & 14,1 & diese Arbeit \\
\hline $\begin{array}{l}\text { pKK } 33 \\
(p R K 415)\end{array}$ & $\begin{array}{l}\text { Tetr, Km; 3,6 kb-EcoRI/Sacl- } \\
\text { Fragment aus pGK11 (filA::nptI, } \\
\text { orfB) }\end{array}$ & 14,1 & diese Arbeit \\
\hline $\begin{array}{l}\text { pKK } 34 \\
(p R K 415)\end{array}$ & 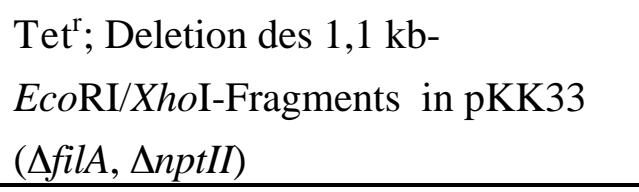 & 13,0 & diese Arbeit \\
\hline $\begin{array}{l}\text { pKP35 } \\
(\text { pRK 415) }\end{array}$ & $\begin{array}{l}\text { Tet'; 0,58 bp-Xbal/stumpfes Ende- } \\
\text { comP-PCR-Produkt in pBK27 (filA- } \\
\text { Promotor vor comP) }\end{array}$ & 11,1 & diese Arbeit \\
\hline $\begin{array}{l}\text { pBN01 } \\
(\mathrm{pBKIIKS+)}\end{array}$ & $\begin{array}{l}\text { A mpr; } 0,69 \text { kb-Pstl/Xbal-PCR- } \\
\text { Fragment von fimA }\end{array}$ & 3,7 & diese Arbeit \\
\hline
\end{tabular}




\begin{tabular}{|c|c|c|c|}
\hline $\begin{array}{l}\text { pBNO2 } \\
(\mathrm{pBKIIKS+)}\end{array}$ & $\begin{array}{l}\text { A mpr; Deletion von EcoRI in MCS } \\
\text { von pBN01 durch Ligation glatter } \\
\text { Enden von Pst und EcoRV }\end{array}$ & 3,7 & diese Arbeit \\
\hline $\begin{array}{l}\text { pBN03 } \\
\text { (pBKIIKS+) }\end{array}$ & $\begin{array}{l}\text { A mpr }{ }^{r}, \mathrm{Km} \text {; } \text { nptll-Marker in EcoRI } \\
\text { von pBN02 (fimA::nptlI) }\end{array}$ & 4,9 & diese Arbeit \\
\hline $\begin{array}{l}\text { pUN09 } \\
\text { (pUC18) }\end{array}$ & $\begin{array}{l}\text { A mpr'; 0,3 kb-BamHI/Xbal-PCR- } \\
\text { Fragment des Promotorbereichs von } \\
\text { fimA }\end{array}$ & 3,0 & diese Arbeit \\
\hline $\begin{array}{l}\text { pBN10 } \\
(\mathrm{pBK})\end{array}$ & $\begin{array}{l}\text { Tet'; 0,3 bp-EcoRI/Xbal-Insert aus } \\
\text { pUK25 (fimA-Promotor lacZ- } \\
\text { fusioniert) }\end{array}$ & 12,7 & diese Arbeit \\
\hline $\begin{array}{l}\text { pMD05 } \\
\text { (pMal-c2) }\end{array}$ & $\begin{array}{l}\text { Ampr', 0,33 kb-PCR-Produkt } \\
\text { (EcoRI/Xbal) von comEA (ohne } \\
\text { Signal sequenz) }\end{array}$ & 6,9 & diese Arbeit \\
\hline $\begin{array}{l}\text { pUD08 } \\
\text { (pUC18) }\end{array}$ & $\begin{array}{l}\text { A mpr }{ }^{r}, 0,75 \text { kb-Pst/Xbal-PCR- } \\
\text { Produkt von comEA in pUS01 } \\
\text { (comEA) }\end{array}$ & 5,4 & diese Arbeit \\
\hline $\begin{array}{l}\text { pUD09 } \\
\text { (pUC18) }\end{array}$ & $\begin{array}{l}\text { Ampr', Sml, Km; nptlI-Marker in } \\
\text { Sspl von pUD08 (comEA::nptlI) }\end{array}$ & 6,6 & diese Arbeit \\
\hline $\begin{array}{l}\text { pBD10 } \\
(\mathrm{pBK})\end{array}$ & $\begin{array}{l}\text { Tetr; 0,46 bp-Pstl/Sacl-Insert aus } \\
\text { pUD08 mit glatten Enden in } \\
\text { EcoRI/Xbal (comEA lacZ-fusioniert) }\end{array}$ & 12,9 & diese Arbeit \\
\hline $\begin{array}{l}\text { pKD11 } \\
(p R K 415)\end{array}$ & $\begin{array}{l}\text { Tetr; 0,75 bp-Pstl/Xbal-Insert aus } \\
\text { pUD08 in Pstl/HindllI (Xbal, } \\
\text { HindllI 'blunt end' ligiert) (comEA) }\end{array}$ & 11,3 & diese Arbeit \\
\hline $\begin{array}{l}\text { pPD12 } \\
(p R K 415)\end{array}$ & $\begin{array}{l}\text { Tet'; 0,48 bp-PCR-comEA-Produkt } \\
\text { in Pst/Sacl von pRP1 (comP- } \\
\text { Promotor vor comEA) }\end{array}$ & 12,4 & diese Arbeit \\
\hline $\begin{array}{l}\text { pMA03 } \\
\text { (pMal-c2) }\end{array}$ & $\begin{array}{l}\text { Ampr; 0,83 kb- EcoRI/Xbal -PCR- } \\
\text { Produkt von comA (C-Terminus) }\end{array}$ & 7,4 & diese Arbeit \\
\hline $\begin{array}{l}\text { pUB01 } \\
\text { (pUC18) }\end{array}$ & $\begin{array}{l}\text { Ampr; } 1,3 \text { kb- Sacl/Xbal -PCR- } \\
\text { Fragment von phaC }\end{array}$ & 4,0 & diese Arbeit \\
\hline $\begin{array}{l}\text { pUB02 } \\
\text { (pUC18) }\end{array}$ & $\begin{array}{l}\text { A mp'; Kmr; nptl I-Marker in BstXI } \\
\text { von pUB01 (phaC::nptlI) }\end{array}$ & 5,2 & diese Arbeit \\
\hline
\end{tabular}




\subsection{Zellanzucht}

\subsubsection{Nährmedien}

Die unten aufgeführten Nährmedien konnten entweder als Flüssigmedium oder als feste Nährböden verwendet werden. Feste Medien wurden durch Zusatz von 1,5\% (w/v) Agar zu der entsprechenden Nährlösung hergestellt, wobei für Mineralmedien Bactoagar und für andere Medien J apanagar verwendet wurde. Mineralmedien wurden mit $\mathrm{H}_{2} \mathrm{O}_{\text {dest. }}$ angesetzt, alle anderen Medien mit $\mathrm{H}_{2} \mathrm{O}_{\text {demin. }}$. Schließlich waren die Medien für 20 min bei $121^{\circ} \mathrm{C}$ zu autoklavieren.

\subsubsection{M ineralmedium}

Das Mineral medium (ORNSTON \& STANIER 1966) für die Anzucht von Acinetobacter setzte sich aus einer Mineral lösung und einem Phosphatpuffer zusammen:

Phosphatpuffer
$\begin{array}{lr}\mathrm{KH}_{2} \mathrm{PO}_{4} & 3,4 \mathrm{~g} \\ \mathrm{Na}_{2} \mathrm{HPO}_{4} \times 2 \mathrm{H}_{2} \mathrm{O} & 4,4 \mathrm{~g} \\ \mathrm{H}_{2} \mathrm{O}_{\text {dett }} \mathrm{ad} & 1000 \mathrm{~m} \\ \mathrm{pH} 6,8 & \end{array}$

\section{Minerallösung}

$\begin{array}{ll}\mathrm{NH}_{4} \mathrm{Cl} & 1 \mathrm{~g} \\ \mathrm{MgSO}_{4} \times 7 \mathrm{H}_{2} \mathrm{O} & 0,58 \mathrm{~g} \\ \mathrm{KNO}_{3} & 0,1 \mathrm{~g} \\ \mathrm{CaCl}_{2} \times 2 \mathrm{H}_{2} \mathrm{O} & 67 \mathrm{mg} \\ \left(\mathrm{NH}_{4}\right)_{6} \mathrm{M} \mathrm{O}_{7} \mathrm{O}_{24} \times 4 \mathrm{H}_{2} \mathrm{O} & 2 \mathrm{mg} \\ \mathrm{SL} 9 & 1 \mathrm{~m} \\ \mathrm{H}_{2} \mathrm{O}_{\text {dest. }} & \text { ad } 1000 \mathrm{~m}\end{array}$

Die beiden Komponenten wurden als $20 f a c h$ konzentrierte Lösungen angesełzt und getrennt autoklaviert. Nach dem Abkühlen auf unter $50^{\circ} \mathrm{C}$ wurden diese im gleichen Verhältnis unter Berücksichtigung der Verdünnung kurz vor Gebrauch gemischt und mit der gewünschten Kohlenstoffquelle versetzt. In Tab. 2.4 sind die dem Mineralmedium zugesetzten Kohlenstoffquel len aufgeführt.

Tab. 2.4: Substrate für das Mineralmedium

\begin{tabular}{lcc}
\hline Substrat & Stammlösung (in $\mathrm{H}_{2} \mathrm{O}_{\text {det. }}$ ) & Endkonzentration \\
\hline Succinat (Na-Salz) & $1 \mathrm{M}$ & $20 \mathrm{mM}$ \\
Benzoat (Na-Salz) & $1 \mathrm{M}$ & $5 \mathrm{mM}$ \\
p-Hydroxybenzoat & $1 \mathrm{M}$ & $5 \mathrm{mM}$ \\
\hline
\end{tabular}


Spurenelementlösung (SL) 9 (TSCHECH \& PFENNIG 1984; modifiziert)

$\begin{array}{lr}\text { Titriplex } & 2,8 \mathrm{~g} \\ \text { Fe(II) } \mathrm{SO}_{4} \times 7 \mathrm{H}_{2} \mathrm{O} & 2 \mathrm{~g} \\ \mathrm{CoCl}_{2} \times 6 \mathrm{H}_{2} \mathrm{O} & 190 \mathrm{mg} \\ \mathrm{MnCl}_{2} \times 4 \mathrm{H}_{2} \mathrm{O} & 122 \mathrm{mg} \\ \mathrm{ZnCl}_{2} & 70 \mathrm{mg} \\ \mathrm{NaMoO}_{4} \times 2 \mathrm{H}_{2} \mathrm{O} & 36 \mathrm{mg} \\ \mathrm{NiCl}_{2} \times 6 \mathrm{H}_{2} \mathrm{O} & 24 \mathrm{mg} \\ \mathrm{H}_{3} \mathrm{BO}_{3} & 6 \mathrm{mg} \\ \mathrm{CuCl}_{2} \times 2 \mathrm{H}_{2} \mathrm{O} & 2 \mathrm{mg} \\ \mathrm{H}_{2} \mathrm{O}_{\text {dest }} & \text { ad } 1000 \mathrm{~m}\end{array}$

\subsubsection{Komplexmedien}

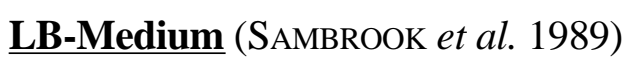

$\begin{array}{lrl}\text { Trypton } & 10 \mathrm{~g} \\ \text { Hefextrakt } & 5 \mathrm{~g} \\ \mathrm{NaCl} & 10 \mathrm{~g} \\ \mathrm{H}_{2} \mathrm{O}_{\text {demin. }} \text { ad } 1000 \mathrm{ml}\end{array}$

SOB-M edium (HANAHAN 1983)

$\begin{array}{ll}\text { Trypton } & 20 \mathrm{~g} \\ \text { Hefeextrakt } & 5 \mathrm{~g} \\ \mathrm{NaCl} & 10 \mathrm{mM} \\ \mathrm{KCl} & 2,5 \mathrm{mM} \\ \mathrm{MgCl}_{2} & 10 \mathrm{mM} \\ \mathrm{MgSO}_{4} & 10 \mathrm{mM} \\ \mathrm{H}_{2} \mathrm{O}_{\text {demin. }} & \text { ad } 1000 \mathrm{~m}\end{array}$

\subsubsection{Antibiotika}

Von den Antibiotika wurden Stammlösungen in $\mathrm{H}_{2} \mathrm{O}_{\text {dest. }}$ angesetzt, die bei $-20^{\circ} \mathrm{C}$ aufbewahrt wurden. Die Antibiotika wurden den autoklavierten Nährlösungen erst nach deren Abkühlen auf weniger als $50^{\circ} \mathrm{C}$ zugegeben. Tetracyclinhaltige Medien wurden lichtgeschützt gel agert. Tab. 2.5 zeigt eine Übersicht der verwendeten Antibiotika und der eingesetzten Konzentrationen. 
Tab. 2.5: Antibiotika

\begin{tabular}{ccc}
\hline Antibiotikum & $\begin{array}{c}\text { Stammlösung } \\
(\mathrm{mg} / \mathrm{m})\end{array}$ & $\begin{array}{c}\text { Endkonzentration } \\
(\mu \mathrm{g} / \mathrm{m})\end{array}$ \\
\hline Ampicillin & 100 & 100 \\
Kanamycin & 20 & 20 \\
Tetracyclin & 15 & 15 \\
Streptomycin & 20 & 20 \\
\hline
\end{tabular}

\subsubsection{Zellanzucht}

Acinetobacter- und E. coli-Stämme wurden aerob in Flüssigkulturen in Reagenzgläsern, Erlenmeyerkolben mit Schikanen oder 3 I-Kleyverkol ben angezogen. Kulturen von Acinetobacter wurden in Mineral medium mit Kohlenstoffquelle oder in LBMedium bei $30^{\circ} \mathrm{C}$, E. coli in LB-Medium bei $37^{\circ} \mathrm{C}$ auf einem Rotationsschüttler (Typ RC 108, Infors AG, Basel) inkubiert. Eine Massenanzucht erfolgte in einem 100 I Fermenter (UD 100) der Firma Braun (Melsungen). Hauptkulturen wurden - wenn nicht anders angegeben - 3\%ig ( $\mathrm{v} / \mathrm{V})$ mit einer Vorkultur angeimpft. Die Kultivierung auf festen Medien erfolgte beim Wachstum auf LB-Platten bei den o.g. Temperaturen über Nacht; auf Mineral medium wurde Acinetobacter für 1 bis 1,5 Tage inkubiert.

\subsubsection{M essung der optischen Dichte}

Der Wachstumsverlauf einer Flüssigkultur konnte photometrisch durch Bestimmung der optischen Dichte bei einer Wellenlänge von $600 \mathrm{~nm}\left(\mathrm{OD}_{600}\right)$ gegen den Medienl eerwert verfolgt werden. DieOD wurde dabei in einer Küvette (Schichtdicke $1 \mathrm{~cm}$ ) mit einem PM 4Spektral photometer (Carl Zeiss, Oberkochen) bestimmt. Um Meßungenauigkeiten zu vermeiden, mulsten die Proben ab einer OD von 0,3 mit Medium verdünnt werden.

\subsubsection{R einheitskontrolle und Stammhaltung}

Die Reinheitskontrolle der Kulturen erfol gte mikroskopisch, wobei Acinetobacter als unbewegliches, abgerundetes Kurzstäbchen - oft assoziiert als Diplokokken - zu erkennen war. Durch Ausstrich auf Selektiv- bzw. Komplexmedium konnten auch Kol oniemorphologie und Färbung als I dentifizienungsmerkmal e herangezogen werden. 
Für eine längere Konservierung der Bakterienstämme mußte eine Stammsarmmlung angelegt werden, die bei $-70^{\circ} \mathrm{C}$ aufzubewahren war. Dafür wurde eine Reinkultur über Nacht in LB-Medium angezogen und mit 30\% (v/v) Glycerin bzw. 10\% (v/v) Dimethylsulfoxid (DMSO) versetzt. Davon wurde $1 \mathrm{ml}$ in einem sterilen SchraubEppendorf-Reaktionsgefäß bei $-70^{\circ} \mathrm{C}$ eingefroren. Um nicht auf die Stammsammlung zurückgreifen zu müssen, wurde für den täglichen Gebrauch der Bakterienstämme eine Kultur auf Agarplatten mit Selektivmediumangezogen. Bei $4^{\circ} \mathrm{C}$ waren dieKulturen, je nach Stamm, mehrereWochen lagerfähig.

\subsection{Standardtechniken für das Arbeiten mit DNA}

\subsubsection{I solierung von Plasmiden}

Für die Isolierung von Plasmiden aus E. coli-Klonen wurde der 'QIApräp Spin'Plasmidisolierungskit (Qiagen $\mathrm{GmbH}$, Hilden) verwendet und in der dort vorgeschriebenen Weise verfahren. Hiebei wurden beim Vorliegen von 'High Copy Plasmiden ' $3 \mathrm{ml}$ einer in LB-Medium (2.2.1.2) über Nacht gewachsenen Zellkultur durch Zentrifugation sedimentiert und der Überstand sorgfältig abgenommen. Die Zellen wurden in $250 \mu \mathrm{l} \mathrm{P1-}$ Puffer sehr gut resuspendiert, mit $250 \mu \mathrm{l}$ P2-Puffer versetzt, vorsichtig gemischt und 5 min bei RT inkubiert. Die Denaturierung der Proteine im Zelllysat erfolgte durch Zugabe von $350 \mu \mathrm{l}$ P3-Puffer und die Sedimentation dieser Proteine und Zelltrümmer durch eine 10minütige Zentrifugation be RT (13000 Upm; Biofuge 17 S). Zur Bindung der Plasmide wurde der klare Überstand auf eine Plasmidpräp-Säule gegeben, 1 min zentrifugiert (13000 Upm, RT) und der Durchfluß verworfen. Diente das Plasmid für eine spätere Sequenzierung, so wurde zur Entfernung von Protein- und Membranrückständen ein zusätzlicher Zentrifugationsschritt mit 500 ml PB-Puffer zwischengeschaltet (1 min, 13000 Upm, RT). Nachdem $750 \mu$ l Waschpuffer (PE) auf die Säule gegeben worden war und zum vollständigen Entfernen des Puffers zweimal 1 min zentrifugiert wurde (13000 Upm, RT), konnten die an dem Säulenmaterial haftenden Plasmide durch Zugabe von $50 \mu$ l Elutionspuffer (EP) oder $\mathrm{H}_{2} \mathrm{O}_{\text {dest, }}$ 1minütiger Inkubation bei $\mathrm{RT}$ und anschließender Zentrifugation (1 min, 13000 Upm, RT) duiert werden.

Für die Isolierung von 'Low Copy Plasmiden' (z.B. pRK415-, pBK-Derivaten) dienteeine $15 \mathrm{ml}-K u l t u r$, dessen geemtete Zellen mit jeweils der doppelten Menge an P1-, P2- und P3-Puffer versehen wurden, wobe wie oben beschrieben zu verfahren war. Durch diesel be Plasmidpräp-Säule wurde daraufhin zweimal hintereinander dieses Lysat zentrifugiert und danach mit den Waschschritten weiter verfahren wie bereits beschrieben. 


\section{Puffer 1}

Tris- $\mathrm{HCl} \quad 1,2 \mathrm{~g}$

EDTA $\quad 0,74 \quad \mathrm{~g}$

$\mathrm{H}_{2} \mathrm{O}_{\text {demin. }} \quad$ ad $200 \quad \mathrm{ml}$

$\mathrm{pH} 8,0$
Puffer 2

$\mathrm{NaOH} \quad 0,8 \mathrm{~g}$

SDS $\quad 1 \%(\mathrm{w} / \mathrm{v})$

$\mathrm{H}_{2} \mathrm{O}_{\text {demin. }}$ ad $100 \mathrm{~m}$

\section{Puffer 3}

$\begin{array}{lrl}\text { K-Acetat } & 63 & \mathrm{~g} \\ \mathrm{H}_{2} \mathrm{O}_{\text {demin. }} & \text { ad } 200 & \mathrm{~m} \\ \mathrm{pH} 5,5 & & \end{array}$

\section{RNase A-Lösung}

Die RNase A wurde in einer Konzentration von $10 \mathrm{mg} / \mathrm{ml}$ in $10 \mathrm{mM}$ Tris- $\mathrm{HCl}$ $\mathrm{pH} 7,5 / 15 \mathrm{mM} \mathrm{NaCl}$ gelöst, $15 \mathrm{~min}$ auf $85^{\circ} \mathrm{C}$ erhitzt, um verhandene DNasen zu denaturieren, und auf RT abgekühlt. DieStammlösung wurde bei $-20^{\circ} \mathrm{C}$ gelagert.

RNase A (Stammlösung) $\quad 70 \mu \mathrm{l}$
TE-Puffer ad $1000 \mu \mathrm{l}$
DieLagerung dieser Lösung erfolgte be $4^{\circ} \mathrm{C}$.

\subsubsection{I solierung chromosomaler DNA mittels DNA-E xtraktionskit}

Der 'Genomic DNA Kit' (Bio-Rad Laboratories GmbH, München) bietet eine schnelle und einfache Methode, um chromosomale DNA aus 0,5 $\mathrm{ml}$ einer über Nacht gewachsenen Kultur unterschiedl ichster Bakterienspezies zu isolieren, wobei ca. 10-30 $\square \mathrm{g}$ DNA extrahiert werden.

DieZellen wurden über Nacht in LB-Medium angezogen, geerntet (RT, 14000 Upm, $30 \mathrm{~s}$, Eppendorf Centrifuge 5417R) und der Überstand entfernt. Durch die Zugabe von $0,3 \mathrm{ml}$ Lyse Lösung und die sich anschließende fünfminütige Inkubation bei $80^{\circ} \mathrm{C}$ efolgte der Aufschlußs der Zellen. Nach Zugabe von 1,5 기 RNaseA-Lösung $(4 \mathrm{mg} / \mathrm{ml})$ wurde die Probe 45 min bei $37^{\circ} \mathrm{C}$ inkubiert bevor bei Raumtemperatur $100 \mathrm{VI}$ Präzipitationslösung hinzugegeben, gut gemixt und die präzipitierten Proteine durch Zentifugation pelletiert wurden (RT, 14000 Upm, 3 min, Eppendorf Centrifuge 5417R). Der Überstand konnte daraufhin in ein frisches Eppendorf-Reaktionsgefäß gegeben werden, worin zuvor 0,3 $\mathrm{ml}$ Isopropanol pi pettiert worden waren. Nach Zentrifugation (RT, 14000 Upm, 1 min, Eppendorf Centrifuge 5417R) war die DNA als weißes Pellet erkennbar. Der Überstand 
wurde entfernt und das Reaktionsgefäß auf saugfähigem Papier getrocknet. Die Resuspendierung erfolgte in 50-100 $\square \mathrm{I}_{2} \mathrm{O}_{\text {dest }}$ über Nacht bei $4^{\circ} \mathrm{C}$.

\subsubsection{Präparative I solierung chromosomaler DNA aus Acinetobacter sp.}

Die Gewinnung von Gesamt-DNA aus Acinetobacter sp. erfolgte über Phonol/Chloroform-Extraktionen, wenn größere Mengen an DNA benötigt wurden (Ausubel et al. 1993). Hierbei lag die Ausbeute bei $0,5 \mathrm{mg}$ DNA. Um die chromosomale DNA vor starken Scherkräften zu bewahren, wurden alle Präparationschritte extrem vorsichtig gehandhabt und für das Pipettieren nur abgeschnittene Spitzen mit großer Öffnung verwendet.

Acinetobacter sp. wurde in $100 \mathrm{ml}$ LB-Medium über Nacht angezogen und am nächsten Tag abzentrifugiert $\left(4^{\circ} \mathrm{C}, 10 \mathrm{~min}, 8000 \mathrm{Upm}\right.$, Sorvall Rotor GSA). Das Pellet wurde in 9,5 ml TE-Puffer (2.3.4) aufgenommen und nach Zugabe von 0,5 ml 10\% (w/v) SDS und $50 \mu \mathrm{l}$ Proteinase K-Lösung ( $20 \mathrm{mg} / \mathrm{ml}$ TE-Puffer) $1 \mathrm{~h}$ bei $37^{\circ} \mathrm{C}$ inkubiert. Nach Zusatz von $1,8 \mathrm{ml} 5 \mathrm{M} \mathrm{NaCl}$ und mehrmaligem Schwenken wurden $1,5 \mathrm{ml} \mathrm{CTAB} / \mathrm{NaCl}-$ Lösung zugegeben und die Suspension für $20 \mathrm{~min}$ be $65^{\circ} \mathrm{C}$ inkubiert. Zur Proteinextraktion wurden $14 \mathrm{ml}$ Chloroform/l soamylalkohol (24:1) zugeseŁt und bei 20000 Upm 20 min zentrifugiert $\left(4^{\circ} \mathrm{C}\right.$, Sorvall, SS34). Die wässrige Oberphase wurde abgenommen und mit $6 \mathrm{ml}$ Phenol versetzt. Nach Zugabe von $6 \mathrm{ml}$ Chloroform/lsoamylalkohol (24:1) mußte nochmals zentrifugiert $\left(4^{\circ} \mathrm{C}, 20 \mathrm{~min}, 20000 \mathrm{Upm}\right.$, Sorvall Rotor SS34) und die DNAhaltige Oberphase nochmals mit $12 \mathrm{ml}$ Chloroform/lsoamylalkohol (24:1) extrahiert werden. Durch Zugabe von 0,8 Vol. Isopropanol wurde die DNA gefällt und $30 \mathrm{~min}$ bei 15000 Upm (RT, Sorvall Rotor SS34) pelletiert. Die DNA konnte bei RT getrocknet, in $1 \mathrm{ml}$ TE-Puffer (2.3.7) oder $\mathrm{H}_{2} \mathrm{O}_{\text {bidest }}$ aufgenommen und anschließend bei $4^{\circ} \mathrm{C}$ aufbewahrt werden.

\section{CTAB/NaCl-Lösung}

$10 \%(w / v)$ Hexadecyltrimethylammoniumbromid

$0,7 \mathrm{M} \quad \mathrm{NaCl}$

\subsubsection{Lagerung von DNA}

Zum Schutz der Pasmid-DNA vor autokatalytischem Zerfall und DNase-Aktivität wurdedieDNA in TE-Puffer gelöst und bei $-20^{\circ} \mathrm{C}$ gelagert Sollte die DNA nur kurze Zeit gel agert und bald weiter verarbeitet werden, so konnte diese in $\mathrm{H}_{2} \mathrm{O}_{\text {dest. }}$ gel öst werden. 


\section{TE-Puffer}

$\begin{array}{lcr}\text { Tris-HCl } & 1,2 & \mathrm{~g} \\ \text { EDTA } & 0,37 & \mathrm{~g} \\ \mathrm{H}_{2} \mathrm{O}_{\text {dest. }} & \text { ad } 1000 & \mathrm{~m} \\ \mathrm{pH} \mathrm{8,0} & & \end{array}$

\subsubsection{Schnelle I solierung von Plasmiden aus E. coli ('C racking')}

Mit Hilfe der schnellen Plasmidisolierung konnten innerhalb kurzer Zeit mehrere E. coli-Klonen auf ihr rekombinantes Plasmid hin überprüft und identifiziert werden. Die isolierten Plasmide wurden nicht restriktionsgeschnitten, sondern anhand des Laufverhal tens der ccc-Form im Agarosegel identifiziert. Diese Methode eignete sich nur für Plasmide mit hoher Kopienzahl.

Kleine Mengen (ca. 0,2 $\mathrm{VI}$ ) einer frisch gewachsenen Kolonie wurden mit einer Pipettenspitze abgenommen und in 15 पI 10 mM EDTA pH 8,0 resuspendiert. Nach Zugabe von $15 \square$ I Cracking-Puffer ( 0,2 M NaOH, 0,5\% [w/v] SDS, 20\% [w/v] Saccharose) wurde dieProbe 5 min bei $70^{\circ} \mathrm{C}$ inkubiert, auf Eis abgekühlt und anschließend mit 1,5 $\square$ $\mathrm{M} \mathrm{KCl}$ und 0,5 $\square \mathrm{l}$ 0,4\% (w/v) Bromphenolblaulösung versekt und gut gemischt. Nach weiteren 5 min auf Eis wurde die Probe zentrifugiert $\left(4^{\circ} \mathrm{C}, 5 \mathrm{~min}, 15000 \mathrm{Upm}\right.$, Biofuge 17 RS) und 20 $\square$ I des Überstands direkt für dieAgarose-Gelelektrophorese (2.3.6) eingesetzt.

\subsubsection{G elelektrophorese von DNA im Agarosegel}

DNA-Fragmente wurden in horizontalen Elektrophoresekammern eigener Bauart elektrophoretisch aufgetrennt. Verwendet wurde 0,8-1,0\%ige Agarose in TAE-Puffer, der auch als Elektrophoresepuffer diente. Das Gelvolumen betrug bei Minigelen 12,5 m, be Midigelen $25 \mathrm{ml}$ und bei Maxigelen $100 \mathrm{ml}$. Vor dem Auftragen wurden die Proben mit 1/10 Vol Farbstoffschwerelösung ( 6 x Loading Dye, MBI Fermentas, Wilna, Litauen) versetzt. Das Einlaufen der Proben in das Gel erfol gte bei $40 \mathrm{~V}$, die Auftrennung bei 60 bis $100 \mathrm{~V}$.

$\begin{array}{lr}\text { TAE-Puffer } & \\ \text { Tris-Acetat } & 4,8 \mathrm{~g} \\ \text { EDTA } & 0,37 \mathrm{~g} \\ \mathrm{H}_{2} \mathrm{O}_{\text {dett }} & \text { ad } 1000 \mathrm{~m} \\ \mathrm{pH} 8,0 & \end{array}$




\subsubsection{Färbung und Fotografie von DNA in Agarose- oder Polyacrylamidgelen}

DNA kann mittels Ethidiumbromidfärbung sichtbar gemacht werden; denn dieser unter UV-Licht floureszierende Farbstoff interkaliert zwischen die Basen und markiert so die DNA. Dafür wurde das $\mathrm{Ge} 15$ min in ein wäßriges Ethidiumbromidbad $(1 \mu \mathrm{g} / \mathrm{m})$ gelegt und anschließend für 5 min in einem $\mathrm{H}_{2} \mathrm{O}-\mathrm{Bad}$ entfärbt. Unter UV-Licht mit einer Wellenlänge von $254 \mathrm{~nm}$ konnte die DNA sichtbar gemacht werden und mit einem Videoprinter (Mitsubishi, Model P78E, Intas, Göttingen) fotografiert werden.

\subsubsection{I solierung von DNA aus A garosegelen}

Diese Methode wurde angewendet, um einzelne DNA-Fragmente aus einem Agarosege zu isolieren. Sie beruht auf der Adsorption von DNA an eine Silicagelmembran in Gegenwart hoher Konzentrationen chaotroper Salze. Benutzt wurde der 'QIAquick Ge Extraction Kit' (Qiagen, Hilden).

Das DNA-Gemisch wurde zunächst in einem Agarosegel aufgetrennt. Das zu isolierende DNA-Fragment mußte unter UV-Licht schnell mit einem Skal pell aus dem Ge ausgeschnitten, in ein zuvor gewogenes 1,5 ml-Reaktionsgefäß überführt und das Gewicht des Gelstückes bestimmt werden. Anschließend wurde das dreifache Volumen des Puffers

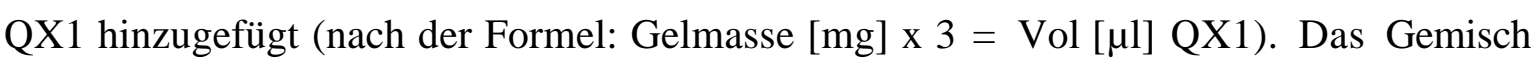
wurde bis zum Auflösen des Gels unter mehrmaligem Schwenken bei $50^{\circ} \mathrm{C}$ inkubiert (ca. 5 min). Es fol gten die Zugabe von $1 \mathrm{Gelvolumen}$ I sopropanol, vorsichtiges Mischen und die Beladung der QIAquick-Säule mit der Lösung. Nach Zentrifugation (RT, 13000 Upm, 1 min, Biofuge 17 RS) wurde der Durchfluß verworfen und die Säule mit 0,75 ml PE-Puffer gewaschen (RT, 13000 Upm, 1 min, Biofuge 17 RS). Zur vollständigen Entfernung des Waschpuffers wurde nach Verwerfen des Durchflusses nochmals zentrifugiert (RT, 13000 Upm, 1 min, Biofuge 17 RS), bevor die Säule in ein 1,5 mReaktionsgefäß überführt wurde. Die Elution der DNA erfolgte durch 1minütige Inkubation mit $30 \mu \mathrm{l} \mathrm{H}_{2} \mathrm{O}_{\text {demin. }}$ und anschließende Zentrifugation (RT, 13000 Upm, 1 min, Biofuge 17 RS). 


\subsection{Enzymatische Modifikationen von DNA}

\subsubsection{Restriktionsverdau von DNA}

Für den enzymatischen Restriktionsverdau von DNA wurden 0,5-1 $\mu \mathrm{g}$ DNA in $\mathrm{H}_{2} \mathrm{O}_{\text {dest }}$ aufgenommen und mit 0,1 Vol Reaktionspuffer (10fach konzentriert) versetzt. Bei einem Reaktionsvolumen von $20 \mu \mathrm{l}$ startete der Verdau mit maximal 0,5 $\mu \mathrm{l}$ Enzymlösung, wonach eine Inkubation für 2-12 h bej der für das jeweilige Enzym optimal en Temperatur (i.d.R. $37^{\circ} \mathrm{C}$ ) erfolgte. Die verdaute DNA konnte anschließend für Ligationen (2.4.4) oder Fragmentisolierungen (2.3.8) eingesetzt werden. Bei Restriktionsspaltungen chromosomaler DNA wurde diese zunächst zum Entknäulen $10 \mathrm{~min}$ bei $60^{\circ} \mathrm{C}$ inkubiert. Dem Restriktionsansatz wurden gegebenenfalls zuvor $2 \mu$ l Spermidin (Stammlösung $1 \mathrm{M}$ ) pro $50 \mu l$ Ansatz zugefügt, um die Spal tbarkeit der DNA zu erhöhen (BOuCHE 1981).

\subsubsection{Herstellung von stumpfen DNA-E nden}

Sollten DNA-Fragmente ligiert werden, die keine oder nur eine mit der Klonierungsstelle des Vektors kompatible Restriktionsschnittstelle aufwiesen, mulsten die 5'-Überhänge mit Hilfe des Klenow-Fragmentes der DNA-Polymerasel aus E. coli mit Nukleotiden zu stumpfen Enden aufgefüllt bzw. abgedaut werden. Die dazu verwendeten Komponenten stammten aus dem Erase-a-Base-System (Promega/Serva, Heidelberg). Die Enzyme im Restriktionsansatz wurden nach Herstellerangaben hitzeinaktiviert, der Ansatz mit $1 \times$ Klenowpuffer auf $18 \mu \mathrm{l}$ aufgefüllt und mit $0,3 \mu \mathrm{l}$ Klenow-Fragment $(2,5 \mathrm{U} / \mu \mathrm{l})$ versetzt. Nach einer zehnminütigen Inkubation bei $37^{\circ} \mathrm{C}$ wurden $1 \mu \mathrm{l}$ dNTP-M ix $(0,4 \mathrm{mM})$ hinzugegeben und der Ansatz weitere 30 min be $37^{\circ} \mathrm{C}$ inkubiert. Dieser konnte nun für eine Ligation stumpfer Enden (2.4.4) eingesetzt werden.

\subsubsection{Dephosphorylierung von DNA}

Zur Vermeidung von Sel bstligationen konnte lineare Plasmid-DNA an den 5-Enden mittels alkalischer Phosphatase aus Kälberdarm (CIP) dephosphoryliert werden (SAMBRock et al. 1989). Dafür wurden $100 \mu$ l Plasmid-DNA-Lösung mit 0,05 U CIP und CIP-Puffer für 30 min be $37^{\circ} \mathrm{C}$ inkubiert. Durch Zugabe von $7 \mu \mathrm{l} 10 \%$ (w/v) SDS, 1,4 m $0,5 \mathrm{M}$ EDTA und $0,7 \mu \mathrm{l}$ Proteinase $\mathrm{K}(20 \mathrm{mg} / \mathrm{ml})$ wurde die Reaktion nach 30minütiger Inkubation bei $56^{\circ} \mathrm{C}$ abgestoppt. 


\subsubsection{Ligation von DNA-Fragmenten}

Bei einer Ligation wird eine Phosphodiesterbindung zwischen doppelstängigen DNA-Fragmenten gebil det, die mindestens ein freies 3'-Hydroxyende und 5' -Phosphatende besitzen. Da der Erfolg einer Ligation u.a. von Länge und Konzentration der Vektor- und der zu inserierenden DNA abhängt, wurde das zu ligierende DNA-Fragment in 4-6fachem Überschuß eingesetzt. Vor der Ligation wurden die Restriktionsenzyme in den DNALösungen durch 10minütiges Erhitzen auf $65-85^{\circ} \mathrm{C}$ inaktiviert. Ligationen erfol gten in einem

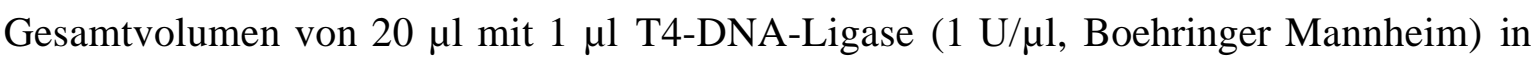
dem vom Hersteller gelieferten Puffer. Der Ligationsansatz wurde für $2 \mathrm{~h}$ bei $22^{\circ} \mathrm{C}$ oder ca. $16 \mathrm{~h}$ bei $16^{\circ} \mathrm{C}$ inkubiert. Anschließend konnte er direkt zur Transformation von E. coli eingesetzt werden (2.7.2.2).

\subsubsection{N-terminale Sequenzierung von Proteinen}

DieN-terminale Ansequenzierung der Proteine wurde von DR. J. KeLLeRMANN (MPI für Biochemie, Martinsried) durchgeführt.

\subsubsection{E nzymatische Spaltungen von Proteinen im Polyacrylamidgel}

DieSpaltung der Proteine im SDS-Gel und deren Elution sowie die Auftrennung der entstandenen Polypeptide wurde nach der fol genden Vorgehensweise durchgeführt:

\section{Spaltung}

- Ge mit Coomassie färben und mit 10\% Essigsäure entfärben

- Proteinbande und Referenzbande aus dem Gel ausschneiden (Gel ohne Protein sol lteso groß wie Proteinbande sein)

- durch ein Sieb drücken und zerkleinern (Poren $30 \mu \mathrm{mx} .100 \mu \mathrm{m}$ )

- Zerquetschtes Gel mit_konz. Inkubationspuffer 2 min waschen (12,5 mM Tris, 0,5 mM EDTA, pH 8,5 bei Endo LysC)

- abzentrifugieren und Puffer entfemen

- $1 \mathrm{~h}$ im "speedvac" antrocknen (ca 5\% Restwasser; "gummiartig")

- Endoprot Lys C in $400 \mu \mathrm{l}$ 12,5 mM Tris-HCl, pH 8,5 lösen

(Enzym: Protein $=1: 10)+0.1 \%$ Laurylmal tosit

- je $200 \mu \mathrm{l}$ zu Probe und Referenz geben und $6 \mathrm{~h}$ (bis über Nacht) bei $37^{\circ} \mathrm{C}$ im Heizblockschüttler inkubieren 


\section{Elution}

- $2 \times 1 \mathrm{~h}$ mit $1 \%$ TFA inkubieren, danach abzentrifugieren

- anschließend $1 \times 3 \mathrm{~h}$ mit 10\% Ameisensäure, 20\% I sopropanol, $60 \%$ Acetonitril eluieren, mit den anderen Eluaten vereien und auf die HPLC auftragen.

\section{Trennung über HPLC}

Säule: Purospher 60 RP18e (Merck, Darmstadt) $1 \mathrm{~mm} \times 150 \mathrm{~mm}$

Puffer A: $0.1 \%$ Trifluoressigsäure

Puffer B: $0.085 \%$ TFA in Acetonitril

Flußrate: $20 \mu /$ min Gradient: 5 - 60\% in 90 min

Detektion: $206 \mathrm{~nm}$

Der N-terminale Abbau der Aminosäuren (EdMAN \& BEGG 1967) erfolgt in einem automatischen Sequencer Procise 492 (Applied Biosystems, PE)

\subsubsection{2 „in situ“-Verdau membrangebundener Proteine (Patterson 1994)}

Die PVDF-Membran mit der Proteinbande (gleiche Prozedur mit Membran ohne Protein als Negativkontrolle) wurde in 3mm x 3mm Stücke geschnitten und in einem 1,5 mlReaktionsgefäßs mit $500 \mu \mathrm{l}$ Quench-Lösung 30 min bei Raumtemperatur inkubieren. Daraufhin wurde der Überstand mit einer Pasteurpi pette abgenommen, die Membranstücke 8x mit $\mathrm{H}_{2} \mathrm{O}_{\text {dest }}$ und anschließend $1 \mathrm{x}$ mit Verdaupuffer gewaschen. Es folgte die Zugabe von 0,75 $\mu \mathrm{g}$ Enzym (Trypsin 'sequencing grade', Boehringer Mannheim) in möglichst wenig Verdaupuffer (Membran mußte bedeckt sein) und eine 8 stündige Inkubation bei $37^{\circ} \mathrm{C}$. Der Überstand wurde abgenommen und in ein zweites 1,5 ml-Reaktionsgefäß überführt bevor die Membran 2x mit 1\% TFA + 0,2\% Laurylmaltosit im Ultraschall gewaschen, abzentrifugiert und ebenfalls in en Reaktionsgefäß überführt wurde. Anschließend mußte nocheinmal mit 10\% Ameisensäure, 20\% Isopropanol, 20\% Acetonitril gewaschen und die Überstände eingeengt werden. Die Polypetide konnten schließlich über die HPLC aufgetrennt werden.

Vor Injektion der Probe auf die HPLC-Säule wurden $50 \mu$ Inkubationspuffer injiziert. 


\section{Trennung über HPLC}

Säule: Purosphere RP18e (Merck, Darmstadt) $1 \mathrm{~mm} \times 150 \mathrm{~mm}$

Puffer A: 0,1\% Trifluoressigsäure

Puffer B: $0,085 \%$ TFA in Acetonitril

Flußrate: $20 \mu \mathrm{l} / \mathrm{min}$ Gradient: 5 - 60\% in 90 min

Detektion: $206 \mathrm{~nm}$

HPLC: Hewlett Packard 1100

Der N-terminale Abbau der Aminosäuren (EDMAN \& BEGG 1967) erfolgt in einem automatischen Sequencer Procise 492 (Applied Biosystems, PE)

Quench-L ösung: $\quad 0,2 \%$ Polyvinyl pyrolidon (PVP 30) in $\mathrm{H}_{2} \mathrm{O}_{\text {dest }}$

Verdauungspuffer: $\quad 0,025 \mathrm{M}$ Tris- $\mathrm{HCl}, \mathrm{pH} 8,5,1 \mathrm{mM}$ EDTA, $10 \% \mathrm{CH}_{3} \mathrm{CN}$, $0,1 \%$ Laurylmal tosit ( $\mathrm{pH}$ vor Spaltung überprüfen)

\subsection{DNA-A mplifikation durch die Polymerase-K ettenreaktion}

Mit Hilfe der Polymerase-Kettenreaktion (PCR) konnten DNA-Bereiche in vitro amplifiziert werden. Als Polymerase wurde die Vent-Polymerase mit $3^{\prime} \square 5^{\prime}$ Korrekturleseaktivität eingesetzt. Da die zu amplifizierenden DNA-Bereiche mit neven Restriktionsschnittstellen flankiert werden sollten, wurden Primer verwendet, die entsprechend der neuen Schnittsequenzen Fehl paarungen zum DNA-Matrizenstrang aufwiesen. Aufgrund dieser Fehl paarung wurde als Primer-Anlagerungstemperatur $40^{\circ} \mathrm{C}$ gewählt. Die verwendeten Primer waren 21-31 bp lang und besaßen 13 Basenfehl paarungen.

Die von A mionosäuesequenzen abge leiteten Primer wiesen aufgrund der Codierung einer Aminosäure durch mehrere verschiedene Basentripletts, die sich meist in der dritten Position unterschieden, variable Basen auf. Hierbei wurde die Tatsache beachtet, daß Guanin-Tymin-Paarungen die Primeranlagerung nicht behindern und somit die Zahl der variablen Basen eingegrenzt werden konnte. Da die Zahl der Fehlpaarungen der 'gewobbelten' Primer mit 5-6 variablen Basen sehr hoch lag, wurde zur Spezifizienung 60 mM TMAC (Trimethylacetat) und zur Endknäulung der chromosomalen DNA, die als Matrize diente, 2\% (v/v) DMSO (Dimethylsulfoxid) hinzugegeben. Darüber hinaus wurde die PCR in einem Gradientencycler (Mastercycler-Gradient, Eppendorf) mit einem Temperaturgradient von $37^{\circ} \mathrm{C}$ bis $57^{\circ} \mathrm{C}$ durchgeführt. 
Der Ansatz für die PCR wurde auf Eis in einem 0,5 ml-Eppendorf-Reaktionsgefäß aus fol genden Komponenten angesetz:

$\begin{array}{lr}\text { Primer 1 } & 20-100 \mathrm{pmol} \\ \text { Primer 2 } & 20-100 \mathrm{pmol} \\ \text { Matrizen-DNA } & 0,5-1,0 \mathrm{Gg} \\ \text { dNTP-Lösung }(10 \mathrm{mM}) & 2-4 \mathrm{Gl} \\ \text { 10x Puffer } & 10 \mathrm{Gl} \\ \mathrm{H}_{2} \mathrm{O}_{\text {dest. }} & \text { ad } 99,5 \mathrm{Gl} \\ \text { Polymerase }(2 \mathrm{U} / \mathrm{ml}) & 0,5 \mathrm{ll}\end{array}$

Bis auf die Polymerase, wurden alle Komponenten zusammengegeben, gemischt und mit 30 I Wachs überschichtet. Anschließend wurde der Ansatz in einen PCRThermoblock (MiniCycler, Biozym, Hess. Oldendorf) gestellt und 5 min bei $97^{\circ} \mathrm{C}$ denaturiert. Nachdem der Ansatz auf $86^{\circ} \mathrm{C}$ herunter temperiert war, konnte die Polymerase zugegeben werden. Die Amplifikation erfolgte in 30 Zyklen mit folgenden Reaktionsschritten:

$\begin{array}{lll}\text { Denaturierung } & 30 \mathrm{~s} & 97^{\circ} \mathrm{C} \\ \text { Primer-Anlagerung } & 45 \mathrm{~s} & 40^{\circ} \mathrm{C} \text { (bzw. } 37-57^{\circ} \mathrm{C} \text {, Gradientencycler) } \\ \text { Synthese } & 1-4 \text { min } & 72^{\circ} \mathrm{C} \text { (1 kb pro min Synthesezeit) }\end{array}$

Die DNA-Amplifikation wurde anschließend im Agarosegel überprüft (2.3.6) und unter Verwendung der neu eingebauten Schnittstel len in den Vektor (Tab. 2.2) kloniert.

\subsection{Southern-Hybridisierung}

\subsubsection{Markierung von DNA mit Digoxigenin-11-dUTP}

Die Markierung von DNA-Sonden mit Digoxigenin-11-dUTP erfolgte nach der 'random primed'-Methode mit demDIG DNA Labeling Kit (Boehringer Mannheim). Diese Methode beruht auf der Hybridisierung einer Mischung von Hexanukleotiden fast aller möglichen Basensequenzen an die zu markierende DNA. Der komplementäre Strang wird anschließend unter Einbau von Dig-11-dUTP von den 3'-Enden der 'random primer' durch das Klenow-Enzym synthetisiert. Für die Markierungsreaktion wurden 3-10 $\mu \mathrm{g}$ DNA durch 10 minütiges Erhitzen auf $95^{\circ} \mathrm{C}$ und anschließendes sofortiges Abkühlen in Eis/ $/ \mathrm{NaCl}$ 
denaturiert. Unter weiterer Inkubation auf Eis wurde die DNA-Lösung mit $2 \mu \mathrm{l}$ Hexanukleotidgemisch und $2 \mu \mathrm{l}$ dNTP-Markierungsgemisch versezt und mit $\mathrm{H}_{2} \mathrm{O}$ auf ein Reaktionsvolumen von $19 \mu \mathrm{l}$ gebracht. Die Markierungsreaktion erfolgte bei $37^{\circ} \mathrm{C}$ über Nacht und wurde durch die Zugabe von $2 \mu$ EDTA $(200$ mM, pH 8,0) abgestoppt. Markierte DNA-Sonden konnten bei $-20^{\circ} \mathrm{C}$ gelagert oder nach einer Hitzedenaturierung (10 min, $100^{\circ} \mathrm{C}$ ) direkt für eine Hybridisierung eingesetzt werden.

\subsection{2 Übertragung von DNA auf Nylonmembranen durch Vakuumblot (Peferoen etal. 1982)}

Die Übertragung der zu untersuchenden DNA von einem Agarosegel auf eine Nylonmembran wurde mit einer Vakuumblotapparatur (Vakuumblotter VBII, Biometra, Göttingen) durchgeführt. Im Gegensatz zum DNA-Transfer nach SOUTHERN (1975) wird hier die Übertragung der DNA nicht durch Kapillarkräfte, sondern durch ein Vakuum bewirkt.

Die im Agarose-Midigel aufgetrennte DNA (2.3.6) wurde mit Ethidiumbromid gefärbt und fotografiert (2.3.7). Zur besseren Übertragung großer DNA-Fragmente, mußte das Agarosegel zur Einführung von Strangbrüchen 5 min mit UV-Licht $(\square=254 \mathrm{~nm})$ bestrahlt werden. Entsprechend der Gelgröße wurden ein Chromatographiepapier (Whatman 3MM) sowie eine Nylonmembran (NEF-976, Gene Screen Plus, Du Pont, Bad Homburg) zurechtgeschnitten, für 10 min in $20 \times$ SSC getränkt und anschließend auf die mit $\mathrm{H}_{2} \mathrm{O}$ angefeuchtete Saugunterlage der Vakuumblot Apparatur gelegt. Mit Hilfe einer Plastikmaske, welche die Ränder der Nylonmembran um mindestens $1 \mathrm{~cm}$ überdeckte, wurde der freieTeil der Unterlage luftdicht abgedeckt. Das Agarosegel mußte luftblasenfrei auf die Membran gelegt werden, wobei darauf zu achten war, daß die Geltaschen außerhalb des Maskenfensters lagen. Nach Befestigung des Deckels konnte in der unteren Kammer der Apparatur ein Unterdruck von 55 mbar angelegt werden. Eine 15minütige Überschichtung des Gels in Depurinisierungslösung führte zur Zerkleinerung der DNAFragmente. Zur weiteren Erleichterung des DNA-Transfers wurde das Gel für je 15 min mit Denaturierungslösung bzw. Neutralisationslösung überschichtet. Nicht durchgesaugte Lösungsreste wurden mit einer Glaspi pette abgenommen. Der eigentliche DNA-Transfer fand durch Überschichten des Gels mit 20 x SSC für 30 min statt, wobei der Unterdruck auf 80 mbar erhöht wurde. Nach dem Transfer wurde die Membran zur endgültigen Fixierung der DNA 3 min von beiden Seiten mit UV-Licht bestrahlt, kurz gewässert und auf Chromatographiepapier (Whatman $3 \mathrm{MM}$ ) für 3 min be $80^{\circ} \mathrm{C}$ getrocknet. Die Membran konnte direkt für eine Hybridisierung eingesetzt oder in Folie eingeschweißt bei $4^{\circ} \mathrm{C}$ gelagert werden. 


\section{Denaturierungslösung}

$\mathrm{NaCl}$

$1,5 \mathrm{M}$

$\mathrm{NaOH} \quad 0,5 \mathrm{M}$

$20 \times$ SSC -Puffer

$\mathrm{Na}_{3}-$ Citrat $x 2 \mathrm{H}_{2} \mathrm{O} \quad 88 \mathrm{~g}$

$\mathrm{NaCl}$

$175 \mathrm{~g}$

$\mathrm{H}_{2} \mathrm{O}_{\text {demin. }}$

ad $1000 \mathrm{~m}$

$\mathrm{pH} 7,0$

\section{Neutralisationslösung}

Tris- $\mathrm{HCl} \quad 1,0 \mathrm{M}$

$\mathrm{NaCl} \quad 2,0 \mathrm{M}$

$\mathrm{pH} 5,5$

\section{Depurinisierungslösung}

$\mathrm{HCl} \quad 0,25 \mathrm{~N}$

\subsubsection{Hybridisierung und Detektion}

Hybridisierungen fanden in verschraubbaren Glasröhrchen (Schott, Mainz) von $16 \mathrm{~cm}$ Länge und 3,8 cm Durchmesser statt. Die Membran wurden mit der DNA-haltigen Seite nach innen in die Röhrchen geschoben. Prähybridisierung, Hybridisierung und Waschungen erfolgten bei gleichmäßiger Temperatur und Rotation in einem Hybridisierungsofen (OV2, Biometra, Göttingen). Die trockene Membran wurden mit $2 \times \mathrm{SSC} / 0,1 \% \mathrm{SDS}(\mathrm{w} / \mathrm{v})$ angefeuchtet und zur Blockierung unspezifischer Bindungsstellen $2 \mathrm{~h}$ mit Hybridisienungslösung ohne Sonde bei $68^{\circ} \mathrm{C}$ prähybridisiert. Für die Hybridisierung wurde anschließend die Vorhybridisierunglösung durch ein Gemisch von Hybridi sierungslösung (2,5 m//100 $\mathrm{cm}^{2}$ Membranfläche) und hitzedenaturierter Dig-DNASonde (20-200 ng/ml) ersetzt. Die Hybridisierung erfolgte bei $68^{\circ} \mathrm{C}$ über Nacht. Nach der Hybridisierung wurde die Hybridisierungslösung abgegossen und konnte bis zu einem J ahr bei $-20^{\circ} \mathrm{C}$ gelagert werden. Um unspezifisch gebundene Sonde zu entfernen, wurde die Membran anschließend $2 \times 5$ min bei RT mit $2 \times$ SSC/0,1\% SDS (w/v), und danach $2 \times 15$ min bei $68^{\circ} \mathrm{C}$ mit $0,1 \times$ SSC/0,1\% SDS (w/v) gewaschen. Anschließend konnte die Membran direkt für die Detektion eingesetzt werden.

\section{Hybridisierungslösung}

Blocking-Stammlösung $20 \mathrm{ml}$

$\mathrm{N}$-Lauroylsarkosin

$2 \mathrm{~m}$

$(10 \%[\mathrm{w} / \mathrm{V}])$

$\operatorname{SDS}(10 \%[\mathrm{w} / \mathrm{v}]) \quad 0,4 \mathrm{ml}$

$20 \times$ SSC-Puffer

$\mathrm{H}_{2} \mathrm{O}_{\text {demin. }}$

$50 \mathrm{ml}$

$\operatorname{ad} 200 \mathrm{ml}$

\section{Blocking-Stammlösung}

Blocking-Reagenz $\quad 10 \mathrm{~g}$

DIG-Puffer 1 ad 100m

Das Blocking-Reagenz wurde im Mikrowellenofen im Puffer gelöst, dann autoklaviert und be $4^{\circ} \mathrm{C}$ gelagert. 
Die Detektion DIG-markierter DNA-Fragmente erfol gte mit dem 'DIG Luminescent Detection Kit (Boehringer Mannheim). Dabei wird das Digoxigenin durch AntiDigoxigenin- $\mathrm{F}_{\mathrm{ab}}-\mathrm{Fragmente,} \mathrm{die} \mathrm{eine} \mathrm{alkal} \mathrm{ische} \mathrm{Phosphatase} \mathrm{tragen,} \mathrm{nachgewiesen.} \mathrm{Be}$ Zugabe von $\mathrm{CSPD}^{\square}$ wird dieses durch die al kal ische Phosphatase dephosphoryliert. Die dabei emittierte Chemilumineszenz ( $\square=477 \mathrm{~nm}$ ) kann auf Röntgenfilmen sichtbar gemacht werden. Die Detektion erfolgte unter leichtem Schwenken bei RT. Die Volumenangaben beziehen sich auf $100 \mathrm{~cm} 2$ Membranfläche Zunächst wurde die Membran 2 min mit $100 \mathrm{ml}$ Waschpuffer gespült, bevor sie $30 \mathrm{~min}$ in $100 \mathrm{ml}$ DIG-Puffer 2 inkubiert wurde. Anschließend wurde die Membran für 30 min in frisch angesetzter Antikörper-KonjugatLösung (4 $\mu$ l Anti-Digoxigenin- $F_{a b}$-Fragment $+40 \mathrm{ml}$ DIG-Puffer 2) inkubiert. Nach $2 \times 15$ minütigem Waschen in $100 \mathrm{ml}$ Waschpuffer erfolgte die Äquilibrienung der Membran für $2 \mathrm{~min}$ in $20 \mathrm{ml}$ DIG-Puffer 3. Anschließend konnte die Membran in Plastikfolie eingeschweißt und $5 \mathrm{~min}$ mit dem chemilumineszenten Substrat $\left(100 \mu \mathrm{l} \mathrm{CSPD}{ }^{\square}+10 \mathrm{~m}\right.$ DIG-Puffer 3) inkubiert werden. Nachdem das Substrat aus der Plastikhülle entfernt worden war, mußte die Membran 15 min in einer Expositionskassette (Intas, Göttingen) bei $37^{\circ} \mathrm{C}$ inkubiert werden. Zur Detektion der emittierten Lumineszenz wurde auf die Folie für 45 min (evt. über Nacht) ein Röntgenfilm exponiert. Der Röntgenfilm wurde anschließend ca. 1 min in Kodak LX24-Lösung entwickelt, kurz gewässert, in Kodak AL4-Lösung fixiert und nach emeuter Wässerung bei RT getrocknet.

Waschpuffer

Tween 20

DIG-Puffer 1
$1,5 \mathrm{~m}$
ad $\quad 500 \mathrm{~m}$

\section{DIG-Puffer 1}

Maleinsäure $\quad 11,6 \mathrm{~g}$

$\mathrm{NaCl} \quad 8,8 \mathrm{~g}$

$\mathrm{NaOH} \quad 7,0 \mathrm{~g}$

$\mathrm{H}_{2} \mathrm{O}_{\text {demin. }} \quad$ ad $1000 \mathrm{ml}$

pH 7,5

\section{DIG-Puffer 3}

Tris $12,1 \mathrm{~g}$

$\mathrm{NaCl}$ $5,8 \mathrm{~g}$ $\mathrm{H}_{2} \mathrm{O}_{\text {demin. }} \quad$ ad $1000 \mathrm{ml}$ pH 9,5 


\subsection{Transfer von DNA in E.coli und Acinetobacter sp.}

\subsubsection{DNA-Übertragung durch K onjugation ('spot mating')}

Um Derivate des Plasmids pRK 415 oder pBK von E. coli DH5a auf Acinetobacter sp. zu übertragen, wurde die Fähigkeit beider Organismen zur Konjugation genut女t (J UNI 1978), wobei hierfür das Helferplasmid pRK2013 erforderlich war. Donor, Rezipient und der E. coli-Stamm, der das Plasmid pRK2013 trägt, wurden getrennt in $5 \mathrm{ml}$ LB-Medium über Nacht unter Selektionsdruck angezogen und am nächsten Morgen abzentrifugiert (RT, 10 min, 3000 Upm, Heraeus Christ-Zentrifuge). Um Antibiotikareste vol Iständig zu entfernen, wurde das Pellet einmal mit LM-Medium gewaschen und anschließend in $4 \mathrm{ml}$ LB-Medium aufgenommen. Für die Konjugation konnten nun Donor, Helferstamm und Rezipient im Verhältnis 1:1:7 zusammengeführt und von diesem Konjugationsgemisch $200 \mu \mathrm{l}$ auf einen Membranfilter (BA85, Schleicher und Schuell, Dassel) pipettiert werden, der zuvor auf eine LB-Platte gelegt wurde. Als Kontrolle (Nachweis auf Spontanmutationen) wurden die jeweils eingesetzten Kulturvolumina des Rezipienten und Donor getrennt auf LB-Platten mit Membranfiltern pipettiert. Konjugationsansatz und Kontrolle wurden nun 1 bis 2 Tage be $30^{\circ} \mathrm{C}$ inkubiert, die bewachsenen Membranfilter daraufhin in $2 \mathrm{~m}$-Reaktionsgefäße mit jeweils 1,5 $\mathrm{m}$ Mineral medium überführt und durch kräftiges Schütteln resuspendiert. Zur Sel ektion der Transkonjuganten wurden 5-50 $\mu \mathrm{l}$ des Konjugationsansatzes und der Kontrollen auf entsprechendem Sel ektivagar ausplattiert. Als Selektionsdruck mußten dabei solche Bedingungen gewählt werden, die nur die Transkonjuganten, nicht aber Rezipiet und Donor wachsen ließen. Für die Selektion bezüglich Acinetobacter erfolgte die Ausplattierung auf Succinat-Mineralmedium-Agar, worauf Acinetobacter schnelles, E. coli sehr langsames Wachstum zeigte. Die Ansätze wurden 1 bis 2 Tage bei $30^{\circ} \mathrm{C}$ inkubiert.

\subsubsection{DNA-Übertragung durch Transformation}

\subsubsection{Herstellung kompetenter E. coli-Zellen (INOUE \&al. 1990)}

E. coli-Zellen wurden bei $18^{\circ} \mathrm{C}$ in $250 \mathrm{ml} \mathrm{SOB-Medium} \mathrm{(2.2.1.2)} \mathrm{in} \mathrm{einem}$ Schüttel wasserbad (Gyrotory, Water Bath Shaker, Modell G76, New Brunswick Scientific, Edison, N.Y., USA) angezogen. Bei einer $\mathrm{OD}_{600}$ von 0,6-0,8 multe die Kultur für 10 min auf Eis gestelt und anschließend abzentrifugiert werden $\left(4^{\circ} \mathrm{C}, 10 \mathrm{~min}, 5500 \mathrm{Upm}\right.$, Sorvall Rotor GSA). Das Pellet wurde in $80 \mathrm{ml}$ eiskaltem TB vorsichtig resuspendiert und für weitere 10 min auf Eis gestellt. Nach erneutem Zentrifugieren $\left(4^{\circ} \mathrm{C}, 10 \mathrm{~min}, 5500 \mathrm{Upm}\right.$, 
Sorvall Rotor GSA) wurde das Pellet in $20 \mathrm{ml}$ TB aufgenommen und unter langsamem Schwenken 1,5 ml DMSO zugegeben. DieZellen wurden für weitere $10 \mathrm{~min}$ auf Eis gestellt und anschließend in $200 \mu \mathrm{l}$ Fraktionen in gekühlte 1,5 ml-Reaktionsgefäße portioniert. Anschließend erfolgte eine Schockeinfrierung der Zellen in flüssigem Stickstoff und die Lagerung bis zur Verwendung bei $-70^{\circ} \mathrm{C}$. Die Zellen blieben mehrere Monate lang kompetent.

\section{Transformationspuffer (TB)}

$\begin{array}{ll}\text { Pipes } & 10 \mathrm{mM} \\ \mathrm{MnCl}_{2} \text { (getrennt autoklaviert) } & 55 \mathrm{mM} \\ \mathrm{CaCl}_{2} & 15 \mathrm{mM} \\ \mathrm{KCl} & 250 \mathrm{mM} \\ \mathrm{pH} \mathrm{6,7} & \end{array}$

\subsubsection{Transformation von E. coli und Blau-W eiß-Selektion}

Kompetente E. coli-Zellen (2.9.2.1) wurden auf Eis aufgetaut, vorsichtig mit einem DNA-Ligationsansatz gemischt und 30 min erschütterungsfre auf Eis inkubiert. Danach wurden die Zellen für $45 \mathrm{~s}$ auf $42^{\circ} \mathrm{C}$ erhitzt und $0,6 \mathrm{ml}$ LB-Medium (2.2.1.2) zugegeben. Nach 60 min Inkubation bei $37^{\circ} \mathrm{C}$ unter leichtem Schütteln wurden die Zellen auf Selektivagar ausplattiert und über Nacht bei $37^{\circ} \mathrm{C}$ inkubiert. Transformanten konnten anhand der plasmidkodierten Antibiotikaresistenzen selektioniert werden. Klone mit rekombinanten Plasmiden ließen sich mittels des 'Blau-Weiß-Tests' erkennen. Der Test beruht darauf, daß der E. coli-Stamm DH5 eine aminoterminale Deletion im $\square$ Galaktosidasegen besitt (IacZ $\square$ M15). Nach der Induktion durch IPTG wird diese verkürzte, enzymatisch inaktive $\square$-Galaktosidase gebildet. Klonierungsvektoren wie pUC18, pBIISK und pRK 415 besitzen strangabwärts ihrer multiplen Klonierungsstelle das lacZ'-Gen, welches für die ersten 146 Aminosäuren der (-Galaktosidase kodiert, das sogenannte $\square$-Peptid. Dieses kann in vivo mit der verkürzten $\square-G a l$ aktosidase zum aktiven

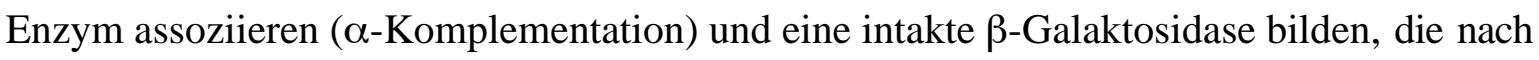
Induktion mit IPTG das Substratanalogon x-Gal zum blauen Farbstoff 5-Brom-4-ChlorIndigo hydrolysiert. Klone, die nur den Vektor ohne Insert tragen, zeigen in Gegenwart von IPTG und x-Gal eine blaue Koloniefärbung. Dagegen bilden Klone, deren Vektor in der multiplen Klonierungsstelle ein DNA-Insert tragen und somit den Leserahmen des lacZ'Gens unterbrechen, keine intakte $\square$-Glaktosidase und sind folglich durch eine weiße Koloniefärbung zu erkennen. Dabei ist zu beachten, daß klonierte Inserts, die den Leserahmen nicht verschieben und kein Stop-Codon tragen, blaueKol onien ergeben können. 
Für den 'Blau-Weiß-Test' wurden die Transformanten auf Selektivagar ausplattiert, der zuvor mit $80 \mu \mathrm{l}$ 2\% (w/v in Dimethylformamid) x-Gal und $20 \mu \mathrm{l}$ 0,1 M IPTG beschichtet wurde. Nach ein- bis zweitägiger Inkubation bei $37^{\circ} \mathrm{C}$ konnten weiße Kolonien gepickt und nach einer analytischen Plasmidisolienung (2.3.1) das klonierte DNA-Fragment nachgewiesen werden.

\subsubsection{Transformation von Acinetobacter sp.}

Alle Transformationstests mit Acinetobacter sp. erfolgten grundsätzlich mit der pobA-Mutante Acinetobacter sp. ADP239. Dieser Stamm geht direkt aus dem Stamm BD413 hervor und ist durch eine Mutation im pobA-Gen gekennzeichnet, woduch er nicht mehr in der Lage ist, p-Hydroxybenzoat als Kohlenstoffquelle über den $\square-K e t o a d i p a t w e g$ zu metabolisieren. Wachstum auf $\mathrm{p}$-Hydroxybenzoat-haltigem Medium kann folglich nur erfolgen, wenn ADP239 das pobA-Wildtypal le über natürliche Transformation aufnehmen und integrieren kann.

Die Überprüfung der Transformationsfähigkeit von Acinetobacter sp. erfolgte durch Inkubation der Zellen mit chromosomaler Widtyp-DNA und anschließendem Wachstumsnachweis auf p-Hydroxybenzoat. Zur Induktion der natürlichen Kompetenz wurden 1,5 ml einer ausgewachsenen Succinat-Übernachtkultur geemtet (RT, 14000 Upm, $30 \mathrm{~s}$, Eppendorf Centrifuge 5417R), in $3 \mathrm{ml}$ frisches Succinat-Mineralmedium resuspendiert und bei $30^{\circ} \mathrm{C}$ schüttelnd für 15 min inkubiert. $100 \mu \mathrm{l} \mathrm{Kultur}$ wurden daraufhin mit $0,1 \mu \mathrm{g}$ DNA versetzt, 30 min bei $30^{\circ} \mathrm{C}$ inkubiert und anschließend auf $p$ Hydroxybenzoat-haltigem Mineral agar in verschiedenen Verdünnungen ausplattiert. Die Inkubation der Ansätze erfolgte für 1-2 Tage bei $30^{\circ} \mathrm{C}$.

Beim Transformationsschnelltest wird die Mutation des Stammes ADP239 (und dessen Abkömmlinge) im pobA-Gen genutzt, welches für die p-HydroxybenzoatHydroxylase codiert Der Defekt in dem Gen führte dazu, daß p-Hydroxybenzoat nicht als Kohlenstoff-Quelle genutzt werden kann. Über die natürliche Transformation besteht die Möglichkeit für das Bakterium ein intaktes pobA-Gen ins eigene Genom zu integrieren und somit die Fähigkeit auf p-Hydroxybenzoat $z u$ wachsen wiederzuerlangen. Beim Transformationstest wurde die Impföse mit Zellsuspension auf einer $p$-HydroxybenzoatAgarplatte durch einen Tropfen chromosomaler DNA des Stammes BD413 gezogen, welcheein intaktes pobA-Gen trug. Bei der Fähigkeit zur natürlichen Transformation kann das defekte pobA-Gen durch das intakte Gen erselzt werden, was zum Wachstum auf der aromatischen Verbindung führt. Für diesen schnellen, einfachen Transformationsnachwe's wurde $p$-Hydroxybenzoat-haltiger Mineral agar an gekennzeichneten Stellen mit 0,1 $\mu \mathrm{g}$ Wildtyp-DNA beschichtet und der zu testende Acinetobacter-Stamm darauf ausgestrichen (Vosman et al. 1991). Das Wachstum konnte nach 24-stündiger Inkubation bei $30^{\circ} \mathrm{C}$ überprüft werden. 
Zur Herstellung von Mutanten von Acinetobacter sp. durch Insertion eines Resistenzmarkers ins Chromosom wurde eine 1,5 ml-Kultur auf Succinat-Mineralmedium über Nacht angezogen, zentrifugiert (RT, 14000 Upm, 30 s, Eppendorf Centrifuge 5417R), anschließend in $3 \mathrm{~m}$ frisches Succinat-Mineral medium resuspendiert und 15 min schüttel nd kultiviert. Nach Zugabe von sättigenden Mengen an Marker-DNA zu 0,2 ml Kultur wurden die Zellen $1 \mathrm{~h}$ ruhend inkubiert und anschließend auf LB-Selektivmedium ausplattiert.

\subsection{Standardtechniken für das Arbeiten mit Proteinen}

\subsubsection{Proteinbestimmung nach BRADFORD (1976; modifiziert)}

Diese Proteinbestimmung beruht auf einer Verschiebung des Extinktionsmaximums des Coomassie-Farbstoffes von $465 \mathrm{~nm}$ auf $584 \mathrm{~nm}$ aufgrund hydrophober und ionischer Wechselwirkungen mit Proteinen in saurer Lösung. Zur Bestimmung von Proteinkonzentrationen wurden die Proben auf ein Volumen von $100 \mu \mathrm{l}$ gebracht, mit $1 \mathrm{ml}$ BRADFORD-Reagenz versełzt und nach 5 min die Extinktion bei einer Wellenlänge von $595 \mathrm{~nm}$ bestimmt. Als Referenz dienteeine mit Rinderserumal bumin (BSA) aufgenommene Eichgerade von 1 bis $25 \mu \mathrm{g}$ Protein. Höhere Proteinkonzentrationen können mit dieser Methode nicht genau quantifiziert werden.

BradFord-Reagenz
$\begin{array}{ll} \\ \text { Serva Blau G-250 } & 70 \mathrm{mg} \\ \text { Ethanol }(96 \%, \mathrm{v} / \mathrm{v}) & 50 \mathrm{~m} \\ \text { Phosphorsäure }(85 \%, \mathrm{v} / \mathrm{v}) & 100 \mathrm{~m} \\ \mathrm{H}_{2} \mathrm{O}_{\text {dest. }} & 850 \mathrm{~m}\end{array}$

\subsubsection{Auftrennung von Proteinen über SDS-Polyacrylamid- gelelektrophorese (SDS-PAGE ) nach LAEM MLI (1970; modifiziert)}

Mit Hilfe des Detergenz SDS (Sodium-Dodecylsulfat) werden Quartär- und Tertiärstrukturen von Proteinen zerstört und diesen entsprechend ihrer Peptidkettenlänge eine äquivalente negative Ladung angelagert. Diese negative Ladung ermöglicht die Auftrennung von Proteinen entsprechend ihrer molekularen Masse im Polyacrylamidgel. 0-Mercaptoethanol reduziert Disulfidbrücken, so daß intra oder interpeptidische Verknüpfungen gelöst werden, um die bestmögliche Entfaltung zu gewährleisten. 
Für die Gelelektrophorese wurde eine Minigel-Elektrophoresekammer (Biometra, Göttingen) mit $10 \mathrm{~cm} \times 10 \mathrm{~cm} \times 0,1 \mathrm{~cm}$-Glasplatten verwendet. Um einen optimalen Trennbereich von 10 - $50 \mathrm{kDa}$ zu erzielen, wurden $15 \%$ ige Polyacrylamidgele, für eine Auftrennung von Proteinen mit 50 - 100 kDa 8\%ige Gele hergestellt. Die Trenn- und Sammelgel lösung konnten auf Vorrat hergestellt und bei $4^{\circ} \mathrm{C}$ lichtgeschüttt für ca. 4 Monate gelagert werden (Tab. 2.6). Zunächst wurde das Trenngel gegossen und vorsichtig mit $\mathrm{H}_{2} \mathrm{O}_{\text {dest. }}$ überschichtet. Nachdem das Trenngel polymerisiert war, wurde das Wasser entfernt, das Sammelgel auf das Trenngel gegossen und anschließend der Kamm Iuftblasenfrei eingesezt Nach der Polymerisation konnte der Kamm aus dem Sarmelge gezogen werden.

Die Proben, die eine Proteinmenge von maximal $10 \mathrm{mg}$ aufwiesen, wurden mit 0,2 Volumen SDS-Probenpuffer versetzt, 5 min bei $95^{\circ} \mathrm{C}$ denaturiert und anschließend in die Geltaschen aufgetragen. Die Gelelektrophorese erfol gtezwischen 20 und 30 mA.

Die Lösungen wurden filtriert und lichtgeschüttt bei $4^{\circ} \mathrm{C}$ gelagert. Für ein Minigel wurdezur Polymerisation von $9 \mathrm{ml}$ Trennge und 2,5 $\mathrm{ml}$ Sammelgel $100 \mu \mathrm{l}$ bzw. $40 \mu \mathrm{l}$ einer wäßrigen $10 \%$ igen (w/v) Ammoniumpersulfat-Lösung und $40 \mu \mathrm{lbzw} .10 \mu \mathrm{l}$ TEMED hinzugegeben.

Tab. 2.6: Trenn- und Sammelgellösungen

\begin{tabular}{l|c|c} 
& Trenngel (15\%/8\%) & Sammelge (4\%) \\
\hline $\mathrm{H}_{2} \mathrm{O}_{\text {dest }}$ & $2,5 \mathrm{ml} / 6,7 \mathrm{ml}$ & $3,0 \mathrm{~m}$ \\
\hline $4 \times$ Trenngelpuffer & $3,75 \mathrm{ml}$ & - \\
\hline $4 \times$ Sammelgelpuffer & - & $1,2 \mathrm{~m}$ \\
\hline Glycerin & $1,6 \mathrm{ml}$ & - \\
\hline $\begin{array}{l}\text { Acrylamid M-BIS 30\% } \\
\text { Stammlösung 19/1 }\end{array}$ & $9,0 \mathrm{ml} / 4,8 \mathrm{ml}$ & $0,8 \mathrm{ml}$ \\
\hline Ammoniumpersulfat (10\%) & $100 \square \mathrm{I}$ & $60 \square \mathrm{I}$ \\
\hline TEMED & $25 \square$ & $10 \square$
\end{tabular}

\begin{tabular}{|c|c|c|c|}
\hline \multicolumn{2}{|c|}{$4 \times$ Trenngelpuffer } & \multicolumn{2}{|c|}{$\underline{4 \times}$ Sammelgelpuffer } \\
\hline Tris-HCl & $1,5 \mathrm{M}$ & Tris-HCl & $0,5 \mathrm{M}$ \\
\hline $\begin{array}{l}\text { SDS } \\
\text { pH 8,8 }\end{array}$ & $0,4 \%(w / v)$ & $\begin{array}{l}\text { SDS } \\
\text { pH 6,8 }\end{array}$ & $0,4 \%(w / v)$ \\
\hline
\end{tabular}




\section{SDS-Probenpuffer}

$4 \times$ Sammelgel puffer

SDS (10\%)

૫-Mercaptoethanol

Glycerin

Bromphenolblau

$(0,2 \%$ in Methanol)

$\mathrm{H}_{2} \mathrm{O}_{\text {dest. }}$

ad $100 \mathrm{ml}$

\section{$10 \times$ SDS-L aufpuffer}

Tris $\quad 30 \mathrm{~g}$

SDS $\quad 10 \mathrm{~g}(\mathrm{w} / \mathrm{v})$

Glycin $\quad 144 \mathrm{~g}$

$\mathrm{H}_{2} \mathrm{O}_{\text {dest }}$ ad $1000 \mathrm{~m}$

\subsubsection{Native Gradienten-PAGE (SCHÄGgER \& V ON JAGOW, 1991; modifiziert)}

Bei der Elektrophorese im nativen Gradientengel wandern Proteine so lange in Richtung Anode, bis die abnehmende Porengröße die weitere Passage verhindert. Voraussetzungen für diese gerichtete Mobilität sind zum einen die negative Nettoladung und zum anderen die freie Beweglichkeit der Proteine; denn gerade Membranproteine tendieren zur Aggregation. Um einer möglichen artifizielle Zusammenlagerung bereits solubilisierter Membranproteine entgegenzuwirken, wurden den Acrylamidlösungen Detergenzien oberhal $b$ der kritischen Mizel lenkonzentration zugesetzt. Da positiv gedadene Proteine nicht ins Gel einwandern, wurde der Proteinfarbstoff Coomassie eingesetzt, der selbst eine negative Ladung besitzt, an die meisten Proteine bindet und somit eine negative Nettoladung verleiht. Die Probe wurde farbl os ohne Bromphenol blau oder Coomassie, mit Saccharose (> 6\%) beschwert, aufgetragen, so daß dieGel tasche weitere 150 l einer zweiten Lösung zur Überschichtung der Probe aufnehmen konnte. Diese zweite Lösung bestand nun aus einer tiefblauen (ca. 0,01\% [w/v]) Coomassielösung (in Kathodenpuffer mit 5\% (w/v) Saccharose). Während der Elektrophorese gelangt der Farbstoff in die Probe, bindet und beschleunigt die Wanderung der Proteine, was zu einer scharfen Bandierung führte

Um die Laufzeiten für native Gele möglichst kurz zu halten, wurde für die Elektrophorese ausschließlich eine Minigel-Kammer (Trenngröße $10 \times 10 \times 0,1 \mathrm{~cm}$ verwendet. Die Elektrophorese erfolgte $12-20 \mathrm{~h}$ bei ein Spannung von $100 \mathrm{~V}$ be $4^{\circ} \mathrm{C}$. Es wurden fol gende Lösungen angesetzt: 
'L eichte Lösung' (4\%,w/v)

Acrylamid

Bisacrylamid

49

Bis-Tris

$0,2 \mathrm{~g}$

6-Aminocapronsäure $10 \mathrm{mM}$

$\mathrm{H}_{2} \mathrm{O}_{\text {dest. }}$

$\mathrm{H}_{2} \mathrm{O}_{\text {dest. }}$

ad $100 \mathrm{~m}$

ad $100 \mathrm{ml}$
'Schwere Lösung' $(20 \%$, w/v)

Acrylamid

$20 \mathrm{~g}$

Bisacrylamid

$1 \mathrm{~g}$

Bis-Tris

$50 \mathrm{mM}$

6-Aminocapronsäure

$10 \mathrm{mM}$

Glycerin

Der pH-Wert der Acrylamidlösungen wurde mit $\mathrm{HCl}$ auf 7,5 eingestellt, die Lösungen filtriert und lichtgeschützt be $4^{\circ} \mathrm{C}$ gedagert.

Kathodenpuffer

$\begin{array}{ll}\text { Bis-Tris } & 15 \mathrm{mM} \\ \text { Tricin } & 50 \mathrm{mM}\end{array}$

\section{Anodenpuffer}

Tris- $\mathrm{HCl} \quad 0,2 \mathrm{M}$

$\mathrm{pH} 8,0$

Der pH-Wert lag bei 7-7,5 (nicht titriert).

Für ein Gradientengel von 4-20\% wurden je 3,4 ml 'Leichte' und 'Schwere' Lösung in dieKarmmem eines kleinen Gradientenmischers gefültt. Um die homogene Schichtung des Gradienten später beurteilen zu können, wurde nur der 'Leichten Lösung' $40 \mathrm{ll}$ Coomassie aus einer 5\%igen wäßrigen Stammlösung zugesełtt. Nach Zugabe von $14 \mu \mathrm{l}$ einer $10 \%$ igen (w/v) APS-Lösung und $4 \mu \mathrm{l}$ TEMED in jede Kammer wurde der Gradientenmischer geöffnet, die Acrylamidlösung mittels einer Peristal tikpumpe (Meredos GS, Fa. Meredos, Nörten-Hadenberg) in die vorbereitete Gelkammer gepumpt und danach das Gel vorsichtig mit $\mathrm{H}_{2} \mathrm{O}_{\text {dest. }}$ überschichtet. Nach der Polymerisation konnte das Wasser entfernt und das Sammelgel gegossen werden. Hierzu wurde die 'Leichte Lösung' mit Gelpuffer (50 mM Bis-Tris-HCl, 10 mM 6-Aminocapronsäure, pH 7,5) 10\%ig verdünnt (z.B. 9 ml 'Leichte

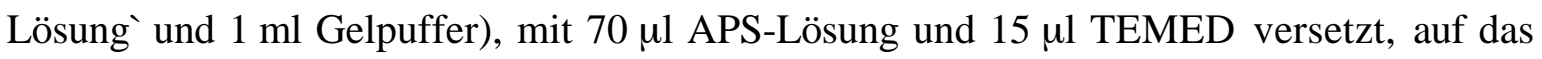
Gradientengel gegossen und mit einem Kamm versehen.

\subsubsection{Z weidimensionale Auftrennung der Proteine}

Die mittels der nativen PAGE aufgetrennten Proteinkomplexe (2.8.3) ließen sich anschließend in einer SDS-PAGE in diejeweiligen Untereinheiten zerlegen. Zunächst wurde wie unter 2.8.2 beschrieben das SDS-Trenngel gegossen, daraufhin ein 5-10 mm breites Sammel gel aufgeschichtet, wobei zum oberen Glasrand eine ca. $8 \mathrm{~mm}$ breite Aussparung freizulassen war. Auch hier diente $\mathrm{H}_{2} \mathrm{O}_{\text {dest }}$ der Überschichtung des Sammelgels, um eine 
ebene Gelkante zu erhalten. Aus dem nativen Gel wurde der mittlere Bereich der gewünschten Spur herausgeschnitten und zwischen die beiden Glasplatten des hergestellten SDS-Gels geschoben. Dabej durften keine Luftblasen oder Wassereinschlüsse zwischen dem Sammelgel und dem nativen Gelstreifen verbleiben. Da die Länge des nativen Gelstreifens geringer war als die Breite des SDS-Gels, wurden die beiderseits entstandenen Freiräume mit erwärmter Agarose [1,5\%ig in Kathodenpuffer (2.8.3)] aufgefüllt und erkalten lassen. Mit Hilfe eine Kanüle konnte in die erstarrte Agarose eine Aussparung gestochen werden, in die nach dem Befüllen der Gelkammer mit Laufpuffer der SDSGrößenstandard aufgetragen werden konnte. Kurz vor dem Start der PAGE erfolgte eine 1$2 \mathrm{~mm}$ breite Überschichtung des Gels mit einer Denaturierungslösung, die aus 10x SDSLaufpuffer - versezt mit 20\% (w/v) Saccharose - bestand. Die Denaturierung der Proteine im nativen Gestreifen erfolgte zunächst bei einer langsamen Elektrophorese bei $3 \mathrm{~mA}$ und mit demEintritt in das Sarmelge bei 20-30 mA. Aufgrund der geringen Proteinmenge, die in der 2. Dimension aufgetrennt wurde, erfolgte die Färbung des Gels mittels Silbernitrat (2.8.7)

\subsubsection{G rößenbestimmung von Proteinen}

Die Bestimmung von Proteingrößen erfolgte nach Auftrennung im Polyacrylamidgel $(2.8 .2,2.8 .3)$ anhand der Laufstrecken eines intemen Standards. Als Größenstandard für die SDS-PAGE diente eine $10 \mathrm{kDa}$-Leiter im Bereich von 10-120 kDa (Gibco BRL). Als Molekulargewichtsstandard für die native PAGE wurde der 'HMW Calibration Kit' (Fa. Pharmacia, Freiburg) verwendet, der den Größenbereich von 67 kDa bis 660 kDa abdeckte.

\subsubsection{Färbung von Proteinen mit Coomassie (Weber \& OSBORn, 1969)}

Nach einer nativen oder SDS-Gelelektrophorese (2.8.2, 2.8.3) konnten die aufgetrennten Proteine mit Coomassie Brilliant Blue gefärbt und sichtbar gemacht werden. Dazu wurde das Polyacrylamidgel für 30 min in Färbelösung gelegt und auf einer Wippe langsam geschwenkt. DieEntfärbung des Gels erfolgteanschließend in Entfärberlösung. Die Proteine behielten während des Entfärbens ihre blaueFärbung bei, während der Hintergrund aufklarte. 
Färbelösung

Serva Blau G-250 0,6 g

ServaBlau R-250 0,6 g

Methanol

Eisessig

$\mathrm{H}_{2} \mathrm{O}_{\text {dest. }}$ $500 \mathrm{ml}$

\section{Entfärber}

Methanol $\quad 330 \mathrm{~m}$

Eisessig $\quad 100 \mathrm{~m}$

$\mathrm{H}_{2} \mathrm{O}_{\text {dest }} \quad \mathrm{ad} 1000 \mathrm{~m}$

\subsubsection{Silber-Färbung (BLUM @tal. 1987; modifiziert)}

Zur Färbung eines Polyacrylamidgels mit Silbernitrat wurden folgende Lösungen benötigt:

\section{Fixierlösung}

Methanol

Eisessig

Formal dehyd ( $37 \%$ ig, v/v)

$\mathrm{H}_{2} \mathrm{O}_{\text {dest. }}$

ad $100 \mathrm{ml}$

auf Vorrat anzusetzten und bei $4^{\circ} \mathrm{C}$ zu

lagern; Formal dehyd wurde erst unmittel bar vor dem Gebrauch zugesetzt.

\section{Imprägnierlösung}

$\mathrm{AgNO}_{3}$

$50 \mathrm{ml}$

$12 \mathrm{ml}$

$0,1 \mathrm{~m}$

Formal dehyd (37\%, v/v)

$0,2 \mathrm{~g}$

$\mathrm{H}_{2} \mathrm{O}_{\text {dest. }}$

$0,1 \mathrm{~m}$

Die Lösung wurde frisch angese zt.

\section{Stopplösung}

EDTA

$1,86 \mathrm{~g}$

$\mathrm{H}_{2} \mathrm{O}_{\text {dest. }}$

ad $100 \mathrm{~m}$

DieLösung wurde mit $\mathrm{NaOH}$ auf einen

$\mathrm{pH}$-Wert von 7-8 titriert und konnte

mehrere Wochen gel agert werden.

\section{Thiosulfatlösung}

$\mathrm{Na}_{2} \mathrm{~S}_{2} \mathrm{O}_{3} \times 5 \mathrm{H}_{2} \mathrm{O} \quad 0,2 \mathrm{~g}$ $\mathrm{H}_{2} \mathrm{O}_{\text {dest }} \quad$ ad $\quad 100 \mathrm{ml}$

Die Lösung wurde frisch angeselzt.

\section{Entwicklerlösung}

$\mathrm{Na}_{2} \mathrm{CO}_{3} \quad 3,5 \mathrm{~g}$

Thiosulfattösung (s.o.) $2 \mathrm{ml}$ $\mathrm{H}_{2} \mathrm{O}_{\text {dest }} \quad$ ad $100 \mathrm{ml}$ Formal dehyd $(37 \%, v / v) \quad 0,1 \mathrm{~m}$ Die Lösung wurde frisch angeselzt. 
Die Gele wurden unter leichtem Schwenken auf einer Wippe folgendermaßen behandelt:

- 1-24hfixieren

- dreimal 20 min in $50 \%(\mathrm{v} / \mathrm{V})$ Ethanol waschen

- 1 min in Thiosul fatlösung inkubieren

- dreimal $20 \sin \mathrm{H}_{2} \mathrm{O}_{\text {dest }}$ waschen

- 20 min imprägnieren

- zweimal kurz mit $\mathrm{H}_{2} \mathrm{O}_{\text {dest }}$ waschen

- entwicken, bis dieBanden deutlich sichtbar sind

- kurz mit $\mathrm{H}_{2} \mathrm{O}_{\text {dest }}$ waschen

- mindestens 10 min in der Stopplösung schwenkend inkubieren

Zur Aufbewahrung wurden die Gele zweimal mit $\mathrm{H}_{2} \mathrm{O}_{\text {demin. }}$ gewaschen, kurz in $1 \mathrm{M}$ Eisessig geschwenkt, in Plastikfolie eingeschweißt und bei $4^{\circ} \mathrm{C}$ gelagert

\subsubsection{K onzentrierung von Proteinen}

Um Proteinlösungen zu konzentrieren, wurden Centriprep-Einweg-KonzentratorRöhrchen (Amicon GmbH/ Millipore GmbH, Eschborn) mit den Ausschlußgrößen 10 kDa, $30 \mathrm{kDa}$ bzw. $50 \mathrm{kDa}$ verwendet. Dabei konnten Proteinlösungen von maximal $15 \mathrm{ml}$ auf $1 \mathrm{ml}$ eingeengt werden. Volumina bis maxima $2 \mathrm{ml}$ wurden mit Centrisart I (Sartorius AG, Göttingen) mit einer Ausschlußgrenze von $20 \mathrm{kDa}$ auf ein Volumen von minimal $200 \mathrm{ll}$ eingeengt. DieZentrifugationen erfolgten dabei in einer Sigma 3 k-1 Zentrifuge im 'Swing out-Rotor'.

\subsubsection{Dialyse von Proteinlösungen}

Vor dem Gebrauch wurden die Dialyseschläuche (Visiking, Fa. Serva, Heidel berg) in den folgenden Lösungen für jeweils ca. 5 min gekocht:

$$
\begin{array}{ll}
\text { - } & 3 \%(\mathrm{w} / \mathrm{v}) \mathrm{Na}_{2} \mathrm{CO}_{3} \\
\text { - } & \mathrm{H}_{2} \mathrm{O}_{\text {dest }} \\
\text { - } & 2 \mathrm{mM} \mathrm{Na}-\mathrm{EDTA} \\
\text { - } & \mathrm{H}_{2} \mathrm{O}_{\text {dest }}
\end{array}
$$

DieSchläuche wurden anschließend in $\mathrm{H}_{2} \mathrm{O}_{\text {dest }}$ bei $4^{\circ} \mathrm{C}$ gelagert. 
Die Proteinlösungen wurden, wenn nicht anders angegeben, in die vorbereiteten Schläuche gefüllt und $48 \mathrm{~h}$ gegen das 200 bis 1000 facheVolumen bei mehrfachem Pufferwechsel bei $4^{\circ} \mathrm{C}$ dialysiert.

\subsection{WESTERN-B lotting}

\subsubsection{Elektrophoretischer Transfer von Proteinen denaturierender Polyacrylamidgele}

Nach der Auftrennung durch SDS-PAGE (2.8.2) wurde für weitere immunologische Analysen Proteine aus dem $\mathrm{Gel}$ auf eine Nitrocellulosemembran übertragen. Die Übertragung erfol gte elektrophoretisch nach dem 'Semi-Dry'-Verfahren unter Verwendung einer 'Blotting'-Kammer (Nova Blot, Pharmacia LKB, Freiburg). Das für den Transfer benötigte Whatmanpapier und die Nitrocellul osemembran (Sartorius AG, Göttingen) wurden auf Gelgrößezugeschnitten und mit demSDS-Gel in Transferpuffer gelegt Auf die Anodenplatte wurden in folgender Reihenfolge 3 Lagen Whatmanpapier, die Nitrocellulosemembran, das Gel und wiederum 3 Lagen Whatmanpapier jeweils unter Vermeidung von Luftblasen aufgelegt und überschüssiger Transferpuffer mit saugfähigem Papier entfernt. Abschließend konnte die Kathodenplatte aufgelegt und leicht beschwert werden. Die Proteine wurden bei konstanter Spannung und beginnend mit $5 \mathrm{~mA} / \mathrm{cm}^{2}$ Membranfläche solange übertragen, bis die Stromstärke auf weniger als die Hälfte des Ausgangswertes abgesunken war. Die auf die Membran tranferierten Proteine konnten mit Ponceau-Rot angefärbt und der Größenstandard mit Bleistift markiert werden. Alternativ konnte derjenige Bereich von der Membran, der den geblotteten Größenstandard enthielt, abgeschnitten und separat mit Coomassie gefärbt werden, wie es für die Färbung der Gele beschrieben wurde (2.6.8). Nach dem Blotten konnte das Gel zur Kontrolle mit Coomassie gefärbt werden (2.6.8).

\section{Transferpuffer}

Tris

Glycin

$15,1 \mathrm{~g}$

Methanol

$\mathrm{H}_{2} \mathrm{O}_{\text {dest }}$ $200 \mathrm{ml}$

$\mathrm{pH}$ 8,6; nicht titriert,

Lagerung bei $4^{\circ} \mathrm{C}$

\section{Ponceau-R ot-Lösung}

Essigsäure (96\%, v/v) 30\% (v/v)

Ponceau S $\quad 0,2 \%(\mathrm{w} / \mathrm{v})$

DieLösung wurde mit $\mathrm{H}_{2} \mathrm{O}_{\text {dest }}$ hergestelt 


\subsubsection{Elektrophoretischer Transfer von Proteinen nativer Polyacrylamid-G radienten-G ele auf Nitrocellulosemembranen}

Beim Blotten von nativen Gradientengelen ist der Transfer auf die Nitrocellulosemembran erschwert, weil sich dieProteine im Gel in einem Vernetzungsgrad des Acrylamids befinden, in dem nur noch eine sehr langsame Wanderung im elektrischen Feld stattfinden kann. Deshalb muß, verglichen mit homogenen Gelen, die Transferzeit entsprechend erhöht und für einen quantitativen Transfer das Protein mit SDS denaturiert werden.

Der Transfer erfolgte in einem 'Semi-Dry'-Verfahren unter Verwendung einer 'Blotting'-Kammer (Nova Blot, Pharmacia LKB, Freiburg), wie es bereits unter 2.9.1 für das Blotten von SDS-Gelen beschrieben worden war. Beim WESTERN Blot nativer Gele wurden zunächst denaturierende Bedingungen eingestellt, indem die für den Transfer benötigten Whatmanlagen der Kathodenseite mit SDS-Laufpuffer getränkt wurden. Die Whatmanlagen der Anodenseite und die Nitrocellulosemembran wurden mit Transferpuffer getränkt (2.9.1). Nach dem Anlegen der Spannung drang das negativ gel adene Detergenz SDS in das native Gel ein, so daß die Proteine denaturieren und bereits teilweise auf die Nitrocellul osemembran gelangten. In einem zweiten Schritt erfolgte der Austausch der Whatmanlagen gegen in Transferpuffer (2.9.1) getränkte Lagen, wobei das Gel auf der Nitrocellulosemembran nicht verschoben werden durfte. Die angelegte Spannung transferierte die imGe verbliebenen Proteine unter Entfernung überschüssigen SDS auf die Membran.

Die auf die Membran transferierten Proteine konnten mit Ponceau-Rot (2.9.1) sichtbar gemacht werden oder Banden des Größenstandard mit Coomassie angefärbt werden; das Gel wurde zur Kontrollemit Coomassie gefärbt (2.8.6).

\subsection{0 Überexpression und Anreicherung von F usionsproteinen}

\subsection{1 Ü ber expression von M alE -F usionsproteinen}

Die Überexpression vom C-Terminus des ComA und von ComEA erfolgte als Fusionsprotein mit dem Mal tosebindeprotein (MBP). Als Überexpressionsvektor diente dabei pMAL-c2 (Tab.2.2). comEA sowie das verkürzte comA-Konstrukt wurden dafür im Leserahmen an das 3'-Ende des malE-Gens kloniert, welches unter der Kontrolle eines $P_{\text {tac }}{ }^{-}$ Promoters steht. Der $\mathrm{P}_{\text {tac }}$-Promotor ist in der Abwesenheit des Induktors IPTG durch den lac - -Repressor blockiert. Zugabe von IPTG induziert die Expression des Fusionsproteins. 
Als Wirtsorganismus diente E. coli DH5 $\square$, dessen eigene RNA-Polymerase am $\mathrm{P}_{\text {tac- }}$ Promotor bindet und die Transkription durchführt.

DieAnzucht des rekombinanten E. coli DH5马 erfolgte für das ComA-Fusionsprotein in $250 \mathrm{ml}$ LB-Medium und für die ComEA-Fusion in 9 I LB-Medium bei $37^{\circ} \mathrm{C}$ (2.2.1.2). Bei einer $\mathrm{OD}_{600}$ von 0,7-0,8 erfolgte die Induktion mit 0,1 mM IPTG. Danach wurden die Zellen für zwei Stunden bei $37^{\circ} \mathrm{C}$ schüttelnd inkubiert und anschließend durch Zentrifugation ( $4^{\circ} \mathrm{C}, 10 \mathrm{~min}, 7000 \mathrm{Upm}$, Sorvall Rotor GSA) geerntet. Das Zellpellet wurde einmal mit $20 \mathrm{mM}$ Tris-HCl gewaschen und in 15 bzw. $300 \mathrm{ml}$ Säulenpuffer aufgenommen. Der Zellauschluß erfolgte eisgekühlt drei Minuten durch Ultraschall (UP 200 s Ultraschall prozessor, Dr. Hielscher $\mathrm{GmbH}$ ) mit 30\% Amplitude in 0,5 Zyklen. Der Zellaufschluß wurde mikroskopisch überprüft und die Zel ltrümmer anschließend durch Zentrifugation $\left(4^{\circ} \mathrm{C}, 10 \mathrm{~min}, 7000 \mathrm{Upm}\right.$, Sorvall Rotor SS34, GSA) vom löslichen Überstand getrennt. Mittels SDS-PAGE (2.8.2) wurde überprüft, ob sich das Fusionsprotein imlöslichen Überstand oder in den Zelltrümmem befand.

\section{Säulenpuffer}

Tris- $\mathrm{HCl}(1 \mathrm{M}, \mathrm{pH} 7,5) 20 \mathrm{ml}$

$\mathrm{NaCl}$

$11,7 \mathrm{~g}$

$\operatorname{EDTA}(0,25 \mathrm{M})$

$4 \mathrm{ml}$

DTE $(0,5 \mathrm{M})$

$3 \mathrm{ml}$

$\mathrm{H}_{2} \mathrm{O}$ dest.

ad $1000 \mathrm{~m}$

Der Puffer wurde filtriert und war vier Wochen hal tbar.

\subsubsection{Aufreinigung von MalE-Fusionsproteinen über Affinitäts- chromatographie}

DieAufreinigung des MalE-Fusionsprotein basiert auf der hohen Bindungsaffinität des MBP zu Amylose-Säul enmaterial. Die Bindungskapazität liegt bei $3 \mathrm{mg}$ MBP pro m Säul enmaterial. Das Amylose-gebundene MalE-Fusionsprotein kann durch geringe Mengen von Maltose von der Säule eluiert werden.

Das Amylosematerial wurde blasenfre in eine $10 \mathrm{~m}$-Säule gefült und anschließend nacheinander mit $3 \times$ Säulenvol umen $\mathrm{H}_{2} \mathrm{O}_{\text {demin. }}$ 3 3 Säul envolumen $0,1 \%$ SDS, $1 \times$ Säulenvolum $\mathrm{H}_{2} \mathrm{O}_{\text {demin. }}$ und $3 \times$ Säul envolumen Säulenpuffer äquillibriert. Entsprechend der Bindungskapazität des Säul enmaterials wurde Proteinrohextrakt auf die Säule geladen. Nachdem der Rohextrakt in die Säule eingelaufen war, wurde die Säule mit 10$12 \times$ Säul envol umen Säulenpuffer gewaschen und anschließend das MalE-Fusionsprotein mit $2 \mathrm{ml}$ Säulenpuffer/10 mM Maltose eluiert. Das Eluat wurde in einem 1,5 mReaktionsgefäß aufgefangen und die Aufreinigung des Fusionsproteins mittels SDS-PAGE 
(2.8.2) kontrolliert. Zur Regenerierung der Säule wurde diese mit 10x Säulenvolumen Säulenpuffer äquilibriert und konnte somit drei- bis fünfmal verwendet werden. Die Lagerung der Säuleerfolgtemit Säulenpuffer bei $4^{\circ} \mathrm{C}$.

Die Bindung von MalE-Fusionsproteinen in großen Lysatvolumina wurde im 'BatchVerfahren` durchgeführt. Die in Säulenpuffer äquilibrierte Matrix wurde in einem Meßzylinder zum Zelllysat gegeben, geschwenkt und im Kühlschrank für ca. $1 \mathrm{~h}$ sedimentiert. Der Überstand konnte verworfen werden und die Amylose zweimal mit jeweils $100 \mathrm{~m}$ Säulenpuffer gewaschen werden, indem diese resuspendiert und wiederum im Kühlschrank sedimentierte Schließlich erfolgte die Elution mit $4 \mathrm{ml} 10 \mathrm{mM}$ Maltose. Der Überstand, welcher jetzt das freigesetzte Fusionprotein enthielt, wurde in $2 \mathrm{ml}$ Reaktionsgefäße überführt und die restliche Matrix abzentrifugiert $\left(4^{\circ} \mathrm{C}, 1 \mathrm{~min}\right.$, 14000 Upm, Biofuge 17 S).

\subsubsection{A ufreinigung von $\mathrm{H}$ is-T ag-Fusionspoteinen}

Die Expression des rekombinanten pJ C40-Derivats führte zu einem Hybridprotein, welches aus zehn abspal tbaren $\mathrm{N}$-terminalen Histidinresten und dem gewünschten Protein bestand. Dieses Hybridprotein konnte über eine $\mathrm{Ni}^{2+}$-NTA-Säule aufgereinigt werden, wobei das Protein mittels seiner Histidinreste mit hoher Affinität für immobilisierte NickeKationen an des Säulenmaterial gebunden wurden. Durch Immidazol konnten die Histidinreste von der Matrix verdrängt werden.

Die Bindung des 10 Histidinrestetragenden Fusionsproteins an das $\mathrm{Ni}^{2+}-\mathrm{NTA}-$ Säulen-Material wurde wie fol gt durchgeführt: Das Zell-Lysat wurde zusammen mit $1 \mathrm{~m}$ 50\%iger ( $\mathrm{v} / \mathrm{v}$ ) Säulenmaterial-Suspension ( $\mathrm{Ni}^{2+}{ }_{-} \mathrm{NTA}$ Agarose, Qiagen $\mathrm{GmbH}$, Hilden) für 30 min gerührt, wobei die Bindekapazität der $\mathrm{Ni}^{2+}$-NTA-Agarose $5-10 \mathrm{mg} / \mathrm{ml}$ betrug. Nach der Inkubation wurde das Gemisch in eine leere 10 ml-Säule (Bio-Rad Laboratories GmbH, München) gefüllt Die Säule mußte, nachdem sich die Matrix abgesetzt hatte, zweimal mit je $40 \mathrm{ml}$ Wasch-Puffer 1 und zweimal mit je $30 \mathrm{~m}$ Waschpuffer 2 gewaschen werden. Die Elution der an dieSäulen-Matrix gebundenen Proteine erfolgte mit $4 \mathrm{~m}$ Elutionspuffer. Die Aufreinigung des Hybridproteins wurde mittels SDS-PAGE überprüft (2.8.2). Dabė durften Immidazol-haltige Proben nicht auf $100^{\circ} \mathrm{C}$ erhitzt, sondern lediglich $10 \mathrm{~min}$ be $37^{\circ} \mathrm{C}$ direkt vor demA uftragen erwärmt werden. 


$\begin{array}{lll}\text { Waschpuffer } 1 & \text { Na-Phosphat-Puffer } & 50 \mathrm{mM} \\ & \mathrm{NaCl} & 0,3 \mathrm{M} \\ & \mathrm{pH} \mathrm{8,0} & \end{array}$

$\begin{array}{lll}\text { Waschpuffer } 2 & \text { Na-Posphat-Puffer } & 50 \mathrm{mM} \\ & \text { NaCl } & 0,3 \mathrm{M} \\ & \text { Glycerin (87\%) } & 10 \%(\mathrm{v} / \mathrm{v}) \\ & \text { Imidazol } & 20 \mathrm{mM} \\ & \text { pH 6,0 } & \end{array}$

$\begin{array}{lll}\text { Elutionspuffer } & \text { Imidazol } & 0,25 \mathrm{M} \\ & \text { Waschpuffer 2 ad } 10 \mathrm{~m} \\ & \mathrm{pH} \mathrm{6,0} & \end{array}$

\subsubsection{Denaturierung von Einschlußkörpern und Renaturierung der freigesetzten Proteine}

BildeteE. coli bei der Überexpression der gewünschten Proteine Einschlußskörper, so befanden sich diese im Sediment zusammen mit den Zelltrümmern. Für eine Aufreinigung mulsten die in Einschlußkörpern befindl ichen aggregierten Proteine gel öst werden.

Für die Denaturierung der Einschl ußkörper wurde das Sediment mit Harnstoff behandelt, so daß die Fusionsproteine denaturiert in Lösung gingen. Dazu wurde zunächst $250 \mathrm{ml}$ induzierte E. coli Kultur geerntet, mittels Ultraschall aufgeschlossen und die Einschlußkörper zusammen mit den Zelltrümmern bei $7000 \mathrm{Upm}\left(4^{\circ} \mathrm{C}, 10 \mathrm{~min}\right.$, Sorvall Rotor GSA) sedimentiert. Die Solubilisierung dieses Sediments erfolgte in $6 \mathrm{M}$ Harnstoff, welcher zuvor in $100 \mathrm{ml}$ Säulenpuffer gel öst worden war. Nichtgel öste Bestandteile wurden bei $14000 \mathrm{Upm}\left(4^{\circ} \mathrm{C}, 10 \mathrm{~min}\right.$, Sorvall Rotor SS34) sedimentiert und der daraus resultierendeÜberstand gegen 4 I Säul enpuffer über Nacht bei $4^{\circ} \mathrm{C}$ dialysiert. Die nach der Dialyse ausgefall lenen Proteine und Lipide mußten wiederum durch Zentrifugation entfernt werden $\left(4^{\circ} \mathrm{C}, 10 \mathrm{~min}, 14000 \mathrm{Upm}\right.$, Sorvall Rotor SS34). Die im Dialysat gelösten Mal tosebi ndeproteine - fusioniert mit dem gewünschten Protein - konnten daraufhin an die Matrix gebunden werden.

\subsubsection{Spaltung von Fusionsproteinen mit dem Faktor $\mathrm{Xa}$}

Die Spaltung des MalE-Fusionsproteins zur Trennung des Zielproteins vom MBP, erfolgte über eine dazwischenliegende Erkennungssequenz für den Proteasefaktor $\mathrm{Xa}$. Dieser Faktor spaltet Peptide hinter der spezifischen Erkennungssequenz Ile-Glu-Gly-Arg. 
Die Spaltungsreaktion wurde in maximal 50 l Säulenpuffer $/ 10 \mathrm{mM}$ Mal tose bei RT über Nacht durchgeführt. Dabei spaltete $1 \square g$ Faktor Xa (New England Biolabs, Schwalbach) $50 \square \mathrm{g}$ Fusionsprotein. Die erfolgreiche Spaltung wurde mittels SDS-PAGE (2.11.2) kontrolliert.

\subsection{I mmunologische M ethode}

\subsubsection{Herstellung polyklonaler Antiseren}

Zur Herstellung polyklonaler Antiseren mit Anti-ComP-Antikörper wurde ein Kaninchen mit aufgereinigtem MBP-ComP-Fusionsprotein immunisiert. Die erste Injektion erfolgte mit $200 \square \mathrm{g}$, die folgenden Injektionen mit jeweils $70 \square \mathrm{g}$ Fusionsprotein. Pro Injektionen konnten maxima $500 \square$ I Antigenlösung mit $500 \square$ l Freund's Adjuvans injiziert werden. Injektion und Blutungen wurden von der Firma BioSience, Göttingen, nach folgendem Protokoll durchgeführt:

$\begin{array}{ll}\text { Injektionen: } & \text { Tage 0, 21, 49 und 56 } \\ \text { Blutungen: } & \text { 0. Tag (Präimmunserum) } \\ & \text { 35. Tag ( } 2 \mathrm{ml}+15 \mathrm{~m} \text { Serum) } \\ & \text { 53. Tag ( } 2 \mathrm{ml}+20 \mathrm{~m} \text { Serum) } \\ & \text { 65. Tag (mind. } 50 \mathrm{ml} \text { Serum) }\end{array}$

Die Seren wurden aliquotiert und be $-20^{\circ} \mathrm{C}$ gelagert.

\subsubsection{Immunodetektion von Proteinen mittels C hemilumineszenz}

Der Nachweis der auf Nitrocellul osemembran transferierten Proteine mit spezifischen Antikörpern erfolgte mit Hilfe einer gekoppelten Peroxidase (Protein A HPR Konjugat; Boehringer, Mannheim). Diese Methode, die im al lgemeinen mit einem vorangegangenen 'Western Blotting 'auch als Ímmunoblotting' bezeichnet wird, basiert auf der spezifischen Bindung eines Antikörpers (primärer Antikörper) an das zu detektierende Protein. Der FcTeil des primären Antikörpers kann danach durch Protein A, welches eine Peroxidase trägt, erkannt und gebunden werden. Der Nachweis dieser Peroxidase kennzeichnet somit indirekt das zu detektierendeZiel protein. Die Nachweisreaktion erfol gt dadurch, daß die Peroxidase das Substrat Luminol (ein Diacylhydrazid) oxidiert, worauf das gebildete Zwischenprodukt Licht emittiert. Eine Intensivierung der Lichtemission bewirkt 4-lodophenol, welches als 
Radikal transmitter zwischen dem gebildeten Sauerstoffradikal und Luminol wirkt. Das Licht kann auf einem Röntgenfilm festgehalten werden.

Nach dem WESTERN-Blot (2.9) wurde die Nitrocellul osemembran unter Schwenken zunächst für $1 \mathrm{~h}$ bei RT mit 'Blocking-Reagenz' [1 ml auf $9 \mathrm{ml}$ PBST; BM Chemiluminescence Blotting Substrate (POD) Kit] behandelt, um unspezifische Bindungen der Antikörper oder des Protein A mit der Membran zu verhindern. Die Bindung der Antikörper erfolgte bei Raumtemperatur für mindestens $2 \mathrm{~h}$ oder über Nacht bei $4^{\circ} \mathrm{C}$, wobei das Antiserum 1:10000 bis 1:20000 mit PBST zu verdünnen war. Nach drej 15minütigen Waschschritten mit PBST konnte das Protein A HPR Konjugat (Boehringer, Mannheim) in 10000facher Verdünnung in PBST für $1-2 \mathrm{~h}$ hinzugegeben werden. Schließlich folgten drei 15 minütige Waschschritte mit PBST, bevor die Membran in Frischhaltefolie an 3 Seiten eingeschweißt wurde und $1 \mathrm{ml}$ Lösung $A$ und $10 \mu \mathrm{l}$ Lösung $B$ durch die offene Seite hinzupipettiert werden konnte (POD-Kit). Nach 2 min Inkubation wurde die Detektionslösung herausgestrichen und in der Dunkelkammer für 1-10 min ein Röntgenfilm (Kodak, Stuttgart) aufgelegt. Anschließend mußte der Film für ca. 2 min in Kodak LX24-Lösung entwickelt, kurz gewässert und in Kodak AL4-Lösung 2 min fixiert werden. Nach dem Abspülen der Fixierlösung mit Wasser konnte der Film bei Raumtemperatur getrocknet werden.

\begin{tabular}{lr}
\multicolumn{1}{l}{ PBST } & \\
$\mathrm{NaCl}$ & $8,2 \mathrm{~g}$ \\
$\mathrm{KCl}$ & $0,75 \mathrm{~g}$ \\
$\mathrm{Na}_{2} \mathrm{HPO}_{4}$ & $2,29 \mathrm{~g}$ \\
$\mathrm{KH}_{2} \mathrm{PO}_{4}$ & $0,27 \mathrm{~g}$ \\
$\mathrm{Tw}_{\text {ween } 20}$ & $0,5 \mathrm{~m}$ \\
$\mathrm{H}_{2} \mathrm{O}_{\text {dest. }}$ & ad $1000 \mathrm{ml}$
\end{tabular}

\subsection{E nzymaktivitätstests}

\subsubsection{Bestimmung der $\square-G$ alaktosidaseaktivität}

Die Aktivität der [-Galaktosidase wurde photometrisch durch die Umsetzung von o-Nitrophenyl-[-D-Galaktopyranosid (ONPG) zu o-Nitrophenol ermittelt. Die dabei auftretende zeitabhängige Gelbfärbung wurde bei $420 \mathrm{~nm}$ gemessen. J eder Meßansatz enthielt $100 \square$ I Zellkultur-Probe (evtl. verdünnt oder konzentriert) und $900 \square$ I Z-Puffer. Der Zellaufschluß erfol gte durch Zugabe von $5 \square$ । 0,1\% SDS und 10 $\square$ I Chloroform Nach 
kräftigem Schütteln wurden die Ansätze 5 min bei $28^{\circ} \mathrm{C}$ inkubiert und anschließend die Umsetzungsreaktion durch Zugabe von $200 \mathrm{ml}$ ONPG $(4 \mathrm{mg} / \mathrm{ml}$ Phosphat-Puffer) gestartet. Beim Auftreten einer Gel bfärbung wurde der Ansatz mit 0,5 $\mathrm{ml} 1 \mathrm{M} \mathrm{Na}_{2} \mathrm{CO}_{3}$ abgestoppt, die Zel trümmer abzentrifugiert (RT, 30 s, 15000 Upm, Biofuge 17 RS) und anschließend die OD bei $420 \mathrm{~nm}$ gemessen. Die ONPG-Umsatzrate wurde nach MILLER (1972) durch folgende Formel berechnet:

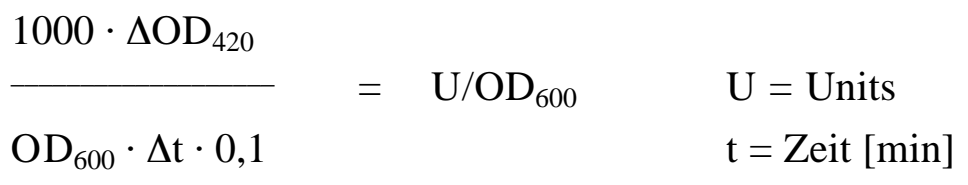

Z-Puffer

Phosphat-Puffer $100 \mathrm{~m}$ $\mathrm{KCl} \quad 75 \mathrm{mg}$

$\mathrm{MgSO}_{4} \times 7 \mathrm{H}_{2} \mathrm{O} \quad 25 \mathrm{mg}$ प-Mercaptoethanol 270 ।I
Phosphat-Puffer

$\mathrm{Na}_{2} \mathrm{HPO}_{4} \times 12 \mathrm{H}_{2} \mathrm{O} \quad 21,5 \mathrm{~g}$

$\mathrm{NaH}_{2} \mathrm{PO}_{4} \times \mathrm{H}_{2} \mathrm{O} \quad 5,5 \mathrm{~g}$

$\mathrm{H}_{2} \mathrm{O}_{\text {dest. }} \quad$ ad $1000 \mathrm{~m}$

$\mathrm{pH} 7,2$

\subsubsection{Bestimmung der NADH-Dehydrogenase-Aktivität}

Die NADH $+\mathrm{H}^{+}$-oxidierende Aktivität von gewaschenen, fraktionierten Membranen aus Acinetobacter sp. BD413 wurde photometrisch bestimmt, indem die Abnahme der gelben Färbung des Elektronenakzeptors Ferricyanid bestimmt wurde. Bei einer Wellenlängevon $420 \mathrm{~nm}$ beträgt der Extinktionskoeffizient ( $\square$ ) des Ferricyanids 1,0 $\mathrm{mM}^{-}$ ${ }^{1} \mathrm{~cm}^{-1}$. Der Enzymtest wurde unter aeroben Bedingungen in einem Volumen von $1 \mathrm{~m}$ durchgeführt und enthielt folgende Komponenten.

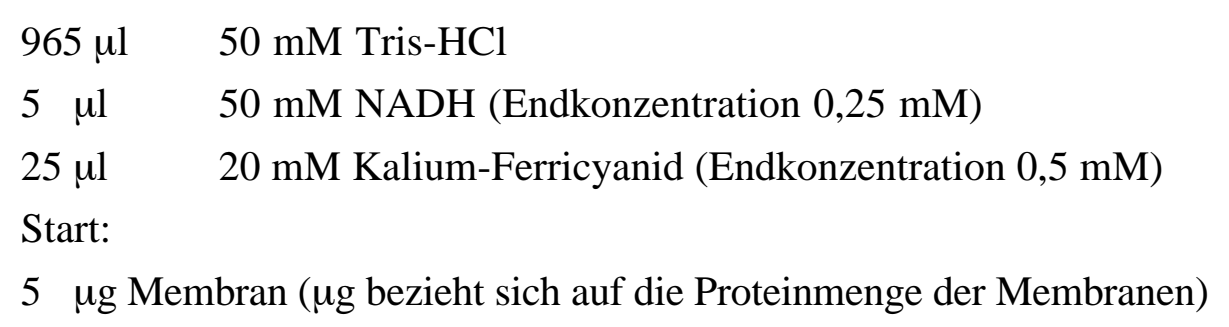

Start:

$5 \square g$ Membran ( $\square g$ bezieht sich auf die Proteinmenge der Membranen)

Die spezifische Enzymaktivität wurde aus dem liniearen Bereich der Kinetik und der Proteinkonzentration nach folgender Beziehung berechnet:

$$
\begin{aligned}
& \square \mathrm{OD}_{420}\left(\mathrm{~min}^{-1}\right) \cdot \mathrm{V} \\
& \mathrm{u} \cdot \mathrm{d} \cdot \mathrm{v} \cdot \mathrm{c} \\
& \begin{aligned}
=\text { spezifische A ktivität } & \text { (U/mg Protein) } \\
& \equiv \text { ( } \square \mathrm{mol} / \mathrm{min} \mathrm{mg} \text { Protein })
\end{aligned}
\end{aligned}
$$




$\begin{array}{ll}\mathrm{U} & \text { : Unit* } \\ \square \mathrm{OD}_{42 \mathrm{~d}} \mathrm{mmin} & : \text { Extinktionsänderung pro Minute } \\ \mathrm{V} & : \text { Gesamtvolumen imAnsatz }(\mathrm{I}) \\ \mathrm{d} & : \text { Schichtdicke der Küvette }(1 \mathrm{~cm}) \\ \mathrm{v} & : \text { Probevolumen der Membran }(\mathrm{I}) \\ \square & : \text { spezifische Extinktionskoeffizient }\left(1,0 \cdot \mathrm{mmol}^{-1} \mathrm{~cm}^{-1}\right) \\ \mathrm{C} & : \text { Proteinkonzentration (der Membran) } \\ * \text { Die internationale Enzymeinheit Unit }(\mathrm{U}) \text { entspricht dem Umsatz von } 1 \square \mathrm{mol} \\ \text { Substrat pro Minute }\end{array}$

\subsection{Isolierung von M embranen und Proteinen}

\subsubsection{Isolierung der dicken und dünnen Pili}

Eine 3I-Kultur von Acinetobacter wurde über Nacht in einem 3I-Kluyver-Kolben in Succinat-Mineral medium angezogen. Die vorsichtige Belüftung sollte Turbulenzen im Medium vermeiden, die zum A bscheren der Pili geführt hätte. Die Zellen wurden geerntet (6000 Upm, $10 \mathrm{~min}, 4^{\circ} \mathrm{C}$; Sorvall Rotor GSA), in $20 \mathrm{ml}$ Tris/SalinePuffer resuspendiert und zweimal durch eine $26 \mathrm{G} \times 1 / 2$ "-Kanüle (Braun Melsungen) gesprittt, so daß die filamentösen Strukturen abscherten. Die Sedimentation der Zellen erfolgte durch zweimal iges Zentrifugieren bei 6000 Upm für jeweils 5 min ( $4^{\circ} \mathrm{C}$; Rotor SS34). Daraufhin befanden sich die abgescherten Pili im Überstand. War die Aggregation der dünnen Pili erwünscht, so wurde durch Dialyse (2.8.9) eine hohe Ionenkonzentration eingestellt. Durch Ultrazentrifugation des Überstandes bzw. des Dialysates (42000 Upm, $4^{\circ} \mathrm{C}, 1 \mathrm{~h}$; Rotor T865 oder Ti60) sedimentierten die Proteine hoher molekularen Masse, die in $300 \mu l$ Puffer (20 mM Tris- $\mathrm{HCl}$, pH 7,5 bzw. Dialysepuffer) aufgenommen wurden. Die Auftrennung nach Dichte erfolgte in einem 20-70\%igen Stufen-Saccharosegradienten, wobei die Stufendifferenz 10\% Saccharose betrug (26000 Upm, $18 \mathrm{~h}, 4^{\circ} \mathrm{C}$; Swing-Out-Rotor TH641). Anschließend konnte mit Hilfe einer Peristal tikpumpe und einer 0,9 x 120 Kanüle (TSK-Supra, Braun Melsungen) der Gradient in neun 1,3 ml-Volumina fraktioniert werden; das Sediment ließ sich in $100 \mu \mathrm{l}$ Tris/Saline-Puffer resuspendieren. Schließlich folgte die Sedimentation der Proteine der einzel nen Fraktionen durch Ultrazentrifugation, wozu diese zuvor mindestens fünffach mit Tris/Saline-Puffer verdünnt wurden (42000 Upm, $1 \mathrm{~h}$, Sorval Rotor Ti60). Die Überprüfung des Pilusgehaltes der in 50-100 $\square$ l resuspendierten Sedimente erfolgte in einer 15\%igen SDS-PAGE (2.8.2). 


\section{Dialysepuffer}

Tris- $\mathrm{HCl}$

$\mathrm{NaCl}$

$\mathrm{MgCl}_{2}$

$\mathrm{pH} 7,5$

\section{Tris/Saline-Puffer}

Tris- $\mathrm{HCl}$

$30 \mathrm{mM}$

Tris- $\mathrm{HCl}$

$30 \mathrm{mM}$

\subsubsection{Präparation von G esamt-M embranen}

Die Anzucht der Bakterien erfolgte in Succinal-Minimalmedium über Nacht (2.2.3). DieBakterien befanden sich zur Zellernte somit in der stationären Wachstumsphase, in der die bisher untersuchten Kompetenzgene von Acinetobacter sp. BD413 am höchsten exprimiert werden (BusCH et al. 1999, HeRZBerg et al. 2000, PoRstendörfer et al. 2000, FRIEDRICH et al. 2001). Für die Anzucht im kleinen Maßstab eigneten sich Schikanekolben, die zur Durchlüftung auf einem Schüttler zu befestigen waren oder $3 \mathrm{I}-K$ leuyver-Kolben. Eine Massenanzucht erfolgte in einem 100 l-Fermenter (UD 100) der Firma Braun (Melsungen). Nach dem Ernten der Kultur durch einen niedertourigen Zentrifugationsschritt (6000 Upm, $10 \mathrm{~min}, 4^{\circ} \mathrm{C}$; Sorvall Rotor, SS34, GSA oder GS3) und dem Waschen mit Tris/Saline-Puffer konnten die Zellen bei $-70^{\circ} \mathrm{C}$ gelagert werden. Die im 100 I-Fermenter angezogenen Zellen wurden mittels Durchlaufzentrifugation in einer CEPA-Spindelzentrifuge (Carl Padberg, Lahr) mit $80 \mathrm{l} / \mathrm{h}$ geerntet. Hierzu wurde ein Schlauch am Bodenauslaß des Fermenters mit Hilfe von Schlauchschellen angeschlossen und mit der Zentrifuge verbunden. Zur Entlerung des Fermenters wurde dieser mit einem Überdruck von 1 bar beschickt.

Den mit Lysispuffer im Verhältnis mindestens von 3:1 (Puffer:Zellen) verdünnten Zellen wurden nach 10 min Inkubation be $30^{\circ} \mathrm{C}$ etwas DNase und RNase zugegeben und

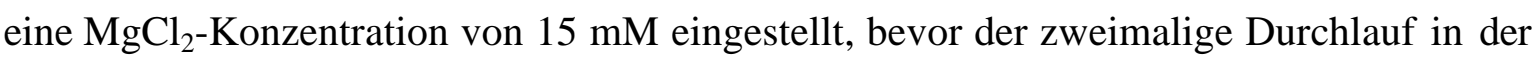
FRENCH-Presse (Fa. SLM Aminco, Urbana, USA) bei einem Druck von 12000 PTI den Großteil der Zellen aufschloß. Durch zwei niedertourige Zentrifugationsschritte ließen sich ganze Zellen entfemen ( $6000 \mathrm{Upm}, 10 \mathrm{~min}, 4^{\circ} \mathrm{C}$; Sorvall Rotor, SS34, GSA oder GS3). Die Membranvesikel sedimentierten in einem Ultrazentrifugationsschritt $\left(42000,1 \mathrm{~h}, 4^{\circ} \mathrm{C}\right.$; Rotor T865 oder Ti60). Um das Cytoplasma auszuverdünnen, mußte das Sediment zweimal mit mindestens dem $10 f a c h e n$ Volumen des Membranpellets Mempranpuffer gewaschen werden. Schließlich wurde das Pellet in 2 Volumina Membranpuffer resuspendiert und gegebenenfalls bei $-70^{\circ} \mathrm{C}$ gelagert. 
Lysepuffer

Tris- $\mathrm{HCl}$

EDTA

$\mathrm{NaCl}$

6-Aminocapronsäure

Der pH-Wert wurde auf 7,5 eingestellt

und kurz vor Gebrauch $20 \mathrm{mg}$ pro $1 \mathrm{~g}$

Zellmasse (Feuchtgewicht) Lysozym

und $1 \mathrm{mM}$ PMSF gelöst.

\section{Membranpuffer}

$\begin{array}{ll}\text { Tris-HCl } & 30 \mathrm{mM} \\ \mathrm{MgCl}_{2} & 5 \mathrm{mM} \\ \mathrm{NaCl} & 50 \mathrm{mM}\end{array}$

6-Aminocapronsäure $5 \mathrm{mM}$

$\mathrm{pH} 7,5$

\section{Tris/Saline-Puffer}

Tris- $\mathrm{HCl} \quad 30 \mathrm{mM}$

$\mathrm{NaCl} \quad 0,9 \%(w / v)$

$\mathrm{pH} 7,5$

\subsubsection{I solierung von cytoplasmatischer und äußerer Membran (HANCOCK \& NIKAIDO, 1987)}

In einem $3 \mathrm{I}-$ Kleuyver-Kolben wurde in Succinat-Mineralmedium eine $3 \mathrm{I}$-Kultur von Acinetobacter sp. BD413 über Nacht angezogen und, wie unter 2.13.2 genauer beschrieben, weiterbehandelt: DieZellen wurden geerntet, gewaschen, anschließend resuspendiert, in der FRENCH-Presse aufgeschl ossen und die noch verbliebenen ganzen Zellen zentrifugiert. Da nach der Sedimentation der Membranen in der Ultrazentrifuge sich diese nur schwer resuspendieren ließen, und danach immer noch kleinste Verklumpungen erkennbar waren, erfolgtezur Abtrennung des Cytoplasmas zunächst nur eine Verdichtung der Membranen, wozu mit einer 70\%igen Saccharosestammlösung (in Membranpuffer) im Zelllysat eine Saccharosekonzentration von $15 \%(w / v)$ eingestellt und auf ein $70 \%$ iges (w/v) Saccharosekissen ( $3 \mathrm{ml})$ zentrifugiert wurde $\left(1 \mathrm{~h}, 4^{\circ} \mathrm{C}, 27000 \mathrm{Upm}\right.$; Swing-Out-Rotor AH629). Hierbei mulste darauf geachtet werden, daß das Zelllysat mit Membranpuffer (bzw. mit der Saccharosestammlösung) vor der Überschichtung des Saccharosekissens mindestens dreifach verdünnt wurde; ansonsten wären die Membranen aufgrund der hohen Viskosität nicht verdichtet worden.

Anschließend konnten die Membranen ( die untersten $6 \mathrm{ml}$ ) auf einen neuen Gradienten (4 ml 70\% Saccharose, $10 \mathrm{ml} 64 \%$ Saccharose, $10 \mathrm{ml}$ 58\% Saccharose, $9 \mathrm{ml}$ $52 \%$ Saccharose, jeweils in Membranpuffer) überschichtet werden. Die Trennung von cytoplasmatischer und äußerer Membran erfol gte durch Zentrifugation über Nacht $\left(4^{\circ} \mathrm{C}\right.$, 
27000 Upm; Swing-Out-Rotor AH-629). Die resultierenden Banden wurden mit einer PASTEUR-Pipette vorsichtig abgenommen, in einen T-865 oder Ti60 Zentrifugenbecher überführt und in Membranpuffer (2.13.2) suspendiert. Die mittlere gel blicheBande bildeten Cytoplasmamembranen und die obere weißliche Bande bestand aus äußeren Membranen. (PORSTENDÖRFER 1998). Die erneute Sedimentation effol gte für $1 \mathrm{~h}$ bei $42000 \mathrm{Upm}\left(4^{\circ} \mathrm{C}\right.$; Rotor T-865 oder Ti60). Die pelletierten Membranen wurden in für die Resuspendierung kleinst möglichen Volumina Membranpuffer (2.13.2) aufgenommen und bei $-20^{\circ} \mathrm{C}$ aufbewahrt.

\subsubsection{Solubilisierung der gewaschenen M embranen}

Zur Lösung der Membranproteine dienten gewaschene Membranen von Acinetobacter-Stämmen. Vor jeder Solubilisierung waren die Membranen mit Membranpuffer (2.13.2) auf die gewünschte Proteinkonzentration einzustellen, so daß sich nach Zugabe des Detergenz eine Proteinkonzentration von 4-5 mg/ml ergab. Daraufhin wurden die Proben unter Rühren 15 min auf Eis inkubiert. Die Trennung der solubilisierten Proteine von ungelösten Membranen erfolgte im präparativen Maßstab durch Zentrifugation in einer Sorvall OTD-55 b Ultrazentrifuge (42000 Upm, 20 min, 4 ${ }^{\circ} \mathrm{C}$; Rotor T-865 oder Ti60), im analytischen Maßstab in einer Tischzentrifuge (15000 Upm, 20 min, $4^{\circ} \mathrm{C}$; Biofuge17 RS).

\subsubsection{Chromatographische M ethoden}

An die Solubilisierung der Membran schlossen sich flüssigkeitschromatographische Schrittean, die mittels einer Gradifrac-Einheit (Pharmacia Biotech Europe GmbH, Freiburg) durchgeführt wurden und aus folgenden Komponenten bestand: Kontroller und Fraktionssammler Gradifrac; Pumpe P50; Probenauftragsventil V 7; UV-Monitor Uvicord SII mit Durchflußzelle und angeschlossenem 2-Kanal-Schreiber REC 102; Leitfähigkeitsmeßgerät mit Durchflußzelle, Mischzelle (1,6 m) und zwei Magnetventile PSV 50, von denen eines zum Aufbau des Salzgradienten und das andere zur Umschaltung zwischen Fraktionssammler und Abfal lgefäß diente. Zum Auftragen größerer Volumina wurde des weiteren eine Pumpe Typ P1 benutzt.

Das Gradifrac-System war programmierbar, so daßs die Elution und Fraktionierung unter Aufzeichnung des Protein- und Salzgehaltes automatisch ablief. Sämtliche benutzte Puffer wurden durch Filtration durch eine in einen Glasfilterhalter mit Fritte eingespannte Cellulose-Acetat-Membran (Porendurchmesser: $40 \mu \mathrm{m}$ ) von Partikeln befreit. Die Entgasung durch das A nlegen eines Vakuums oder durch das Autoklavieren der Lösungen 
sollte die spätere Bildung von Luftblasen in der Säule vermeiden. Die Durchführung der Chromatographie be $4^{\circ} \mathrm{C}$ verlangsamte die proteolytischen Prozesse.

\subsubsection{A nionenaustausch-C hromatographie an Q-Sepharose}

Für die Anionenaustausch-Chromatographie wurde das Gelmaterial Q-Sepharose in Verbindung mit einer XK 50/20-Säule (beides Fa. Phamacia Biotech Europe GMBH, Freiburg) genutzt. DieTrennung beruht darauf, daß Molekülemit negativen Ladungen - wie beispielsweise Proteine oder $\mathrm{Cl}^{-}-$Ionen - an die Matrix binden. Dabei konkurrieren verschiedene Anionen um dieBindungsstellen mit unterschiedlichen Affinitäten. So können an das Material gebundene Proteine durch einen $\mathrm{NaCl}$-Gradienten in der Reihenfol ge ihrer Bindungsstärke verdrängt und nacheinander el uiert werden. Da die Nettol adung der Proteine $\mathrm{pH}$-abhängig ist, erfolgt die Bindung an den Anionenaustauscher erst bei pH-Werten oberhal b des isoel ektrischen Punktes des jeweiligen Proteins. Die Bindung kann demach durch eine weitere Erhöhung des $\mathrm{pH}$-Wertes verstärkt werden.

Die benötigte Menge Gelmaterial wurde nacheinander mit $500 \mathrm{ml} \mathrm{0,5} \mathrm{M} \mathrm{HCl}$ und $0,5 \mathrm{M} \mathrm{NaOH}$ auf einer $1 \mathrm{I}$-Fritte gewaschen, mit $500 \mathrm{ml}$ einer $3 \mathrm{M} \mathrm{NaCl}$-Lösung abgesättigt, mit der gleichen Menge $30 \mathrm{mM}$ Tris- $\mathrm{HCl}(\mathrm{pH}$ 7,5) äquilibriert und resuspendiert.

Zur Eichung des Gradifrac-Systems wurde anstelle der Säule eine Schlauchverbindung zwischen Ventil und UV-Meßgerät eingesetzt. Die Kalibrierung der Induktionsmeßzelle erfolgte durch Pumpen von Hochsalz-Elutionspuffer (30 mM Tris-HCl, 1,5 M NaCl, pH 7,5; evtl. Detergenz oberhalb der Mizellenkonzentration) und Betätigung der $100 \%$ Taste und danach durch Spülen mit dem salzfreien Äquilibrierungspuffer (30 mM Tris$\mathrm{HCl}, \mathrm{pH} 7,5$, evtl. Detergenz) und Betätigung der $0 \%$ Taste. Es folgt die Eichung des Uvicord SII durch Einstellen eines 10\%-Wertes für den Proteingehalt am Schreiber. Die Empfindlichkeit des Proteinmeßgerätes wurde schrittweise erhöht und die Änderung des Schreiberausschlags am Null punkt-J ustierknopf jedesmal ausgeglichen. Dieses bewirkte, daßs die Grundlinie in al len Empfinlichkeitsstufen identisch war und während der Elution ohne Verlust der Grundl inieneinstellung auf den Proteingehal t abgestimmt werden konnte. Anschließend konnte der untere Adapter der Säule angeschl ossen und mit dieser befestigt werden. Nach dem Einfüllen des Sepharose Q-Materials und dem Anbringen des oberen Adapters ließ sich das Material mit Äquilibrierungspuffer bei einer Durchflußrate von 2,5 m//min packen. Bei konstanter Sedimentationshöhe und einem Salzgehalt von unter $1 \%$ konnte der Stempel des oberen Adapters positioniert und die Säule in Betrieb genommen werden.

Nach dem Auftragen des Membransolubilisat (2.13.4) mit $1 \mathrm{ml} / \mathrm{min}$ wurde solange mit $30 \mathrm{mM}$ Tris-HCl (pH 7,5) gespült, bis alle nichtgebundenen Stoffe entfernt worden waren (mindestens 4 Gelvolumina, Durchflußrate $2 \mathrm{ml} / \mathrm{min}$ ). Danach erfolgte die 
stufenweise Elution mit $2 \mathrm{ml} / \mathrm{min}$ mittels ansteigender $\mathrm{NaCl}$-Konzentrationen, wobei die Elutionsvolumina jeder Stufe 4 Gelvolumina betrugen. DieFraktionsvolumina betrugen ca. 15-30\% des Matrixvolumens.

Einen Überblick über die Proteingehalteergab die Messung der Extinktion be $280 \mathrm{~nm}$ in der Durchflußzelle des Uvicord SII, die per Schreiberaufzeichnung dokumentiert wurde; ebenso wurden die Sal zkonzentration und dieFraktionsgröße festgehal ten.

Die Regeneration des Anionenaustausch-Materials erfolgte wie oben beschrieben und dieLagerung be $4^{\circ} \mathrm{C}$ in $20 \%$ (v/v) Ethanol.

\subsubsection{G elfiltration mit Sephadex S-300}

Das Prinzip der Gelfiltration beruht auf der unterschiedlichen Verweildauer von Proteinen verschiedener Größe in einem porösen Gelmaterial. Bei dem hier verwendeten Gel befinden sich all diejenigen Proteine im Ausschluß̌volumen, die größer als $1500 \mathrm{kDa}$ sind. Kleinere Partikel verweilen mit abnehmender Größe zunehmend länger in den Poren und werden dementsprechend später eluiert. Der Trennbereich von Sephacryl S-300 HR (Fa. Phamacia Biotech Europe GMBH, Freiburg) erstreckte sich von 10 kDa bis 1500 kDa. Um Aggregationen während der Elution zu vermeiden, wurde dem Gelfiltrationpuffer 2 mM Dodecylmal tosid zugegeben.

Die Gelfiltration kann bei globulären Proteinen zur Bestimmung der molekularen Masse herangezogen werden. Dazu wurde die Säul ezunächst geeicht, indem eine Beziehung zwischen Retardationsvol umen und molekularer Masse hergestelt wurde. $0,5 \mathrm{ml}$ folgender Eichproteine (4 mg/ml) passierten nacheinender die Säule: Ferritin (450 kDa), Katalase (240 kDa), Aldolase (158 kDa) und Albumin (45 kDa). Um Wechselwirkungen mit der Gelmatrix und Aggregationen der zu untersuchenden gelösten Membranproteinen zu verhindern, wrde dem Gelfiltrationspuffer $100 \mathrm{mM} \mathrm{NaCl}$ und $2 \mathrm{mM}$ Dodecylmaltosid (Endkonzentration) zuzusetzt.

Die fertig gepackte Säule wurde luftblasenfrei an das Gradifrac-System angeschlossen und bei $0,5 \mathrm{ml} / \mathrm{min}$ mit $200 \mathrm{ml}$ Gelfiltrationspuffer gewaschen. Nun konnte die Eichung des Nullwertes des UV-Meßgerätes für die Proteindetektion erfolgen (2.13.5.1). Die Flußrate wurde daraufhin auf $0,3 \mathrm{ml} / \mathrm{min}$ heruntergeregelt und mittels der Auftragspumpe die Probe aufgetragen.

Zur Reinigung des Säul enmaterials wurden in entgegengesetzter Laufrichtung jeweils $50 \mathrm{~m} 2 \mathrm{M} \mathrm{NaCl}, 0,5 \mathrm{M} \mathrm{NaOH}, 10 \mathrm{mM} \mathrm{HCl}$ und zur Konservierung abschließend $20 \%(v / v)$ Ethanol durch die Säule gepumpt. 


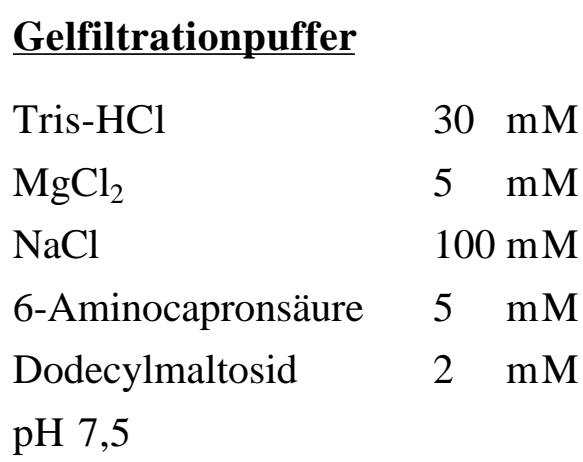

\subsection{Reinigung humaner Erythrocyten mittels Dichtegradientenzentrifugation (L eucoSep K it)}

Die Aufreinigung der humanen Erythrocyten wurde freundlicherweise von Frau Dr. Vehmeyer (Universitätsklinikum, Göttingen; Hämotologie) vorgenommen und die gereinigten Erythrozyten zur Verfügung gestellt

Die Vorgehensweise der I solierung der Roten Blutkörperchen wurde nach Anleitung des LeucoSep Kits vorgenommen. Das LeucoSep Kit besteht aus einem Röhrchen mit Filterscheibe und einer Ficoll-Trennlösung. $15 \mathrm{ml}$ Ficoll-Trennlösung wurden zunächst auf die Filterscheibe des Leicosep-Röhrchens gegeben und dann zentrifugiert (1 min, 400 x g, $4^{\circ} \mathrm{C}$ ), so daßs sich das Ficoll unterhal b der Filterscheibe befand. Anschließend wurden $20 \mathrm{ml}$ Blut (mit Gerinungshemmer: Hanks/EDTA) auf die Filterscheibe gegeben. Durch erneute Zentrifugation (10 $\mathrm{min}, 1000 \times \mathrm{g}, 4^{\circ} \mathrm{C}$ ) reicherten sich die Erythrocyten und die Granul ozyten unterhalb der Filterscheibe an, während sich darüber ein Ring aus PBMC (Peripheral blood mononuclear cells) bildete. Für die weitere Reinigung der Erythrocyten wurde die Filterschei be vorsichtig durchstoßen und die darunter befindliche Lösung in ein leeres $50 \mathrm{ml}$ Röhrchen gegossen, mit Hanks-Lösung auf $50 \mathrm{ml}$ aufgefültt und zentrifugiert ( $15 \mathrm{~min}, 400 \times \mathrm{g}, 4^{\circ} \mathrm{C}$ ), so daß die Roten Blutkörperchen sedimentierten. Der Überstand wurde verworfen.

\subsection{E lektronenmikroskopische Untersuchungen}

\subsubsection{Herstellung von K ohle-Trägerfolien}

Die Kohlefolien wurden nach BRADLEY (1958) durch indirekte Widerstandsbedampfung mit konisch zugespitzten Kohl estäbchen (Spektral kohle höchster 
Reinheit, Ringsdorf, Bonn-Bad Godesberg) in einer Hochvakuum Bedampfungsanlage (E 306, Edwards High Vaccum Ltd., Crawley, Sussex, Großbritannien) auf frisch gespaltenemGlimmer (Plano, W. Plannet GmbH, Marburg) hergestelt. Die Schichtdicke der Folien schwankte in A bhängigkeit von der Bedampfungsdauer zwischen 5 und $20 \mathrm{~nm}$.

\subsubsection{Negativkontrastierung}

Ein ca. $3 \times 3 \mathrm{~mm}$ großes kohlebedampftes Glimmerstück (2.15.1) wurde zugeschnitten und schräg in einen Tropfen der zu untersuchenden Proteinlösung oder Zellsuspension getaucht, so daß der Kohlefilm partiell auf der Tropfenoberfläche abflottieren konnte. Je länger die Folie auf den Tropfen verblieb, desto mehr Proteine adsorbierten dabei an die Kohlefilmoberfläche. Der Kohlefilm wurde anschließend auf die gleiche Art in einem Tropfen $\mathrm{H}_{2} \mathrm{O}_{\text {dest }}$ gewaschen, auf einem Tropfen Kontrastienungslösung (4\%ige Uranylacetat, pH 4,0 oder 3\% Phosphorwolframsäure, pH 7,0) vollständig abflottiert und anschließend auf einem Kupfergrid aufgenommen. Überschüssige Kontrastierungslösung wurde vorsichtig mit einem Filterpapier abgesaugt

\subsubsection{Elektronemikroskopische A bbildung}

Die Elektronenmikroskopie erfolgte an einem Transmissionsel ektronenmikroskop TEM 902 (Zeiss, Oberkochen) mit einer Beschleunigungsspannung von $80 \mathrm{kV}$. Vergrößerungen wurden mit einer Kreuzgitter-Replika (Bazers Union, Liechtenstein) ermittelt. Als Fotonegativmaterial dienten Planfilme der Abmessung 8,3 x 10,2 cm (Scienta 23D-56, Agfa Gevaert, Leverkusen).

\subsubsection{Einbettung von Zellen für elektronenmikroskopische Dünnschichtdarstellungen}

Für Ultradünnschnitte von Zellen mußten diese eingebettet werden. Hierzu wurden die Zellen in 15 m LB-Medium, dem 0,5\% (w/v) Glucose zugesetzt worden war, über Nacht angezogen, geernet und zweimal mit PBS $(50 \mathrm{mM}, \mathrm{pH} 7,5)$ gewaschen (Zentrifugationsschritte bei $4^{\circ} \mathrm{C}, 10 \mathrm{~min}$, Sorvall Rotor SS34). Den in $5 \mathrm{ml}$ PBS resuspendieren Zellen wurde $0,7 \mathrm{ml} 25 \%$ Glutaral dehyd zugesetzt und für 90 min auf Eis inkubiert, bevor die fixierten Bakterien in PBS gewaschen wurden $\left(4^{\circ} \mathrm{C}, 10 \mathrm{~min}\right.$, Sorvall Rotor SS34). Das in ein 1,5 ml-Eppendorf-Reaktionsgefäß überführte Zellpellet wurde daraufhin mit $2 \%$ igem auf $40^{\circ} \mathrm{C}$ erwärmten Agar (in PBS) sorgfältig gemischt, wobei das Verhältnis von Pelletvolumen und Agarlösung 1:1 betragen mußte, und anschließend für 
10 min auf Eis abgekühlt. Um die in Agar eingebetteten Zellen aus dem Reaktionsgefäß zu befreien, wurde die Spitze mit eine Klinge abgeschnitten und der Inhalt auf einen Glasobjektträger geschoben, wo dieser in ca. $2 \mathrm{~mm}$ Stücke geschnitten wurde. Diese Stücke mußsten, umein Austrocknen zu vermeiden, sofort in 3,5 ml Präparatengläser (12 × $35 \mathrm{~mm}$, Ochs) weiterverarbeitet werden.

Die Einbettung wurde nach SPURR (1969) durchgeführt. Die Proben wurden mit der Doppelfixierung nach BEHN \& ARNOLD (1974) vorbehandelt und in SPURR-Harz eingebettet. Es wurde nach folgendem Plan vorgegangen:

- Dreimal 20 min in PBS bei $0^{\circ} \mathrm{C}$ waschen

- Fixierung in $1 \%(\mathrm{w} / \mathrm{v})$ Osmiumteroxid in PBS bei $4^{\circ} \mathrm{C}$ für 30 min

- Dreimal 20 min in $\mathrm{H}_{2} \mathrm{O}_{\text {dest }}$ bei $4^{\circ} \mathrm{C}$ waschen

- Entwässerung in einer aufsteigenden Acetonrei he bei $0^{\circ} \mathrm{C}$

- 10 min in 10, 30 und $50 \%$ wäßrigem Aceton

- über Nacht oder $3 \mathrm{~h}$ in $2 \%$ (w/v) Uranylacetat in 70\% Aceton

- 10 min in 70, 90 und 100\% Aceton (über wasserfreiem $\mathrm{CuSO}_{4}$ getrocknet)

- 20 min in $100 \%$ Aceton bei RT

- Verdopplung des Volumens mit Kunstharz bei RT (Harz:Aceton 1:1)

- nach 30 min erneut $V$ erdopplung des Volumens mit Kunstharz

- nach 90 min Austausch gegen frisches Kunstharz

- am nächsten Tag erneuter A ustausch gegen frisches Kunstharz

- nach $3 \mathrm{~h}$ in 0,5 ml Gelatinekapseln (G. Pohl-Boskamp, Hohenlockenstedt/ Holstein) übertragen

- Gelatinekapseln zu 3/4 mit Kunstharz füllen

- 10 min Evakuierung, um Gasblasen zu entfernen

- $8 \mathrm{~h}$ bei $70^{\circ} \mathrm{C}$ polymerisieren

Z usammensetzung des K unstharzes (Serva):

\begin{tabular}{ll} 
Vinylcyclohexendioxid (ERL 4206) & $15,0 \mathrm{~g}$ \\
DER 732 (oder DER 736 nur 9,0 g) & $13,5 \mathrm{~g}$ \\
Nonenylbernsteinsäureanhydrid (NSA) & $39,0 \mathrm{~g}$ \\
\hline T-Dimethylaminoethanol (S1) & $0,6 \mathrm{~g}$
\end{tabular}

\subsubsection{Ultramikrotomie}

Die polymerisierten Proben wurden mit einer Diamantfräse (TM 60, Reichert, Österreich) so angespitzt, daß ein Pyramidenstumpf mit einer quadratischen Spitze von 
maximal 0,5 $\mathrm{mm}^{2}$ Oberflächeentsteht. Die Dünnschnitte wurden mit einem Ultramikrotom (UltromeIII, LKB. Bromma, Schweden) unter Verwendung von Glasmessern angefertigt

Die Messer wurden aus $25 \mathrm{~mm}$ breiten und 6,5 $\mathrm{mm}$ dicken Glasstreifen (LKB, Bromma, Schweden) mit einem Messerbrecher (Knifemaker LKB 7800) hergestellt und besaßen bei einem Gegenstück von ca. $0,5 \mathrm{~mm}$ Dicke einen realen Winkel um $55^{\circ}$ an der Messerkante. Sie wurden mit einem Kunststofftrog zur Aufnahme von filtrierten $\mathrm{H}_{2} \mathrm{O}_{\text {dest, }}$, auf dem die Schnitte abflottierten, versehen und konnten mehrere Tage ohne Qualitätsverlust gelagert werden.

Die auf der Wasseroberfläche abflottierten Ultradünnschnitte besaßen bei silberner Interferenzfarbe eine Dicke von 60-90 nm. Die Schnitte wurden mit formvarbeschichteten Kupfergrids aufgenommen.

\subsection{Zentrifugationen}

Für alle molekularbiologischen und proteinchemischen Arbeiten wurden je nach Lösungs- bzw. Kulturvolumen unterschiedliche Zentrifugen und Rotoren genutzt. Sofem nicht anders angegeben, wurden Volumina bis 2,0 $\mathrm{ml}$ in einer Biofuge $15 \mathrm{bzw}$. Biofuge 17 RS der Firma Heraeus, Osterode/Harz zentrifugiert. Dabei entsprachen beispielsweise $15000 \mathrm{Upm}=18000 \times \mathrm{g}$. Volumina, die oberhalb $2 \mathrm{ml}$ lagen, wurden in einer Sorvall RC 5B-Zentrifuge der Firma. Du Pont, Bad Homburg, mit den Rotoren SS-34, GS-3 oder GS-A zentrifugiert. Dabei entsprachen beispielsweise $15000 \mathrm{Upm}=27000 \mathrm{xg}$. Membranen wurden in einer Ultrazentifuge der Firma Du Pont, Bad Homburg, mit dem Rotor T-865 (50000 Upm $=\sim 170000 \times$ g) bzw. mit den „Swing-Out-Rotoren“ AH-629 und TH-641 (28000 Upm $=\sim 170000 \times$ g) durchgeführt.

\subsection{Bezugsquellen für Chemikalien, Biochemikalien und E nzyme}

Soweit nicht anders angegeben, wurden Chemikalien von den Firmen Merck (Darmstadt), Riedd de Haen (Hannover), Roth (Karlsruhe) oder Fluka Chemie AG (NeurUIm) mit den Reinheitsgraden 'reinst' oder 'pro analysis' verwendet. Restriktionsendonukleasen stammten von den Firmen Gibco BRL (Eggenstein), MBI Fermentas (Wilna, Litauen) und Pharmacia (Freiburg). Spezielle Chemikalien und Biochemikalien wurden von den fol genden Fimen bezogen: 
$\begin{array}{ll}\text { AGS, Heidelberg: } & \text { Agarose } \\ \text { Biomol Feinchemikalien, Hamburg: } & \text { IPTG }\end{array}$

Biozym Diagnostik (Vertrieb für EpicentreTechnologies, Madison, Wisconsin, USA):

SequiThermExcel DNA Sequencing Kit

BoehringerMannheim, Mannheim DIG DNA Labeling Kit, DIG DNA Luminescent Detection Kit, DIG Glycan Detection Kit RNaseA, T4 DNA-Ligase BM Chemiluminescence Blotting Substrate Kit, Protein A HPR Konjugat, Rnase, Triton X-100

Fluka, Schweiz: p-Hydroxybenzoat, Glycerin, Hexadecyltrimethylammoniumbromid (CTAB), Kaliumacetat, Saccharose, Bis-Tris

Genomed, Bad Oeynhausen: JETquick Plasmid Miniprep Spin Kit, JETstar Plasmid Midi Kit 2.0

GERBU Biotechnik, Gaiberg: Ampicillin, X-Gal, Acrylamid M-Bis

Gibco BRL, Eggenstein: Hefeextrakt, Protein-Größenstandard

MBI Fermentas, Wilna, Litauen:

DNA-Größenstandard (1 kb-Leiter)

Merck, Darmstadt:

Proteinase K, Lysozym

Kodak, Stuttgart:

Entwickler LX24, Fixierer AL4, RöntgenfilmeXOmat AR

Oxoid, Basingstoke, England: Trypton

Pharmacia, Freiburg: High MoleculareWeight (HMW) Marker-Proteine

Promega (Vertrieb durch Serva): ProtoBlot Western Blot AP System

Roth GmbH \& Co, Karlsruhe: Isoamylalkohol, Roti-Phenol, Tris

ServæeinbiochemikaHeidelberg: EDTA, Erase-a-Base-System, Ethidiumbromid, Harnstoff, Kanamycin, Long Ranger Gel Solution, SDS, TEMED, Tween 20

SigmaAldrich Chemie, Deisenhofen: N-Lauroylsarkosin, Spermidin, Tetracyclin 


\section{Experimente und Ergebnisse}

\subsection{Untersuchung der Beteiligung von c-PHB an der natürlichen Transformation}

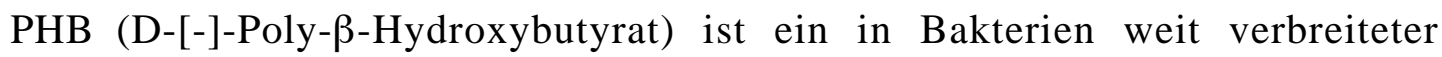
Speicherstoff, der aus (R)-3-Hydroxybutyrat enzymatisch synthetisiert wird. Dieses hochmolekulare Polymer (60-1000 kDa) liegt in der Zelle in Einschlußkörpern vor (DAwes \& Senior 1973, Anderson \& Dawes 1990). Daneben wurde PHB mit niedrigerem Molekulargewicht $(\sim 12 \mathrm{kDa})$ in bakteriellen Zellmembranen identifiziert und als c-PHB bezeichnet (REUSCH \& SADHOFF 1983, REUSCH et al. 1986).

REUSCH und SADHOFF (1988) identifizierten in den Zellmembranen von E. coli und anderen Bakterien zylindrisch aufgebaute Komplexe, die aus c-PHB (c steht für Cytoplasmamembran) und anorganischem Calcium-Polyphosphat aufgebaut sind und Calcium-Ionen durch Membranen transportieren (REUSCH et al. 1995). Dabei soll das amphiphilische c-PHB eine helikale polare Pore bilden, welche das passierende CalciumPolyphosphat umgibt und löst. Eine weitere Funktion für c-PHB wurde bei der DNAAufnahme postuliert: Der Gehalt des Polymers c-PHB in den Zellmembranen korreliert mit der Kompetenzentwicklung in Azotobacter vinelandii, Bacillus subtilis, Haemophilus influenzae und E. coli (REUSCH et al. 1986, REUSCH \& SADHOFF 1983); doch die direkte Beteiligung an der DNA-Aufnahme wurde bisher nicht gezeigt.

\subsubsection{Unterbrechung der PHB-Synthase in Acinetobacter sp. ADP239}

In der Gattung Acinetobacter ist PHB als Speicherstoff weit verbreitet (SCHEMBRI et al. 1994, 1995, 1995a). Durch Unterbrechung des Gens, welches für die PHB-Synthase in BD413 codiert, kann seine Auswirkung hinsichtlich der natürlichen Transformation untersucht werden. Über Datenbankabgleiche konnte ein einziger ORF auf dem Chromosom von BD413 identifiziert werden, dessen Genprodukt Ähnlichkeiten zu einer Vielzahl von bereits untersuchten PHB-Synthasen (PhaC) in anderen Organismen aufweist. Exemplarisch ist ein Aminosäuresequenz-Abgleich mit den PHB-Synthasen (PhaC) aus Bacillus megaterium und Allochromatium vinosum dargestellt, die Identitäten von $30 \%$ bzw. $42 \%$ und Ähnlichkeiten von 59\% bzw. 60\% zu dem potentiellen PhaC aus BD413 zeigen (Abb. 3.1). 


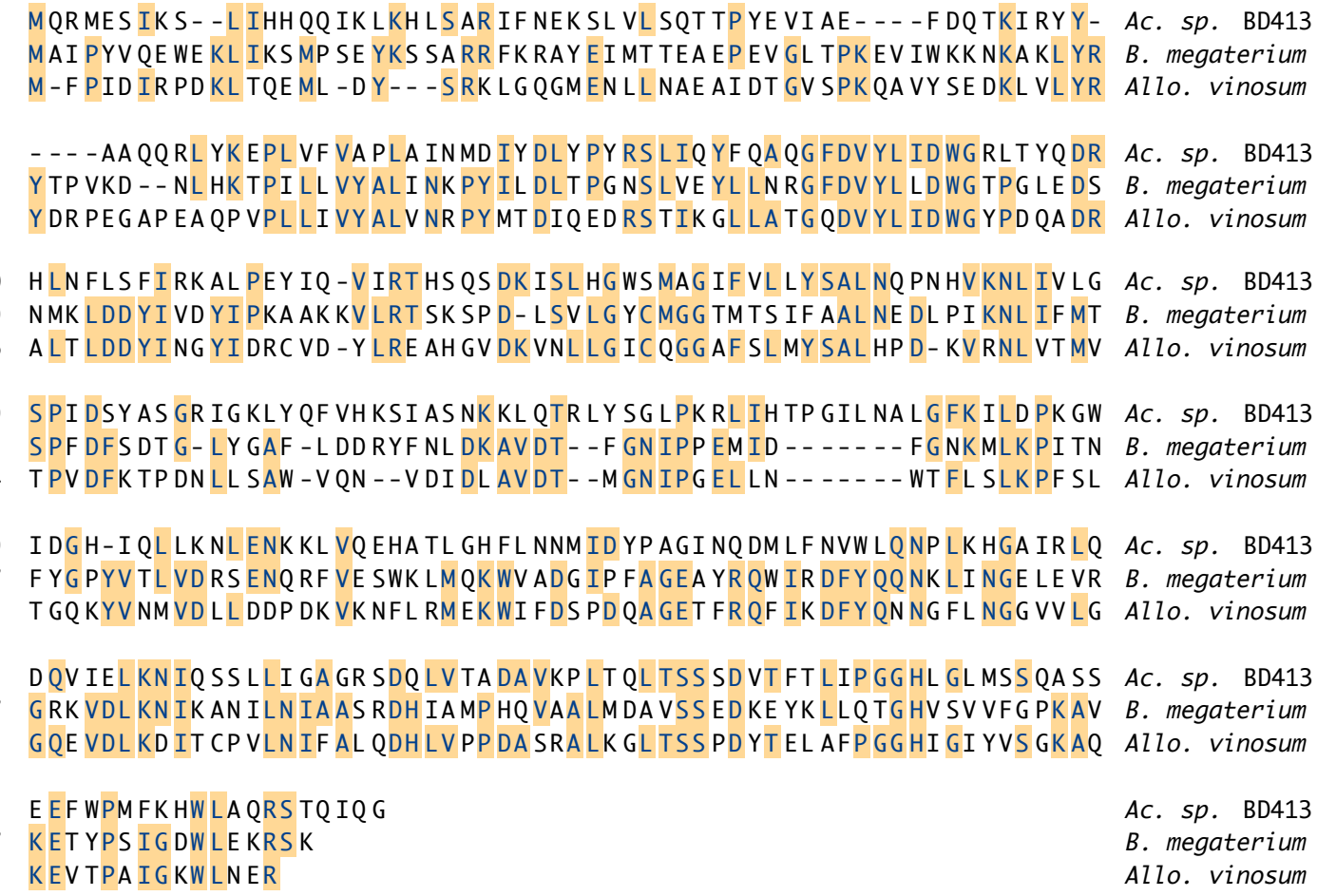

Abb. 3.1: Sequenzvergleich der PHB-Synthase PhaC von Acinetobacter sp. BD413. PhaC aus BD413 zeigt (über die 'Clustal'-Methode ermittelten) Ähnlichkeiten zu PHBSynthasen aus Bacillus megaterium (PhaC) und Allochromatium vinosum (PhaC).

Die Amplifikation des potentiellen PHB-Synthase-Gens phaC für die spätere Unterbrechung in ADP239 erfolgte mit den Primern PHB-SacI-N2 (5 -CTTTTTCG GAGCTCAGAAATATGC-3`) und PHB-XbaI-C2 (5'-GCTTGAACTGCTCTAGATAA TTCAAC-3`). Das mit SacI und XbaI geschnittene PCR-Produkt (1,3 kb) wurde in die äquivalenten Schnittstellen von pUC18 ligiert, wodurch das Plasmid pUB01 resultierte. In die BstXI-Schnittstelle des Inserts von pUB01 wurde nach dem Restriktionsverdau mit $B s t$ XI die überhängenden Enden mit Klenow-Fragment aufgefüllt und mit dem HincIIgeschnittenen nptII-Marker aus pUC4K mit glatten DNA-Fragmentenden ligiert. Für die homologe Rekombination in das Chromosom von Acinetobacter ADP239 ergaben sich somit im resultierenden Plasmid pUB02 den Resistenzmarker flankierende Genbereiche von 230 bp und 1070 bp. Die Mutante mit der Unterbrechung im phaC-Gen, welches für die mögliche PHB-Synthase codiert, wurde als B100 bezeichnet.

Die Überprüfung der einmaligen und homologen Integration des Resistenzmarkers fand über einen SOUTHERN Blot statt. Dazu wurde die isolierte chromosomale DNA des Stammes B100 mit EcoRV und SalI sowie mit SalI und XbaI geschnitten, im Agarosegel elektrophoretisch aufgetrennt, geblottet und mit einer Kanamycin-Sonde hybridisiert. Die relevanten EcoRV- und SalI-Schnittstellen schlossen vor der Mutagenisierung im 
ADP239-Chromosom einen DNA-Bereich von 1,9 kb ein. Mit dem eingefügten Kanamycin-Marker von ca. 1,2 kb ergaben sich daraufhin 3,1 kb (Abb. 3.2, Spur 1). Für die SalI/XbaI-geschnittene chromosomale DNA vergrößerte sich die Basenpaaranzahl entsprechend von ursprünglich 2,3 kb auf 3,5 kb (Abb. 3.2, Spur 2). Diese Detektion der erwarteten DNA-Fragmentlängen bestätigte die richtige Integration des nptII-Markers ins Zielgen.

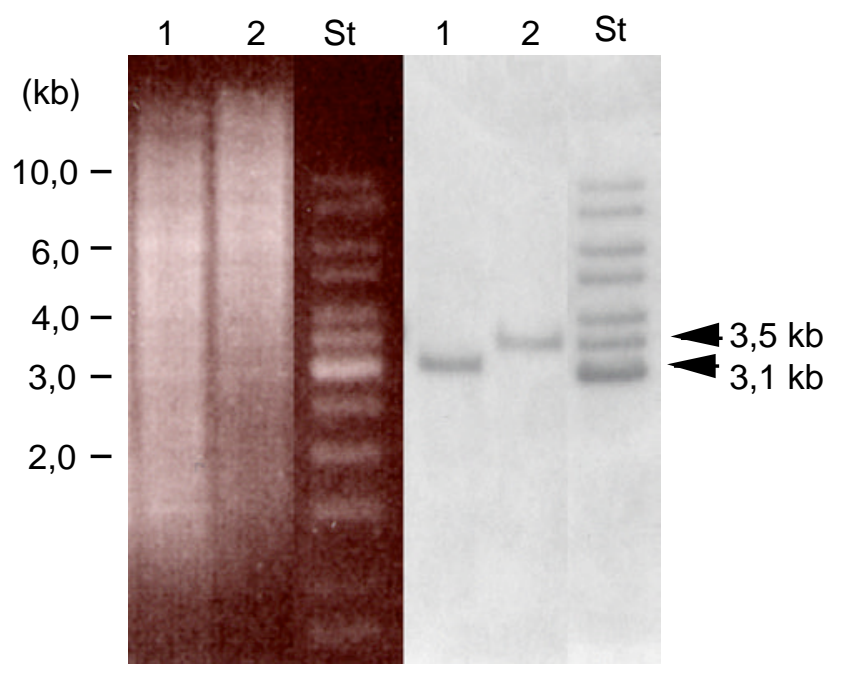

Abb. 3.2: SOUtherN Hybridisierung restriktionsverdauter DNA der phaC-Mutante B100 gegen eine Kanamycin-Sonde. Die isolierte chromosomale DNA von Acinetobacter sp. B100 wurde mit EcoRV Sall (Spur 1) und Sall/Xbal (Spur 2) verdaut, im Agarosegel aufgetrennt und nach dem Blot mit einer Kanamycin-Sonde hybridisiert. Die Sonde detektierte unspezifisch die DNA des DNAGrößenstandards (St) im Bereich von 3-10 kb. Auf der linken Seite ist das Ethidiumbromid-gefärbte Gel und auf der rechten der SOUTHERN Blot dargestellt.

\subsubsection{Untersuchung der phaC-Mutante B100 auf Speicherstoff-Synthese}

Nach der Unterbrechung des phaC-Gens in Acinetobacter sp. ADP239 wurde zur Kontrolle die PHB-Synthese des Wildtyp-Stamms mit der des Mutanten-Stamms B100 verglichen. Hierfür wurden die zwei Stämme über Nacht in Succinat-Mineralmedium unter Phosphat-limitierten Bedingungen angezogen, indem dem Medium nur 1/100 der üblichen Menge Phosphatpuffer zugesetzt worden war. Nach der Ernte der Kulturen erfolgte die in „Material und Methoden“ ausführlich beschriebene Einbettung der Zellen in Kunstharz.

In Abbildung 3.3 sind die Ultradünnschnitte von ADP239 und der phaC-Mutante B100 gezeigt. Der Wildtyp synthetisierte PHB-Speichergranula, die einen großen Teil des cytoplasmatischen Raums beanspruchten. Exeplarisch sind zwei Zellen dargestellt (Abb. 3.3, A/B) Im Cytoplasma der phaC-Mutante B100 dagegen waren keine derartigen 
Einschlußkörperchen zu sehen (Abb. 3.3, C/D). Dies zeigt, daß das identifizierte und unterbrochene Gen phaC im Stamm B100 tatsächlich für die Synthese dieses Speicherpolymers verantwortlich ist und zudem kein Isoenzym diese Aufgabe übernehmen kann.
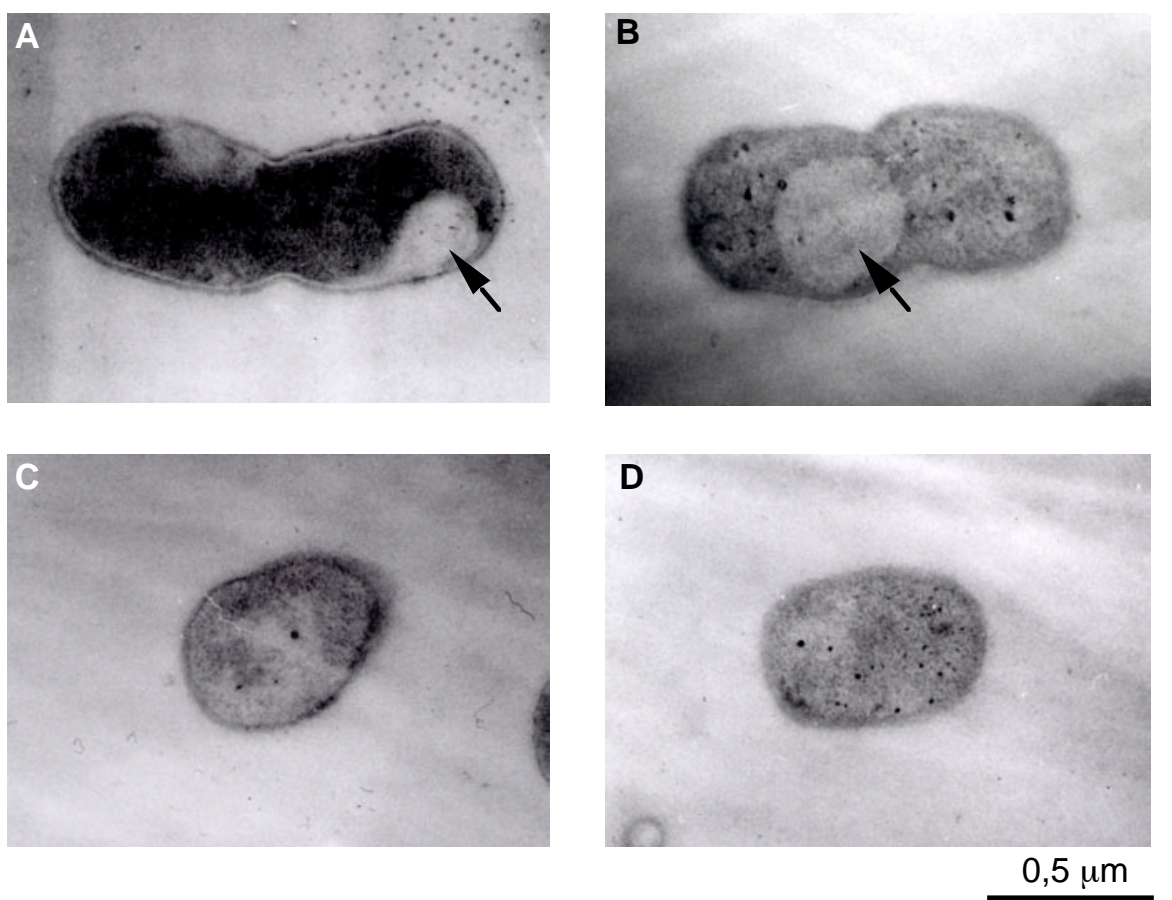

Abb. 3.3: Elektronenmikroskopische Darstellung von PHB-Granula in Ultradünnschichtschnitten von Acinetobacter. Der Wildtyp-Stamn Acinetobacter sp. BD413 bildet nach dem Wachstum auf SuccinatMineralmedium unter Phosphatmangel Einschlußkörper, die deI Speicherstoff PHB enthalten (A und B). Die PHB-Granula sind mit Pfeilen markiert.. Die phaC-Mutante B100, die einen Defekt in der PHB-Synthase besitzt, bildet keine PHB-Granula (C und D).

\subsubsection{Transformationstest der phaC-Mutante B100}

Wäre das membranständige Polymer c-PHB an der natürlichen Transformation beteiligt, so müßte die Mutante B100 mit einem Transformationsdefekt oder mit niedrigerer Transformationsfrequenz reagieren. Zur Klärung dieser Frage wurde ein Transformationsschnelltest durchgeführt (Material und Methoden 2.7.2.3).

Acinetobacter sp. ADP239 wuchs vor dem Passieren der BD413-DNA nicht auf der p-Hydroxybenzoat-Agar-Platte, was den Defekt im pobA-Gen demonstrierte; nach Kontakt mit der BD413-DNA zeigten sich dagegen Kolonien, so daß von einem intakten natürlichen Transformationssystem im Kontrollstamm ausgegangen werden kann (Abb. 3.4). Da sich die Mutante B100 in gleicher Weise verhielt, kann geschlossen werden, daß 
B100 keinen Transformationsdefekt aufweist. Die ermittelten Transformationsfrequenzen der PhaC-Synthase-Mutante B100 lagen im gleichen Größenbereich von Acinetobacter sp. ADP239 (lag-Phase bei $10^{-3}-10^{-4}$ ).

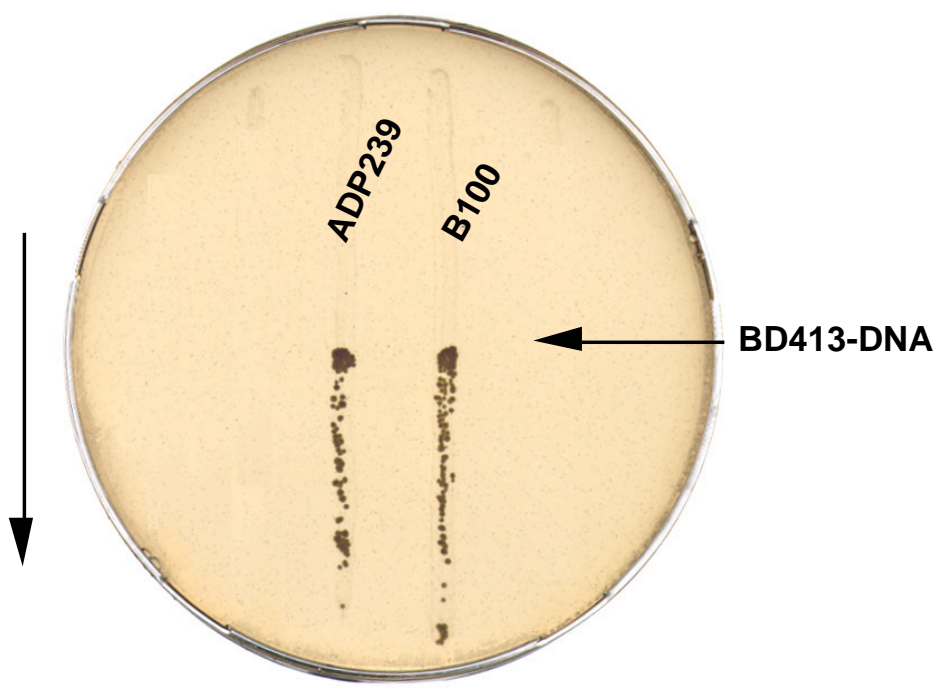

Abb. 3.4: Transformationstest der phaC-Mutant Acinetobacter sp. B100. Da ADP239 und die generierte Mutante B100 einen Defekt im pobA- (HydroxybenzoatHydroxylase-) Gen besitzen, wachsen die Stämme nicht auf p-Hydroxybenzoat. Nach dem Passieren der Impföse durch einen Tropfen chromosomaler DNA von Acinetobacter sp. BD413 findet aufgrund der Fähigkeit zur natürlicher Transformation Wachstum statt. Der senkrechte Pfeil gibt die Richtung der ausgestrichenen Zellen an.

Nach dieser Untersuchung verhielt sich die Mutante B100, die eine Unterbrechung in dem Gen trägt, welches für die PHB-Synthase PhaC codiert, hinsichtlich ihrer natürlichen Fähigkeit zur Transformation identisch zum Wildtyp, welches die Schlußfolgerung zuläßt, daß das Polymer PHB nicht essentiell an der DNA-Aufnahme von BD413 beteiligt ist. Obwohl Acinetobacter sp. BD413 kein zweites Gen besitzt, dessen Genprodukt Ähnlichkeiten zu PHB-Synthasen aufweist, ist dennoch nicht ausgeschlossen, daß eine Synthese von membranständigem c-PHB über einen anderen Biogeneseweg erfolgt. Der cPHB-Gehalt in den Zellmembranen von Wildtyp und Mutante B100 müßte zur endgültigen Klärung der Frage, ob c-PHB an der natürlichen Transformation beteiligt ist, hierzu bestimmt werden. 


\section{2 Überexpression und Reinigung von Proteinen des Transformationssystems von Acinetobacter sp. BD413}

Um die Kompetenzproteine ComA und ComC, die an der DNA-Aufnahme durch die Zellhülle von Acinetobacter sp. BD413 beteiligt sind, in späteren Lokalisierungs- und Charakterisierungsversuchen nachweisen zu können, sollten polyklonale Antikörper gegen diese Polypeptide hergestellt werden. Ihre spezifische Bindung erlauben eine Detektion der Proteine in verschiedenen Zellfraktionen. Dieses setzt eine Überexpression und anschließende Reinigung voraus.

Die Unterbrechung von comC in Acinetobacter sp. BD413 führte zu einem vollständigen Transformationsdefekt und einer verminderten Fähigkeit doppelsträngige DNA auf der Zelloberfläche zu binden (LINK et al. 1998). Die ausgehend vom ersten potentiellen Startcodon der comC-Nukleotidsequenz abgeleitete Aminosäuresequenz besteht aus 1208 Aminosäuren (3624 bp) mit einer errechneten molekularen Masse von $132 \mathrm{kDa}$ (Link et al. 1998). Datenbankabgleiche ergaben Ähnlichkeiten zu den gut untersuchten Proteinen PilC1 und PilC2 aus Neisseria gonorrhoeae (JoNSSON et al. 1991) und Neisseria meningitidis (NASSIF et al. 1994) sowie PilY1 aus Pseudomonas aeruginosa (Alm et al. 1996), die an der Biosynthese von Typ-IV-Pili und der gleitenden Fortbewegung 'Twitching Motility' beteiligt sind. Mit Ausnahme von PilC2 aus Neisseria gonorrhoeae sind die PilC-Proteine außerdem für die Anheftung der Bakterien an die Wirtszelle verantwortlich und erfüllen bei Neisseria gonorrhoeae zusätzlich eine Funktion bei der natürlichen Transformation (MORAND et al. 2001, SCHEUERPflug et al. 1999, RAHMAN et al. 1997). Immunologische Studien bei Neisseria gonorrhoeae ergaben, daß ComC in der äußeren Membran lokalisiert und ebenso an der Spitze des Typ-IV-Pilus zu finden ist. Bei BD413 führte eine Unterbrechung des Kompetenzgens comC nicht zu einem veränderten Pilus-Phänotyp und nicht zu einer beeinträchtigten Fähigkeit zur gleitenden Fortbewegung.

In Acinetobacter sp. BD413 wurde ein Kompetenzgen comA identifiziert, dessen Genprodukt Ähnlichkeiten zu den gut untersuchten Kompetenzproteinen ComA aus Neisseria gonorrhoeae, comEC aus Bacillus subtilis, Rec-2 aus Hemophilus influenzae sowie CelB aus Streptococcus pneumoniae aufweist (FRIEDRICH et al. 2001, CAMPBELL et al. 1998, CLIFTON et al. 1994, FACIUS \& MEYER 1993, HAHN et al. 1993). Für diese bereits untersuchten Kompetenzproteine wurde eine Lokalisation in der Cytoplasmamembran nachgewiesen, wobei 8-10 transmembrane Helices angenommen werden. Bezüglich seiner Funktion wird eine Beteiligung bei der Translokation der aufgenommenen DNA (nach Bildung von Einzelstrang-DNA) durch die innere Membran postuliert (FACIUS et al. 1996, HAHN et al. 1993, INAMINE \& DUBNAU 1995). 


\subsection{1 Überexpression und Reinigung des Kompetenzproteins ComC}

Für die Überexpression eines Proteinfragmentes von ComC aus BD413 wurde das 1280 bp-HindIII/BamHI-Fragment (426 Aminosäuren, ca. $50 \mathrm{kDa}$ ), welches von der 583. bis zur 1863. Base reichte, aus dem 3624 bp-comC-Gen (kloniert in pRK9) direkt in den ebenso geschnittenen Überexpressionsvektor pJC40 ligiert, woraus das Plasmid pCC01 resultierte. Die Klonierung eines größeren Genbereichs oder des vollständigen $\operatorname{com} C$-Gens führte zu toxischen Effekten, was einer Überexpression entgegenstand. Die Expression des comC-Fragments im rekombinanten pCC01-Vektors führte zu einem Hybridprotein, welches aus zehn N-terminalen Histidinresten und dem ComC-Fragment bestand. Die Polyhistidinreste dienten der späteren Isolierung des gewünschten Proteins, da Histidine eine hohe Affinität zu Nickelionen besitzen und somit über die $\mathrm{Ni}^{2+}$-NTA Matrix aufgereinigt werden können. Nach der Transformation von pCC01 in E. coli BL21 erfolgte die Anzucht einer $250 \mathrm{ml}$ Kultur in LB-Medium bei $37^{\circ} \mathrm{C}$. Bei einer $\mathrm{OD}_{600}$ von $0,7-0,8$ wurde der vor dem klonierten Genfragment lokalisierte T7-Promotor durch Zugabe von IPTG induziert und die Zellen zwei weitere Stunden inkubiert. Die Synthese des induzierten Proteins führte zu keiner Beeinträchtigung des Zellwachstums. Nachdem die Zellen geerntet, gewaschen und durch Ultraschall aufgeschlossen worden waren, wurde die Überexpression durch SDS-PAGE überprüft.

Die IPTG-Induktion lieferte im SDS-Gel eine Bande starker Intensität bei $50 \mathrm{kDa}$, die vor der Induktion nicht vorhanden gewesen war und die der erwarteten molekularen Masse des Hybridproteins entsprach. Die daraufhin vorgenommene Zellfraktionierung zeigte, daß sich das gewünschte Protein ausschließlich in der partikularen, Membran- und Zelltrümmer-haltigen Fraktion befand, so daß das überexprimierte ComC-Hybridprotein in Form von Einschlußkörpern vorlag. Gelöstes Hybridprotein, welches dann in der cytoplasmatischen Fraktion lokalisiert sein mußte, lag nicht vor. Durch kurze niedertourige Zentrifugation (3000 Upm, $2 \mathrm{~min}, 4^{\circ} \mathrm{C}$, Eppendorf Zentrifuge 5417R) konnten die Einschlußkörper von gelösen Fremdproteinen und dem größten Teil der Membranen abgetrennt werden (Abb. 3.5). Für die Aufreinigung über die $\mathrm{Ni}^{2+}$-NTA Matrix wurde das Sediment zunächst mit $6 \mathrm{M}$ Harnstoff behandelt, so daß die Fusionsproteine denaturiert in Lösung gingen, und danach gegen PBS dialysiert. Entsprechend der Bindekapazität des Säulenmaterials wurde die Säule mit dem dialysierten, renaturierten Protein beladen und anschließend gewaschen. Die Elution des Fusionsproteins erfolgte mit Imidazol-haltigem Puffer. Dieses Eluat wurde daraufhin zur Entfernung des Imidazols gegen PhosphatSaline-Puffer (PBS) dialysiert. Auf diese Art konnten aus $250 \mathrm{ml} \mathrm{Kultur} \mathrm{ca.} 4$ ml Eluat mit einer Proteinkonzentration von $400 \square \mathrm{g} / \mathrm{ml}$ gewonnen werden. 


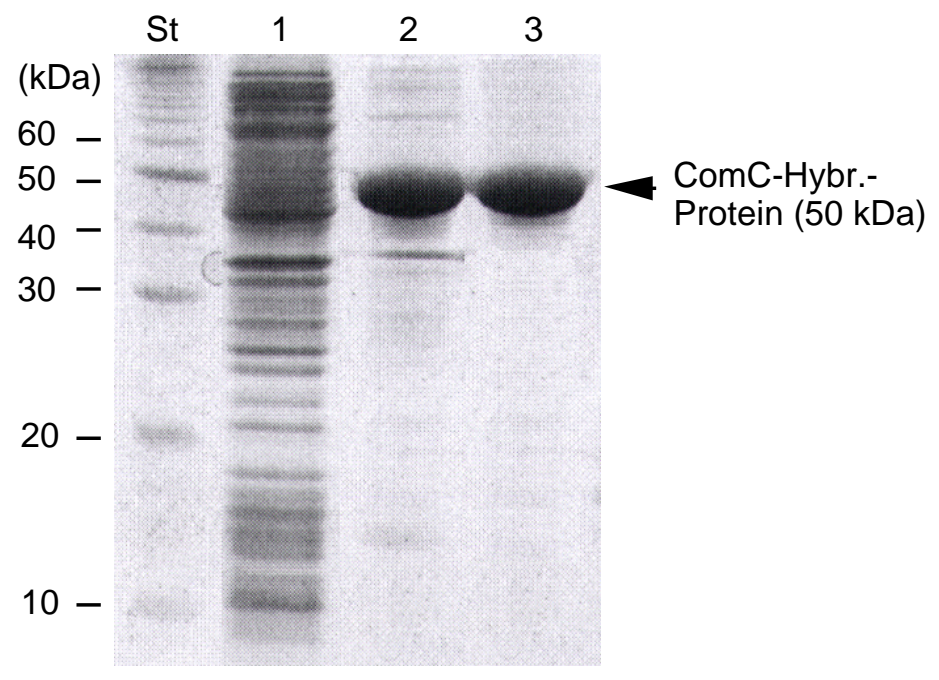

Abb. 3.5: Aufreinigung des überexprimierten ComCHybridproteins mittels Ni-NTA-Affinitätschromatographie. Im SDS-Gel wurden die lösliche cytoplasmatische (S pur 1), die partikuläre Fraktion (Spur 2) und das gereinigte Fusionsprotein (S pur 3 ) aufgetragen.

Obwohl nach der Reinigung über die $\mathrm{Ni}^{2+}$-NTA Matrix neben dem gewünschten Fusionsprotein weitere Banden mit geringerer molekularen Masse im SDS-Gel zu erkennen waren, erwies sich das Eluat als sauber (Abb. 3.5). Mit Hilfe von Antikörpern gegen die Histidinreste konnte in Immunoblots gezeigt werden, daß es sich bei diesen Banden ausschließlich um Abbruchfragmente des ComC-Hybridproteins handelte, die ebenso an das Säulenmaterial gebunden hatten und mit Imidazol eluierten (Abb. 3.5).

\subsubsection{Untersuchungen zur spezifischen Bindung der Anti-ComC- Antikörper}

Um für Lokalisationen von ComC ein Nachweissystem zu etablieren, welches die spezifische Detektion und Markierung von ComC ermöglicht, wurde ein Kanninchen mit dem überexprimierten und aufgereinigten ComC-Hybridprotein immunisiert. Hierdurch konnte nach zwei Monaten Antiserum gewonnen werden, welches für mehrere Tests, wie z.B. ELISAs ('enzyme linked immunoabsorbent assay'), 'Dotblots` und 'Immunoblots` mit dem aufgereinigten ComC-Hybridprotein sowie Acinetobacter sp. BD413-Zellextrakt und äußere und innere Membranfraktionen eingesetzt wurden. Es zeigte sich dabei, daß das Antiserum einen hohen Titer an spezifischen Antikörpern gegen das aufgereinigte ComCHybridprotein enthielt. 0,1 $\square \mathrm{g}$ des Hybridproteins konnte mit Antiserum nachgewiesen werden, welches in einem Volumen von $10 \mathrm{ml}$ 1:100 000 verdünnt wurde. Mit 1:25 000 verdünntem Antiserum konnte eine minimale Hybridproteinmenge von 5 ng detektiert werden. 
Obwohl spezifische Antikörper vorlagen, konnte ComC jedoch in Acinetobacter nicht nachgewiesen werden. Wurden hohe Protein- und/oder Anitserum-Konzentrationen für den Immunoblot eingesetzt, so stieg die Zahl der Proteine, die Kreuzreaktionen mit Antikörpen eingingen, eine spezifische Detektion von ComC konnte auch dann nicht dargestellt werden. Immunoblots von Acinetobacter sp. ADP239, der den Wildtyp repräsentiert, und der ComC-Mutante T308 wiesen identische Bandenmuster auf, welche auf unspezifische Kreuzreaktionen des Antiserums zurückzuführen waren.

Obwohl spezifische Antikörper gegen das ComC-Hybridprotein vorlagen, die Markierung von ComC in Zellextrakten jedoch zu keinem Detektionssignal führte, kann an zwei Gründe gelegen haben. Zum einen wies möglicherweise die Faltung des ComCFragmentes, welches für die Immunisierung eingesetzt worden war, Unterschiede zu der Tertiärstruktur des von der Zelle synthetisierten ComC auf. Dies führt zur Exposition von unterschiedlichen Epitopen und schließlich zu der Generierung von Antikörpern, die zwar das für die Immunisierung eingesetzte Hypidprotein detektieren, die Epitope des ComCProteins aber nicht erkennen. Zum anderen könnte die fehlende Detektion von ComC in den Zelllysaten auf die geringe Konzentration dieses Proteins zurückzuführen sein, welche dann unterhalb der Empfindlichkeit des auf Chemilumineszenz basierenden Detektionsystems liegt.

Um unspezifische Kreuzreaktionen bei der Detektion hoher Zelllysat-Proteinkonzentrationen zu minimieren, könnte sich eine Reinigung des Antiserums bezüglich Anti-ComC-Antikörpern anschließen. Hierzu müßte das Antiserum zuerst im Immunoblot gegen Proteine der ComC-Mutante und darauffolgend dasselbe Serum gegen Proteine des Wildtyps eingesetzt werden. Durch den vorgeschalteten ersten Schritt werden diejenigen Antikörper gebunden, die unspezifische Proteine markieren und des ComC-Signal möglicherweise überlagern.

\subsection{3 Überexpression und Reinigung des Kompetenzproteins ComA}

Um die Funktion des Proteins ComA bei der natürlichen Transformation von Acinetobacter sp. BD413 aufzuklären, seine Lokalisation in der Zelle zu bestimmen und mögliche Proteinassoziationen zu identifizieren, mußte das Protein für die Herstellung von Antikörpern zunächst überexprimiert werden. Da die vermehrte Expression des gesamten Gens aufgrund toxischer Effekte nicht möglich gewesen war, wurde in dieser Arbeit der hydrophile C-Terminus von ComA als Fusionsprotein gereinigt. Als Überexpressionsvektor diente hierfür pMal-c2, wobei das malE-Gen, welches für das Maltosebindeprotein MBP codiert, stomaufwärts des comA-Genfragments kloniert vorlag. 
Zunächst wurde mittels des Primerpaares ComA-EcoRI-N2 (5`-GTGGTTCCAGAATTC TGGTCAG-3`) und ComA-XbaI-C2 (5`CTGCAACCATCTAGACGACTGACG-3`) ein $830 \mathrm{bp}$-Genfragment des 3 -Ende von $\operatorname{comA}$ amplifiziert $(\approx 30 \mathrm{kDa})$, in die EcoRI- und XbaI-Schnittstelle von pMal-c2 ligiert, so daß das Plasmid pMA03 entstand. Nach Überprüfung des Inserts durch Sequenzierung wurden Mutationen und Verschiebungen des Leserasters ausgeschlossen. Für die Überexpression erfolgte nach der Transformation von pMA03 in E. coli DH5 $\square$ die Kultivierung in $250 \mathrm{ml} \mathrm{LB}-$ Medium bei $37^{\circ} \mathrm{C}$. Bei einer $\mathrm{OD}_{600}$ von 0,7-0,8 wurde der vor dem malE-Gen lokalisierte $P_{\text {tac }}$-Promotor durch Zugabe von IPTG induziert und die Zellen für zwei weitere Stunden inkubiert. Die durch IPTGInduktion bewirkte Expression des ComA/MalE-Fusionsproteins hatte keine negative Auswirkung auf das weitere Wachstum der Kultur.

Nachdem die Zellen geerntet, gewaschen und durch Ultraschall aufgeschlossen worden waren, wurde die Expression durch SDS-PAGE überprüft. Es zeigte sich im Gel nach der IPTG-Induktion eine intensiv gefärbte Proteinbande von $72 \mathrm{kDa}$, die vor der Induktion nur sehr schwach zu erkennen gewesen war (Abb. 3.6). Dieses Protein setzte sich aus dem 42 kDa-Maltosebindeprotein und dem 30 kDa-ComA-Fragment zusammen. Die Fraktionierung des Zelllysats in partikuläre Bestandteile (Zelltrümmer/Membranen) und lösliche cytoplasmatische Bestandteile ließ weiterhin erkennen, daß sich das $72 \mathrm{kDa}-$ ComA-Fusionsprotein im Sediment befand; die lösliche Fraktion dagegen enthielt dieses Protein nicht. Demzufolge bildete sich während der Überexpression Einschlußkörper, die im Folgenden gelöst werden mußten. Hierfür wurde das Sediment mit $6 \mathrm{M}$ Harnstoff behandelt, so daß die Fusionsproteine denaturiert in Lösung gingen. Durch Dialyse erfolgte daraufhin die Entfernung des Harnstoffs und somit eine Rückfaltung der Proteine, was für die Aufreinigung des gewünschten Proteins über die Bindung an die Amylose-Matrix notwendig war.

Die Aufreinigung des ComA/MalE-Fusionsproteins basierte auf der hohen Bindungsaffinität des MBP (Maltosebindeproteins) zum Amylose-Säulenmaterial. Entsprechend der Bindekapazität des Säulenmaterials wurde die Säule mit dem dialysierten, renaturierten Protein beladen und anschließend gewaschen. Die Elution des Fusionsproteins erfolgte mit Maltose-haltigem Phosphat-Saline-Puffer (PBS). Auf diese Art konnten aus $250 \mathrm{ml}$ Kultur ca. $3 \mathrm{ml}$ Eluat mit einer Proteinkonzentration von $400 \square \mathrm{g} / \mathrm{ml}$ gewonnen werden. Obwohl nach der Reinigung über die Amylose-Matrix neben dem gewünschten Fusionsprotein weitere Banden mit geringerer molekularen Masse im SDS-Gel zu erkennen waren, erwies sich das Eluat als sauber (Abb. 3.6). Mit Hilfe von Anti-MBP-Antikörpern konnte in Immunoblots gezeigt werden, daß es sich bei diesen Banden ausschließlich um Abbruchfragmente des MBP handelte, die wie das Fusionsprotein an das Säulenmaterial gebunden waren und mit Maltose eluierten (Abb. 3.6). 


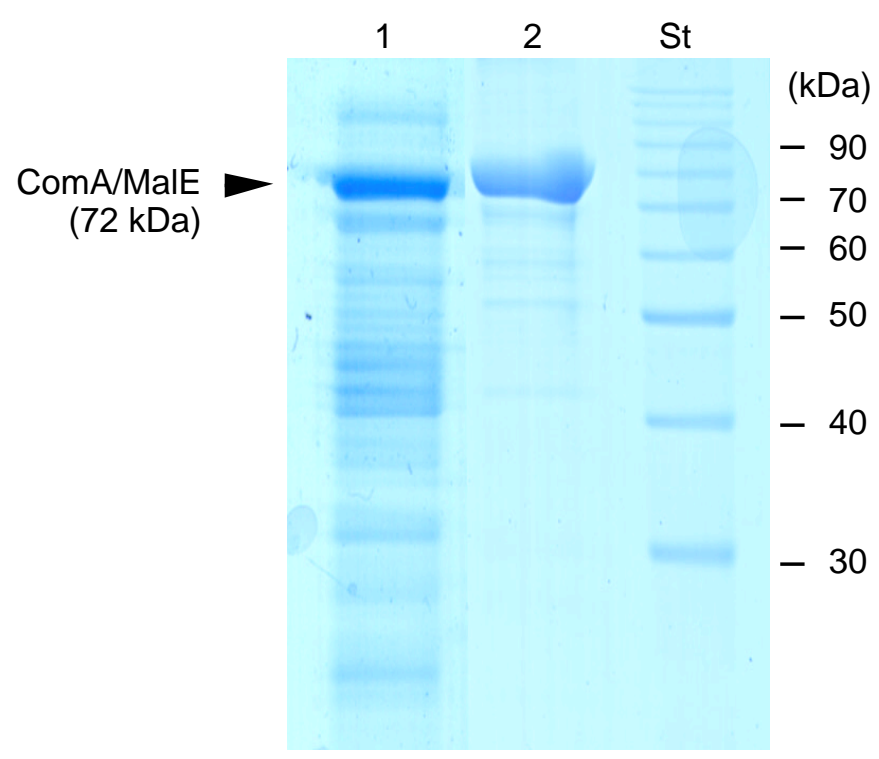

Abb. 3.6: Aufreinigung des überexprimierte। ComA/MalE-Fusionsproteins mittels AmyloseAffinitätschromatographie. Im SDS-Gel wurden dit partikuläre Fraktion (Spur 1) und das gereinigte Fusionsprotein (Spur 2) aufgetragen.

\subsubsection{Untersuchungen zur spezifischen Bindung der Anti-ComA- Antikörper}

Für Lokalisationsstudien von ComA in den Zellkompartimenten von Acinetobacter sp. BD413 sollte die Nachweismethode über Markierung des gewünschten Proteins mit spezifischen Antikörpern genutzt werden. Die Generierung von Anti-ComA-Antikörpern erfolgte über die Immunisierung eines Kanninchens mit dem überexprimierten und aufgereinigten ComA/MalE-Fusionsprotein. Hierdurch konnte nach zwei Monaten Antiserum gewonnen werden, welches für mehrere Tests, wie z.B. ELISAs ('enzyme linked immunoabsorbent assay'), 'Dotblots` und 'Immunoblots` mit dem aufgereinigten ComA/MalE-Fusionsprotein sowie Acinetobacter sp. BD413-Zellextrakt und äußere und innere Membranfraktionen eingesetzt wurde. Es zeigte sich dabei, daß das Antiserum einen hohen Titer an spezifischen Antikörpern gegen das aufgereinigte ComA/MalEFusionsprotein sowie ebenso gegen das abgespaltene ComA-Proteinfragment enthielt. 0,1 $\square \mathrm{g}$ des Hybridproteins (nach Spaltung mit dem Faktor Xa) konnte mit Antiserum nachgewiesen werden, welches in einem Volumen von $10 \mathrm{ml}$ 1:75 000 verdünnt wurde. Mit 1:25 000 verdünntem Antiserum konnte eine minimale Hybridproteinmenge (nach Spaltung mit dem Faktor Xa) von 7,5 ng detektiert werden.

Obwohl spezifische Antikörper vorlagen, konnten ComA jedoch in Acinetobacter nicht nachgewiesen werden. Die elektrophoretische Auftrennung hoher Proteinmengen von 
Zelllysaten oder Membranfraktionen und die Detektion mit ansteigender Konzentration von Anti-ComA-Antiserum führten im Immunoblot lediglich zu Kreuzreaktionen, eine spezifische Detektion von ComA konnte nicht dargestellt werden. Immunoblots von Acinetobacter sp. ADP239, der den Wildtyp repräsentierte, und der comA-Mutante T701 wiesen identische Bandenmuster unspezifisch detekierter Proteine auf. Da die Detektion auf der Höhe des zu erwartenden ComA-Signals bei 90-95 kDa keine Signale erkennen ließ, konnte eine Überlagerung eines ComA-Signals durch unspezifische Kreuzraktionen ausgeschlossen werden.

Das Vorliegen spezifischer Antikörper gegen das ComA-Proteinfragment und das negative Ergebnis der immunologischen Markierung von ComA in Zellextrakten spiegelt die Problematik der Detektion von ComC wider (3.2.2). Wie für ComC und das dafür generierte Antiserum bereits diskutiert, liegen die Gründe der fehlenden Detektion von ComA in der Zelle möglicherweise in der zum nativen ComA unterschiedlichen Faltung des ComA-Fragmentes als Bestandteils des MalE-Fusionsproteins oder an einem zu geringen ComA-Gehalt in der Zelle.

\subsection{Identifizierung weiterer Kompetenzgene in Acinetobacter sp. BD413}

Die Untersuchungen von Transformationssystemen unterschiedlicher Bakterien haben ergeben, daß sie ähnliche Komponenten einschließen, ungeachtet der phylogenetischen Distanz dieser Bakterien. Für bereits vollständig sequenzierte Genome von Organismen besteht somit die Möglichkeit durch Sequenzabgleiche nach potentiellen konservierten Kompetenzproteinen zu suchen. Da die komplette genomische Sequenz von Acinetobacter sp. BD413 seit kurzem vorliegt und uns zugänglich ist, eröffnet sich somit die Möglichkeit weitere potentielle Kompetenzgene im Acinetobacter-Genom zu identifizieren.

\subsubsection{Identifizierung des comEA-Gens in Acinetobacter sp. BD413}

Ein DNA-bindendes Kompetenzprotein wurde in Bacillus subtilis (ComEA), Streptococcus pneumoniae (ComEA) sowie in Neisseria gonorrhoeae und Neisseria meningitidis (ComE) identifiziert und charakterisiert (CHEN \& GoTSCHLICH 2001, Provvedi \& Dubnau 1999). Während ComEA der Gram-positiven Organismen neben der basischen N-terminalen Domäne, die DNA-Bindung vermittelt, einen C-terminalen hydrophoben Bereich aufweist, der die Verankerung des Proteins in der Zellmembran vermittelt, besteht ComE aus Neisseria gonorrhoeae und Neisseria meningitidis allein aus 
der basischen Domäne. Da die Transformationssysteme untereinander homolog sind, war es sehr wahrscheinlich, daß Acinetobacter sp. BD413 ein zu ComE bzw. ComEA äquivalentes Protein besitzt.

Über den Aminosäuresequenz-Abgleich der DNA-bindenden Kompetenzproteine ComEA (C-Terminus) bzw. ComE mit den abgeleiteten Proteinen des Chromosoms von Acinetobacter sp. BD413 konnte ein ORF identifiziert werden, dessen abgeleitete Aminosäure-Sequenz zu $55 \%$ bzw. $52 \%$ identisch und zu $71 \%$ bzw. $70 \%$ ähnlich zu ComEA (C-Terminus) bzw. ComE war. Dieser ORF aus Acinetobacter sp. BD413 wurde comEA genannt. Wie ComE aus Neisseria gonorrhoeae weist ComEA aus BD413 einen basischen DNA-bindenden Bereich auf, der aus zwei konservierten 'Helix-turn-Helix`Motiven besteht (Abb. 3.7). Diese beiden Sequenzabschnitte umfassen jeweils 20 Aminosäuren, die in charakteristischer Weise die basische Aminosäure Lysin tragen und somit zu dem anhand der Aminosäure-Zusammensetzung ermittelten basischen pI-Wert von 10,5 beitragen. Bei ComE aus Neisseria gonorrhoeae und Neisseria meningitidis weist das prozessierte Protein nach der Abspaltund eines 19 Aminosäure-Signalpeptids eine molekulare Masse von 8 kDa auf (CHEN \& GoTSCHLICH 2001). Eine derartige potentielle Prozessierungssequenz von ${ }_{+1}$ VNINxA ist ebenso bei ComEA von Acinetobacter sp. BD413 zu finden (Abb. 3.7), so daß für das prozessierte Protein eine errechnete molekulare Masse von 7,6 kDa postuliert werden konnte.

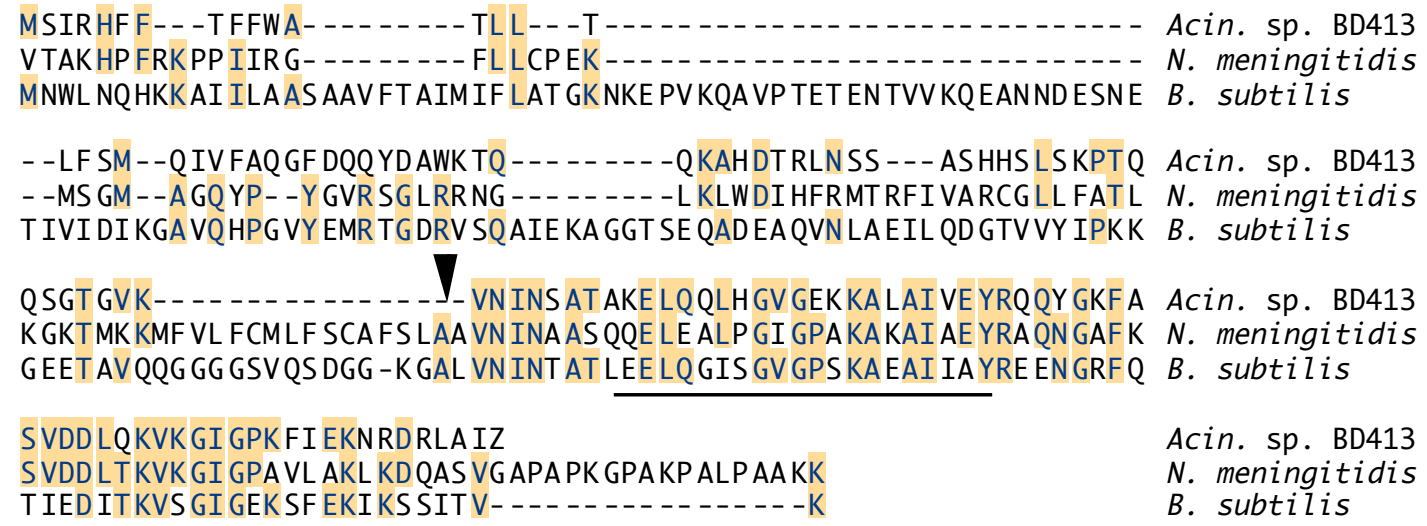

Abb. 3.7: Sequenzabgleich des Proteins ComEA von Acinetobacter sp. BD413 (nach 'Clustal'). ComEA aus BD413 zeigt Ähnlichkeiten zu DNA-bindenden Kompetenzproteinen aus Neisseria menigitidis (ComE) und Bacillus subtilis (ComEA). Die Pfeilspitze markiert die Prozessierungsstelle. Die unterstrichenen Bereiche markieren 'Helix-turn-Helix'-Motive für die DNA-Bindung. 
Das Genom von Neisseria gonorrhoeae weist vier Kopien des DNA-bindenden Proteins ComE auf, dessen Gene in der Zelle exprimiert werden (CHEN \& GOTSCHLICH 2001). Um einen vollständigen Transformationsdefekt zu erzeugen, mußten demzufolge die vier comE-Gene gemeinsam unterbrochen werden. Nach den Homologiestudien liegt in Acinetobacter sp. BD413 dagegen nur ein potentiellen comEA-ähnliches Gen vor. Betrachtet man die chromosomale Lage dieses Gens, so finden sich keine Parallelen zu genomischen Lokalisationen von Genen, die für DNA-bindende Kompetenzproteine codieren. ComEA aus BD413 wird stromaufwärs von einem MazG-ähnlichen Protein und einer potentiellen Reduktase/Dehydrogenase flankiert. Stromabwärts liegen Gene, dessen Produkte für eine mögliche Poly(A)-Polymerase und eine Pyrophosphokinase codieren. Im Vergleich dazu liegen die vier comEs aus Neisseria gonorrhoeae stromabwärts von rRNAOperonen (CHEN \& GOTSCHLICH 2001).

Zusammenfassend läßt sich sagen, daß Acinetobacter sp. BD413 einen ORF besitzt, dessen Genprodukt Ähnlichkeiten zu identifizierten und charakterisierten DNA-bindenden Kompetenproteinen aufweist. Diese Gen liegt auf dem Chromosom von BD413 als einzige Kopie vor.

\subsubsection{Unterbrechung des Kompetenzgens comEA aus Acinetobacter sp. BD413}

Die Unterbrechung des über Datenbank-Abgleiche identifizierte comEA im Genom von ADP239 sollte klären, ob es sich bei diesem Gen tatsächlich um ein Kompetenzgen handelte. Da für das Einfügen des nptII-Markers in das gewünschte Gen nur die SspISchnittstelle in Frage kam, mußte vor der Klonierung dieses Genbereichs die SspISchnittstelle im Vektor pUC18 entfernt werden. Da die SspI-Schnittstelle glatte DNAEnden liefert, wurde für die Eliminierung dieser Schnittstelle ein DNA-Fragment hineinkloniert. Dazu wurde die $\Omega$ Streptomycin-Kassette mit EcoRV/HincII aus pBS01 in die SspI-Schnittstelle von pUC18 ligiert, so daß der Vektor pUS01 entstand, der daraufhin sowohl eine Ampicillin- als auch eine Streptomycin-Resistenz besaß (Abb. 3.8).

Nach der Amplifizierung des comEA an der chromosomalen BD413-DNA mittels der Primer-ComEA-PstI NA1.2 (5`-CTAAGTGAGTTTGAAGCTGCAGTGCATAAG-3`) und ComEA-XbaI-CB4 (5 -GTCGATAACCCACATCTAGACGCGCGCAAG-3`) wurde das 750 bp PCR-Produkt mit PstI und XbaI in pUS01 kloniert, woraus das Plasmid pUD08 entstand (Abb. 3.8). In die SspI-Schnittstelle des Inserts konnte daraufhin der nptII-Marker gesetzt werden. Dazu wurde der Marker mit PstI aus dem Plasmid pUC4K geschnitten, mit Klenow-Enzym behandelt und mit glatten Enden in die SspI-Schnittstelle ligiert. Aus dem 
entstandende Plasmid pUD09 konnte das mit dem Kanamycin-Gen unterbrochene Insert mit Pst $\mathrm{I} / X b a \mathrm{I}$ herausgeschnitten und in Acinetobacter sp. ADP239 transformiert werden. Über die den Marker flankierenden Bereiche von 470 bzw. 280 bp fand eine Rekombination in das gewünschte Gen statt, woraus der Stamm T100 resultierte.

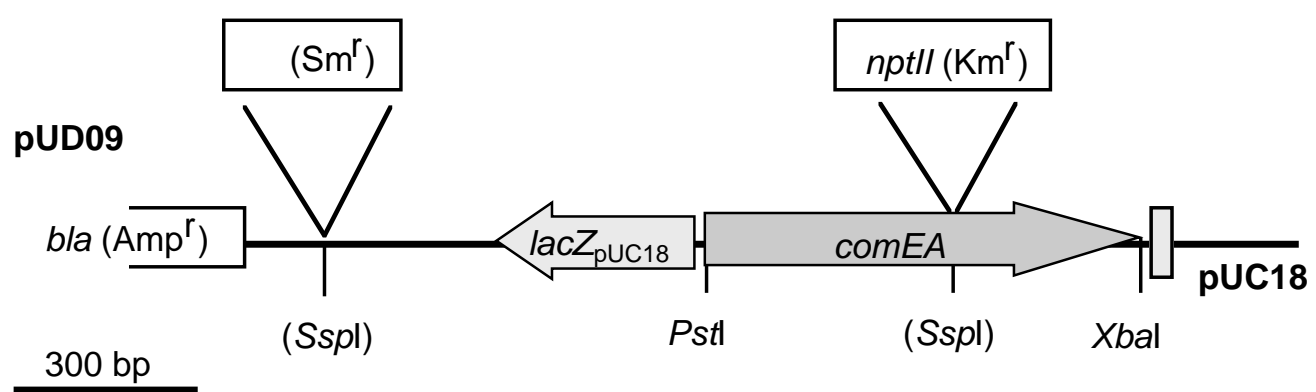

Abb. 3.8: Plasmidkonstruktion für die Unterbrechung von comEA. In die SsplSchnittstelle von pUC18 wurde zunächst zur Eliminierung dieser Schnittstelle die $\Omega$ Streptomycin-Kassette aus pBS01 mit EcoRI und Hincll kloniert, woraus pUS01 resultierte. Nach der Amplifikation des comEA-Gens wurde das PCR-Produkt mit $P s t l$ und Xbal in die MCS des Vektors kloniert (pUD08) und zur Unterbrechung des Gens der nptII-Marker in die Sspl-Schnittstelle ligiert (pUD09). Die Resistenzgene sind nicht maßstabsgetreu wiedergegeben. Das lacZ-Gen von pUC18 gibt die Leserichtung des vektoreigenen Promotors an. Die in Klammern dargestellten Schnittstellen können nicht mehr restriktionsverdaut werden.

Die Überprüfung der einmaligen und homologen Integration des Resistenzmarkers fand über einen SOUTHERN Blot statt. Hierfür wurde die isolierte chromosomale DNA des Stammes T100 mit EcoRV bzw. mit HincII vedaut, elektrophoretisch aufgetrennt, geblottet und mit einer Kanamycin-Sonde hybridisiert. Die beiden relevanten EcoRV-Schnittstellen schlossen vor der Mutagenisierung im ADP239-Chromosom einen DNA-Bereich von 2,0 kb ein. Mit dem eingefügten Kanamycin-Marker von ca. 1,2 kb ergaben sich daraufhin 3,2 kb (Abb. 3.9, Spur 1). Für die HincII-geschnittene chromosomale DNA vergrößerte sich die Basenpaaranzahl entsprechend von ursprünglich 2,4 kb auf 3,6 kb (Abb. 3.9, Spur 2). Diese detektierten DNA-Fragmentlängen bestätigte die richtige Integration des nptII-Markers ins Zielgen. 


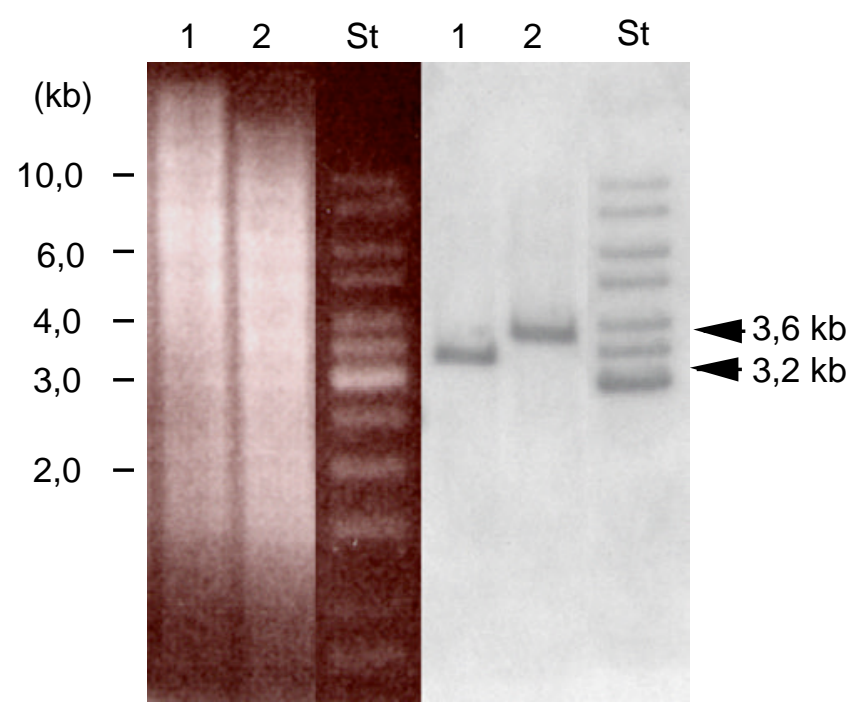

Abb. 3.9: SOUTHERN Hybridisierung restriktionsverdauter DNA der comEA-Mutante T100 gegen eine KanamycinSonde. Die isolierte chromosomale DNA von Acinetobacter sp. T100 wurde mit EcoRV (Spur 1) und Hincll (Spur 2) geschnitten, im Agarosegel aufgetrennt und nach dem Blot mit einer Kanamycin-Sonde hybridisiert. Die Sond $\epsilon$ hybridisierte unspezifisch mit der DNA des Größenstandards (St) im Bereich von 3-10 kb. Auf der linken Seite ist das Ethidiumbromid-gefärbte $\mathrm{Gel}$ und auf der rechten deI SOUTHERN Blot dargestellt.

\subsubsection{Transformationstest der comEA-Mutante T100}

Die Überprüfung der erhaltenen Mutante T100 auf ihre Fähigkeit zur natürlichen Transformation erfolgte im Transformationsschnelltest (2.7.2.3). Für diesen Test wurde die mit Zellsuspension benetzte Impföse durch einen Tropfen chromosomaler BD413-DNA gezogen, der sich auf einer Mineralmedium/ $p$-Hydroxybenzoat-Agarplatte befand. Abbildung 3.11 zeigt in Spur 1, daß sich nach dem Passieren des DNA-Tropfens beim Kontrollstamm ADP239 Wachstum einstellte. Die generierte Mutante T100 mit einer Unterbrechung in comEA (ein Abkömmling des Stammes ADP239) wuchs auch nach Kontakt mit BD413-DNA nicht auf $p$-Hydroxybenzoat, was den $p o b A$-Defekt demonstrierte und auf einen Transformationsdefekt schließen ließ (Abb. 3.11, Spur 2). Demzufolge mußte in der generierten Mutante T100 ein Kompetenzgen unterbrochen worden sein.

Um zu zeigen, daß der Verlust der natürlichen Kompetenz auf den Defekt in der ComEA-Synthese zurückzuführen war und nicht auf einen durch das Kanamycin-Gen verursachten polaren Effekt auf stromabwärts liegende Gene, sollte der Stamm T100 mit dem intakten comEA-Gen in trans komplementiert werden. Als Vektor diente pRK415, in 
welchen das PstI/XbaI-Insert (comEA) aus pUD08 (Abb. 3.8) kloniert wurde, wobei durch die Auswahl der Schnittstellen für die Klonierung die Leserichtung von comEA entgegen dem Vektor-eigenen lacZ-Promotor liegen mußte. Aus diesem Grund konnten die Restriktionsschnittstellen $P s t \mathrm{I}$ und $\mathrm{XbaI}$ in pRK415 nicht für eine direkte Integration des comEA als $P$ stI/XbaI-Insert genutzt werden. Das comEA-Insert in dem resultierenden Plasmid pKD11 besaß am 5 -Ende die intakte PstI-Schnittstelle; am 3`-Ende wurde hingegen die XbaI-Schnittstelle mit Klenow-Enzym aufgefüllt und mit glatten DNA-Enden in den Vektors pRK415 ligiert (Abb. 3.10). Dafür wurde zuvor der Vektor mit HindIII geschnitten, mit Klenow-Enzym behandelt, sowie schließlich mit PstI verdaut. Nachdem pKD11 konjugativ in Acinetobacter sp. T100 übertragen worden war, konnte mit diesem Stamm der Transformationsschnelltest durchgeführt werden.

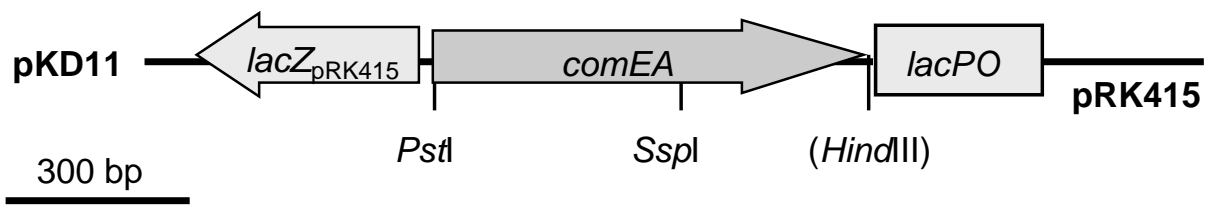

\begin{abstract}
Abb. 3.10: Plasmidkonstruktion von pKD11. pRK415 wurde mit HindIII geschnitten, mit Klenow-Enzym behandelt und daraufhin mit Pstl verdaut. Für die Klonierung von comEA in den geschnittenen pRK415 wurde pUD08 zunächst mit Xbal geschnitten, mit Klenow-Enzym behandelt und schließlich mit Pstl verdaut. Nach der Ligation in pRK415 lag das comEA-Gen entgegen der Leserichtung des vektoreigenen lacZ-Promotors. Die gezeigte HindllISchnittstelle kann aufgrund der vorangegangenen Behandlung mit KlenowEnzym nicht mehr geschnitten werden.
\end{abstract}

Die transformationsdefekte Mutante T100, die nach dem Kontakt mit BD413-DNA kein Wachstum auf $p$-Hydroxybenzoate zeigte, regenerierte die natürliche Kompetenz durch den Besitz des comEA-tragenden Plasmids pKD11 (Abb. 3.11), was bestätigte, daß allein die Mutation in comEA zu dem Transformationsdefekt führte.

Nach diesen Untersuchungen ließ sich zeigen, daß die gezielte Unterbrechung von comEA einen vollständigen Transformationsdefekt zur Folge hatte und daß es sich bei diesem Gen um ein Kompetenzgen handelt. Die erfolgreiche Komplementation des Defektes zeigte weiterhin, daß vor comEA eine Promotorstruktur liegt und der Transformationsdefekt nicht auf einen polaren Effekt auf stromabwärts liegende Gene beruhte. 


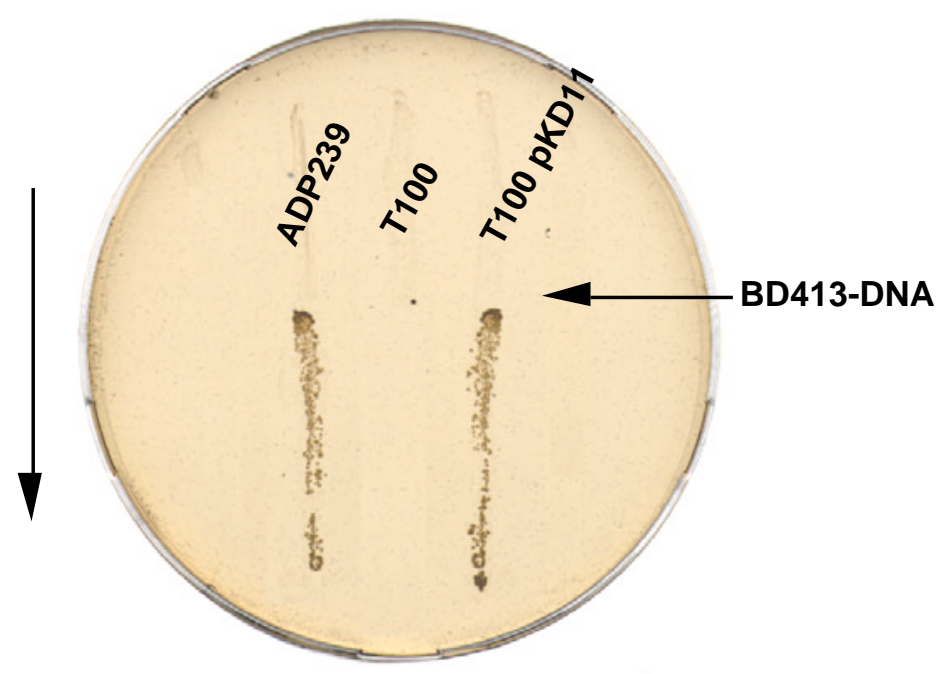

Abb. 3.11: Transformationstest der comEA-Mutante Acinetobacter sp. T100. Da ADP 239 und die generierte Mutante T100 einen Defekt im pobA- (HydroxybenzoatHydroxylase-) Gen besitzen, wachsen die Stämme nicht auf $p$-Hydroxybenzoat. Nach dem Passieren der Impföse durch einen Tropfen chromosomale DNA von Acinetobacter sp. BD413 findet bei der Fähigkeit zur natürlicher Transformation Wachstum statt. Der senkrechte Pfeil gibt die Richtung der ausplattierten Zellen an.

\subsubsection{Transkriptionale R egulation von comEA}

Die bisher untersuchten Kompetenzproteine ComA, ComB, ComC, ComE, ComF und ComP werden auf transkriptionaler Ebene auf ähnliche Weise reguliert, wobei die Expression mit dem Überimpfen in frisches Succinat-Mineralmedium auf ein niedriges Niveau abfält, um mit dem Eintritt in die stationäre Wachstumsphase wieder anzusteigen (Herzberg et al. 1999, Porstendörfer et al. 2000, Friedrich et al. 2001). Demgegenüber wird die maximale Transformationsfrequenz erst kurz nach dem Überimpfen in frisches Medium erreicht Im Folgenden sollte überprüft werden, inwieweit die Expression des Kompetenzgens comEA entsprechend der bereits charakterisierten Kompetenzgene aus Acinetobacter sp. BD413 oder entsprechend des Verlaufs der Transformationsfrequenz reguliert wird. Weiterhin sollte die Expressionsrate Hinweise auf den Gehalt von ComEA in der Zelleliefern.

Mit Hilfe des lacZ-Reportergens, dessen Genprodukt - eine -G-Galaktosidase - im optisch enzymatischen Test quantifiziert werden konnte, wurde Wachstumsphasenabhängig die vom comEA-Promotor ausgehende Transkription verfolgt. Das dafür eingesezte lacZ lag im Vektor pBK mit Ribosomen-Bindestelle aber ohne eigenen Promotor vor. In die stromaufwärts zum lacZ-Gen liegenden Restriktionsschnittstellen 
EcoRI und Xbal wurde unter Entfernung des gusA-Reportergens das aus dem Plasmid pUD08 stammende Pstl/Sstl-Fragment, welches das 5'-Ende von comEA enthielt, mit glatten DNA-Enden ligiert. Vor dem ersten potentiellen ATG-Startcodon, welches eine 66 A minosäuren lange Signal sequenz liefert, liegen 260 bp, die das 3`-Ende (253 bp) des stromaufwärts von comEA lokalisierte Gen beinhaltete. Neben dem ersten ATG von comEA sind weiterhin 60 bp stromabwärts ein ATG und 42 bp, 45 bp, 138 bp sowie 165 bp ein potentielles TTG-Startcodon Iokalisiert. Anhand der Basensequenz kann kein eindeutiger Transkriptionsstart vorhergesagt werden.

Diejenigen Pstl/Sst-comEA-Genfragmente, die die richtige Orientierung in dem resultierenden Plasmid pBD10 hatten, bewirkten eine Blaufärbung der auf X-Gal-LBMedium gewachsenen E. coli-Kolonien.

Für die Bestimmung der $\square$-Galaktosidaseaktivität wurde das Plasmid pBD10 in Acinetobacter sp. ADP239 konjugativ übertragen. Als Kontrolle diente der Vektor pBK. Eine damit durchgeführte Null wertbestimmung in Acinetobacter sp. ADP239 ergab keine meßsbare [-Gal aktosi daseaktivität. Deshal b konnte im fol gendem Versuch die gemessene Aktivität auf die stromabwärts des comEA-Promotors klonierte $\square-G a l a k t o s i d a s e$ zurückgeführt werden. Aufgrund der im Vergleich zu dem chromosomal lokalisierten comEA höheren Kopienzahl des eingesetzten Plasmids pBD10, ließ sich die gemessene Aktivität nicht unmittel bar in eine absolute Transkriptionsrate übertragen. Sie ermöglicht in erster Linie Aussagen darüber, inwiefern ein Gen unter bestimmten Bedingungen und in welcher Relation zu anderen Genen exprimiert wird.

Zur Messung der Wachstumsphasen-abhängigen Transkription wurden $50 \mathrm{ml}$ Succinat-Mineral medium mit einer ausgewachsenen Vorkultur inokkuliert und bei $30^{\circ} \mathrm{C}$ schüttelnd inkubiert. Zu verschiedenen Zeitpunkten wurden Proben entnommen und das Kulturwachstum über die optische Dichte verfolgt. Für die Bestimmung der Gal aktosidaseaktivität wurde so viel Probenvol umen entnommen und eventuell durch Zentrifugation konzentriert, daß schließlich in jeder Probe eine optische Dichte (600 nm) von 5 resultierte. Die Enzymaktivität wurde nach MILLER (1972) durch Umsetzung von oNitrophenolyl-[-D-Galaktopyranosid (ONPG) zu o-Nitrophenol pro Zeit und pro Zell dichte bestimmt. Die Zeit der Inkubation und die Zel ldichte wurde in dem Versuch für alle Proben konstant gehalten, so daß sich die Gelbfärbung durch die Entstehung von oNitrophenol zu den ermittelten MILLER-Units direkt proportional verhielt.

Für comEA zeigte sich vor dem Überimpfen der ausgewachsenen Vorkultur in frisches Medium und in der stationären Wachstumsphase maximale [Galaktosidaseaktivität von 140 MILLER-Units, die während der lag-Phase und des beginnenden exponentiellen Wachstums auf ein Grundniveau von 70 MILLER-Units 
abnahm (Abb. 3.12). Zum Ende des exponentiellen Wachstums bis hin zur späten stationären Phase stieg der Wert langsam wieder auf den maximalen Wert.

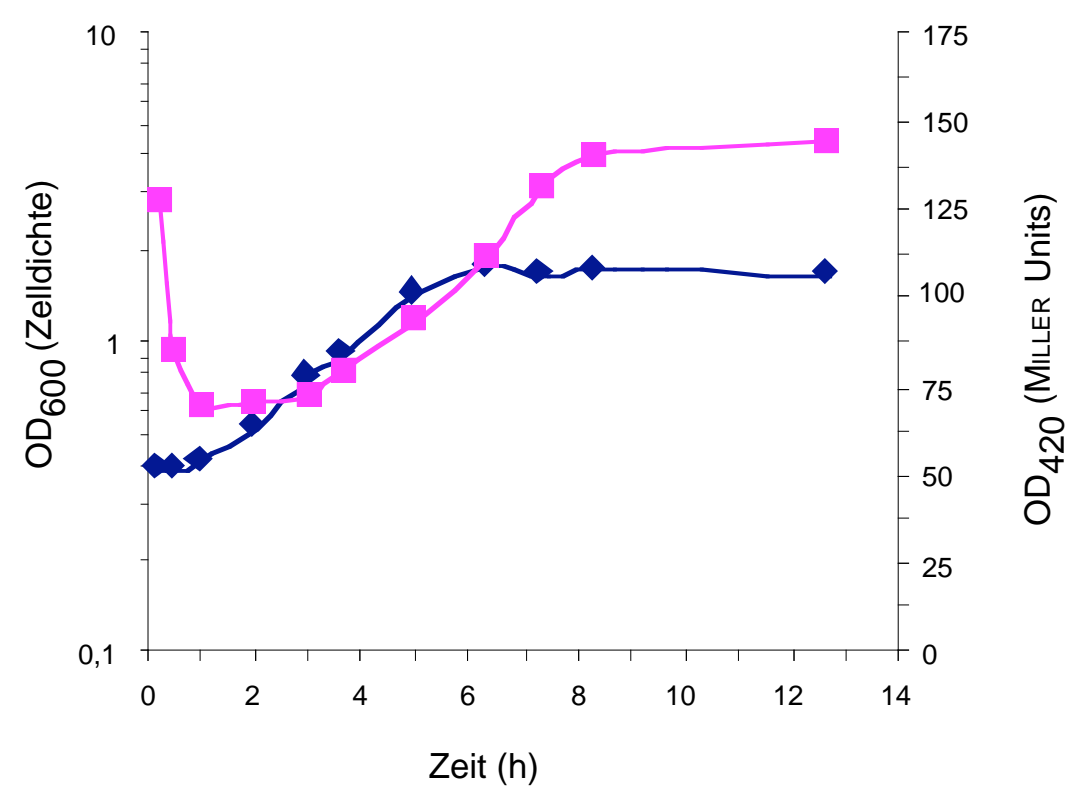

Abb. 3.12: Expression des Kompetenzgens comEA. Di Promotoraktivität von comEA wurde als lacZ-Transkriptionsfusion im Verlauf einer statischen Kultur in Succinat-Mineralmedium $\mathcal{A}$ bestimmt. Die Promotorregionen wurden jeweils vor das lacZ-Gen kloniert und die 0 -Galaktosidaseaktivität im enzymatischen Test gemessen ( $\square$ ).

Die -Galaktosidase-Aktivitätsmessung ergab, daß comEA Wachstumsphasenabhängig exprimiert wird, so daß von einer Regulation auf Transkriptionsebene ausgegangen werden kann. Verglichen zu den bereits untersuchten Kompetenzgenen comA, -B, -E, -F und comP aus Acinetobacter sp. D413 zeigte comEA einen identischen wachstumsphasenabhängigen Verlauf der Expression.

\subsection{Untersuchungen zur Lokalisation und Funktion des K ompetenzproteins C omEA}

In natürlich transformierbaren Bakterien erfolgt nach der Kompetenzinduktion die Synthese des DNA-A ufnahmeapparates, der die freie DNA durch die Zellhülle schleust. Der erste Schritt dieses Transportvorganges besteht zunächst in der Bindung der DNA an die Zelloberfläche DNA-bindende Kompetenzproteine wurden bereits in Bacillus subtilis (ComEA), Streptococcus pneumoniae (ComEA) sowie in Neisseria gonorrhoeae und Neisseria meningitidis (ComE) identifiziert und charakterisiert (CHEN \& GOTSCHLICH 
2001, Provvedi \& Dubnau 1999). Mit comEA konnte in Acinetobacter sp. BD413 ein ähnliches Kompetenzgen identifiziert werden, welches als einmalige Kopie im Chromosom vorliegt und eine essentielle Funktion bei der natürlichen Transformation ausübt.

Nach der genetischen Untersuchung des comEA-Gens sollte nun eine Charakterisierung des Genproduktes auf proteinchemischer Ebene folgen, was die Herstellung von spezifischen Antikörpern gegen ComEA und die Überprüfung der DNAbindenden Eigenschaft beinhaltete.

\subsection{1 Überexpression und A ufreinigung von C OME A}

Die Untersuchung der Funktion von ComEA bei der DNA-A ufnahme, die Bestimmung seiner Lokalisation und der Nachweis von Proteininteraktionen setzt die Generierung von Antikörpern voraus.

Aufgrund der Ähnlichkeit von ComEA aus Acinetobacter sp. BD413 zum Kompetenzprotein ComE aus Neisseria gonorrhoeae und Neisseria meningitidis konnte eine Signal sequenz für ComEA aus BD413 postuliert werden (3.3.1). Da Signal sequenzen i.d.R. beim Transport durch die Cytoplasmamenbran abgespalten werden und aus diesem Grund keine Domäne des funktionsfähigen Proteins in seinem Zielkompartiment darstellen, wurde ComEA ohne das Signalpeptid überexprimiert. Die anhand der Aminosäuresequenz errechnete molekulare Masse des prozessierten ComEA-Proteins beträgt 7,6 kDa. Da für eine optimale Immunantwort ein Polypeptid eine minimale Molmasse von $20 \mathrm{kDa}$ aufweisen sollte, wurde das Maltosebindeprotein (MBP)Fusionssystem genutzt. Hierfür wurde das Gen des Zielproteins im Leseraster stromabwärts von malE des Überexpressionsvektors pMal-c2 kloniert. ComEA - fusioniert mit MalE (42 kDa) - besaß als immunogenes Antigen eine errechnete molekulare Masse von 49 kDa. Nach der Expression konnte über die MalE-Komponente das Fusionsprotein an eine Amylose-Affinitätssäule selektiv gebunden und schließlich mit Maltose eluiert werden.

Für die Klonierung in pMal-c2 wurde zunächst derjenige 330 bp comEA-Genbereich mit den Primern ComEA-EcoRI-NB3 (5`-CTGGCACTGGGGTGGAATTC AATATTAAC-3') und ComEA-Xbal-CB4 (5'-GTCGATAACCCACATCTAGA CGCGCGCAAG-3') an der chromosomalen DNA des Stammes BD413 amplifiziert, welcher nach der Translation das prozessierte Protein lieferte. Die als Primer eingesezten Oligonukleotide enthi elten die Schnittstellen EcoRI und Xbal, was die spezifische Ligation unter Berücksichtigung des malE-Leserasters mit dem ebenso geschnittenten Vektor 
erlaubte. Das dabei entstandene Plasmid pMD05 konnte nach der Transformation in E. coli

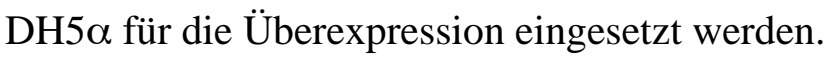

Vorversuche zur Überexpression belegten, daß sich das gewünschte Protein ausschließlich in der löslichen Zellfraktion befand, doch nur in relativ geringer Mengen gebil det wurde. Um dennoch genügend Fusionsprotein für eine Immunisierung zu erhalten, wurden 9 | Zellkultur angezogen. Hierfür wurde E. coli DH5 pMD05 in 3×3 I LBMedium (Kluyver-Kolben) be $37^{\circ} \mathrm{C}$ bis zu eine OD von 0,7-0,8 angezogen, der vor dem malE-Gen lokal isierte $P_{\text {tac }}$-Promotor durch Zugabe von IPTG induziert und die Zellen für zwei weitere Stunden inkubiert. Die durch die IPTG-Induktion bewirkte Expression des MalE/ComEA-Fusionsproteins hatte keine negative Auswirkung auf den weiteren Verlauf des Wachstums der Kultur.

Nachdem die Zellen gewaschen und resuspendiert in $300 \mathrm{ml}$ Säulenpuffer durch Ultraschall aufgeschlossen worden waren, wurde die Überexpression durch SDS-PAGE überprüft. Die Induktion lieferte nach der Auftrennung im SDS-Ge eine Proteinbande von ca. $49 \mathrm{kDa}$, die vor der IPTG-Behandl ung nicht sichtbar gewesen war. Dieses Protein sezte sich aus dem $42 \mathrm{kDa}$-Maltosebindeprotein und dem 7,0 kDa-ComEA-Protein zusammen. Das Fusionsprotein lag in gelöster Form im Cytoplasma und nicht zusammengelagert in Einschlußkörpern vor, die gemeinsam mit Membranen und Zelltrümmern nach der Ultrazentifugation in der partikulären Fraktion sedimentiert worden wären (Abb. 3.13).

Die Aufreinigung des MalE/ComEA-Fusionsproteins basiert auf der hohen Bindungsaffinität des Maltosebindeproteins zur Amylose-Matrix. Entsprechend der Bindekapazität wurde das Amylose-M aterial zu der löslichen Fraktion des Zellaufschlusses gegeben, im Meßzylinder sedimentiert, gewaschen und schließlich mit Maltosehaltiger PBS eluiert. Auf diese Weise konnten aus 9 । Kultur $6 \mathrm{ml}$ Eluat mit eine Proteinkonzentration von $120-150 \mathrm{gg} / \mathrm{m}$ gewonnen werden. Da diese Konzentration für eine Immunisierung nicht ausreichte, wurde das Eluat in Centriprep-Röhrchen auf ein Volumen von $2 \mathrm{ml}$ mit $400 \mathrm{~g} \mathrm{~g} / \mathrm{ml}$ eingeengt. Die Überprüfung der Aufreinigung des MalE/ComEA-Fusionsproteins in einer SDS-PAGE lieferte die Gewißheit, daß alle Fremdproteine abgetrennt worden waren; nur die $49 \mathrm{kDa}$-Proteinbande war nach Färbung mit Silbernitrat erkennbar (Abb. 3.13, Spur 3). 


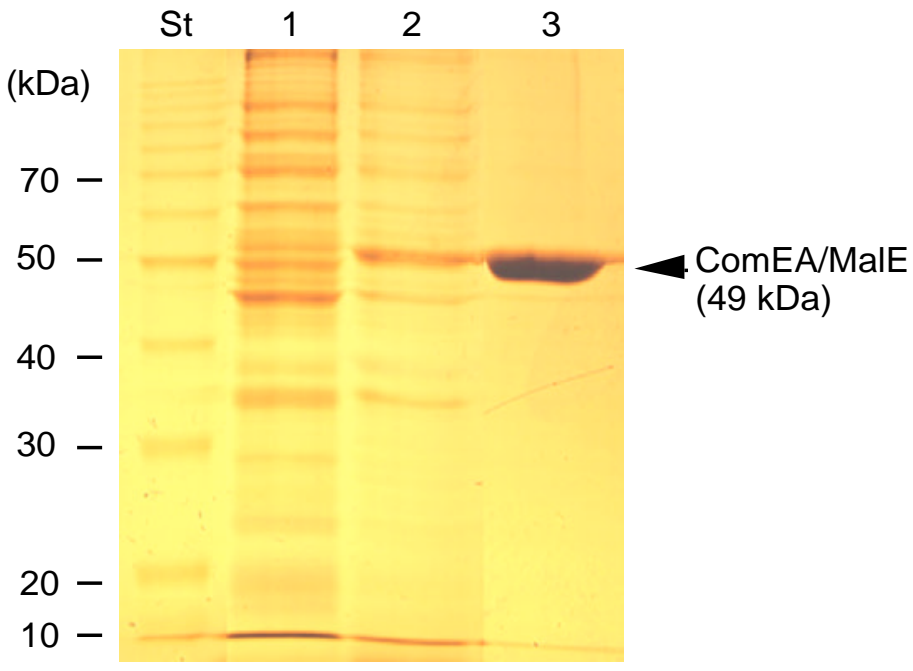

Abb. 3.13: Aufreinigung des überexprimierten ComEA/MalE-Fusionsproteins mittels AmyloseAffinitätschromatographie. In einer SDS-PAGE wurden die partikuläre Fraktion (Spur 1), die lösliche Fraktion (Spur 2) und das gereinigte Fusionsprotein (Spur 3) aufgetragen.

Für die Herstellung eines polyklonalen Antiserums gegen ComEA wurde ein Kaninchen mit insgesamt $600 \square \mathrm{g}$ Fusionsprotein immunisiert. Da ComEA mit einer molekularen Masse von 7,6 kDa zu klein war und folglich nicht immunogen genug gewesen wäre, wurde das Fusionsprotein für die Immunisierung nicht mit dem Faktor Xa gespalten, sondern vollständig injiziert. Das so gewonnene Antiserum enthielt demnach Antikörper gegen ComEA und das Mal tosebindeprotein MalE.

\subsubsection{Untersuchungen zur spezifischen Bindung der Anti-C omEA- Antikörper}

Lokalisationsstudien von ComEA in den Zellmembranen von Acinetobacter sp. BD413 sollten über immunologische Verfahren mittels spezifischer Antikörper durchgeführt werden. Das durch die Immunisierung eines Kaninchens mit dem ComEA/MalE-Fusionsprotein hergestel Ite Antiserum wurde für ELISAs ('enzyme linked immunoabsorbent assay '), 'Dotblots' und 'Immunoblots' mit dem aufgereinigten ComEA/MalE-Fusionsprotein, Acinetobacter sp. BD413-Zellextrakt sowie äußerer und innerer Membranfraktionen eingeseztt. Es zeigte sich dabei, daßs das Antiserum einen hohen Titer an spezifischen Antikörpern gegen das aufgereinigte ComEA/MalEFusionsprotein sowie ebenso gegen das abgespal tene ComEA-Proteinfragment enthielt, was das Vorliegen von spezifischen Antikörpern gegen ComEA demonstrierte $0,2 \square g$ von ComEA des mit dem Faktor $X$ a gespal tenen Hybridproteins konnte nach der Auftrennung 
in einer SDS-PAGE in einem I mmunobl ot mit Antiserum nachgewiesen werden, welches in einem Volumen von $10 \mathrm{ml}$ 1:70 000 verdünnt wurde. Mit 1:25 000 verdünntem Antiserum konnte eine minimale ComEA-Menge von 10 ng detektiert werden. Das von Acinetobacter synthetisierte ComEA konnte auch nach elektrophoretischer A uftrennung hoher Proteinkonzentrationen (bis $10 \square \mathrm{g}$ Protein) dennoch nicht detektiert werden.

Das Vorliegen spezifischer Antikörper gegen ComEA in Verbindung mit dem negativen Detektionsergebnis von ComEA in Zelllysaten spiegelt die Problematik der Detektion von ComA und ComC wider (s.o.). Wie bereits erwähnt, lag der Grund möglicherweise in der zum nativen Protein unterschiedlichen Faltung des Fusionsproteins oder an einem zu geringen Gehalt des gewünschten Proteins in der Zelle. Für ComEA trifft vermutlich letzteres zu, da das comEA-Gen in Acinetobacter nur sehr gering exprimiert wird (3.3.4). Darüber hinaus lag das Fusionsprotein nach der Überexpression in E. coli DH5 $\square$ in nativer Form gelöst im Cytopl asma vor, was eine intakte Fal tung favorisierte und zu spezifischen Antikörpern führen müßte. Um zu prüfen, ob das fehlende spezifische Signal nach der immunologischen Detektion auf den zu geringen Gehalt des Proteins zurückzuführen war, sollte comEA in Acinetobacter höher exprimiert werden.

\subsubsection{Steigerung der Expressionsrate von comEA}

Die geringe Expressionsrate von comEA und das fehlende spezifische Signal in immunologischen Nachweismethoden der Zellextrakte von Acinetobacter sp. BD413 mittels Anti-ComEA-Antikörper, ließ dieVermutung zu, daß der ComEA-Gehalt der Zelle für eine Detektion über Chemilumineszenz zu gering ist. Für die Erhöhung der Expression von comEA wurde der vor dem Kompetenzgen comP lokal isierte $\square^{54}$-abhängige Promotor genut女t (PORSTENDÖRFER et al. 2000). ComP konnte bisher in BD413 als einziges Protein immunol ogisch detektiert werden, was eine Synthese von ComP anzeigt, die duch die Markierung mit Antikörpern darstell bar ist. Dieser Promotor bot möglicherweise eine moderat erhöhte Transkription im Verlauf der natürlichen Kompetenzentwicklung von Acinetobacter, was für die spätere subzel luläre Lokal isation von ComEA als funktionaler Bestandteil des natürlichen Transformationssystems wesentich war.

Für die Klonienung hinter den comP-Promotor mußte zunächst mittels PCR derjenige Bereich amplifiziert werden, der das vollständige Gen und seine Ribosomenbindestelle beinhal tete. Da der Transkriptionsstart von ComEA nicht eindeutig bestimmt werden konnte, wurde das potentielles ATG-Startcodon berücksichtigt, welches 198 bp stromaufwärts der Prozessierungsstelle (GGGTGAAAGTC) liegt. Zwischen diesem Startcodon und der Prozessierunssequenz befindet sich kein Stopcodon und keine 
Terminatorstruktur des benachbarten Gens, so daß mögl iche Transkriptionsstarts, die nach dem postulierten Start-ATG folgen, ebenso zu der gewünschten gesteigerten Expression von comEA führen. DieTranskription durch einen eventuel vorhandenen comEA-eigenen Promotor würde dennoch einer Verstärkung des stromaufwärts klonierten comP-Promotors unterliegen.

Mittels der Primer ComEA-Pstl-N (5`-CTGGAATCAAGCCAAACTGCAG CTGAATAA-3') und ComEA-Sacl-C (5'-GATGTTGCTAATCAGAGCTCTAACCT GAG-3') wurde an dem Plasmid pUD08 (Abb. 3.8) ein 480 bp DNA-Fragment amplifiziert. Dieses Fragment beinhaltete stromaufwärts des potentiellen ATG-Startcodon von comEA weitere $20 \mathrm{bp}$ und stromabwärts des TAA-Stopcodons $70 \mathrm{bp}$. Als Klonierungsvektor diente pRP1 (ein pRK 415-Derivat), der ein 1,4 kb großes Bglll/SaclFragment mit comP und orfC trägt (PORSTENDÖRFER 1998, Abb. 3.14). Da die PstlSchnittstelle in der MCS von pRP1 eliminiert worden war, konnte die in comP lokalisierte Pstl-Schnittstelle für die Integration des PCR-Produktes genutzt werden. PRP1 wurde dafür zunächst mit Pstl und Sacl restriktionsverdaut, so daß ein 0,9 kb-Fragment herausgeschnitten wurde. Die Ligation des geschnittenen Plasmids erfol gte schließlich mit dem äquival ent geschnittenen PCR-Produkt, woraus das Plasmid pKD12 resultierte (Abb. 3.14).

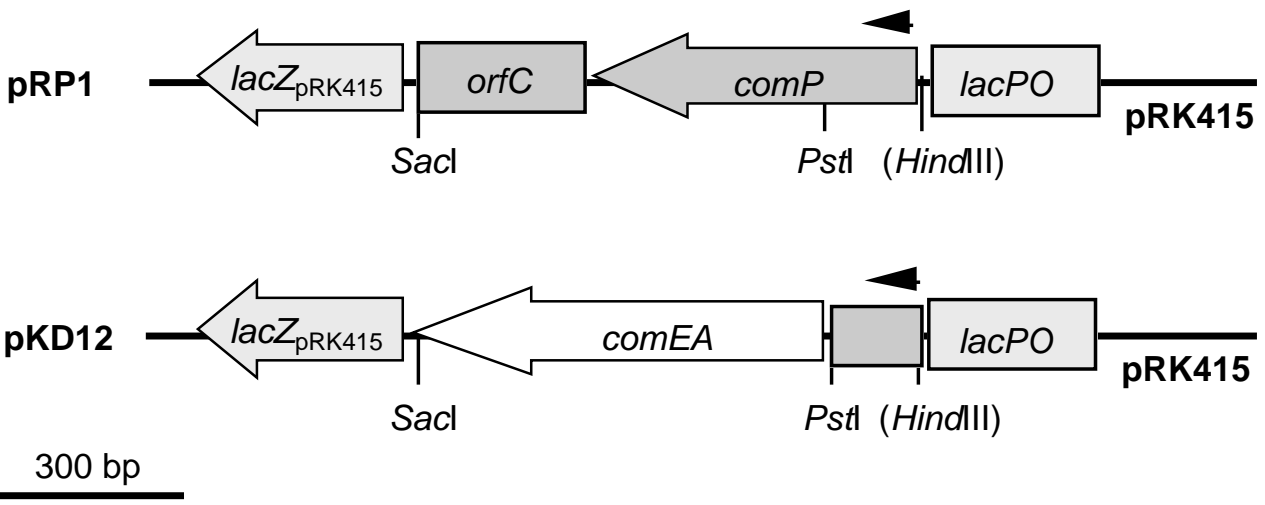

Abb. 3.14: Plasmidkonstruktion von pKD12 aus pRP1. pRP 1 wurde mit Pstl und Sacl geschnitten und mit dem durch Amplifikation generierten comEA ligiert. Die gezeigte HindIII-Schnittstelle kann aufgrund der vorangegangener Behandlung mit Klenow-Enzym nicht mehr geschnitten werden. Der P feil markiert die Promotorregion von comP. Dargestellt sind nur die für die Klonierung relevanten Schnittstellen. 
Durch die konjugative Übertragung von pKD12 in Acinetobacter sp. T100, der aufgrund der Unterbrechung im chromosomalen comEA einen vollständigen Transformationsdefekt aufwies (3.3.3), konnte die Komplementation dieses Defekts überprüft werden. Die über einen Transformationstest ermittelte uneingeschränkte Fähi gkeit zur natürlichen Transformation von Acinetobacter sp. T100 pKD12 indizierte die Funktionsfähigkeit von ComEA hinter demcomP-Promotor.

\subsubsection{Detektion von C omE A in Zellysaten}

Mit Hilfe des Anti-ComEA-Antiserums sol lte ComEA zunächst in Zelllysaten von Acinetobacter sp ADP239 pKD12, dessen Plasmid den starken comP-Promotor vor comEA trägt, verglichen zu ADP239, der den Wildtyp repräsentiert und der comEA-MutanteT100 detektiert werden.

Die über Nacht in Succinat-Mineral medium angezogenen Kulturen wurden geerntet und mit SDS-Probenpuffer behandelt, so daß die Zellen lysierten. Für den WESTERN Blot erfol gte zunächst die Auftrennung von $10 \square g$ Protein der Zelllysate aller dre Stämme in einer 15\%igen PAGE. Für die immunologische Detektion des Blots wurde das AntiComEA-Antiserum 1:20 000 verdünnt.

Der Immunobl ot von Proteinextrakte der drei StämmelieferteSignale, die zum einen in allen Spuren und zum anderen nur bei dem pKD12-tragenden Stamm erkennbar waren (Abb. 3.15). Das spezifische Signal, welches ComEA entspricht, durfte nicht in Acinetobacter sp. T100 erscheinen, da in diesem Stamm die Synthese von ComEA defekt war. Aus diesem Grund sind die in allen Zelllysaten markierten Proteine auf Kreuzreaktinen des Antiserums zurückzuführen. Da ein Signal starker Intensität nur in Acinetobacter sp. ADP239 pKD12 erkennbar war, der eine erhöhte Expression von comEA aufwies und da es nach der el ektrophoretischen Auftrennung bei ca. 7-8 kDa lag, mußte es sich bei diesem detektierten Protein um das 7,6 kDa große ComEA handeln. Eine sehr schwach detektierte Proteinbande auf dieser Laufhöhe war ebenso im Zellextrakt von ADP239 zu erkennen, was den sehr geringen Gehalt des Proteins in der Zelle demonstrierte (Abb. 3.15). 


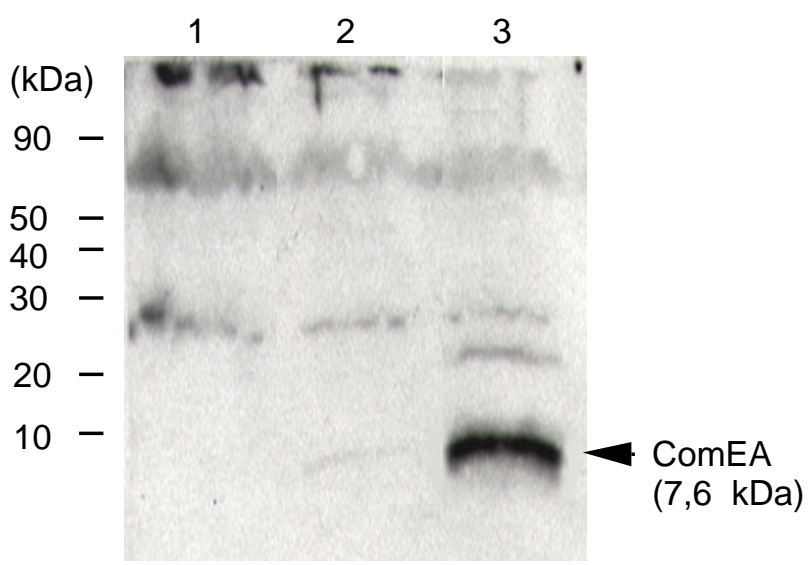

Abb. 3.15: Detektion von ComEA in GesamtzellLysaten. Acinetobacter sp. T100 (comEA-Mutante) (Spur 1), ADP239 (Spur 2) und ADP239 pKD12 (Spur 3) wurden in Succinat-Mineralmedium angezogen, geerntet und mit SDS-Probenpuffer lysiert. J eweils $10 \square g$ Protein wurden in einer $15 \%$ igen SDS-PAGE aufgetrennt und nach dem Western Blotting mit Anti-ComEA-Antiserum (1:20000) detektiert.

Diese Untersuchungen zeigten, daß das mit dem ComEA/Mal E-Fusionsprotein hergestel Ite Antiserum spezifische Antikörper gegen das von Acinetobacter synthetisierte ComEA besaß. Aufgrund des geringen ComEA-Gehalts in Acinetobacter sp. ADP239 und der Kreuzreaktionen des Antiserums mit anderen Proteinen des Zell lysats kann ComEA im Wildtyp nicht eindeutig detektiert werden. Erst eine erhöhte Expression von comEA führte zu einer spezifischen Detektion.

Da die hergestellten Antiseren gegen ComA bzw. ComC Antikörper gegen die Fusionsproteine enthielten, die Ziel proteine in Zelllysaten von ADP239 aber nicht markiert werden konnten (3.2.2/3.2.4), ist es wahrscheinlich, daß auch ComA und ComC nur schwach synthetisiert werden und durch erhöhte Expression mittels des comP-Promotors detektierbar sind.

\subsubsection{L okalisation von C omE A}

Zur Lokalisation von ComEA in Acinetobacter sp. ADP239 pKD12 wurden Immunoblots mit Anti-ComEA-Antiserum und verschiedenen Zell fraktionen durchgeführt. Es sollte die subzelluläre Lokalisation von ComEA geprüft werden, wodurch sich möglicherweise Hinweise auf eine Funktion bei der DNA-A ufnahme ergeben. Da ComEA Ähnlichkeiten zu DNA-bindenden Proteinen aufweist, könnte dieser Kompetenzfaktor an der Bindung der DNA auf der Zelloberfläche beteiligt wein. Ein weiteres in BD413 gut untersuchtes Kompetenzprotein ist das Pilin-ähnliche Protein ComP, dessen Defekt die 
Bindung der DNA auf der Zelloberfläche inhibiert (PORSTENDÖRFER et al. 1997). Dies läßt vermuten, daß ComP an der Exposition von ComEA beteiligt ist. Das Fehlen von ComP könnte somit zu einer veränderten Lokalisation von ComEA führen. Aus diesem Grund wurde die Lokalisation von ComEA in der comP-MutanteT206 im Vergleich zu ADP239 pKD12 untersucht. Hierfür wurde das Plasmid pKD12 konjugativ in Acinetobacter sp. T206 transferiert.

Die Isolierung von Proteinextrakten verschiedener Zellfraktionen erfolgte entsprechend der in "Material und Methoden" dargestel ten Weise. DieZellen wurden über Nacht in $250 \mathrm{ml}$ Succinat-Mineral medium angezogen, geerntet und in einem Volumen von $20 \mathrm{ml}$ mittels FrenCH-Pressen aufgeschlossen. Dieser Ansatz stellte das Gesamt-Zelllysat dar. Anschließend wurde die lösliche cytoplasmatische Fraktion von den Zellmembranen durch Zentrifugation getrennt. Die Zellmembranen wurden schließlich über einen Saccharosegradienten in innere und äußere Membran getrennt und in 0,5 ml Volumen resuspendiert. Die obere weißliche Bande stel Ite die äußere Membran dar und die in der Mitte des Saccarosegradienten gel blich erscheinende Bande die Cytoplasmamembran. Die Reinheit der äußeren Membran wurde über die Bestimmung der Aktivität der in der Cytoplasmamembran lokalisierten NADH-Dehydrogenase bestimmt. Verglichen zur inneren Membran war in der äußeren Membran eine NADH-Dehydrogenase-Aktivität von 10-15\% zu messen, was für die Interpretation hinsichtlich der Lokalisation von ComEA berücksichtigt werden muß.

Das Gesamt-Zellysat und die cytoplasmatische Fraktion, die jeweils ein Volumen von $20 \mathrm{ml}$ ausmachten, wiesen Proteinkonzentrationen von 1,3 mg/ml bzw. 1,1 mg/ml auf. Die Differenz der Proteinkonzentrationen von Gesamt-Zelllysat und Cytoplasma ergibt die Proteinkonzentration der Zellmembranen, die somit bezogen auf $20 \mathrm{ml}$ Volumen $0,2 \mathrm{mg} / \mathrm{ml}$ betragen muß. Eingeengt auf $1 \mathrm{ml}$ Volumen ergibt dies den theoretischen Wert von $4 \mathrm{mg} / \mathrm{ml}$. Die jeweils in 0,5 $\mathrm{ml}$ resuspendierten cytoplasmatischen und äußeren Zellmembranen wiesen beide eine Proteinkonzentration von ca. 1,0 mg/ml auf (insgesamt $1 \mathrm{ml} \mathrm{mit} \mathrm{1,0} \mathrm{mg/ml).} \mathrm{Die} \mathrm{Ausbeute} \mathrm{der} \mathrm{gereinigten} \mathrm{und} \mathrm{getrennten} \mathrm{Zellmembranen} \mathrm{betrug}$ daher 25\%. Da die Proteinkonzentration der Membranen in elektrophoretischer Auftrennung und I mmunobl ot für eine Auftragung äquivalenter Volumina von Cytoplasma und Membranfraktion zu gering war, wurden jeweils $10 \mathrm{gg}$ Protein eingesetzt. Die Relation zwischen innerer und äußerer Membran blieb bestehen, da beide Fraktionen die gleiche Proteinkonzentration aufwiesen.

Die Auftrennung der Proben in einer 15\%igen PAGE und nachfolgender Silberfärbung des Gels ließ erkennen, daß das Gesamt-Zelllysat und die Cytoplasmafraktion ein ähnliches Bandenmuster aufweisen (Abb. 3.16). Dies war dadurch zu begründen, daß die Zellen zu ca. 85\% aus Iöslichen Proteinen aufgebaut sind (vgl. Proteinbestimmung). Die äußeren und inneren Membranen zeigten dagegen ein 
unterschiedliches Proteinmuster: Während in der Cytoplasmamembran zwei Proteine dominieren, die molekulare Massen von ca. 41 kDa und ca. 75 kDa aufweisen, zeigte die äußere Membran eine homogene Proteinverteilung unterschiedl icher molekularen Massen. Auffällig war die gräulich erscheinende diffuse Bande, die unterhal b der Höhe des $10 \mathrm{kDa}$ Markerprotein in der äußeren Membran-Fraktion angefärbt wurde (Abb. 3.16). Da Zuckerreste in der Silberfärbung oft eine graue Färbung annehmen, könnte diese Bande die Polysaccharide darstellen, die sich auf der Oberfläche von Zellen finden.

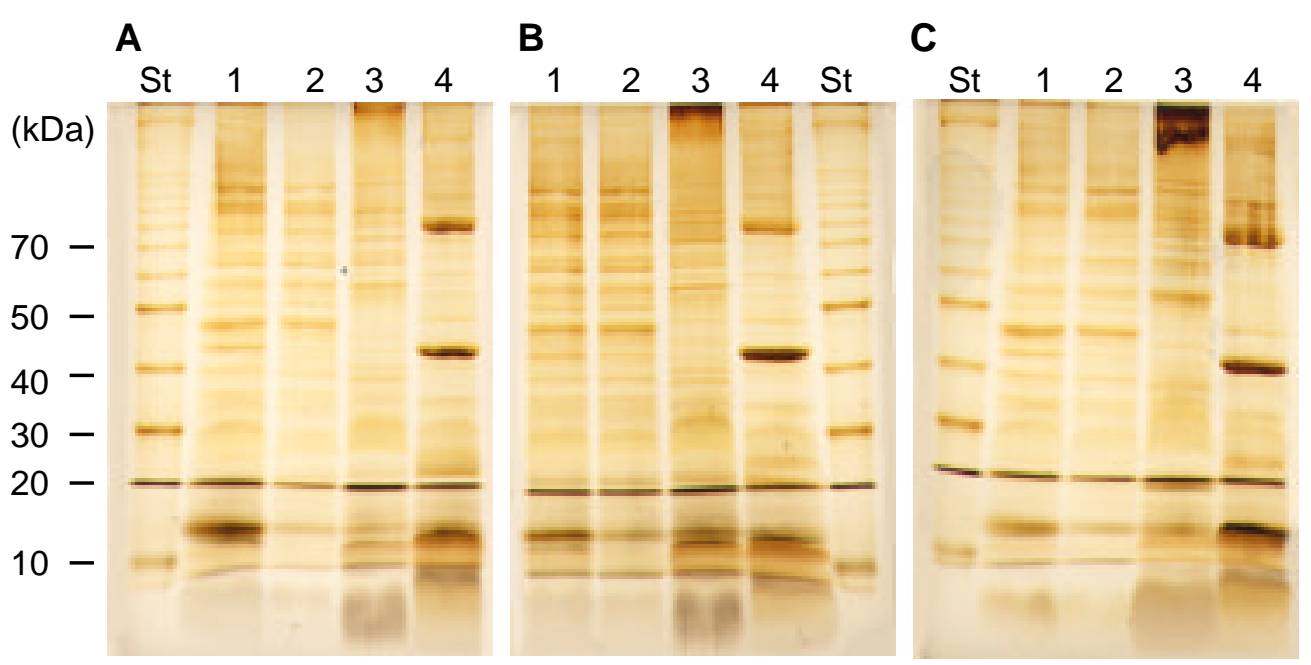

\begin{abstract}
Abb. 3.16: Elektrophoretische Auftrennung der Zellkompartimente. Die Zellen wurden in Succinat-Mineralmedium angezogen, geerntet und mittels FRENCH Pressen aufgeschlossen. Gleiche Proteinmengen (10 $\mathrm{Gg})$ des Gesamt-Zelllysats (Spur 1), Cytoplasmas (Spur 2) sowie der äußeren (Spur 3) und inneren (Spur 4) Membran wurden in einer $15 \%$ igen SDS-PAGE aufgetrennt und mit Silbernitrat gefärbt. Das Gel (A) stellt die comEA-Mutante T100 dar; in Gel (B) ist ADP239 pKD12 und in (C) T206 pKD12 aufgetragen.
\end{abstract}

Aufgrund des optimaleren Vergleichs der Bandenmuster wurden für den Immunobl ot die gleichen Zellkompartimente der drei Stämme (T100, ADP239 pKD12, T206 pKD12) nebeneinander aufgetragen. Nach der Detektion des WESTERN Blots mit Anti-ComEAAntiserum konnte ein Protein markiert werden, welches an der unteren Lauffront der Gelelektrophorese bei ca. 7-8 kDa aufgetrennt worden war und in der comEA-M utante T100 fehlte (Abb. 3.17). Darüber hinaus lieferte die Markierung mit den Antikörpern weitere Singnale, die jedoch ebenso in der comEA-Mutante erschienen und somit als unspezifische Kreuzreaktionen identifizierbar waren. Das spezifische ComEA-Signal war im Gesamt-Zelllysat der Stämme ADP239 pKD12 und T206 pKD12 in vergleichbarer Intensität, in der cytoplasmatischen Fraktion dagegen nur sehr schwach zu erkennen. Diese beiden Stämme zeigten weiterhin eine ähnliche Verteilung von ComEA in den Zellmembranen (Abb. 3.17). Neben einem ComEA-Signal schwacher Intensität in der 
cytoplasmatischen Membran zeigte sich eine relativ starke Intensität in der äußeren Membran. Die Doppelbanden des Blots sind auf die schlechte elektrophoretische Auftrennung zurückzuführen, da der Lipidgehalt durch die Auftragung von $10 \square g$ Protein sehr hoch gewesen war und die Auftrennung im unteren Bereich des Gels störte. (Wurde weniger Protein aufgetragen so ließ sich ComEA nicht detektieren.)

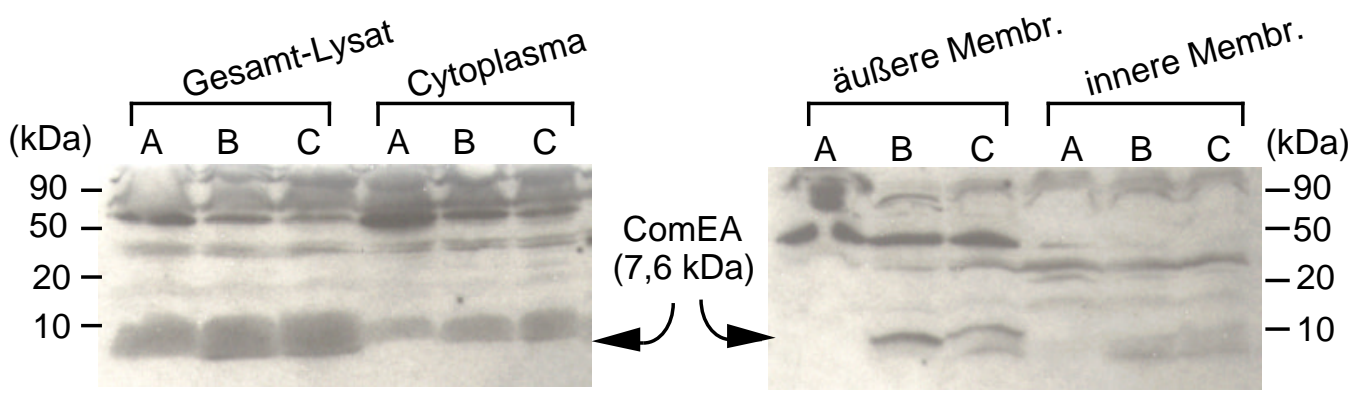

Abb. 3.17: Detektion von ComEA in Zellkompartimenten. Die Zellen der comEAMutante T100 (A), von ADP239 pKD12 (B) und T206 pKD12 (C) wurden in SuccinatMineralmedium angezogen, geerntet und mittels $\mathrm{FRENCH}-\mathrm{P}$ ressen aufgeschlossen Daraufhin erfolgte eine Fraktionierung der Zellen in Cytoplasma sowie äußere und innere Membran. Proben dieser Fraktionen wurden in einer 15\% igen SDS-PAGE aufgetrennt und der WeSTERN Blot mit Anti-ComEA-Antiserum behandelt.

Diese Untersuchungen zeigten, daß nach der Expression von comEA durch den comP-Promotor ComEA in den Zellkomparimenten detektiert werden konnte. Der höchste Gehalt diese Proteins war in der äußeren Membran zu verzeichnen gewesen, in geringerer Konzentration in der inneren Membran- und Cytoplasma-Fraktion. Der Defekt in der Synthese des Typ-IV-Pilin-ähnlichen Kompetenzproteins ComP führte zu keiner veränderten Lokal isation von ComEA.

\subsubsection{DNA-Bindestudien mit C omE A}

Das in dieser Arbeit identifizierte Kompetenzprotein ComEA weist für DNABindeproteine typische 'Helix-turn-Helix'-Motive mit basischem Charakter auf (3.3.1). Die DNA-Bindung des Proteins sollte durch die Verzögerung des Laufverhaltens eines Plasmids im Agarosegel demonstriert werden. Hierfür wurden ansteigende Konzentrationen (20, 40, 80, 120, 200 und 400 ng) des zuvor mit dem Faktor Xa gespaltenen MalE/ComEA-Fusionsproteins mit $100 \mathrm{ng}$ des Plasmids pBIISK und $5 \mathrm{mM}$ EDTA (Endkonzentration) versetzt, 5 min bei Raumtemperatur inkubiert und mit DNABeschwererlösung in einem 0,8\%igem Agarosegel bei $50 \mathrm{~V}$ aufgetrennt. Je höher die zugesetzte Proteinmenge war, desto langsamer war der elektrophoretische Lauf im Gel, 
was auf der sukzessiv gesteigerten molekularen Masse des Plasmids nach Bindung von ComEA beruhte (Abb. 3.18). Um auszuschließen, daß das Maltosebindeprotein (MBP) MalE mit der DNA interagierte wurde das Plasmid allein mit MalE (100 und $400 \mathrm{ng}$ ) inkubiert und aufgetrennt. Da diese Kontrolle keinen 'Shift' im Agarosegel bewirkte, konnte eine Wechsel wirkung von MalE mit der DNA ausgeschlossen werden (Abb. 3.18).

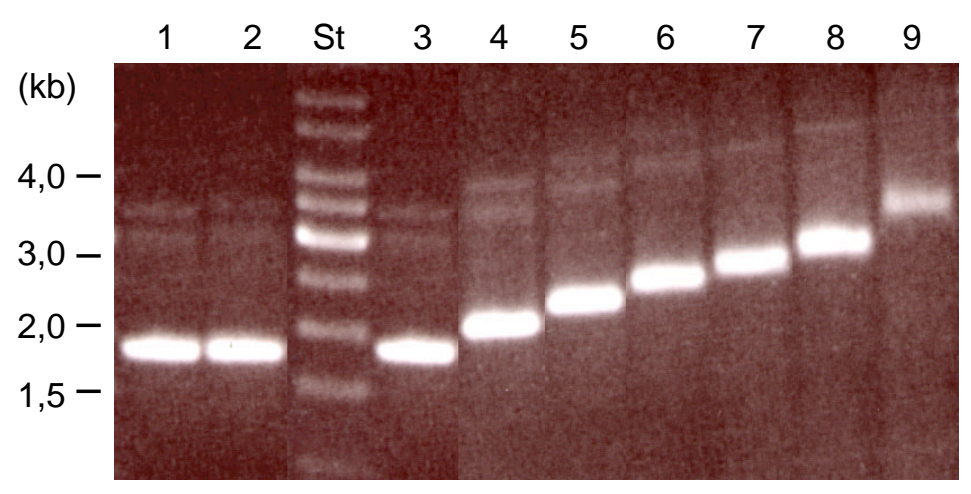

Abb. 3.18: Bindung von ComEA an zirkuläre Plasmid-DNA. Das als ComEA/MalE-Fusionsprotein überexprimierte unc aufgereinigte DNA-Bindeprotein wurde mit dem Faktor Xa in die beiden Komponenten pMal und ComEA gespalten und in ansteigender Konzentration zu dem Plasmid pBIISK (je $100 \mathrm{ng}$ ) gegeben. Die zugesetzten P roteinmengen der Proben betragen $20 \mathrm{ng}$ (Spur 4), $40 \mathrm{ng}$ (Spur 5), $80 \mathrm{ng}$ (S pur 6), $120 \mathrm{ng}$ (S pur 7), $200 \mathrm{ng}$ (Spur 8) und $400 \mathrm{ng}$ (Spur 9). Spur 3 enthält kein Protein. In den Spuren 1 und 2 wurde das Plasmid mit $100 \mathrm{ng}$ bzw. 400 ng MalE-Protein versetzt.

Unmarkierte doppelsträngige DNA kann durch Negativkontrastierung mit Uranylacetat elektronenmikroskopisch nicht abbgebildet werden, da der Durchmesser der DNA zu gering ist. Das globuläre Fusionsprotein MalE/ComEA besitzt eine molekulare Masse von $49 \mathrm{kDa}$, was einen Durchmesser von ca. $2 \mathrm{~nm}$ entspricht und demzufolge elektronenmikroskopisch erkennbar ist.

Für die elektronenmikroskopische Abbildung der Bindung des ComEA/MalEFusionsproteins an DNA wurden $200 \mathrm{ng}$ pBIISK und $20 \square \mathrm{l}$ einer $40 \square \mathrm{g} / \mathrm{ml}$ MalE/ComEALösung $(0,8 \square \mathrm{g})$ in Anwesenheit von $5 \mathrm{mM}$ EDTA (Endkonzentration) $10 \mathrm{~min}$ bei Raumtemperatur inkubiert (Gesamtvolumen $60 \mathrm{II}$ ) und daraufhin mit 4\% Uranylacetat kontrastiert. Das Fusionspotein lagerte sich an die Plasmid-DNA an, so daß die linear verschlungene Struktur der DNA indirekt durch das Protein abgebildet werden konnte (Abb. 3.19). Durch die Zusammenlagerung der DNA-bindenden Proteine an das Plasmid erhielt diese Struktur einen Durchmesser von 2-4 nm. Nicht gebundene Proteine lagen einzel n und ungeordnet auf dem Grid, so daß sie keine kontrastreiche Struktur ergaben. Bei der Betrachtung von einerseits nur Plasmid-DNA und andererseits nur ComEA/MalE- 
Fusionsprotein, oder nach der Inkubation von DNA mit dem MBP MalE allein - ohne die ComEA-Komponente -, waren die filamentösen Strukturen der DNA-Proteinkomplexe nicht vorhanden. Dieses Ergebnis zeigte, daß ComEA als Fusionsprotein an DNA bindet.
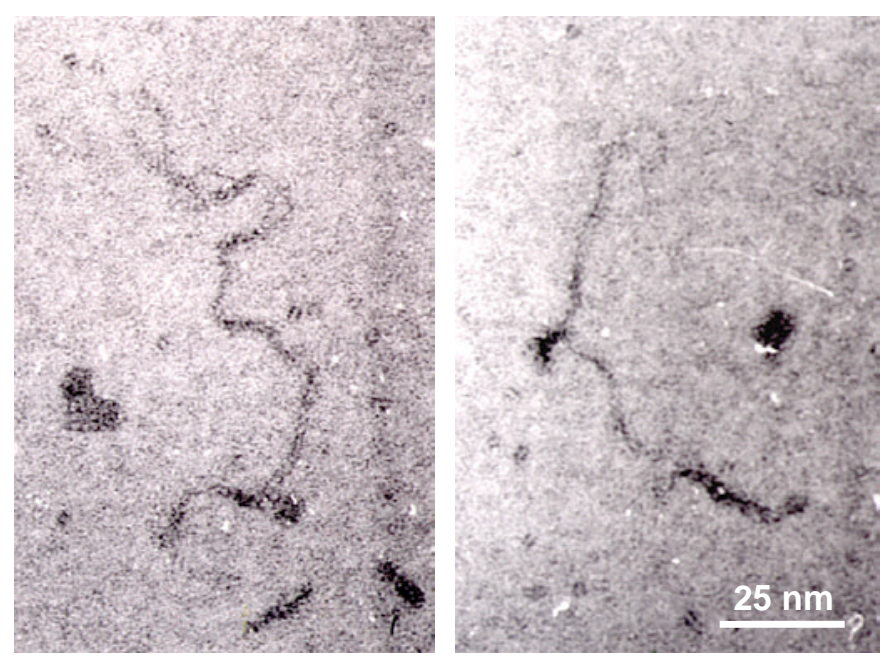

Abb. 3.19: Bindung des ComEA/MalE-Fusionsproteins an zirkuläre Plasmid-DNA. In einen Gesamtprobevolumen von $60 \square$ l wurden 0,8 $\square$ g Fusionsprotein und $200 \mathrm{ng}$ Plasmid pBIISK in Anwesenheit von $5 \mathrm{mM}$ EDTA inkubiert. Die Bindung des Proteins an die DNA wurde elektronenmikroskopisch durch dis Kontrastierung mit 4\% Uranylacetat dargestellt. Gezeigt sind zwei Plasmide, an die das Fusionsproteir gebunden hat.

\subsection{Identifizierung von Protein/Protein-Interaktionen im DNA- A ufnahmesystem von Acinetobacter sp. BD413}

Untersuchungen der Komponenten des Transformationssystems, der Typ-IVPilusbiogenese und des Typ-II-Sekretionswegs zeigten, daß die drei Systeme wahrscheinlich einen gemeinsamen evolutiven Ursprung haben. Bei natürlich kompetenten Bakterien, die Typ-IV-Pili synthetisieren, sind die identischen Proteine der Pilusbiogenese ebenso an der DNA-A ufnahme beteiligt. Doch stellt die Anwesenheit von Pilusstrukturen auf der Zelloberfläche keine Bedingung für die natürliche Transformation dar. So synthetisieren das Gram-negative Bakterium Haemophilus influaenzae und alle bisher untersuchten Gram-positiven Organismen, die natürlich transformierbar sind, keine Typ- 
IV-Pili. Da Pilin-ähnliche Komponenten ebenso für die Typ-II-Sekretion und die DNAAufnahme essentiell sind, obwohl keine Pilusstruktur auf der Zelloberfläche synthetisiert wird, muß neben der Filamentbildung auf der Zelloberfläche dem Strukturprotein eine weitere Funktion als essentielle Komponente bei Proteinexport oder DNA-Import zugeschrieben werden. Die regulatorischen Größen oder die Involvierung von Proteinen, die in einem Falle die Biogenese eines Typ-IV-Pilus bewirken und in dem anderen Fall Strukturen ausbilden, die nicht als Filament auf der Zelloberfläche erscheinen, sind unbekannt.

Mit den Kompetenzproteinen ComB, ComE, ComF und ComP wurden bei Acinetobacter sp. BD413 vier Typ-IV-Pilin-ähnliche Komponenten identifiziert, wobei ComP mittels A ntikörper detektiert werden konnte, für Piline in charakteristischer Weise glykosyliert wird und in den Zellmembranen und Periplasma lokalisiert ist. (PorstendöRfER et al. 1997, Link et al. 1998, BusCh et al. 1999, HeRZBERG et al. 2000, PORSTENDÖRFER et al. 2000). Weiterhin stellt ComP keine Komponente der Pili von Acinetobacter sp. BD413 dar, was mit den Beobachtungen übereinstimmt, daß Unterbrechungen in den bereits untersuchten Kompetenzgenen, dessen Genprodukte Ähnlichkeiten zu den Komponenten der Typ-IV-Pilusbiogenese aufweisen, zu einem unveränderten Pilusphänotyp führen.

Da der Mechanismus und das Zusammenspiel der einzel nen Kompetenzproteine bei der DNA-A ufnahme ungeklärt ist, sollten Protein/Protein-I nteraktionsstudien mit der Pilinähnlichen Komponente ComP erste Hinweise diesbezüglich liefern. ComP ist als in den Zellmembranen lokalisierte Komponente an der Bindung der DNA auf der Zelloberfläche beteiligt, so daß eine sehr kurze Pilusstruktur postuliert werden kann, die nur den periplasmatischen Raum durchspannt und eventuell DNA-bindende Proteine exponiert. Die schonende Solubilisierung von Zellmembranen mit milden Detergenzien, sollte demnach Pilus-ähnliche ComP-Assoziationen erhalten.

\subsubsection{Solubilisierung von Zellmembranen}

Vorangegangene Sol ubilisierungexperimente mit isol ierten Zellmembranen ergaben, daß das Detergenz Dodecylmaltosid ComP quantitativ herauslöste; Triton X-100 und CHAPS lösten dagegen maximal 80\%, was durch eine eine Erhöhung der Detergenzkonzentration nicht gesteigert werden konnte (GoHL 2000). Durch Fraktionierung der Zellkompartimente konnte weiterhin gezeigt werden, daß eine Verteilung von ComP in den Zellmembranen zu ca. 80\% in der Cytoplasmamembran und zu ca. 20\% in der äußeren Membran vorliegt (GoHL 2000, PORSTENDÖRfER et al. 2000). Für eine weitere Charakterisierung eines ComP-Komplexes wurden im Folgenden Gesamtmembranen aus Acinetobacter sp. BD413 isoliert und mit Dodecylmal tosid gelöst. 
Acinetobacter sp. BD413 wurde im Fermenter bis zur stationären Wachstumsphase in Succinat-Mineralmedium angezogen und durch Zentrifugation geerntet. Nach dem Aufschluß von $35 \mathrm{~g}$ Zellmasse (Feuchtgewicht; in $70 \mathrm{ml}$ Lysispuffer resuspendiert) mittels FRENCH-Pressen erfol gte die Abtrennung ganzer Zellen und die I solierung der Membranen durch Zentrifugations- und Resuspendierungsschritte (Membranpuffer; jeweils $200 \mathrm{ml}$ ) wie in „Material und Methoden“ beschrieben ist. Die schließlich in $70 \mathrm{ml}$ Membranpuffer resuspendierten Membranen wurden mit $130 \mathrm{ml}$ einer $10 \mathrm{mM}$ Dodecylmaltosid-Lösung (20 mM Tris- $\mathrm{HCl}, \mathrm{pH}$ 7,5) solubilisiert (Endkonzentration 6,5 mM Detergenz), so daß eine Proteinkonzentration von $4 \mathrm{mg} / \mathrm{ml}$ resultierte. Nicht gelöste Bestandteile sedimentierten durch Ultrazentrifugation, wonach sich eine Proteinverteilung von $3,1 \mathrm{mg} / \mathrm{ml}$ im Überstand und $0,9 \mathrm{mg} / \mathrm{ml}$ im Sediment ergab (Protein des Sediments bezogen auf das äquivalente Volumen von $200 \mathrm{ml}$ ).

Abbildung 3.20 verdeutlicht, daß sich ComP nahezu quantitativ im Überstand befand: Nachdem gleiche Proteinmengen $(0,5 \square \mathrm{g})$ von Überstand und Sediment in der SDS-PAGE aufgetrennt worden waren, wurde ComP immunologisch detektiert. Während der Überstand ein starken Signal lieferte, lag der ComP-Gehalt im Sediment an der unteren Detektionsgrenze
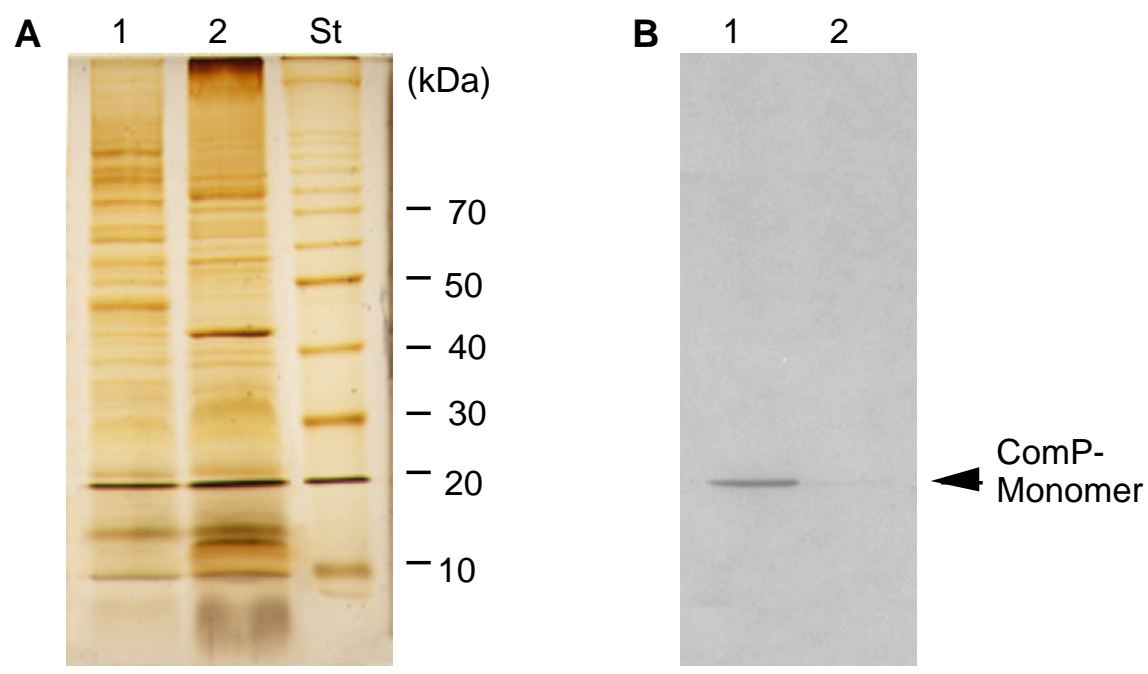

Abb. 3.20: Detektion von ComP im Membransolubilisat. Acinetobacter sp. BD413 wurde nach der Anzucht in Succinat-Mineralmedium mit der FRENCH-P resse aufgeschlossen, die Membranen isoliert und mit Dodecylmaltosid gelöst. Durch Ultrazentrifugation erfolgte die Trennung in lösliche (1) und unlösliche Fraktion (2). Die beiden Fraktionen $(0,5 \square \mathrm{g}$ Protein) wurden in einer SDS-PAGE aufgetrennt (A) und der WESTERN Blot mit Anti-ComP-Antiserum detektiert (B). 
Bei Isolierungen von Proteinkomplexen aus aufgeschlossenen Zellen muß berücksichtigt werden, daß Proteininteraktionen durch die Passage der FrENCH-Presse zerstört werden können. Aus diesem Grund wurden ganze Zellen in gleicher Weise wie Membranen behandelt. Die mit Lysozym (in Lysispuffer) behandelten Zellen (4 mg/m) wurden hierfür für die Solubilisierung mit 6,5 mM Dodecylmaltosid (Endkonzentration) eingesektt. Die Abtrennung nicht gelöster Bestandteile erfol gte durch Ultrazentrifugation. Der Überstand enthielt daraufhin gelöstes ComP.

Die Abschätzung der molekularen Masse des durch Dodecylmal tosid freigesetzten ComP, sowohl der solubilisierte Membranfraktion als auch der gelösten ganzen Zellen, effolgte in einer 'Blue Native PAGE' und die Detektion von ComP mittels Immunoblot. Ein ComP-Signal war nach dieser Auftrennung und Detektion sowohl im Zellsolubilisat als auch im Membransolubilisat auf gleicher Höhe bei ca. $240 \mathrm{kDa}$ zu erkennen (Abb. 3.21). Die comP-Mutante T206 liefete kein Signal. Da ComP als Monomer eine molekulare Masse von $20 \mathrm{kDa}$ aufweist, mußte das Signal bei $240 \mathrm{kDa}$ auf einen Proteinkomplex zurückzuführen gewesen sein (Gohl 2000). Um den Aufbau dieses Komplexes zu untersuchen und die Struktur elektronenmikroskopisch abbilden zu können, schloß sich eine Aufreinigung an.

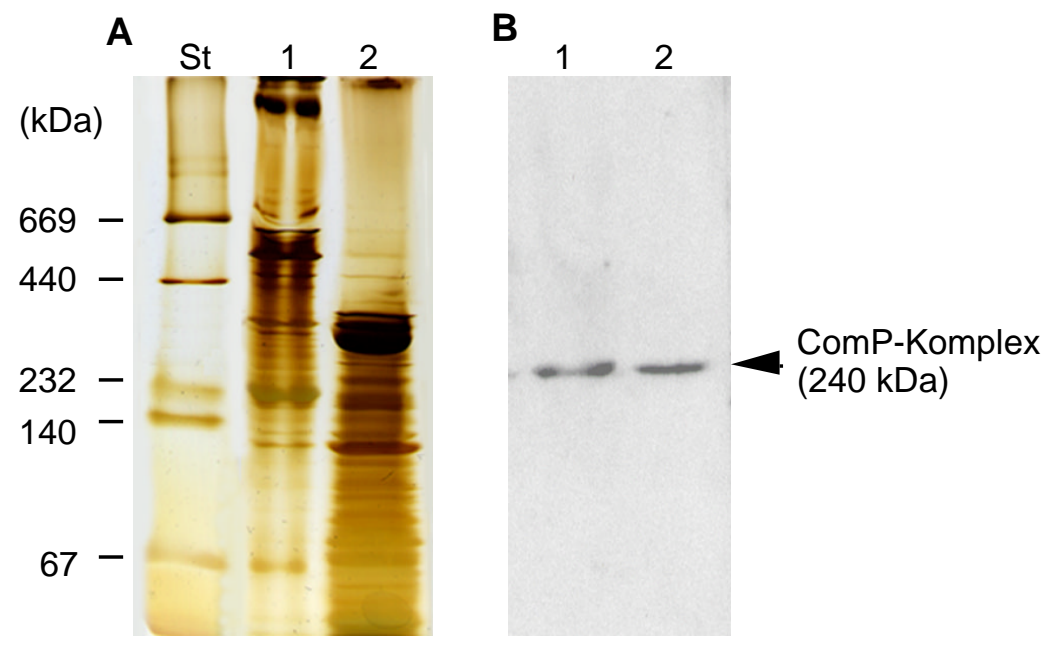

Abb. 3.21: Detektion eines ComP-Komplexes. Gereinigte Membranen (Spur 1) und ganze Zellen (Spur 2) mit jeweils einer Proteinkonzentration von $4 \mathrm{Gg} / \mathrm{ml}$ wurden mit $6,5 \mathrm{mM}$ Dodecylmaltosid gelöst, 5 gg Protein in einer 'Blue Native PAGE' aufgetrennt (A) und geblottet. Anti-ComP-Antikörper detektierten einen $240 \mathrm{kDa}$ P roteinkomplex (B). 


\subsubsection{R einigung des gelösten C omP-K omplexes}

Erste Versuche einen ComP-haltigen Komplex zu reinigen wurden bereits durchgeführt (Gohl 2000). Eine Affinitästchromatigraphie an immobilisierten Anti-ComPAntikörpern führte zu keine Bindung des gewünschten Proteinkomplexes. Die Reinigung des Comp-Komplexes an milden Anionenaustauschern wie DEAE-Sepharose und Hydroxylapathit hatte nur eine geringe Trennwirkung auf das Membransolubilisat (Gohl 2000). Aus diesem Grund wurde in dieser Arbeit der stärkere Anionaustauscher Sepharose $Q$ verwendet.

Für die spätere Auftrennung von $180 \mathrm{ml}$ Membransolubilisat wurden $50 \mathrm{ml}$ Sepharose Q-Matrix in eine XK 26/20-Säule gepackt und mit $20 \mathrm{mM}$ Tris-HCl/2 mM Dodecylmaltosid ( $\mathrm{pH} 7,5)$ äquilibriert. Nach dem Beladen der Säule mit dem Solubilisat erfolgte die Elution der nicht gebundenen Proteine mit $200 \mathrm{ml}$ Äquilibrierungspuffer. Die sukzessive Elution der gebundenen Proteine wurde durch die stufenweise Erhöhung der

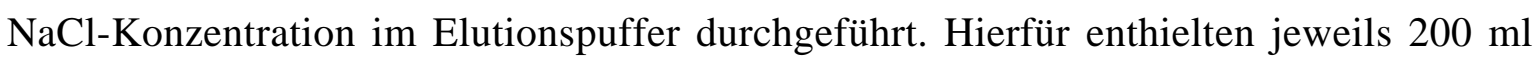
Puffer in ansteigender Konzentrationen $50 \mathrm{mM} \mathrm{NaCl}, 100 \mathrm{mM}, 150 \mathrm{mM}, 200 \mathrm{mM}$, $250 \mathrm{mM}, 300 \mathrm{mM}, 500 \mathrm{mM}$ und $1500 \mathrm{mM} \mathrm{NaCl}$. DieFraktionsgröße betrug $15 \mathrm{ml}$.

In Abbildung 3.22 (A) ist das Elutionsprofil der Sepharose Q-Säule zu sehen, wobei die Proteinkonzentration der einzel nen Fraktionen gegen das Elutionsvol umen aufgetragen wurde. Die Fraktionen der ersten drei Elutionsstufen enthielten jeweils maximal $0,12 \mathrm{mg} / \mathrm{ml}$ Protein; mit $200 \mathrm{mM} \mathrm{NaCl}$ eluierte ca. $0,2 \mathrm{mg} / \mathrm{ml}$, und die folgenden Elutionsschritte wuschen jeweils bis zu 0,35 mg/ml Protein von der Matrix. Nach dem letzten Elutionsschritt waren die Proteine quantitativ von der Säulenmatrix entfernt worden, da sich keine Proteine im Eluat fanden, welches aus der Regenerierung der Matrix resultierte. Die Detektion des eluierten ComP-Komplexes in einem WESTERN Blot erfolgte nach der Auftrennung der Fraktionen eines jeden 'Peaks' in einer SDS-PAGE, wobei äquival ente Proteinmengen aufgetragen wurden (A bb. 3.22). Daraufhin war zu erkennen, daß ComP im 2. 'Proteinpeak' eluierte und in niedrigerer Konzentration ebenso im

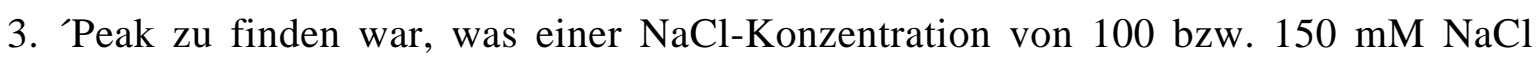
entsprach. 
A

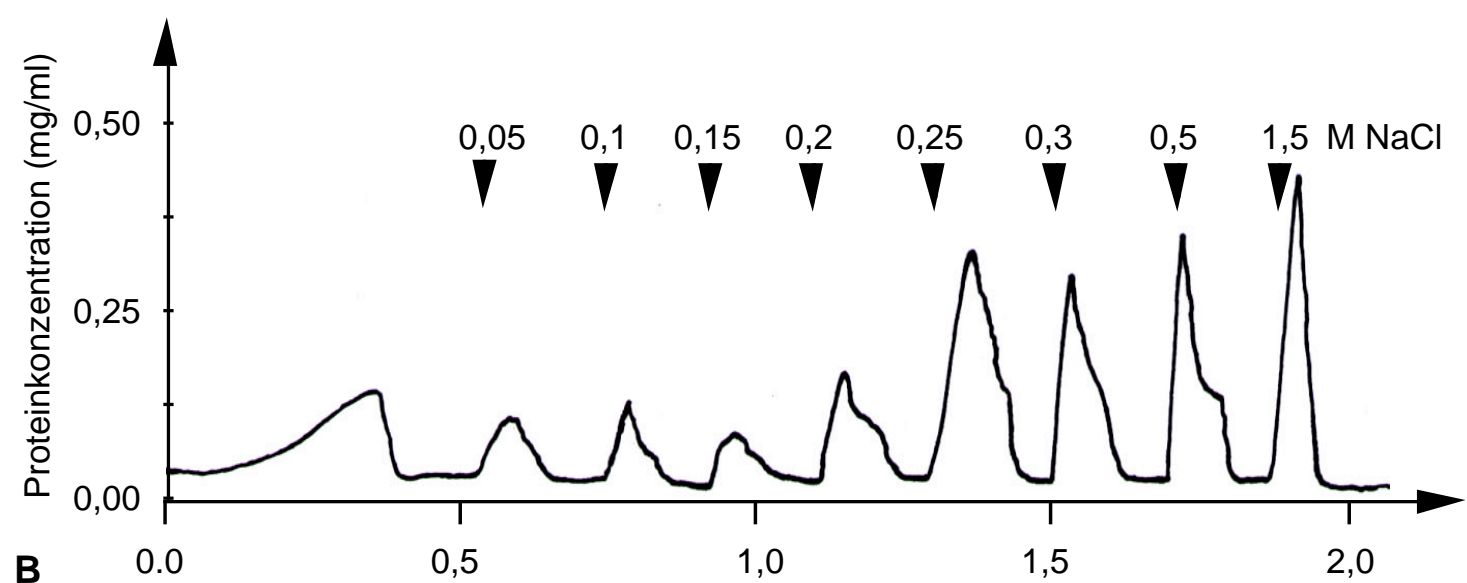

B

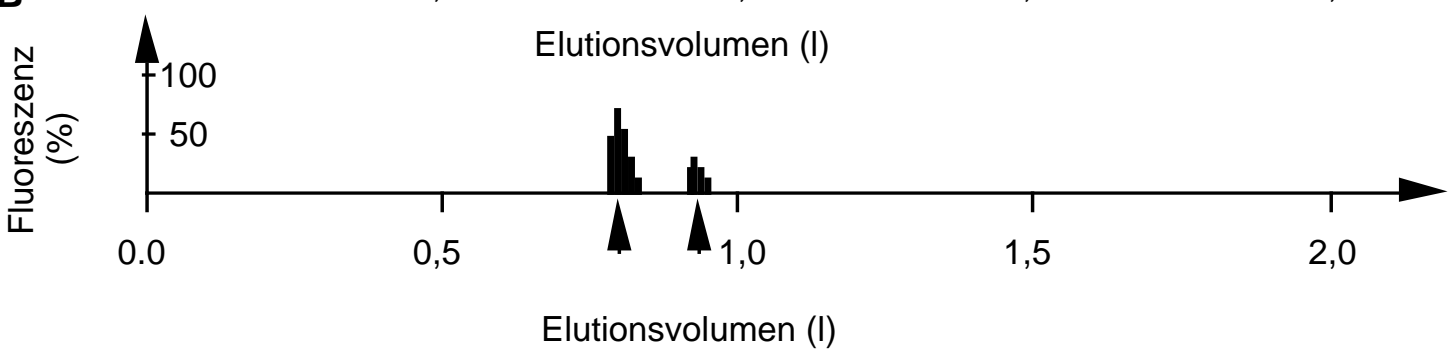

Abb. 3.22: Anionenaustausch-Chromatographie des Membransolubilisats an Sepharose Q. (A) Die Scheiberaufzeichnung gibt die Konzentration der eluierten Proteine an, die mit steigender $\mathrm{NaCl}$-Konzentration von der Sepharose Q-Matrix gewaschen wurden. (B) Der ComP-Gehalt der gesammelten Fraktionen wurden im Western Blot (1 Dg Protein) gegen Anti-ComP-Antiserum bestimmt und im Fluoreszenzphotometer bestimmt. Die P feile in Abbildung B markieren die Fraktionen, die für die nachfolgende Gelfiltration eingesetzt wurden.

Die Bestimmung der molekularen Masse des ComP-Komplexes in den aufgereinigten Fraktionen erfolgte über die Retention beim Passieren über eine S300Sephacryl Gelfiltrationsäule. Hierfür wurden jeweils $0,5 \mathrm{ml}$ des über die Sepharose QMatrix aufgereinigte ComP-Komplexes auf die Geffiltrationssäule gegeben und eluiert. Hierbei handelte es sich um eine Fraktionen des ersten ComP-haltigen Protein-Peaks (100 mM NaCl) und eine Fraktion des zweiten Peaks (150 mM NaCl), die jeweils den höchsten ComP-Gehalt aufwiesen. Die gesammelten Fraktionen wurden daraufhin immunologisch mittels WESTERN Blot auf ihren ComP-Gehalt geprüft. Als Größenmarker für die Gelchromatographie dienten Ferritin (450 kDa), Katalase (240 kDa), Aldolase (158 kDa) und Albumin (45 kDa), diejeweils in gleicher Weise auf die Säul e gegeben und eluiert wurden. Die Detektion der Markerproteine erfolgte hier über eine BRADFORDProteinbestimmung der gesammelten Fraktionen. In Abbildung 3.23 ist das Elutionsverhal ten der Markerproteine und das des ComP-Komplexes dargestelt, indem die molekulare Masse logarithmisch gegen das Elutionsvolumen aufgetragen wurde. Die poröse Matrix der Geffiltration bewirkte, daß kleine Partikel, also Proteine mit geringer 
molekularen Masse in die Poren diffundierten und somit länger in der Säule zurückblieben und später eluierten; Proteine hoher molekularer Masse verblieben dagegen im sogenannten A usschl uß̉volumen und eluierten zuerst von der Säule I I I dealfall ergab sich für globuläre Proteine eine logarithmische Beziehung zwischen molekularer Masse und Elutionsvolumen. Anhand des Elutionsvolumens konnte für den ComP-Komplex eine Masse von 200-260 kDa ermittelt werden, was mit der über die 'Blue Native PAGE' abgeschätzten Masse von 240 kDa übereinstimmt (Abb. 3.23).

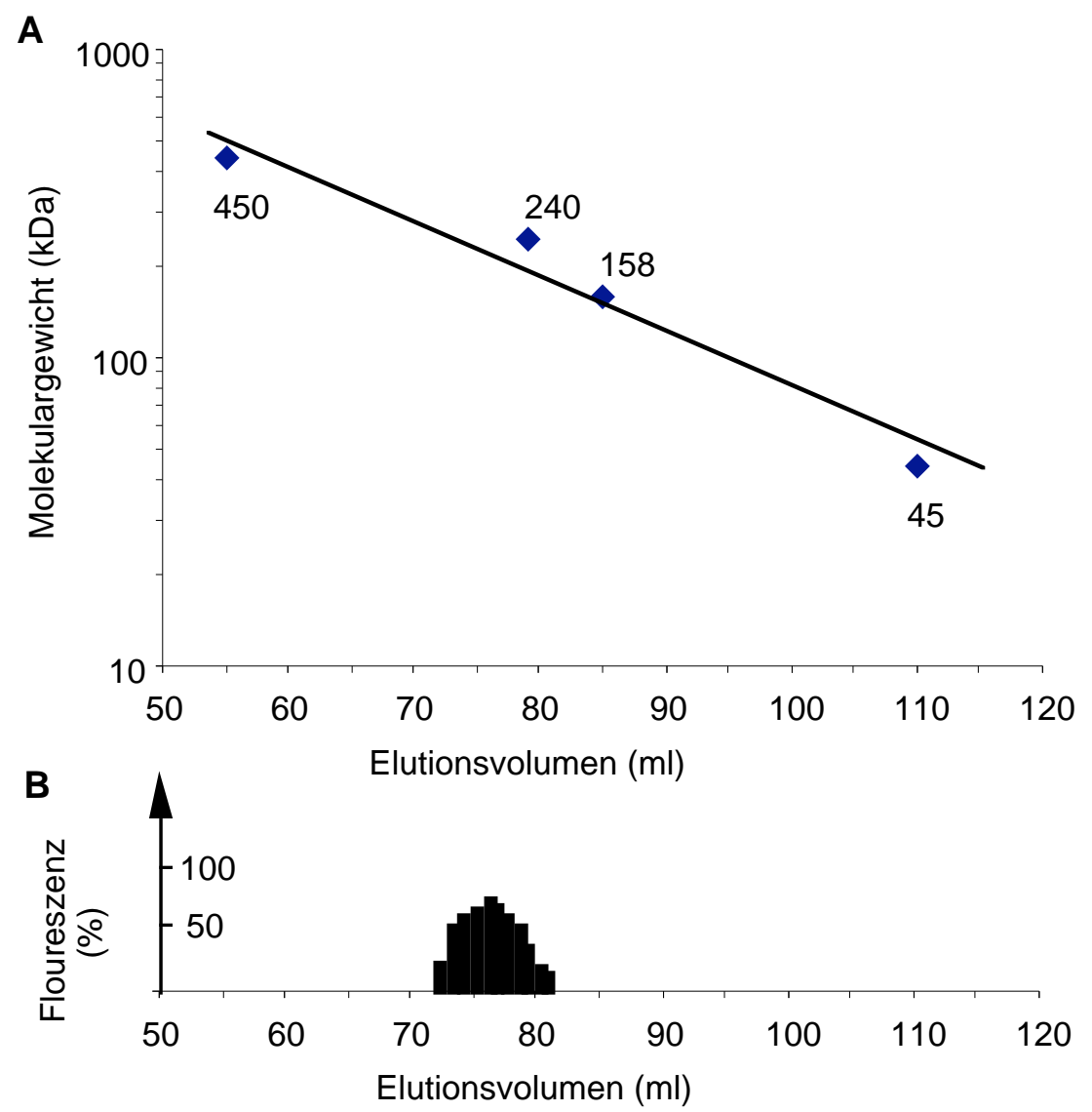

Abb. 3.23: Gelfiltrationschromatographie des ComP-Komplexes. (A) Die bekannten Molekulargewichte der Markerproteine wurden halblogarithmisch gegen das Elutionsvolumen aufgetragen. $\mathrm{Mi}$ abnehmender Masse wurden die folgenden Marker-Protein aufgetrennt: Ferritin (450 kDa), Katalase $(240 \mathrm{kDa})$, Aldolase (158 $\mathrm{kDa}$ ) und Albumin (45 kDa). (B) Das Elutionsvolumen des über die Sepharose Q-Matrix aufgereinigten ComP-Komplexes wurde in einer zweiten Gelchromatographie bestimmt. Die Bestimmung des ComP Gehalts der Fraktionen erfolgte mittels Immunoblotting, wobei die Signalstärke über die Intensität der Fluoreszenz bestimmt wurde. 


\subsubsection{A uftrennung des ComP-Komplexes in einer 2D-G elelektrophorese}

Der aus den Zellmembranen von Acinetobacter sp. BD413 solubilisierte ComPhaltige Proteinkomplex, der eine molekulare Masse von ca. $240 \mathrm{kDa}$ aufweist, stellt entweder ein Homomultimer dar, der aus ComP-Monomeren aufgebaut ist, oder ein Heteromultimer, in dem neben ComP weitere Proteine assoziiert vorliegen. Der Untereinheiten-Aufbau des Multimers sollte im Folgenden durch eine zweidimensionale (2D-) Gelelektrophorese dargestellt werden. Für die elektrophoretische Auftrennung diente der über Sepharose Q aufgereinigte ComP-Komplex, der bei $100 \mathrm{mM} \mathrm{NaCl}$ von der Säulen-Matrix eluierte (3.5.2).

Die erste Dimmension der 2D-Gelelektrophorese stellte eine 'Blue Native PAGE' dar, wodurch eine Auftrennung des ComP-Komplexes und der noch vorhandenen Fremdproteinen erzielt wurde. Das bei $240 \mathrm{kDa}$ detektierte Protein des I mmunoblots der nativen PAGE bestätigte, daß die Proteinbande stärkster Intensität auf der Höhe von 240 kDa den ComP-Komplex darstellt (Abb. 3.24). Proteine, die kein Bestandteil des ComP-Komplexes waren, wiesen im Silber-gefärbten Gel keine distikte Bandierung auf und konnten aufgrund der verglichen zum $240 \mathrm{kDa}$-Komplex höheren molekularen Masse vom ComP-Multimer unterschieden werden.

In der zweiten Dimension wurde der Zerfall des Proteinkomplexes durch SDS genutzt. Nachdem der ComP-Komplex in der ersten Dimension elektrophoretisch aufgetrennt worden war, wurden die Spur des nativen Gels horizontal auf ein SDS-Gel gelegt, mit SDS-Auftragspuffer überschichtet und die Proteine unter denaturierenden Bedingungen in der zweiten Dimension aufgetrennt. Dies hatte zur Folge, daß die Proteine des Komplexes vertikal aufgetrennt wurden. Die Denaturierung des $240 \mathrm{kDa}$-ComPKomplexes lieferte nur einen Proteinspot bei $20 \mathrm{kDa}$, welcher das ComP-Monomer repräsentierte, was mittels Immunoblot gezeigt werden konnte (Abb. 3.24).

Die Trennung des ComP-Komplexes ausschließlich in ComP-Monomere indizierte, daß ein ComP-Homomultimer vorliegen mußte. Aufgrund der relativ starken Intensität des ComP-Proteinspots im SDS-Gel und der Annahme, daß maximal 12 Monomere den Komplex bildeten, wäre auch nur eine andersartige Komponente - dann ca. in 12fach geringerer Intensität angefärbt - imSDS-Gel sichtbar gewesen. 

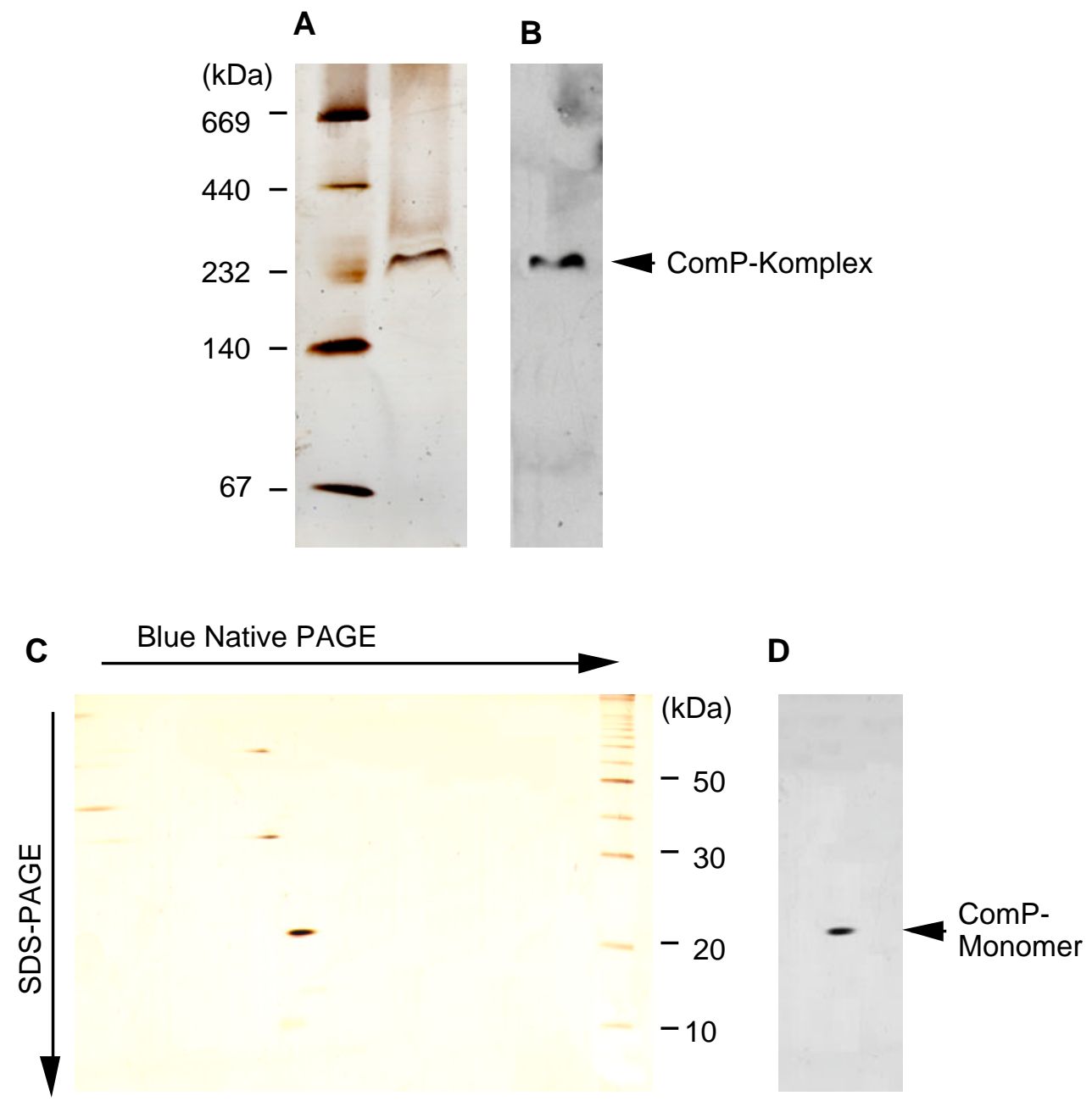

Abb. 3.24: Zweidimensionale Auftrennung des ComP-Komplexes. Der über Anionenaustausch-Chromatographie gereinigte ComP-Komplex wurde in einer 'Blue Native PAGE' aufgetrennt (A) und im Immunoblot mit Anti-ComP-Antikörper detektiert (B). Die native Gel-Spur wurde in einer SDS-PAGE aufgetrennt (C) und ComP wiederum im Immunoblot detektiert (D).

Die Ergebnisse der Gelfiltration, 'Blue Native PAGE` und 2D-Gelelektrophorese demonstrierten, daß ComP einen aus den Zellmembranen solubilisierbaren Komplex bildet, der eine Masse von ca. 240 kDa aufweist und ein ComP-Homomultimer darstellt

\subsubsection{E lektronenmikroskopische Darstellung des ComP-K omplexes}

Ein $240 \mathrm{kDa}$-ComP-Komplex konnte über Anionenaustasch-Chromatographie an Sepharose Q gereinigt werden (3.5.2). Die Struktur dieses aus Typ-IV-Pilin-ähnlichen Proteinen aufgebauten Komplexes sol lte daraufhin elektronenmikroskopisch abgebildet werden. Vor dem Hintergrund, daß die Untereinheiten des Typ-IV-Pilus eine helikale Struktur ausbilden, ist es naheliegend, daß der identifizierte ComP-Komplex des Transformationssysterms einen ähnlichen Aufbau aufweist. 
In der helikalen Pilusstruktur, die einen Durchmesser von 5-6 nm besitzt, bilden fünf Piline jeweils eine Umdrehung mit einer Steighöhe von ca. 4 nm (PARGE et al. 1995, FOREST \& TAINER 1997). Geht man davon aus, daß das 240 kDa-Multimer aus 12 Untereinheiten des $20 \mathrm{kDaC}$ ComPs aufgebaut ist, so ergeben sich 2 Umdrehungen, die eine Höhe von von $8 \mathrm{~nm}$ einnehmen. Für den ComP-Komplex bedeutet dies einen zylindrischen Aufbau mit den Abmessungen von $6 \times 8 \mathrm{~nm}$. Da in der elektronenmikroskopischen Abbildung diese geringe Differenz von $2 \mathrm{~nm}$ zwischen Breite und Höhe des Proteinaggregates nicht in Erscheinung tritt, ist die Annahme einer globulären Struktur des ComP-Multimers wahrscheinlicher als die elektronenmikroskopische Abbildung einer länglichen Pilusstruktur.

Für die elektronenmikroskopische Darstellung wurde der gereinigte ComP-Komplex mit 4\% Uranylacetat negativ kontrastiert. Abbildung 3.25 (A) zeigt eine Übersicht der globulären Proteinkomplexe, die Durchmesser von maximal 5-8 nm aufweisen. Die Proteinkomplexe geringerer Größe stellten vermutlich Abbruchfragmente dar, dessen Zerfall der saure pH-Wert von 4 des Kontrastierungsmittels bewirkt haben könnte. Nach der vergrößerten Darstellung ausgewählter ComP-Komplexe war erkennbar, daß ihre Orientierung auf dem Grid nicht einheitlich erschien und keine charakteristische (helikale) A nordnung der Untereinheiten auszumachen war. Es ist denkbar, daß Uranylacetat zu einer teilweisen Denaturierung einer potentiellen helikalen Struktur geführt hatte. Die Aufsicht der Komplexe ließ 4-5 gleichartige Untereinheiten erkennen, was somit in Anbetracht der globulären Struktur auf eine Gesamtzahl von 8-14 Untereinheiten schließen läßt. Diese Aufsicht auf 4-5 Untereinheiten würde mit der Anordnung in der Typ-IV-Pilusstruktur übereinstimmen, in der 5 Untereinheiten eine Umdrehung ausmachen.

A

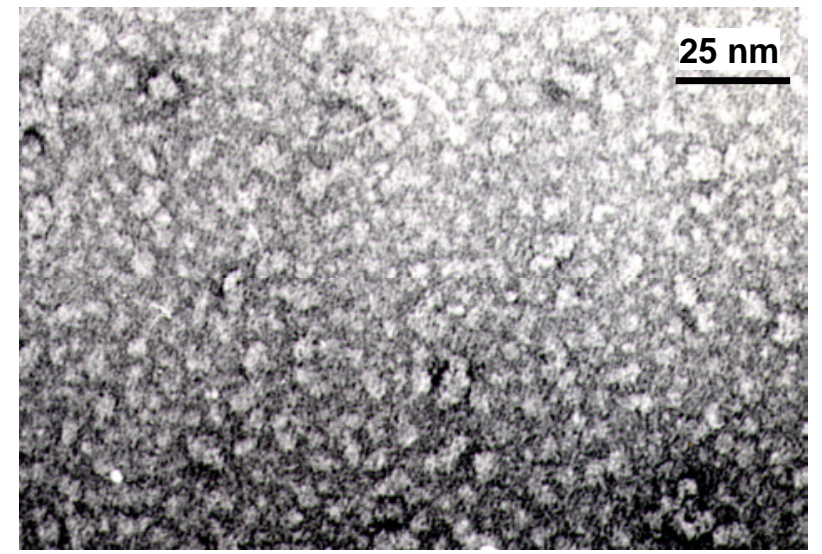

B
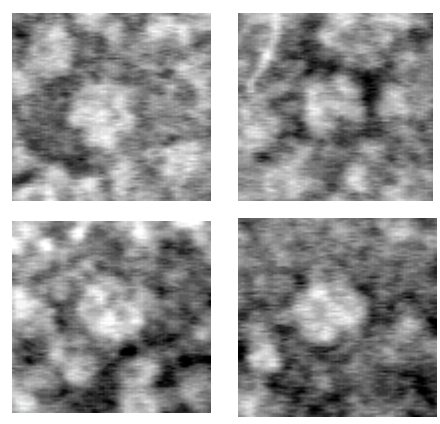

$10 \mathrm{~nm}$

Abb. 3.25: Elektronenmikroskopische Darstellung des gereinigten ComP. Komplexes. Der ComP-Komplex wurde mit Dodecylmaltosid aus den Zellmembranen von Acinetobacter sp. BD413 gelöst und über Anionenaustausch-Chromatographie aufgereinigt. (A) Für die elektronenmikroskopische Abbildung efolgte dit Negativkontrastierung mit 4\% Uranylacetat. (B) Für eine detailliertere Darstellung wurden exemplarisch vier ComP-Komplexe vergrößert. 
Zusammenfassend zeigen die elektronenmikroskopischen Untersuchungen, daß der Komplex aus 8-14 gleichartigen Untereinheiten aufgebaut ist, was mit den Ergebnissen der Bestimmung der molekularen Masse des ComP-Komplexes von $240 \mathrm{kDa}$ übereinstimmt.

\subsubsection{Vergleich der ComP-Komplexgröße vor und nach Behandlung mit Triton-X 100}

Hu et al. (2002) postulierte, daßs das Typ-IV-Pilin-ähnliche Protein XpsG, welches eine essentielle Komponente des Typ-II-Sekretionssystems von Xanthomonas campestris darstellt, eine Pseudopilusstruktur ausbildet. Nach dem Aufschluß der Zellen mittels FRENCH-Pressen und der Fraktionierung der Zellkompartimente befand sich XpsG sowohl in der Membranfraktion als auch in der löslichen Fraktion, die das Cytoplasma, das Periplasma und die Scherfraktion bildete. Gelchromatographische Untersuchungen belegten weiterhin, daß das lösliche XpsG Bestandteil eines Komplexes ist, welcher eine molekulare Masse größer als $443 \mathrm{kDa}$ aufweist. Nach der Behandlung mit dem milden Detergenz Triton X-100 zerfiel dieser Komplex in Untereinheiten, die nach der Gelfiltration im Bereich der molekularen Massen von 66 bis 443 kDa eluierten. Zu einem weiteren Zerfall des Proteinkomplexes führte die Behandlung mit Desoxycholat, so daß eine molekulare Masse von ca. $36 \mathrm{kDa}$ detektiert wurde.

Im Folgenden sollte überprüft werden, ob ComP eine zum XpsG-Komplex vergleichbare Proteinassoziation ( $>443 \mathrm{kDa}$ ) ausbildet. Hierfür wurde das durch den Zellaufschluß freigesetzte ComP nicht mit Detergenz behandelt, sonders sofort für die Bestimmung der molekularen Masse eingesetzt. Die comP-Mutante Acinetobacter sp. T206 wurde als Negativkontrolle eingesetzt.

DieZellen einer über Nacht in Succinat-Mineral medium angezogenen $250 \mathrm{ml}$-Kultur wurden dafür geerntet, mit der FRENCH-Presse aufgeschlossen, die Zelltrümmer und Membranen durch Ultrazentrifugation abgetrennt und der Überstand zur partiellen Reinigung in einem Saccharosegradient, der sich von 8\%-50\% Saccharose erstreckte, aufgetrennt. Nach der Fraktionierung des Gradienten erfol gte die Detektion von ComP in den Proben nach der Auftrennung in einer 15\%igen SDS-PAGE mittels I mmunobl ot gegen Anti-ComP-Antiserum. Der WESTERN Blot verdeutlichte, daß ComP von der auf den Saccharosegradienten aufgetragenen Probe in die unteren Saccharoseschichten zentrifugiert worden war. In der (obersten) 6. Fraktion konnte ComP nicht detektiert werden; der höchste Gehalt das Protein lag in der 2., 3. und 4. Fraktion und in geringerer Menge in den Fraktionen 1 und 5 vor (A bb. 3.26). 
A

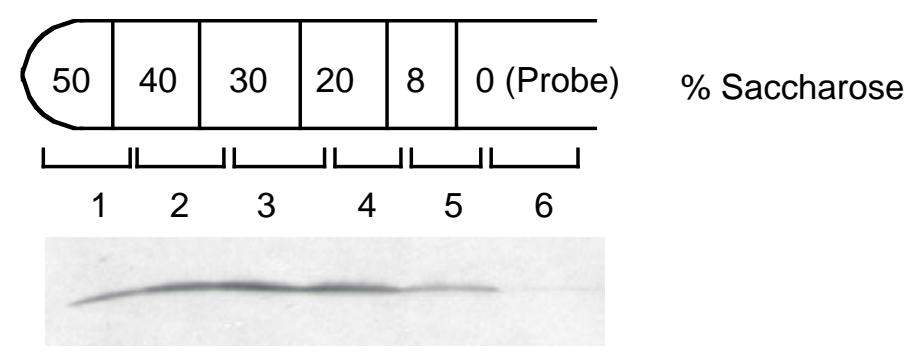

B

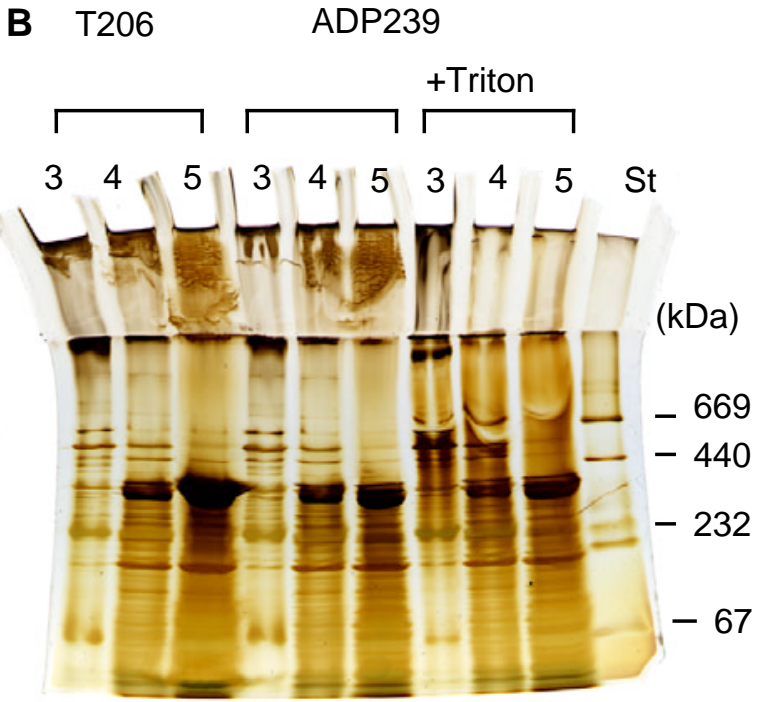

T206

ADP239

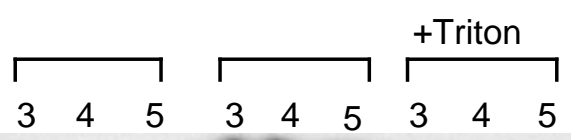

Abb. 3.26: Detektion eines ComP-Komplexes. Kulturen von Acinetobacter sp. ADP 239 und der comP-Mutante T206 wurden über Nacht in Succinat-Mineralmedium angezogen und geerntet. Die lösliche Fraktion der durch FRENCH -Pressen aufgeschlossenen Zellen wurde im Saccharosegradienten (8\%-50\%) aufgetrennt und der ComP-Gehalt in den Fraktionen 1-6 im WeSTERN Blot analysiert (A). Die Fraktionen 3, 4 und 5 wurden in einer 'Blue Native PAGE' aufgetrennt und im WESTERN Blot gegen Anti-ComP-Antiserum detektiert (B).

Die 3., 4. und 5. Fraktionen von ADP239 und T206 wurden in einer nativen Gradienten-PAGE aufgetrennt und im WESTERN Blot mit Anti-ComP-Antikörpern behandelt. Parallel dazu wurden Proben der 3., 4. und 5. Fraktionen von ADP239 mit $1 \%(\mathrm{v} / \mathrm{v})$ Triton X-100 (Endkonzentration) versetzte und ebenso elektrophoretisch aufgetrennt und im WESTERN Blot ComP detektiert. Die als Negativkontrolle aufgetragenen Proben der ComP-Mutante T206 zeigten erwartungsgemäß keine Signale, da ComP in dieser Mutante nicht synthetisiert wird (Abb. 3.26, B). Die Fraktionen 3, 4 und 5 des Wildtyp-Stammes ADP239 enthielten ComP-haltige Komplexe, die nicht in das $3 \%$ ige Gel der nativen PAGE eingewandert waren und in den Auftragstaschen verblieben. (Abb. 3.26, B). Die A bmessung des ComP-haltigen Aggregates mußte demzufol ge größer als die Porenweite des 3\%igen Polyacylamidgels gewesen sein. Nach der Behandl ung mit 
Triton X-100 ließ sich ComP elektrophoretisch auftrennen, so daß ein Komplexe von ca. $240 \mathrm{kDa}$ detektiert werden konnte, der bereits bei der Solubilisierung der Zellmembranen von Acinetobacter identifiziert wurde (3.5.2). Daraus ist zu schließen, daß die Behandl ung mit dem milden Detergenz Triton X-100 zu einem teil weisen Zerfall der ComP-haltigen Assoziation zu dem $240 \mathrm{kDaComP-Komplex} \mathrm{führte.}$

Die Untersuchungen des XpsG-haltigen Komplexes schlossen zwar ein Vorliegen von XpsG-haltigen Membranvesikel aus, doch die potentielle Detektion von ComPhal tigen Vesikeln anstelle von ComP-haltigen Proteinkomplexen muß in weiteren Studien untersucht werden. Vor dem Hintergrund, daß die Kompetenzproteine ComB und ComC aus Acinetobacter sp. BD413 Ähnlichkeiten zu Typ-IV-Pilinen bzw. Assemblierungfaktoren der Typ-IV-Pili aufwiesen (LINK et al. 1998, HeRZBERg et al. 2000), ist es somit wahrscheinlich, daß ComB und ComC für die Assemblierung des ComP-Proteinkomplexes essentiell sind. Fehlen die ComP-Komplexe in den Mutanten, so handelt es sich möglicherweise nicht um ComP-haltige Membranvesikel. 


\subsection{Charakterisierung der Pili von Acinetobacter sp. B D413}

Acinetobacter sp. BD413 besitzt auf der Zelloberfläche zwei morphologisch unterscheidbare Pilustypen. Zum einen sind dies starre, oft in Bündeln assoziierte Filamente mit einem Durchmesser von 2-3 nm und zum anderen flexible Strukturen, die eine Länge von mehreren $\square \mathrm{m}$ erreichen und einen Durchmesser von ca. $6 \mathrm{~nm}$ aufweisen (HenRICHSEN 1975, PoRstendöRfER et al. 1997, 2000). Die dünneren Pili sind mit der Adsorption des Bakteriums an hydrophobe Oberflächen in Verbindung gebracht worden (ROSENBERG et al. 1981), während die dickeren Filamente physiologisch nicht untersucht sind. Der für Typ-IV-Pili charakteristische Durchmesser, der von $4 \mathrm{~nm}$ bis $6 \mathrm{~nm}$ reicht, und dieFähigkeit von BD413 zur gleitenden Fortbewegung, ließ die Vermutung zu, daß es sich bei den dicken Pili um Typ-IV-Pili handeln könnte. Dagegen sprach jedoch die Tatsache, daß die bei Acinetobacter sp. BD413 bisher identifizierten Kompetenzgene, die Ähnlichkeiten zu Pilinen oder Typ-IV-Pilus-Assemblierungsfaktoren zeigten, nicht in die Pilusbiogenese und die gleitende Fortbewegung involviert sind, wie Mutantenstudien der transformationsdefekten Mutanten ergaben (PORSTENDÖRFER et al. 1997, LINK et al. 1998, BusCH et al. 1999, HERZBERG et al. 2000, RosenPLÄNTER pers. Mitteilung). Im Gegensatz dazu sind bei bisher untersuchten natürlich kompetenten Bakterien, die Typ-IV-Pili synthetisieren, die Komponenten der Pilusbiogenese an der Transformation beteiligt. Weiterhin weisen die Pili von Acinetobacter sp. BD413 eine peritriche Anordnung auf, während die 'Twitching Motility` vermittel nden Typ-IV-Pili polar lokalisiert sind.

\subsubsection{Reinigung der Pilusstrukturen und $\mathbf{N}$-terminale Sequenzierung der Pilusuntereinheiten}

Die Charakterisierungen der beiden Pilustypen von Acinetobacter sp. BD413 auf genetischer Ebene und die Generierung Pilussynthese-defekter Stämme sollte die Frage klären, ob dieser Strukturen an der natürlichen Transformation und 'Twitching Motility' beteiligt sind. Darüberhinaus wäre eine eindeutige Klassifizierung und Charakterisierung beider Pilustypen möglich.

Zur Aufreinigung der Pilusstrukturen wurde Acinetobacter sp. BD413 in einem $3 \mathrm{I}$ Kluyverkolben mit Mineralmedium und Succinat über Nacht angezogen, geerntet und seine filamentösen Strukturen von der Zelloberfläche abgeschert, was durch das zweimalige Passieren durch eine Kanüle erfolgte, wie in "Material und Methoden“ ausführlich beschrieben ist. Nach Abtrennung der Zellen durch niedertourige Zentrifugation pelletierten in der Ultrazentrifuge die abgescherten Pili. Daraufhin ließen sich die resuspendierten Filamente in einem 20-70\%igen Saccharosegradienten reinigen. Die Proben des fraktionierten Gradienten wurden el ektronenmikroskopisch und nach der 
Auftrennung in einer 15\%igen SDS-PAGE auf ihren Pilusgehalt hin überprüft. Die dicken Filamente waren daraufhin bei $40 \%-45 \%(w / v)$ Saccharose und die dünneren im Bereich zwischen 38-43\% (w/v) zu finden. Wurde die Scherfraktion vor dem Beladen auf den Saccharosegradienten gegen $100 \mathrm{mM} \mathrm{NaCl} / 150 \mathrm{mM} \mathrm{CaCl} 2$ dialysiert, so aggregierten die dünnen Pili und sedimentierten nach der Dichtegradienten-Zentrifugation auf den Boden des Röhrchens; die dicken Pili lagen dagegen weiterhin als Einzelfilamente vor, was auf eine polare, hydrophile Pilusoberfläche hindeutete. Die Aggregation bei hoher Ionenkonzentration spiegelt den hydrophoben Charakter der dünnen Pili wider. Die elektronenmikroskopische Abbildung 3.27 (B) zeigt die Fraktionen mit gereinigten aggregierten, starren dünnen Pilusstrukruren und mit flexiblen einzeln vorliegenden dicken Pili.
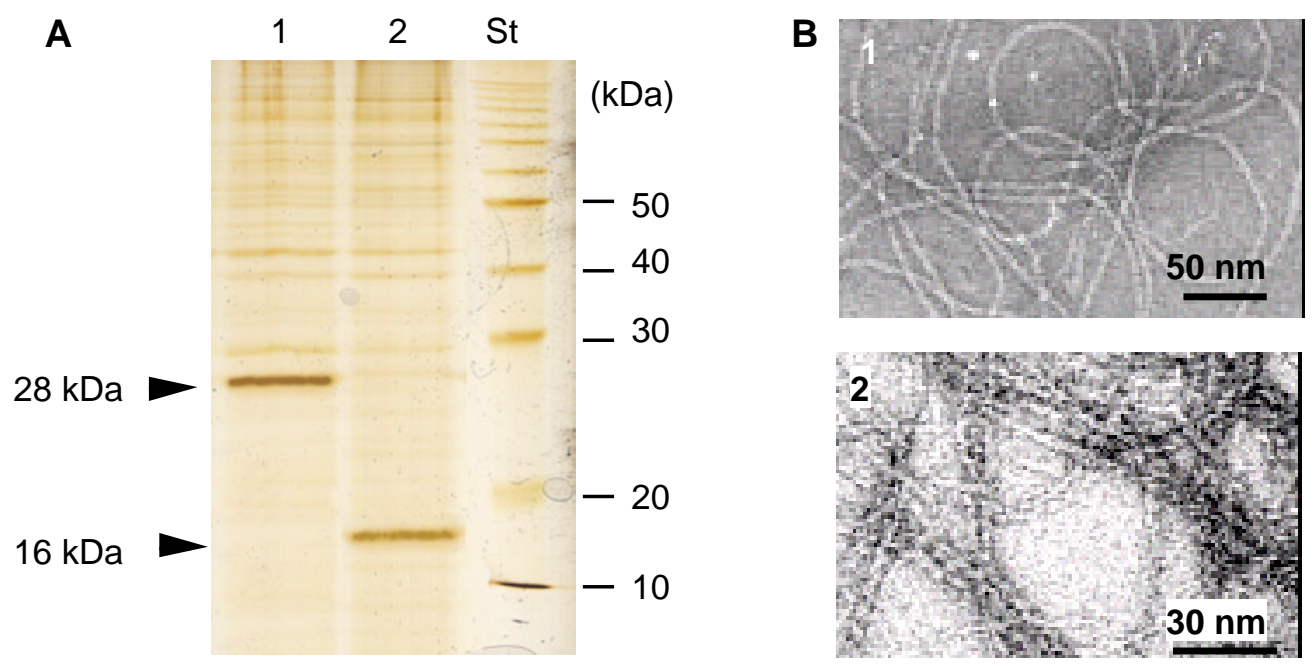

Abb. 3.27: Reinigung der Pilusstrukturen von Acinetobacter sp. BD413. (A) Auftrennung der mittels Saccharosegradienten-Zentrifugation aufgereinigten dicken und dünnen Pili in einem 15\%igen SDS-Gel. Die Untereinheiten des dicken Pilus bandierten bei $28 \mathrm{kDa}$ (Spur 1) und die der dünnen Pili bei $16 \mathrm{kDa}$ (Spur 2). (B) Elektronenmikroskopische Abbildung der gereinigten dicken (1) und dünnen (2) Pili.

Für die spätere N-terminale Ansequenzierung der Pilusuntereinheiten erfolgte eine Auftrennung der $28 \mathrm{kDa}$ und der $16 \mathrm{kDa}$-Untereinheit im 15\%igen SDS-Gel (Abb. 3.27, A). Die Proteine eines Gels wurden mit Coomassie angefärbt, die eines zweiten Gels auf eine PVDF-Membran geblottet. Vor der N-terminal en Sequenzierung wurden die Proteine einer Trypsinspaltung unterzogen, wobei mehrere Peptide entstanden und somit interne Sequenzen zugänglich waren (EdMAN \& BeGg 1967, PATTERSON 1994). Diese Arbeit wurde von Dr. J. Kellermann (MPI für Biochemie, Martinsried) freundlicherweise durchgeführt. Die $28 \mathrm{kDa}$-Untereinheit des dicken Pilus lieferte neben dem N-Terminus drei weitere interne Sequenzen (Abb. 3.28, A). 


\subsubsection{K lonierung der Pilusstrukturgene}

Für die spätere Charakterisierung und Unterbrechung des Strukturgens, welches für die 28 kDa-Untereinheit des dicken Pilus codiert, mußte das Gen isoliert und in einen Vektor kloniert werden. Umzunächst das entsprechende Gen an der chromosomalen DNA von Acinetobacter sp. BD413 zu ampl ifizieren (die chromosomal e Sequenz von BD413 lag zu diesem Zeitpunkt noch nicht vor), wurden gewobbelte Primer mit Hilfe der Aminosäure-Abfolge des N-Terminus (DNAG) und einer internen Sequenz (VEVAG) abgeleitet. Dabei wurde beachtet, daß Thymin/Guanin-Paarungen die Primeranlagerung nicht negativ beeinflussen (CRICK 1965). Der N-terminale Primer DICK-N2 besaß die Basenfolge 5'-GATAATGC(GT)GG(GT)AT(AT)-3` und der C-terminale Primer DICK-I3 die Basenfolge 5'-CC(GT)GC(GT)ACTTC(GT)CC-3`. An partiell Xbal-restriktionsverdauter chromosomaler BD413-DNA, in Anwesenheit von 2\% DMSO und $60 \mathrm{mM}$ TMAC (Trimethylammoniumacetat) konnte bei einer Primer-Anlagerungstemperatur von $42^{\circ} \mathrm{C}$, bei der die Primer an den Matrizenstrang anlagerten, ein Genfragment amplifiziert werden, welches eine Länge von ca. 680 bp aufwies. Nachdem dieses PCR-Produkt mit stumpfen Enden in die EcoRV-Schnittstelle von pBIISK kloniert worden war, woraus des Plasmid pBK01 resultierte, erfolgte eine Überprüfung des Inserts durch Sequenzierung.

Die erhal tene Basenabfolge wurde in die A minosäure-Sequenz übersetzt und mit den Aminosäure-Sequenzen verglichen, die aus den $\mathrm{N}$-terminalen Sequenzierungen der Trypsin-verdauten Pilusuntereinheit stammten. Angrenzend an die beginnende und endende Primersequenz waren die Aminosäure-Abfolgen zu finden, die identisch zu denjenigen waren, die durch die N-terminal e Sequenzierung gefunden worden waren (Abb. 3.28, B). Daneben waren zwei weitere aus der N-terminalen Sequenzierung bekannte Abfolgen von 17 bzw. 21 Aminosäuren zu finden, die hinter Trypsin-Spal tungsstellen lagen. Diese Übereinstimmungen zwischen der Sequenz des PCR-Produkts und derjenigen der Peptide (der N-terminalen Ansequenzierung) belegten, daß ein Fragment des Pilusgens kloniert worden war. 
A

$\mathrm{N}$-terminale Sequenz:

! DGLNIGIKLDNAGISIGKLY interne Sequenzen:

ETNPTEILSGLTLSLGK NNSAQNINTYIQGVHLGSSTA SIGDVEVAGLNVGNSTI

B

DNAGISIGKLYVHDNDGLGTDTNITGATG TAGAIAINGVTVKQTNTSENLLDL KIDTN GSATTSNGAQGA FLNIAATVGAVDIDI GSIGIGSSNTAVN TTTGLRGIK ETNPTEILSGLTLSLGKVAANIQ LGATPQGAMIVLNSTLQKGLTISNLGINDAA GGGQIYLDNIYVRGADNTTGDLTLN ATVGVTANGIVIKNNSAQNINTYIQGVHL GSSTAKSIGDVEVAGADN TTGDLTLN A T V G V T ANSAQQNNNMIQQG $\underline{\text { }}$ HLGSSTAKSIGDVEVAG

Abb. 3.28: N-terminale und interne Sequenzen sowie Aminosäuresequenz des über PCR amplifizierten Fragmentes der Untereinheit des dicken Pilus. (A) Die aufgereinigten Untereinheiten wurden für die $\mathrm{N}$-terminale Sequenzierung Trypsinverdaut, so daß neben dem $\mathrm{N}$-Terminus interne Sequenzen generiert werden konnten. (B) Mittels gewobbelter Primer wurde ein ca. 680 bp DNA-Fragment des Gens amplifiziert, welches für die Untereinheit des dicken Pilus codiert. Dieses Fragment (in seine Aminosäuresequenz übersetzt) enthält die ermittelten internen Sequenzen der Nterminalen Sequenzierung (unterstrichene Bereiche).

Während die N-terminale Sequenzierung mit vorangegangener Trypsin-Spaltung der Untereinheit des dicken Pilus insgesamt vier Sequenzen ergeben hatte, lieferte die TrypsinSpal tung der Untereinheit des dünnen Pilus zwei Proteinfragmente. Da der N-Terminus der Untereinheit für die N-terminale Sequenzierung nicht zugänglich war, konnte nur eine interne Sequenz von 16 Aminosäuren (GITLGGPTNSAQYVAG) generiert werden, was eine Amplifikation des Gens an der chromosomalen DNA von Acinetobacter sp. BD314 ausschloß. Mittlerweile lag die von INTEGRATEd GenOMICS (Inc., Chicago, USA) zur Verfügung gestellte vorläufige genomische Sequenz des Stammes BD413 vor, so daß das dünne Pilusgen anhand eines A bgleiches identifiziert werden konnte. Dies ermöglichte die Amplifikation des Gens, welches für die $16 \mathrm{kDa}$ Untereinheit des dünnen Pilus codiert, mit den Primern Dü-Pstl-N2B (5'-ATTAAATTGATCTGCAGCTAGTGATG-3') und DünnXbal-C (5'-ATGCGAGTATCTAGAATGCTG-3'). Dieses 690 bp-Genfragment wurde mit Pstl und Xbal in pBIISK kloniert werden, woraus das Plasmid pBN01 resultierte.

Diese ersten Untersuchungen führten zu der Klonierung von Genfragmenten von sowohl der Untereinheiten des dicken als auch des dünnen Pilus, so daß im Folgenden Pilus-Mutanten generiert werden konnten. 


\subsubsection{Unterbrechung der Pilusgene von Adinetobacter Sp. ADP239}

Durch die Generierung N-terminaler und interner Aminosäuresequenzen der strukturellen $28 \mathrm{kDa}$-Untereinheit des dicken Pilus, konnte ein Genfragment amplifiziert und in pBIISK kloniert werden, wonach das Plasmid pBKO1 resultierte (3.6.2). Um das Gen unterbrechen zu können, wurde das Genfragment in pBK01 mit einem KanamycinGen (nptI-Marker) unterbrochen, welches aus pUC4K stammte. Dafür wurde die mit PstI geschnittene Resistenz-Kassette mit Klenow-Fragment behandelt und mit glatten DNAEnden in die EcoRV-Schnittstelle des Inserts von pBK01 ligiert (Abb. 3.29). Die Kanamycin-Kassette befand sich nun in dem resultierenden Plasmid pBK03 zwischen 450 bp und 230 bp flankierender DNA, die aus Bereichen des Pilusgens bestanden. Das herausgeschnittene Insert, welches jetzt 1880 bp aufwies, diente der Mutagenisierung von Acinetobacter sp. ADP239 durch Rekombination des mutagenisierten Gens in des Genom, wozu die natürliche Transformation genutzt wurde. Die Mutante mit der Unterbrechung im Gen, welches für die Untereinheit des dicken Pilus codiert, wurde mit K101 bezeichnet.

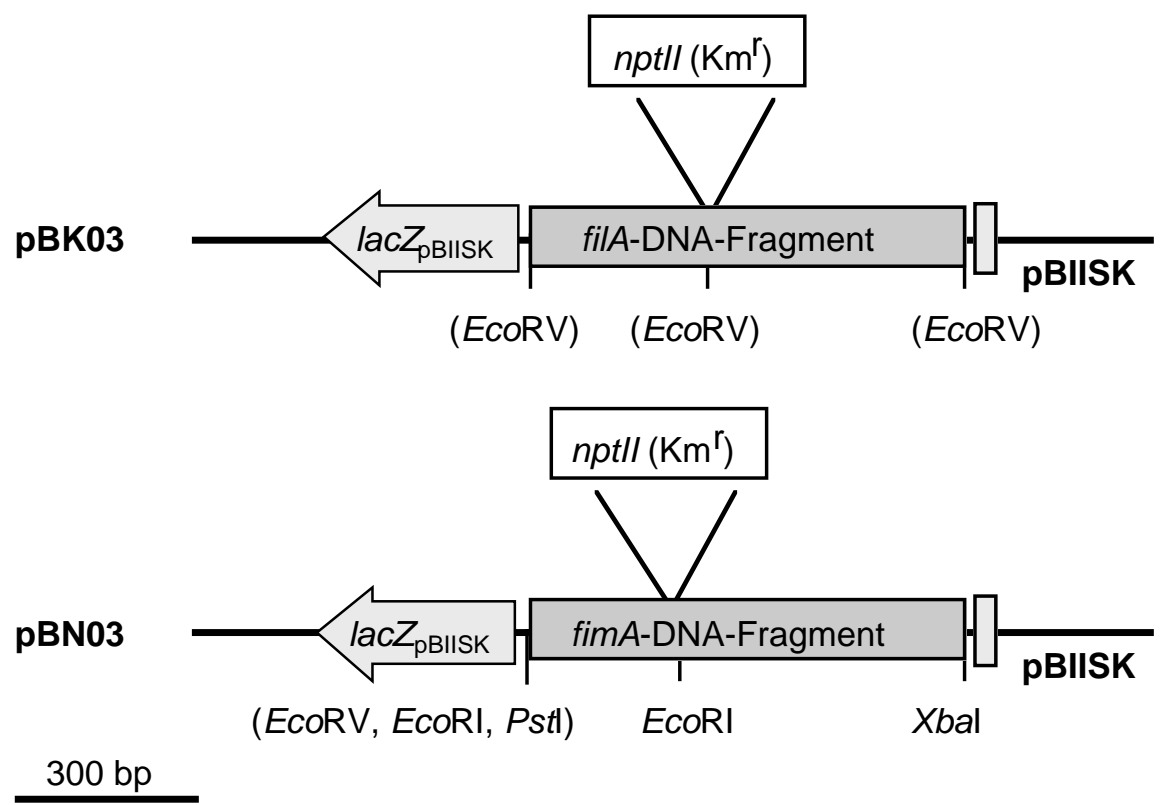

Abb. 3.29: Plasmidkonstruktionen für die Unterbrechung deı Pilusgene. DNA-Fragmente der Gene, die für die Untereinheit des dicken bzw. des dünnen Pilus codieren, wurden amplifiziert und in pBIISK kloniert, woraus die Plasmide pBK01 bzw. pBN02 resultierten. Das Resistenzgen wurde bei pBK01 in die EcoRV-Schnittstelle und bei pBN02 in die EcoRISchnittstelle ligiert, so daß pBK03 und PBN03 entstanden. Die in Klammern dargestellten Namen der Restriktionsschnittstellen könner aufgrund der Ligationen mit glatten DNA-Enden nicht mehr geschnitten werden. Es sind nur die für die Klonierungen relevanten Schnittstellen gezeigt. Die Resistenzgene (nptll) sind nicht maßstabsgetre wiedergegeben. Das lacZ-Gen von pBIISK gibt die Leserichtung des vektoreigenen Promotors an. filA bezeichnet das Gen für die Untereinheit des dicken Pilus und fimA das Gen für die Untereinheit den dünnen Pilus von Acinetobacter sp. BD413. 
Der Abgleich der internen Aminosäuresequenz der $16 \mathrm{kDa}$-Untereinheit des dünnen Pilus mit dem Genom von Acinetobacter sp. BD413 führte zu einem offenen Leserahmen (ORF), der mittels PCR amplifiziert und kloniert werden konnte, woraus das Plasmid pBN01 resultierte (3.6.2). Für die Unterbrechung des Inserts sollte seine EcoRISchnittstelle genutzt werden. Um zunächst die EcoRI-Schnittstelle in der MCS zu entfernen, mußste pBNO1 mit Pstl und EcoRV geschnitten und nach Klenow-Behandlung mit stumpfen Enden ligiert werden. In dieses modifizierte Plasmid pBN02, welches mit EcoRI linearisiert wurde, konnte die ebenfalls mit EcoRI geschnitteneK anamycin-Kassette (nptlI-Marker) aus pUC4K ligiert werden, was zu dem Vektor pBN03 führte (A bb. 3.29). Durch diese Insertion befand sich die Kanamycin-Kassette zwischen 180 bp und 510 bp flankierender DNA, die aus Bereichen des dünnen Pilusgen bestanden. Das herausgeschnittene Insert, welches jekt 1890 bp aufwies, diente der Mutagenisierung von Acinetobacter sp. ADP239, wozu die natürliche Transformation genutzt wurde. Die Mutante mit der Unterbrechung im Gen, welches für die Untereinheit des dünnen Pilus codiert, wurde N100 bezeichnet.

Die Überprüfung auf einmalige und richtige Integration des nptI I-Markers erfolgte durch SOUTHERN-Hybridisierung. Dazu wurde die chromosomale DNA des Stammes N100 mit Scal/EcoRV in einem Ansatz und mit Scal/Nhel in einem anderen verdaut. Die chromosomale DNA des Stammes K101 wurde mit EcoRI bzw. EcoRI/Sacl geschnitten. Die Restriktionsverdaue konnten danach elektrophoretisch aufgetrennt, geblottet und mit einer Kanamycin-Sonde die Laufhöhe der Resistenz-Marker sichtbar gemacht werden.

Abbildung 3.30 (A) zeigt für K101 die Anwesenheit des Resistenz-Markers in einem DNA-Fragment von 5,9 kb nach dem EcoRI-Verdau. Vor der Intergration des 1,2 kbMarkers lagen beide EcoRI-Schnittstellen 4,7 kb voneinander entfernt; nach der Unterbrechung des Gens, welches für die 28 kDa-Pilusuntereinheit codiert, vergrößerte sich der Abstand auf 5,9 kb. Der Doppelverdau mit EcoRI und Sacl lieferte weiterhin den Beweis, daß der integrierte Marker den Genbereich um 1,2 kb erweiterte: Nicht die ursprüngliche Basenzahl von 2,4 kb, sondern ein 3,6 kb-Fragment wurde detektiert (Abb. 3.30, A). Die Größendi fferenzen der detektierten DNA-Fragmenteentsprachen den Größen der Kanamycinkassette, d.h. daßs das mutagenisierte Gene homolog ins Genom rekombiniert wurde. 
A

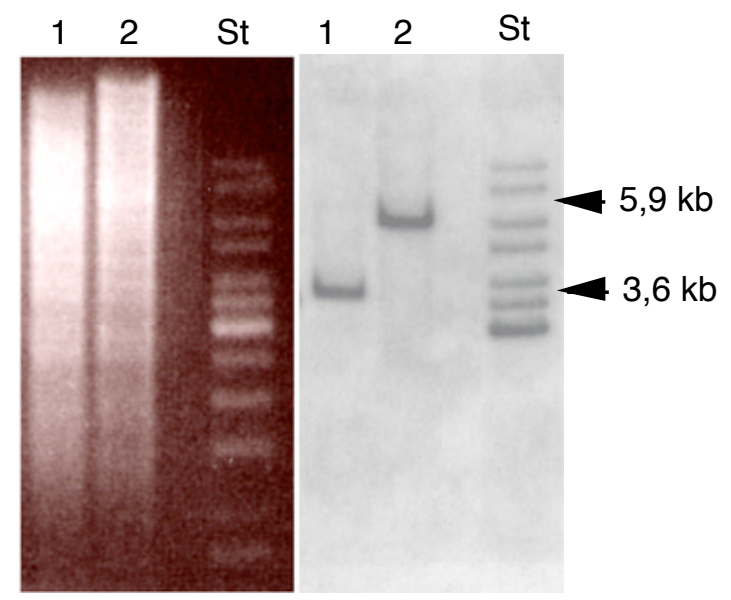

B

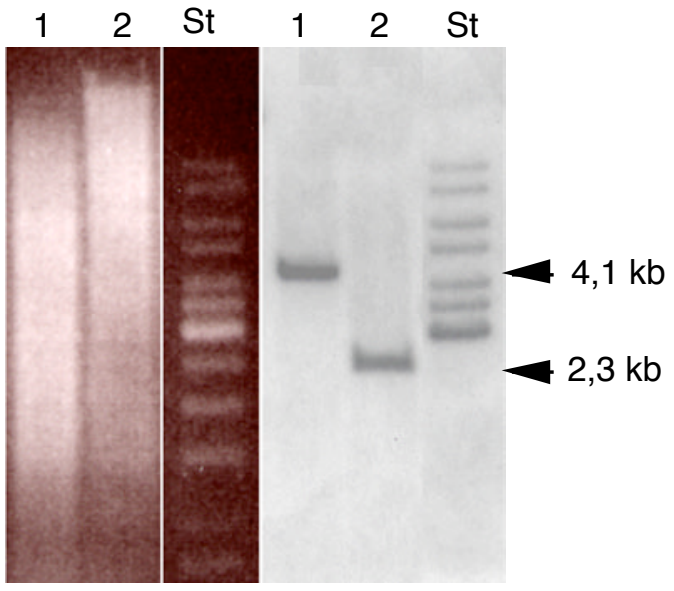

Abb. 3.30: Southern Hybridisierung restriktionsverdauter DNA gegen eine Kanamycin-Sonde. (A) Die isolierte chromosomale DNA von Acinetobacter K101 wurde mit EcoRl/Sacl (Spur 1) und EcoRI (Spur 2) geschnitten, im Agarosegel aufgetrennt und nach dem Blotten gegen eine Kanamycin-Sonde hybridisiert. (B) Die chromosomale DNA von Acinetobacter sp. N100 wurde mit Scal/EcoRV (Spur 1) und Scal/Nhel (Spur 2) geschnitten und das Kanamycin-Gen mit einer Sonde detektiert. Die Sonde hybridisierte unspezifisch mit der DNA des Größenstandards (St) im Bereich von 3-10 kb. Auf der linken Seite beider Abbildungen (A/B) ist das Ethidiumbromid-gefärbte Gel und auf der rechten der SOUTHERN Blot dargestellt.

In gleicher Weise wurde der durch die Restriktionsschnittstellen eingeschlossene Genbereich des Gens, welches für die 16 kDa-Untereinheit des dünnen Pilus codiert, um $1,2 \mathrm{~kb}$ vergrößert. Die Scal/EcoRV geschnittene chromosomale DNA lieferte ein Fragment von 4,1 kb (ursprünglich 2,9 kb), die Scal/Nhel geschnittene DNA ein Fragment von 2,3 kb (ursprünglich 1,1 kb) (Abb. 3.30, B).

Die Detektionen des nptI I-Markers indizierte die richtigen I ntegrationen des Markers in das Zielgen. Darüber hinaus lieferte die geschnittene chromosomale DNA nur ein Signal, was eine mehrfache (nicht-homologe) Rekombination ausschloß.

\subsubsection{Generierung einer Doppelmutante mit Defekten in den Unter einheiten der dicken und dünnen Pili}

Die alleinige morphologische Betrachtung von filamentösen Strukturen auf der Zelloberflächeläßst eine eindeutige Unterscheidung und Klassifizierung in Pilustypen nicht zu. Zum einen können Filamente gleicher Morphologie ebenso zu unterschiedlichen Pilustypen gehören oder andererseits homologe Strukturproteine Filamente unterschiedlichen Durchmessers bilden.

Acinetobacter sp. BD413 besitt zwei elektronenmikroskopisch unterscheidbare Pilusstrukturen von 2-3 nm und $6 \mathrm{~nm}$ im Durchmesser, die auf genetischer und 
molekularer Ebene nicht untersucht sind. Diese Filamente liegen in hoher Zahl vor, sind peritrich angeordnet und zum Teil zu Bündel aggregiert (PORSTENDÖRfER et al. 1997, 2000). Ein dritter Filamenttyp, der möglicherweise nur in geringer Zahl vorliegt und einen Durchmesser von 2-6 nm aufweist, könnte auf der Zelloberfläche übersehen werden. Um beweisen zu können, daß das Bakterium tatsächlich nur zwei Pilustypen synthetisiert, mußten die beiden Pilusgene unterbrochen werden. Sind danach noch Pili sichtbar, so gibt es möglicherweise einen dritten Typ, der an der Transformation beteiligt sein könnte.

Während für die Unterbrechung der Pilusgene mit dem 1,2 kb großen nptI-Marker flankierende chromosomale DNA von ca. 450 bp bzw. 230 bp ausreichten, wurde für die Unterbrechung des dicken Pilusgen mit der 2,0 kp Streptomycin-Kassette $\square$ zum einen ein größerer Bereich flankierender DNA (510 bp bzw. 450 bp) amplifiziert und zum anderen das betreffende Strukturgen um 830 bp deletiert. Die Primer DiDel-1-EcoRI (5`GTAGAATATTCAGAATTCTGAAAAATGATA-3') und DiDel-2-Xbal (5`-CCAA AGCCAATCTAGAGAATATTTTCATTC-3`) bzw. DiDel-3-Xbal (5`-AAATGTAG GTAACTCTAGATTACCATTAG-3') und DiDel-4-EcoRI (5`-CGTACAATTCCTC GGAATTCTTCCTCTATG-3') amplifizierten an der BD413-DNA die Bereiche, die stromaufwärts bzw. stromabwärts des dicken Pilusgen lagen. Diese beiden PCR-Produkte wurden mit EcoRI/Xbal jeweils in pUC18 kloniert (resultierende Plasmide pUK 12 bzw. pUK13, Abb. 3.31). In das pUC18-Derivat pUK12, welches den stromaufwärts liegenden Bereich enthielt, wurde daraufhin die mit EcoRV und Hincll geschnittene StreptomycinKassette aus pBS01 in die Hincll-Schnittstele (MCS) gesetzt, wonach pUK29 resultierte (Abb. 3.31). Dies führte dazu, daß das klonierte PCR-Produkt an seinem 3'-Ende von dem Streptomycin-Marker begrenzt wurde; nun mußte das zweite PCR-Produkt, welches kloniert in pUK13 vorlag, den Streptomycin-Marker zur anderen Seite begrenzen. Dies erfolgte, indem die Streptomycin-K assette zusammen mit dem klonierten PCR-Produkt aus pUK29 durch den Restriktionsverdau mit EcoRI und PstI herausgeschnitten, mit KlenowFragment die überhängenden Enden aufgefüllt wurden und das DNA-Fragment mit stumpfen DNA-Enden in die Hincl I-Schnittstelle (MCS) von pUK13 ligiert wurde. Daraus resultierte das Plasmid pUK 30 (Abb. 3.31).

Zur Transformation von Acinetobacter sp. N100, welcher bereits das durch den nptII-Marker unterbrochene Strukturgen der Untereinheit des dünnen Pilus trug, konnte die Streptomycin-Kassette mit flankierender DNA durch einen Verdau mit EcoRI und Pstl von Vektor-DNA befreit werden. 


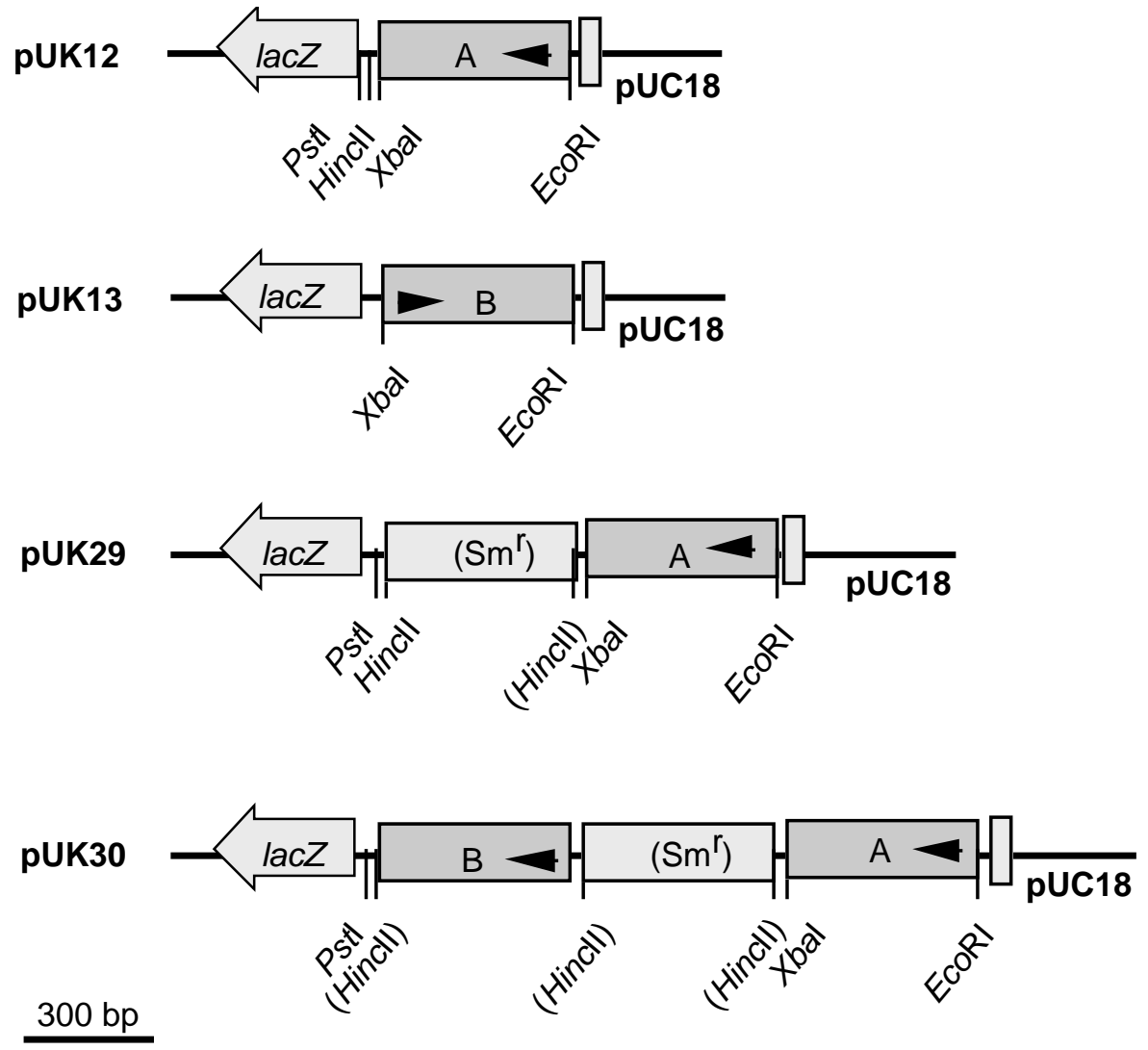

Abb. 3.31: Plasmidkonstruktionen für die Unterbrechung des Pilusgen filA der Untereinheit des dicken Pilus mit einem StreptomycinresistenzMarker. Die PCR-Produkte von DNA-Bereichen stromauf- (A) unc stromabwärts (B) des Gens, welches für die Untereinheit des dicken Pilus codiert, wurden jeweils in die Schnittstellen EcoRI und Xbal von pUC18 kloniert, woraus pUK12 bzw. pUK13 resultierten. In die Hincll-Schnittstelle von pUK12 wurde die Streptomycin-Kassette ligiert und daraufhin in das entstandene Plasmid pUK29 das Insert (B) aus pUK13 in richtiger Orientierung gesetzt. Daraus resultierte pUK30, in dem die DNA-Bereiche stromauf- und stromabwärts des Gens der Untereinheit des dicken Pilus durch das Resistenzgen unterbrochen sind. Die Pfeile markieren die Leserichtung des Pilusgens. Die in Klammern dargestellten Namen der Restriktionsschnittstellen können aufgrund der Ligationen mit glatten DNAEnden nicht mehr geschnitten werden. Der Streptomycin-Marker ist nicht maßstabsgetreu wiedergegeben. Das lacZ-Gen von pUC18 gibt die Leserichtung des vektoreigenen Promotors an.

Nach der Transformation des Inserts aus pUK30 in die Mutante N100, die bereits eine nptII-Insertion im Gen trägt, welches für die Untereinheit des dünnen Pilus codiert, lag im Chromosom der daraus resultierenden Mutante KN100 zusätzlich eine Deletion des Strukturgens, welches für die Untereinheit des dicken Pilusgen codiert, mit dem Streptomycin-Marker $\square$ vor.

Die Überprüfung der neu eingefügten Mutation durch den Streptomycin-Marker erfolgte mittels SOUTHERN-Blot. Dafür wurde die isolierte chromosomale DNA des 
Stammes KN100 zum einen mit EcoRI und zum anderen mit EcoRI und Sacl verdaut, im Agarosegel aufgetrennt, gebl ottet und gegen eine Streptomycin-Sonde detektiert. Durch die Hybridisierung wurde ein 3,6 kb-Fragment markiert, welches der EcoRI/SaclRestriktionsverdau lieferte (Abb. 3.32). In der chromosomalen DNA des Wildtyps ADP239 lagen diese beiden Schnittstellen 2,45 kb auseinander; unter Berücksichtigung der 0,83 kb-Deletion des dicken Pilusgen und nach der Unterbrechung mit der 2,0 kb Streptomycin-Kassette ergaben sich die detektierten 3,6 kb. Die relevanten EcoRISchnittstellen schlossen im Wildtyp BD413-Chromosom 4,56 kb ein. Nach der homologen Rekombination des Konstruktes, bei dem das dicke Pilusgen durch den StreptomycinMarker ersetzt worden war, rückten die EcoRI-Schnittstellen um weitere 1,17 bp auseinander, so daß auf dem SOUTHERN Blot eine Bande von 5,7 kb detektiert wurde (Abb. 3.32, Spur 2).

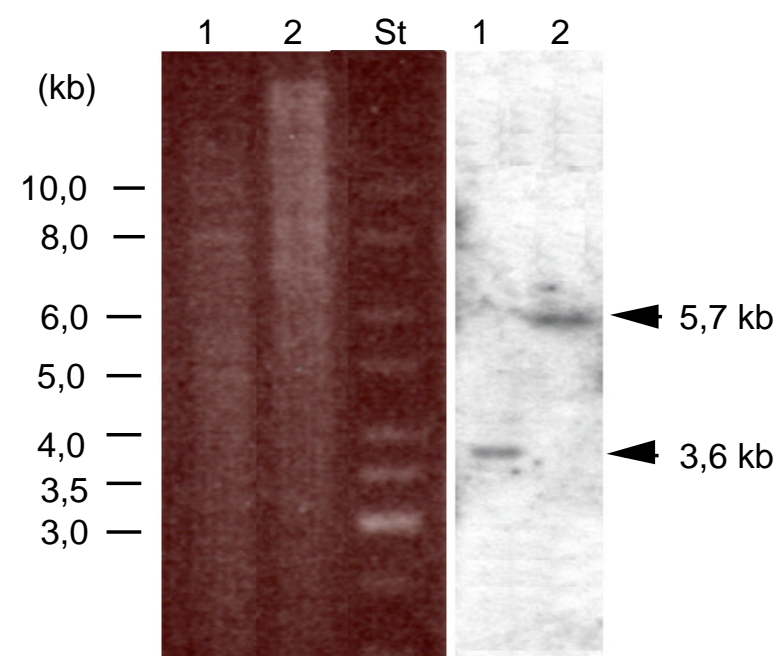

Abb. 3.32: SOUthern Blot der Pilusdoppelmutante KN100. Die chromosomale DNA von Acinetobactei KN100 wurde mit EcoRI/Sacl (Spur 1) und EcoRI (Spur 2) geschnitten. Nach der Auftrennung in einem 0,8\%igen Agarosegel und dem Blotten erfolgte die Hybridisierung gegen einer Streptomycin-Sonde. Links ist das Ethidiumbromid-gefärbte $\mathrm{Gel}$ und rechts der Blo dargestellt.

Die Detektion der Streptomycin-Kassette in restriktionsverdauter chromosomaler DNA nach der Auftrennung im Agarose-Gel auf derjenigen Laufhöhe, die mit der theoretisch ermittelten DNA-Fragmentlänge übereinstimmte bestätigte die richtige homologe Rekombination ins Zielgen. 


\subsubsection{Untersuchung der Zelloberfläche nach Unterbrechung der Pilusgene}

Nach der Isolierung der beiden Pilusstrukturen von Acinetobacter sp. BD413 und Nterminaler Sequenzierung der Untereinheiten konnten die Gene der Strukturproteine identifiziert und daraufhin unterbrochen werden. Die Überprüfung der Mutanten-Stämme N100 (nptI-Insertion im Gen der Untereinheit des dünnen Pilus), K101 (nptI I-Insertion im Gen der Untereinheit des dicken Pilus) und KN100 (Unterbrechungen in beiden Strukturgenen) hinsichtlich ihrer Pilusbiogenese erfolgte auf morphologischer Ebene mit Hilfe der Elektronenmikroskopie und proteinchemisch durch Auftrennung der Scherfraktionen in einer SDS-PAGE.

Für die Negativkontrastierung mit 4\% Uranylacetat wurden die Zellen in $3 \mathrm{ml}$ Succinat-Mineral medium über Nacht angezogen, zentrifugiert und in $2 \mathrm{ml}$ PhosphatSaline-Puffer (PBS) resuspendiert. Eine 3 I-Übernacht-Kultur in einem Kluyverkolben diente zur Herstellung der Scherfraktion, was in „Material und Methoden“ ausführlich beschrieben ist. Nach der Zellernte erfolgte das Abscheren der Pili durch die 2malige Passage der Kultur durch eine Kanüle. Nach dem Abtrennen der Zellen durch niedertourige Zentrifugation sedimentierten in der Ultrazentrifuge bei 42000 Upm die abgescherten Pili zusammen mit weiteren Proteinaggregaten und Vesikeln. Eine hinreichende Aufreinigung der dünnen und dicken Pili erfolgte, indem das resuspendierte Sediment auf einen zweistufigen Saccharosegradient, bestehend aus 20\% und 60\% Saccharose, zentrifugiert wurde. Die Interphase zwischen 20\%iger und 60\%iger Saccharoselösung stellte die Pilusfraktion (beider Pilustypen) dar. Die Untersuchung dieser proteinhaltigen Phase bezüglich der Pilusstrukturen erfol gte in einem 15\%igen SDS-Gel, wel ches mit Sil bernitrat gefärbt wurde.

Nach Auftrennung der Pilusfraktion der Positivkontrolle ADP239 in der SDS-PAGE waren die Untereinheiten der dicken Pili bei $28 \mathrm{kDa}$ und die der dünnen Pili bei $16 \mathrm{kDa} z \mathrm{zu}$ erkennen (Abb. 3.33, A), was die inakte Pilussynthese beider Filamenttypen signal isierte. Die elektronenmikroskopische Abbildung 3.33 (B) bestätigte das Vorhandensein der beiden Pilustypen, da zum einen die dicken Pili mit einem Durchmesser von $6 \mathrm{~nm}$ und zum anderen die dünneren, zum Teil aggregierten Strukturen mit Durchmessern von 2-3 nm erkennbar waren. $90 \%$ der Zellen wiesen beide Pilustypen auf. 
A

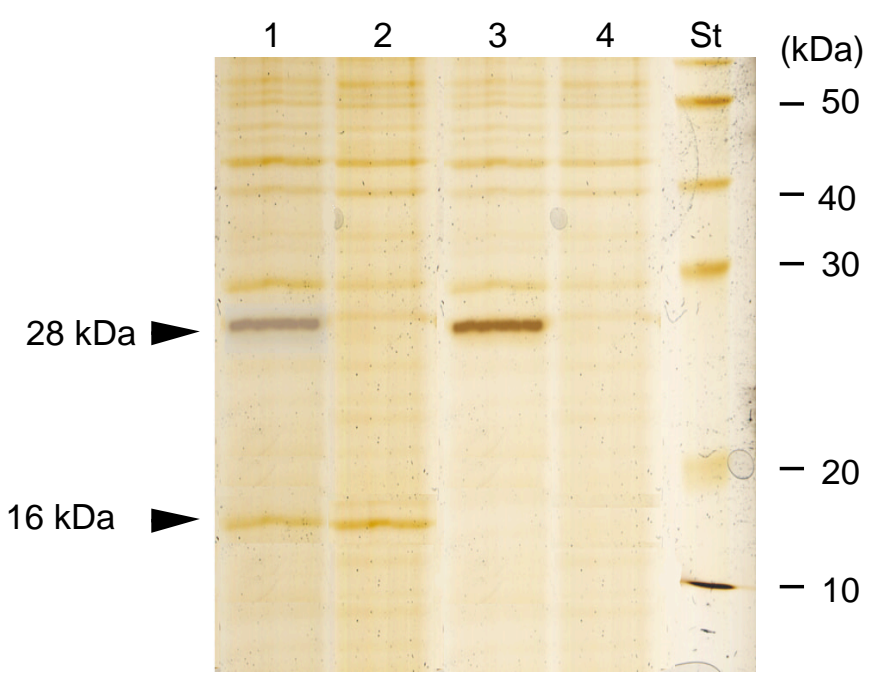

B
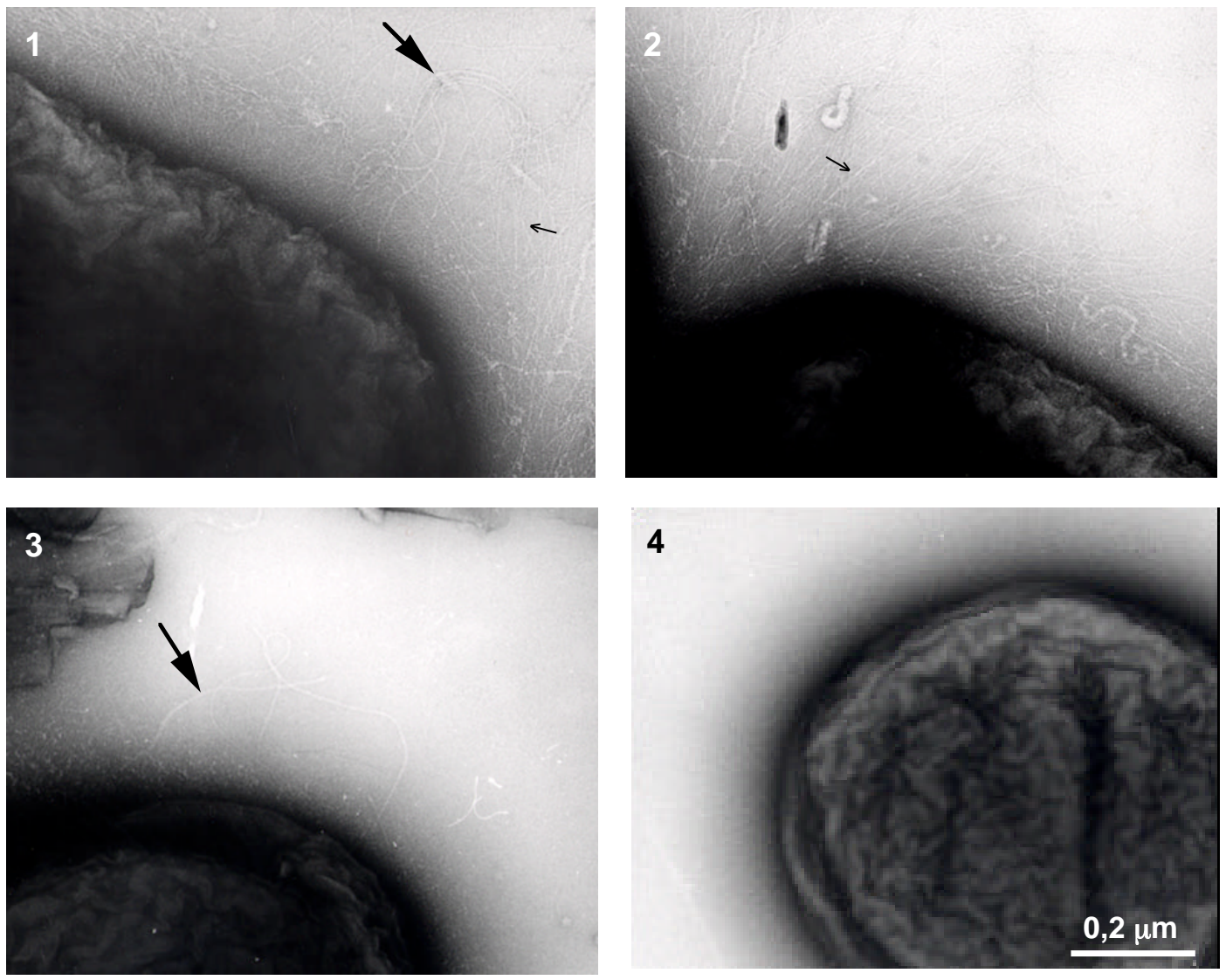

Abb. 3.33: Pilusbiogenese auf der Zelloberfläche von Acinetobacter-Stämmen. (A) Nach dem Abscheren der Pili von den Zelloberflächen wurden diese in Saccharosegradienten gereinigt und die Pilus-Fraktion im 15\% igen SDS-G el aufgetrennt. (B) Die Zellen wurden über Nacht in Mineralmedium angezogen, gewaschen und mit 4\% Uranylacetat negativ kontrastiert. (1) BD413; (2) K101; (3) N100; (4) KN100. Die ausgefüllten, großen $\mathrm{P}$ feilspitzen markieren dicke Pili und die kleineren P feile dünne Pili. 
Dem Stamm K101, der eine Unterbrechung im dicken Pilusgen trägt, fehl te die dicke Pilusstruktur und somit die 28 kDa-Bande im SDS-Gel (Abb. 3.33), was die Unterbrechung des Strukturgens indizierte. Hier war auf der Zelloberfläche ausschließlich der dünne Pilus-Typ zu sehen, wie in Abbildung 3.33 (B/2) exemplarisch gezeigt ist. Die erkennbare 16 kDa-Bande und die fehlende 28 kDa-Bande im SDS-Gel bestätigen diesen Pilus-Phänotyp. Umgekehrt verhielt es sich mit dem Stamm N100, der die nptl I-MarkerInsertion im Strukturgen der 16 kDaPilusuntereinheit trägt: Allein die dicken Pili wurden synthetisiert, deren Untereinheiten im SDS-Gel bei 28 kDa erkennbar waren; dünne Pili und die dazugehörige 16 kDa-Bande fehlten aufgrund der Unterbrechung des Strukturgens des dünnen Pilus (Abb. 3.33, B/3).

Dem Stamm KN100 fehl ten in der el ektronenmikroskopischen A bbildung sowohl die dicken als auch die dünnen Pili, was die Unterbrechungen der beiden Strukturgene widerspiegel te. Daß die Pili keinen Bestandteil der Scherfraktion darstelten, konnte durch die beiden fehlenden Banden bei 28 bzw. 16 kDa im SDS-Gel verifiziert werden (Abb. 3.33, A/4). Die morphologische Betrachtung der Zelloberfläche von KN100 ergab, daß diese Mutante mit Unterbrechungen beider Pilusstrukturgene weder dicke noch dünne Pili synthetisierte, was durch die fehlenden Pilusprotein-Banden in der SDS-PAGE bestätigt wurde. Die elektronenmikroskopische Betrachtung von jeweils ca. 50 Zellen des Stamms KN100, die unter verschiedenen Bedingungen (LB-/Mineralmedium, Flüssig-/AgarKulturen, Kluyverkolben) angezogen worden waren, versicherten weiterhin, daß Acinetobacter sp. BD41 keinen dritten Pilustyp synthetisiert.

Vor dem Hintergrund, daß über die N-terminale Ansequenzierung der gereinigten Strukturproteine pilusspezifische Basensequenzen generiert wurden, die zur I dentifizierung und Klonierung der jeweiligen Gene führten, und die Unterbrechungen der beiden Pilusstrukturgene die erwarteten Phänotypen erzeugten, kann eindeutig der Schl uß gezogen werden, daß es sich bei diesen Genen um die Gene der strukturellen Untereinheiten der dicken bzw. der dünnen Pili handelt.

\subsubsection{Physiologische Untersuchung der Pilus-M utanten}

Bei den bisher untersuchten natürlich kompetenten Bakterien sind die Komponenten der Typ-IV-Pilusbiogenese in die DNA-A ufnahme involviert. Darüber hinaus vermittelt dieser Pilustyp eine gleitende Fortbewegung ('Twitching Motility') auf festen feuchten Oberflächen. Da Acinetobacter sp. BD413 auf der Zelloberfläche Pili synthetisiert, sich gleitend fortbewegen kann und natürlich transformierbar ist, wurde das Vorhandensein von Typ-IV-Pili und die Beteiligung dieser filametösen Strukturen in die DNA-Aufnahme postuliert. Zur Klärung der Frage einer möglichen Involvierung der filamentösen 
Strukturen von BD413 in die Transformation oder in die gleitende Bewegung sollten die Stämme K101 und N100, mit Unterbrechungen in den Genen für die Untereinheit der dicken bzw. der dünnen Pili und der Stamm KN100, der Unterbrechungen in beiden Strukturgenen trägt, diesbezüglich untersucht werden.

\subsubsection{T ransformationstest der Pilus-M utanten}

Der Test auf natürliche Transformationsfähigkeit erfolgte über den in „Material und Methoden“ beschriebenen Transformationsschnelltest. Abbildung 3.34 zeigt die pHydroxybenzoat-Agarpl atte mit den linear ausgestrichenen Stämmen.

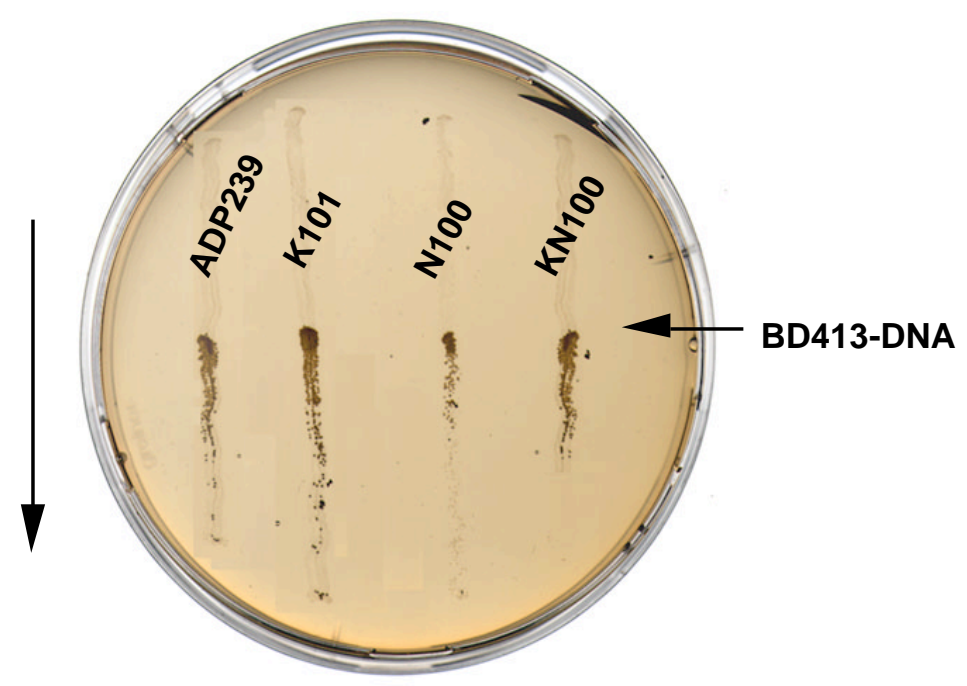

Abb. 3.34: Transformationstest der Pilus-MutantenStämme K101, N100 und KN100. Da die Unterbrechung der Pilusgene in der pobA-Mutante Acinetobacter sp. BD413 durchgeführt worden war, konnte die Transformation über den Schnelltest durch Wachstum auf $p$-Hydroxybenzoat überprüft werden. Nach dem Passieren der Impföse durch einen Tropfen chromosomale DNA von Acinetobacter sk findet bei der Fähigkeit zur natürlichen Transformatior Wachstum statt. Der senkrechte P feil markiert die Richtung des Ausstrichs.

Der erste Strich repräsentiert die PositivkontrolleADP239, dievor dem Passieren der BD413-DNA keine Koloniebildung aufwies, nach dem Benezen mit DNA aufgrund natürlicher Transformationsfähigkeit die Verwertung der vorliegenden Kohlenstoff-Quelle regenerierte Die parallel angeordneten Pilus-defekten Stämme K101, N100 und KN100 zeigten bezüglich ADP239 ein identisches Bild, was die Fähigkeit zur natürlichen Transformation indizierte (Abb. 3.34). Demnach konnte eine essentielle Funktion der 
Pilusstrukturen von Acinetobacter sp. BD413 bei der natürlichen Transformation ausgeschlossen werden.

Dieses Ergebnis läßt den eindeutigen Schl uß zu, daß die dicken und dünnen Pili von Acinetobacter sp. BD413 nicht an der natürlichen Transformation beteiligt sind.

\subsubsection{Test auf gleitende B ewegung der Pilus-M utanten}

Die Untersuchung der gleitenden Fortbewegung der verschiedenen Pilusmutanten K101 (defekt in der Synthese dicker Pili), N100 (defekt in der Synthese dünner Pili) und KN100 (Pilusdoppelmutante) verglichen zum Wildtypstamm ADP239 erfolgte über die Morphologie der über Nacht bei hoher Luftfeuchtigkeit gewachsenen Kolonien auf frisch gegossenen Succinat-Mineral medium-A garplatten bzw. LB-Platten. Die Zellen in dem auf die Agarplatte aufgesetzten 0,5 ㄱ Kulturtropfen vermehrten sich in dieser Zeit und bil deten danach Koloniedurchmesser von ca. 4 cm (Abb. 3.35).

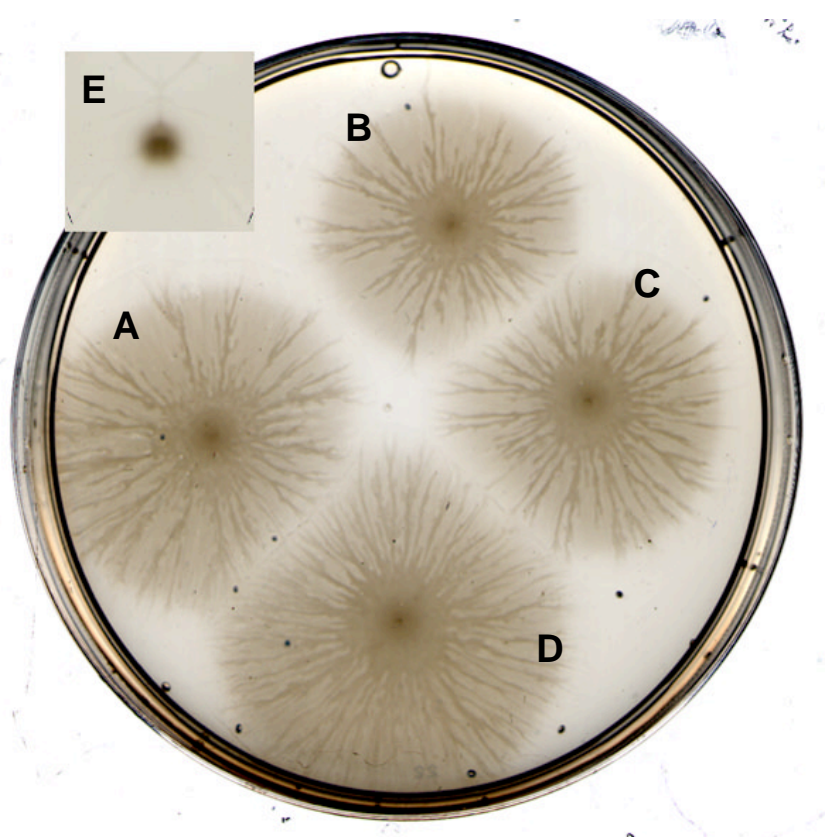

Abb. 3.35: Gleitende Bewegung von Acinetobacter. 0,5 $\square$ Zellsuspension einer in LB-Medium angezogenen Kultur wurde auf eine frisch gegossene Agarplatte gegeben und über Nacht unter feuchter Atmosphäre inkubiert. (A) ADP239; (B) K101 (filA-Mutante); (C) N100 (fimA-Mutante);

(D) KN100 (filA-/fimA-Doppelmutante); (E) E. coli DH5a

Sowohl nach der Inkubation der Zellen auf LB-Medium als auch auf Mineral medium zeigten sich ähnliche Kulturdurchmesser und -morphologien. Dabe handelte es sich um flach auslaufende rundliche Gebilde mit der höchsten Erhebung im Zentrum, wobei die 
Ränder weit und leicht gelappt ausliefen. In radialer Richtung bildeten sich beim Wachstum rippenartige Erhebungen. Im Gegensatz zu den Acinetobacter-Stämmen wuchsen E. coli-Zellen, die sich auf Agarplatten nicht fortbewegen können und somit als Negativkontrolle dienten, zu einer halbrund nach oben gewölbten Kolonie heran. Der Durchmesser dieser Kolonie betrug hierbei 0,5 cm (Abb. 3.35, E).

Der 'Twitching'-Test verdeutlichte, daß das Fehlen der dicken bzw. der dünnen Pili bei den Stämmen K101 bzw. N100 und das Fehlen beider Filamentstrukturen bei der Mutante KN100 nicht zu einer veränderten Koloniemorphologie führte. Aus diesem Grund muß das Gleiten von Acinetobacter sp. BD413 Pilus-unabhängig erfolgen.

Daß die Ausbildung der flachen, breit auslaufenden Kolonien auf aktives Gleiten zurückzuführen war und nicht auf oberflächenbedingte Abstoßungsreaktionen der Bakterien beruhte, wurde daraufhin lichtmikroskopisch überprüft. Anstelle der Agarplatten dienten hierbei mit Mineral medium beschichtete Objektträger, die mit 0,5 $\square$ l der jeweiligen Zellsuspensionen punktiert über Nacht bei hoher Luftfeuchtigkeit in Petrischalen inkubiert wurden. Bé Vergrößerungen von 100 und 400 zeigte sich der wellenförmige Vorschub der Zellfront, zuäußerst bestehend aus einer Zellage, dem nachfolgend Richtung Zentrum stufenartig weitere Zellebenen aufgelagert waren (Abb. 3.36, A/1). Bemerkenswert dabei ist, daß sich eine geschlossene einzellige Lage auf einen weiten Bereich von bis zu 100 200 - $m$ m erstreckte. Da auch hier die Koloniemorphologie der Pilusmutanten K101, N100 und KN100 - wie die makroskopische Betrachtung bereits indiziert hatte - verglichen zum Wildtypstamm ADP239 keine Unterschiede aufwiesen, sind im Folgenden die Abbildungen des Wildtyps und der Pilusdoppelmutante KN100 exemplarisch gezeigt.

Die Kolonieränder der Stämme ADP239 und KN100 wiesen zwar vom Zellverband abgetrennte Zellgruppen und vereinzelte Bakterien auf, doch lagen diese relativ dicht, so daß sich nach weiteren Zellteilungen unter dem Vorschub der geschlossenen EinzelzellLage die erwähnten rund-gelappten Randbereiche ergaben und sich keine weit abwandernden Tochterkolonieren bildeten (Abb. 3.36, A/1). Während demzufolge am Rand der Kolonie Wachstum und gleitende Fortbewegung auf der Agaroberfläche zu finden waren, wuchsen die Zellen zur Mitte hin zunehmend in die Höhe. Dabei ist nicht auszuschließen, daß die Bakterien in den oberen Zellagen ebenso gleitende Bewegungen ausführten. Der unbewegliche Stamm E. coli wuchs dagegen als runde Zellaggregation, in welcher der Randbereich ausschließlich durch Zellteilung und Wachstum eine Ausdehnung erfuhr (Abb. 3.36, A/3). Hier waren keine Bakterien außerhalb dieser Randlinie und keine geordnete Zellschichtung zu erkennen. 
A
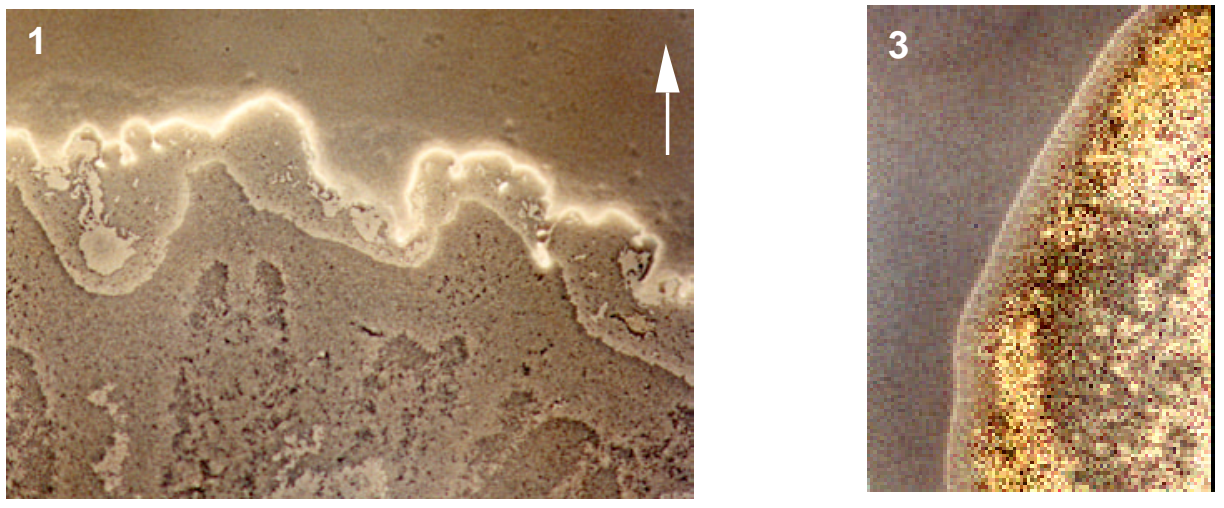

$100 \square \mathrm{m}$

$\underline{50 \square \mathrm{m}}$

B
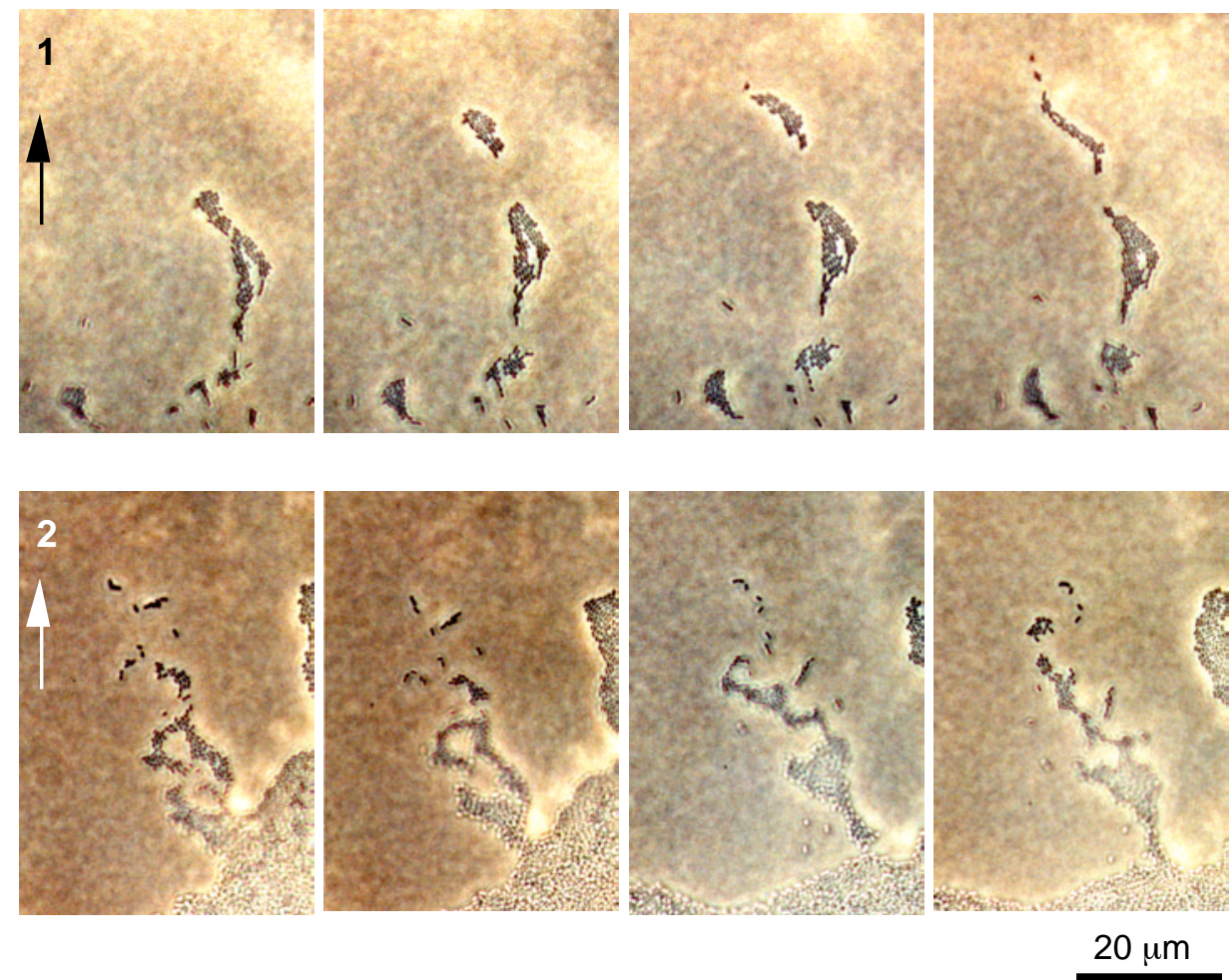

Abb. 3.36: Lichtmikroskopische Darstellung der gleitenden Bewegung von Acinetobacter. (A) Nach dem Wachstum von Acinetobacter sp. ADP 239 (1) und E. coli DH5a (3) auf frisch gegossenen Agarplatten unter feuchter Atmosphäre sind die Kolonieränder dargestellt. (B) Die Bildserie zeigt die gleitende Bewegung von ADP239 (1) und der Pilusdoppelmutante KN100 (2). Die Fotos wurden in 8 minütigen Intervallen geschossen. Die Pfeile markieren die Richtung der gleitenden Bewegung.

Die sich am Rand der Kolonie teilenden Zellen des Stammes ADP239 bildeten zunächst eine Zellgruppierung von ca. 20 Bakterien, die sich daraufhin vom Kolonierand entfernten und schließlich eine langgestreckte Linie bildeten. Während dieses Gleitens fand in dem beobachteten Zeitraum von 24 min keine weitere Zel Iteilung statt. In ähnlicher Weise bewegten sich die Zellen des Stammes KN100 vom Rand der Kolonie in Richtung 
der nicht bewachsenen Agarfläche. Nach Zellteilungen fand eine Streckung des Zellaggregates statt, wobei sich auch hier der Zellverband nicht auflöste, sondern die Bakterien in Kontakt miteinander blieben. Unter Berücksichtigung, daß die Bilderfolgen in einem Abstand von 8 min aufgenommen wurden, konnte eine Geschwindigkeit der gleitenden Bewegung von 2-3 $\square \mathrm{m} /$ min kalkuliert werden (A bb. 3.36, B).

Die lichtmikroskopische Betrachtung von Einzelzellverbänden verdeutlichte, daß die gleitende Bewegung von Acinetobacter sp. BD413 einen aktiven Prozeß darstellte und nicht allein auf Wachstum und Zel Iteilungen mit anschließender horizontal er Verschiebung der Bakterien untereinander beruhte. Weiterhin erfolgte das Gleiten unabhängig der dicken und dünnen Pili, so daß hier eine pilusunabhängige Fortbewegung vorliegen mußte.

\subsubsection{M olekulare $\mathrm{C}$ harakterisier ung des dicken Pilus}

Die Unterbrechung des Strukturgens, welches für die Untereinheit des dicken Pilus codiert, resultierte in dem Stamm K101, der keine dicken Pili auf der Zelloberfläche synthetisiert und verglichen zum Wildtyp-Stamm eine unveränderte Fähigkeit zur natürlichen Transformation und zur gleitenden Bewegung aufweist (3.6.6.1/3.6.6.2). Um die vollständige Sequenz des Pilus-Strukturgens zu erhalten (die genomische Sequenz von BD413 lag zu dieser Zeit noch nicht vor), sollte zunächst der Mutationsort aus der chromosomalen DNA des Stamms K101 und anschließend nach einer neuen nptIIInsertion in das benachbarte Gen schließlich das Wildtypalle kloniert werden. Für eine weitere Charakterisierung des dicken Pilus sollte die genomische Lokalisation des Strukturgens und die Involvierung benachbarter Gene in die Pilusbiogenese untersucht werden.

\subsubsection{Untersuchung der A minosäuresequenz und $Q$ uartärstruktur der 28 kDa-Untereinheit des dicken Pilus}

Für einen Datenbankabgleich der Pilusuntereinheit mit bereits seqenzierten Genomen von Mikroorganismen und für Untersuchungen der Primärstruktur des Proteins wurde zunächst der Mutationsort von Acinetobacter sp. K101 kloniert und der DNA-Bereich, der den nptI-Marker flankiert, sequenziert.

Nach dem Restriktionsverdau der isolierten chromosomal en DNA von Acinetobacter sp. K101 mit Sacl und Xbal und der Ligation in den ebenso geschnittenen Vektor pGEM$7 f(+)$ konnte ein ca. 11 kb-Fragment, welches den Kanamycin-Marker besaß, kloniert werden. Durch die Sequenzierung des die Resistenzkassette flankierenden DNA-Bereichs in dem resultierenden Plasmid pGK 03 lag das dicke Pilusgen in seiner Sequenz vol Iständig 
vor. Das Gen bestand aus 244 A minosäuren (864 bp), was einer errechneten molekulare Masse von 28,9 kDa entsprach. Da die N-terminale Aminosäuresequenz des prozessierten Proteins bestimmt worden war (3.6.1), mußte ein Leaderpeptid mit einer molekularen Masse von 3,8 kDa (36 Aminosäuren) vorgelegen haben. Daraufhin besaß das prozessierte Protein eine errechnete molekulare Masse von 25,1 kDa, was mit der über die SDS-PAGE bestimmten Masse von 28 kDa in der gleiche Größenordnugn lag. Der N-Terminus des Präproteins war vorwiegend aus hydrophoben Aminosäuren aufgebaut, wobei für Leadersequenzen in charakteristischer Weise direkt am N-Terminus an 2. und 6. Position die basische Aminosäure Lysin stand. Die Prozessierungsstelle (-5ATTGQ ${ }^{\square} \mathrm{DG}_{+2}$ ) wies weiterhin die für Signal sequenzen charakteristischen Aminosäuren Alanin, Serin und Glycin auf (MARTOGLIO \& DOBBERSTEIN 1998).

Das Hydrophobizitätsdiagramm der Untereinheit des dicken Pilus zeigte jeweils zwei hydrophile und hydrophobe Bereiche, die sich alternierend zusammensetzten, wobei der überwiegende Anteil der Aminosäuren einen hydrophoben Charakter aufweist (Abb. 3.37). Da die dicken Pili von BD413 einen hydrophilen Charakter besitzen (3.6.1/3.6.10), sind vermutlich die gel adenen und polaren A minosäure-Reste exponiert und die unpolaren zum Zentrum der Pilusstruktur gerichtet. Diese Verteilung der Polaritäten konnte für die Typ-Iund Typ-IV-Pili gezeigt wurde, die in helikaler Anordnung assembliert werden und in der Kernregion durch hydrophobe Wechsel wirkungen Stabilität erlangen (FOREST \& TAINER 1997, FERNÁNDEZ \& BERENGUER 2000).

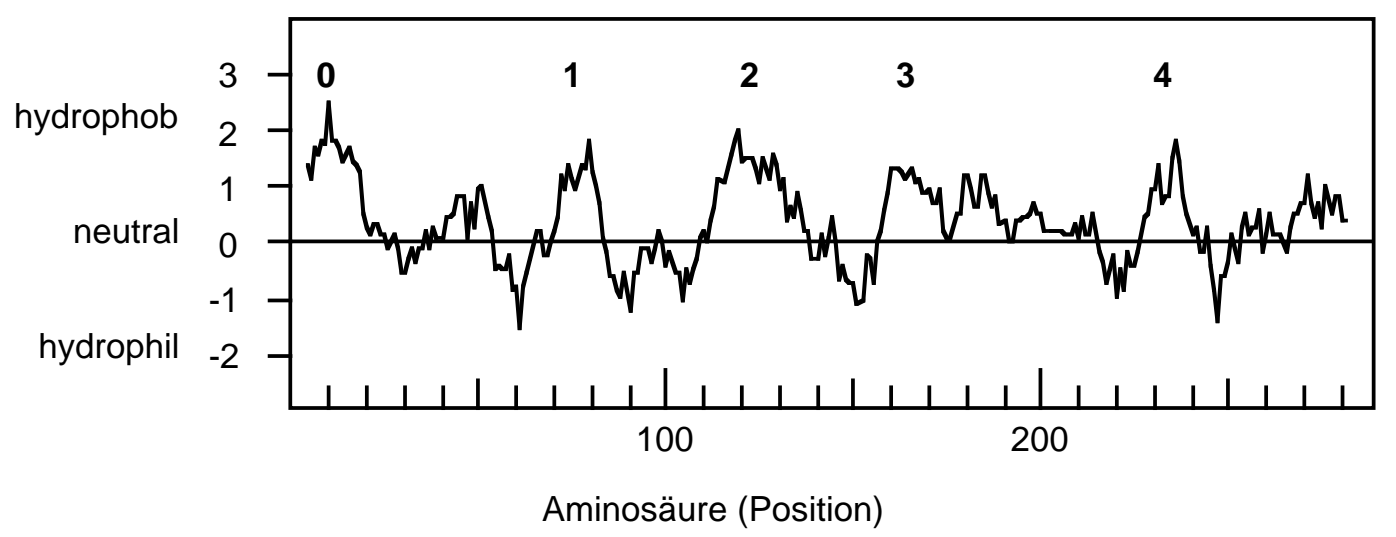

Abb. 3.37: Hydrophobizitätsdiagramm der Untereinheit FilA des dicken Pilus nach KYTE \& DoolitTLE (1982). Die Ordinate gibt die relative Hydrophobizität wieder. Positive Werte geben hydrophobe und negative Werte hydrophile Bereiche an. Die Abszisse zeigt die Position der Aminosäure ausgehend vom N-Terminus an. Die mit Ziffern (0-4) markierten Bereiche zeigen hydrophobe Proteindomänen an, wobei die Domäne, die mit Ziffer 0 versehen ist, die Signalsequenz darstellt. 
Daß der dicke Pilus dem allgemeinen Bauprinzip stabiler Filamente als helikale Struktur fol gt, konnten elektronenmikroskopische Darstel lungen belegen. Der $6 \mathrm{~nm}$ breite Pilus zeigte eine helikale Anordnung der Untereinheiten, wobei die Steighöhe jeder Umdrehung 4-5 nm beträgt (Abb. 3.38). Die hohe Auflösung verdeutlichte vereinzelt Bereiche in der Pilusstruktur, die schmaler erschienen als $6 \mathrm{~nm}$ In diesen Bereichen liegt die Pilus-Spirale in gestreckter Form vor, wobei die Höhe einer Umdrehung ca. 10 nm beträgt

A

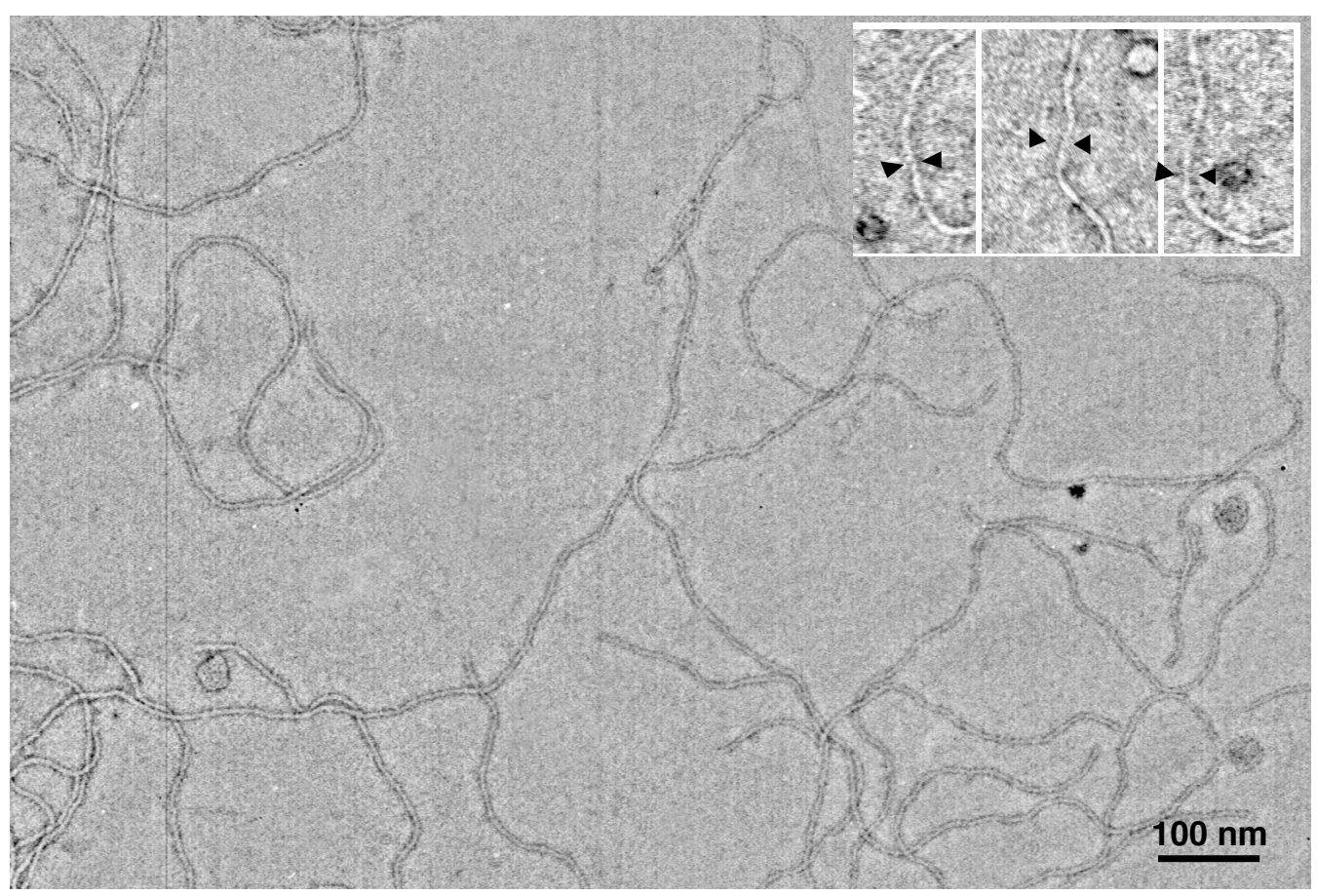

B

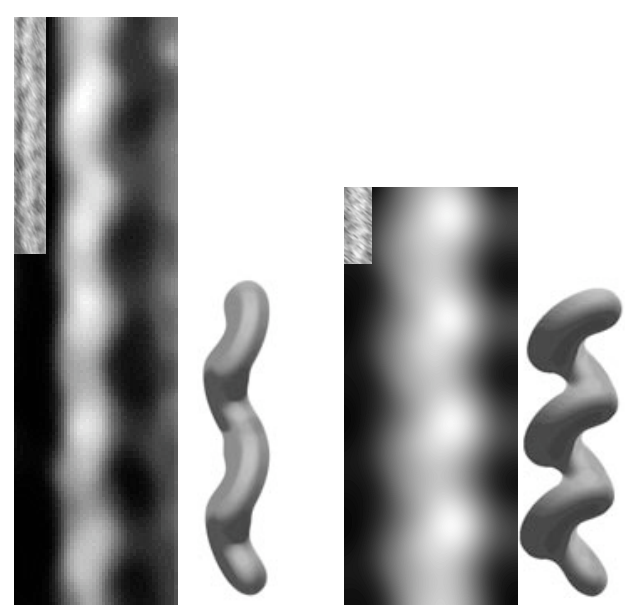

Abb. 3.38: Struktur der dicken Pili von Acinetobacter sp. BD413. Dit dicken Pili, die einen Durchmesser von $6 \mathrm{~nm}$ und eine helikale Untereinheitenstruktur aufweisen, zeigen ir einigen Bereichen eine gestreckte Helix mit einem Durchmesser von $4 \mathrm{~nm}$. In Abbildung (A) ist die elektronenmikroskopische Darstellung der Pili zu sehen, wobei die Bildfolge oben rechts auf die gestreckte Helix verweist (durch Pfeile markiert). In Abbildung (B) ist die gestreckte (links) und gestaucht (rechts) Helixstruktur schematisc wiedergegeben. 
Der Datenbankabgleich der Aminosäuresequenz der Untereinheit des dicken Pilus ergab keine signifikante Ähnlichkeit zu bekannten Proteinen oder uncharakterisierten hypothetischen Proteinen bereits sequenzierter Organismen. Weiterhin weisen A bschnitte des Proteins keine charakteristischen Sequenzen bekannter Domänen auf. Eine Verwandtschaft zu bekannten Pilusuntereinheiten konnte somit ausgeschlossen werden. Die strukturelleUntereinheit des dicken Pilus wurde daraufhin FilA genannt.

Da die strukturellen Untereinheiten von Pili im allgemeinen eine hohe Aminosäuresequenz-Variabilität auszeichnet, kann der dicke Pilus von Acinetobacter $\mathrm{sp}$. BD413 erst durch die Untersuchung seiner genomischen Lokalisation und des Pilusbiogenese-Wegs einem bekannten Typ oder einem neuen Pilustyp zugeordnet werden.

\subsubsection{Analyse des filA-L okus}

Da in Prokaryonten vielfach Gene dersel ben Biosyntheseeinheit geclustert oder in einem Operon vorliegen, lassen sich oftmals durch Vergleiche noch nicht untersuchter Gencluster Zusammenhänge zu bereits untersuchten Transkriptionseinheiten finden, die bei der Betrachtung eines einzelnen Gens nicht in Erscheinung treten. Da die in dieser Arbeit identifizierte Untereinheit FilA des dicken Pilus keine Ähnlichkeit zu bekannten Strukturproteinen aufwies, sollte die Untersuchung benachbarter ORFs, die Assemblierungfaktoren darstellen könnten, mögliche Hinweise auf eine Verwandtschaft zu einer bekannten Pilusklasse liefern oder im Falle von Biosynthesefaktoren, die keine Ähnlickeit zu bereits identifizierten Assemblierungsproteinen aufweisen, einen neuen Pilustyp bestätigen.

Das Strukturgen filA bildet das erste Gen in einem potentiellen Cluster von insgesamt sechs ORFs gleicher Leserichtung (A bb. 3.39). Die abgel eitete A minosäure-Sequenz drei der stromabwärts lokalisierten ORFs weisen Ähnlichkeiten zu hypothetischen Proteinen auf, die ihrerseits aufgrund von Ähnlichkeiten zu hypothetischen Proteinen annotiert wurden. Diesen Annotationen liegt demnach keine proteinchemische Charakterisierung zugrunde, so daß die Zuordnung einer Funktion aufgrund von hypothetischen Proteinen, denen eine potentielle Funktion zugeschrieben wurde, fraglich erscheint. Aus diesem Grund sind in der fol genden Beschreibung die Ähnlichkeiten zu hypothetischen Proteinen erwähnt, doch lassen diese Ähnlichkeiten keinen Schluß hinsichtlich ihrer Funktion zu, da dieAnnotation der ähnlichen Proteine nicht experimentel überprüft worden sind. 
A

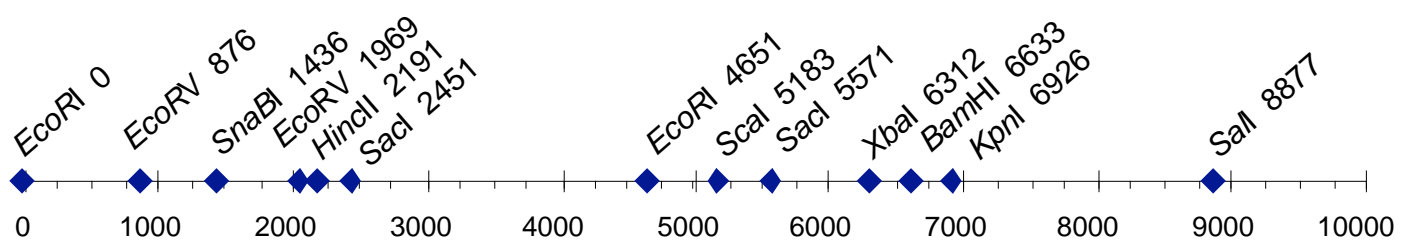

B

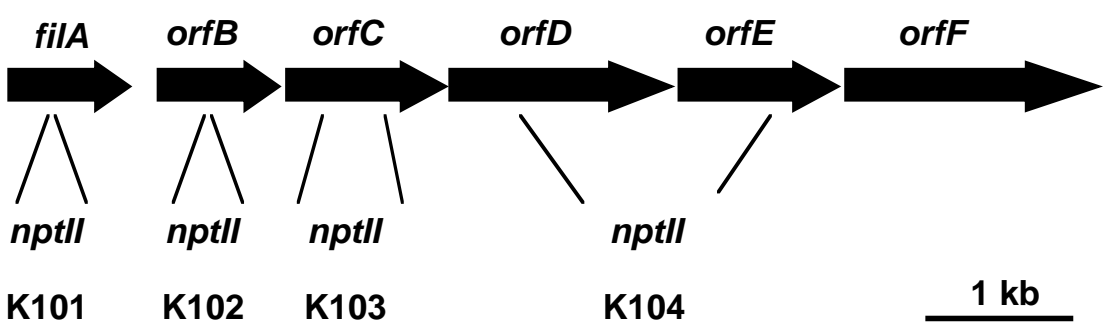

Abb. 3.39: Organisation des fil-Genclusters. filA bildet das erste $G$ en in einem Cluster mit insgesamt 6 ORFs gleicher Leserichtung. (A) Relevante Restriktionsschnittstellen sind auf der Skala markiert, die die Basen-P osition angibt. (B) Die Mutanten-Stämme K101 und K102 tragen Unterbrechungen in filA bzw. orfB. Im Chromosom der Stämme K103 und K103 wurden orfC bzw. orfD/orfE durch den nptllMarker deletiert.

Der zweite ORF des potentiellen fil-Clusters, orfB, zeigt Ähnlichkeiten zu hypothetischen ATP-bindenden Komponenten von ABC-Transportern oder hypothetischen Bacteriocin-Resistenz-Proteinen (< $35 \%$ Ähnlichkeit). orfC weist geringe Sequenzähnlichkeien zu hypothetischen A cetatkinasen auf (<30\% Ähnlichkeit). Zu bereits charakterisierten Proteinen wurden für beide Genprodukte keine Ähnlichkeiten gefunden. Der vierte ORF, orfD, stellt möglicherweise aufgrund hydrophober AminosäuresequenzBereiche ein äußeres Membranprotein dar (< 42\% Ähnlichkeit); doch auch hier bestand keine signifikante Ähnlichkeit zu untersuchten Proteinen. Dem fünften und sechsten ORF des Genclusters, orfE und orfF, konnte keine mögliche Funktion zugeordnet werden, da in der Datenbank keine Ähnlichkeiten gefunden wurden. Auch hier bestand - wie bei FilA keine Ähnlichkeit zu uncharakterisierten hypothetischen Proteinen in bereits sequenzierten Organismen.

Die Datenbankabgleiche ergaben für die ORFs des potentiellen fil-Clusters keine Ähnlichkeit zu Komponenten bereits identifizierter Pilusbiosynthesewegen. Aufgrund der gleichen Leserichtung der Gene im fil-Cluster, wurde die Hypothese aufgestellt, daß die Genprodukte der stromabwärts des Strukturgens filA lokalisierten ORFs in die Biogenese des dicken Pilus von Acinetobacter sp. BD413 involviert sind und daß es sich um eine neue Klasse und einen neuen Biosyntheseweg von filamentbi ldenden Strukturen handelt. 


\subsubsection{Unterbrechung und Deletionen der OR Fs im fil-Cluster}

Um die Frage zu klären, ob die stromabwärts des filA-Gens liegenden ORFs in die Biosynthese der dicken Pilusstruktur von BD413 involviert sind, wurde zunächst orfB gezielt unterbrochen. Weiterhin sol Iten zwei Bereiche von 1,1 kb bzw. 2,7 bp deletiert werden, diezum einen orfC und zum anderen orfD zusammen mit orfE betrafen.

Zur Herstel lung des Konstruktes für die Unterbrechung des zu filA benachbarten orfB diente das Plasmid pGK 03, welches das aus der chromosomalen DNA von Acinetobacter sp. K101 stammende $11 \mathrm{~kb}$-Xbal/Sacl-Fragment trug (3.6.7.1). Auf diesem Plasmid liegt das mit dem nptl I-Marker unterbrochene Gen filA und der dazu stromabwärts liegende orfB. Nach der Subklonierung des 1,0 kb-SnaBI/Sacl-Bereiches aus pGK03 in pGEM$7 f(+)(S m a l / S a c l)$ entstand das Plasmid pGK06, welches jezt allein den gewünschten orfB trug (vgl. Restriktionskarte in Abb. 3.39). Nach der Integration des mit Hincllgeschnittenen nptII-Markers (aus pUC4K) in die Hincll-Schnittstelle des Inserts von pGK 06 entstand pGK07 (A bb. 3.40). Daraufhin befand sich das Resistenzgen zwischen 740 bp und 260 bp flankierender DNA, die aus Bereichen des orfB bestanden. Das herausgeschnittene Insert, welches jetzt 2,2 kb aufwies, diente der Mutagenisierung von Acinetobacter sp. ADP239, wozu die natürliche Transformation genutzt wurde. Die Mutante mit der Unterbrechung in orfB wurde als $\mathrm{K} 102$ bezeichnet.

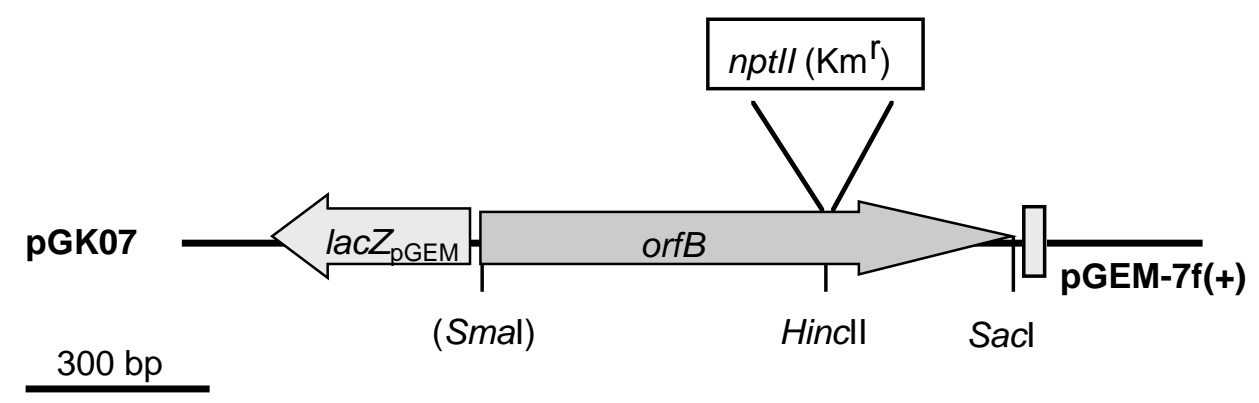

Abb. 3.40: Plasmidkonstruktion für die Unterbrechung von orfB. In die Hincll-S chnittstelle des in pGEM-7f(+) klonierten SnaBI/Sacl-Fragments wurde die Kanamycin-Kassette ligiert. Das Resistenzgen ist nicht maßstabsgetreu wiedergegeben. Dargestellt sind nur die für die Klonierung relevanten Schnittstellen, wobei die in Klammern dargestellte Smal-Schnittstelle aufgrund der Ligation mit der SnaBISchnittstelle des Inserts nicht mehi restriktionsverdaut werden kann. Das lacZ-Gen von pGEM-7f(+) gibt die Leserichtung des vektoreigenen Promotors an.

Die Überprüfung der homologen Rekombination ins Zielgen erfolgte mittels SOUTHERN Hybridisierung, indem die isolierte chromosomale DNA der entstandenen Mutante K102 mit EcoRI bzw. mit EcoRI/Sacl restriktionsverdaut, im Agarosegel elektrophoretisch aufgetrennt und gebl ottet wurde. Die Größe des nptII-Marker-tragenden 
DNA-Fragments konnte mit einer Kanamycin-Sonde detektiert werden. Vor der Intergration des 1,2 kb-Resistenz-Markers lagen beide relevanten EcoRI-Schnittstellen 4,7 kb voneinander entfernt; nach der Unterbrechung von orfB vergrößerte sich der Abstand auf 5,9 kb, die im Southern Blot detektiert wurden (Abb. 3.41). Der Doppelverdau mit EcoRI und Sacl lieferte weiterhin den Beweis, daß der integrierte Marker den Genbereich um 1,2 kb erweiterte: Nicht die ursprüngliche Basenzahl von 2,4 kb, sondern ein 3,6 kb-Fragment wurde detektiert (Abb. 3.41). Die Übereinstimmung der theoretisch ermittelten nptII-Marker-tragenden DNA-Fragmentlängen mit denjenigen, die der SOUTHERN Blot lieferte, demonstierte die richtige Integration des Markers ins Zielgen.

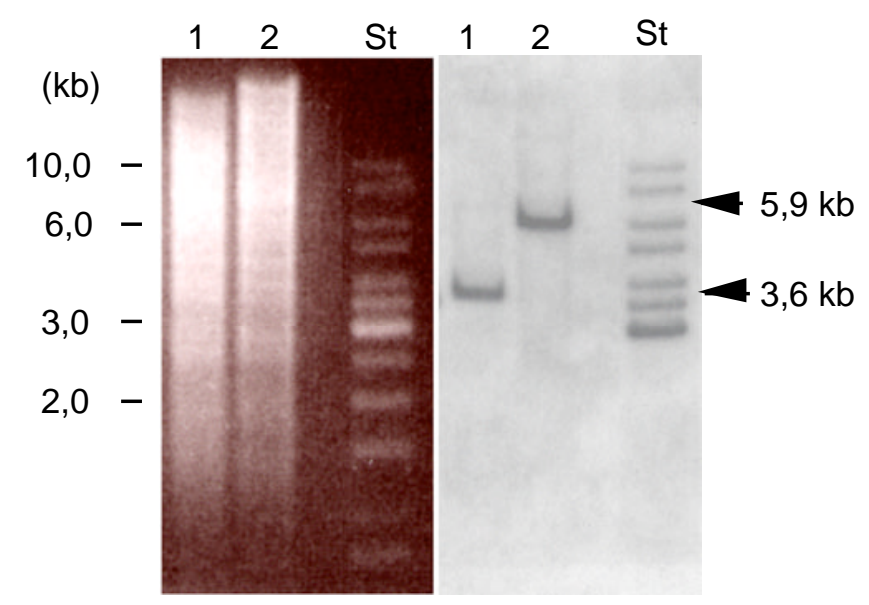

\begin{abstract}
Abb. 3.41: SOUthern Hybridisierung restriktionsverdauter DNA gegen eine Kanamycin-Sonde. Dif isolierte chromosomale DNA von Acinetobacter sp. K102 (orfB-Mutante) wurde mit EcoRI/Sacl (Spur 1) und EcoRI (Spur 2) geschnitten, im Agarosegel aufgetrennt und nach dem Blotten gegen eine Kanamycin-Sondt hybridisiert. Die Sonde markierte unspezifisch die DNA Banden des Größenstandards (St) im Bereich von 3-10 $\mathrm{kb}$. Auf der linken Seite ist das E thidiumbromid-gefärbte Gel und auf der rechten der SOUthern Blot dargestellt.
\end{abstract}

Da orfC keine geeignete Schnittstelle für eine Resistenzmarker-Insertion aufwies, wurden die DNA-Bereiche, die später den Marker flankieren sol Iten, getrennt mittels PCRamplifiziert. Die generierten Primer wiesen dazu Restriktionsschnittstellen auf, die eine Klonierung mit dem nptII-Marker erlaubten. Die Primer AcKinMu-Sacl-NA1 (5'-CATT AAAGAGAGAGCTCCAGGGACAGTTC-3') und AcKinMu-BamHI-CA1 (5'-GAGCTC TCTTCATTGGATCCACCACATTAT-3') amplifizierten an der BD413-DNA stromaufwärts von orfc einen Bereich von 790 bp, der nach dem Restriktionsverdau mit Sacl/BamHI in pGEM-7f(+) kloniert wurde, wonach das Plasmid pGK 16 resultierte (Abb. 3.42). In den mit Smal (MCS) linearisierten pGK16 wurde daraufhin der mit Hincll 
geschnittene nptl I-Marker aus pUC4K ligiert. Aus diesem resultierenden Plasmid pGK21 konnte das gesamte Insert (nptll-Marker und PCR-Produkt) mit Sacl/EcoRI herausgeschnitten und in den äquivalent geschnittenen pGK17 kloniert werden. pGK17 (ein pGEM-7f(+)-Derivat) enthielt das mit EcoRI/Xbal klonierte 790 bp PCR-Produkt, welches mit den Primern AcKinMu-EcoRI-NB1 (5`-CAATGGAACATTGG GAATTCGCTTAACTGAAG-3') und AcKinMu-Xbal-CB1 (5`-CAGCAGAAGCAAA TCTAGAATAACGTCATTG-3') zuvor amplifiziert worden war. Das entstandene Plasmid pGK23 enthielt schließlich den nptlI-Marker und angrenzend die für die spätere homologe Rekombination flankierenden DNA-Bereiche (Abb. 3.42). Für die Transformation von Acinetobacter sp. ADP239 konnte das gesamte Insert mit Sacl und Xbal harausgeschnitten werden. Die Mutante mit der Deletion von orfC wurde als K103 bezeichnet.

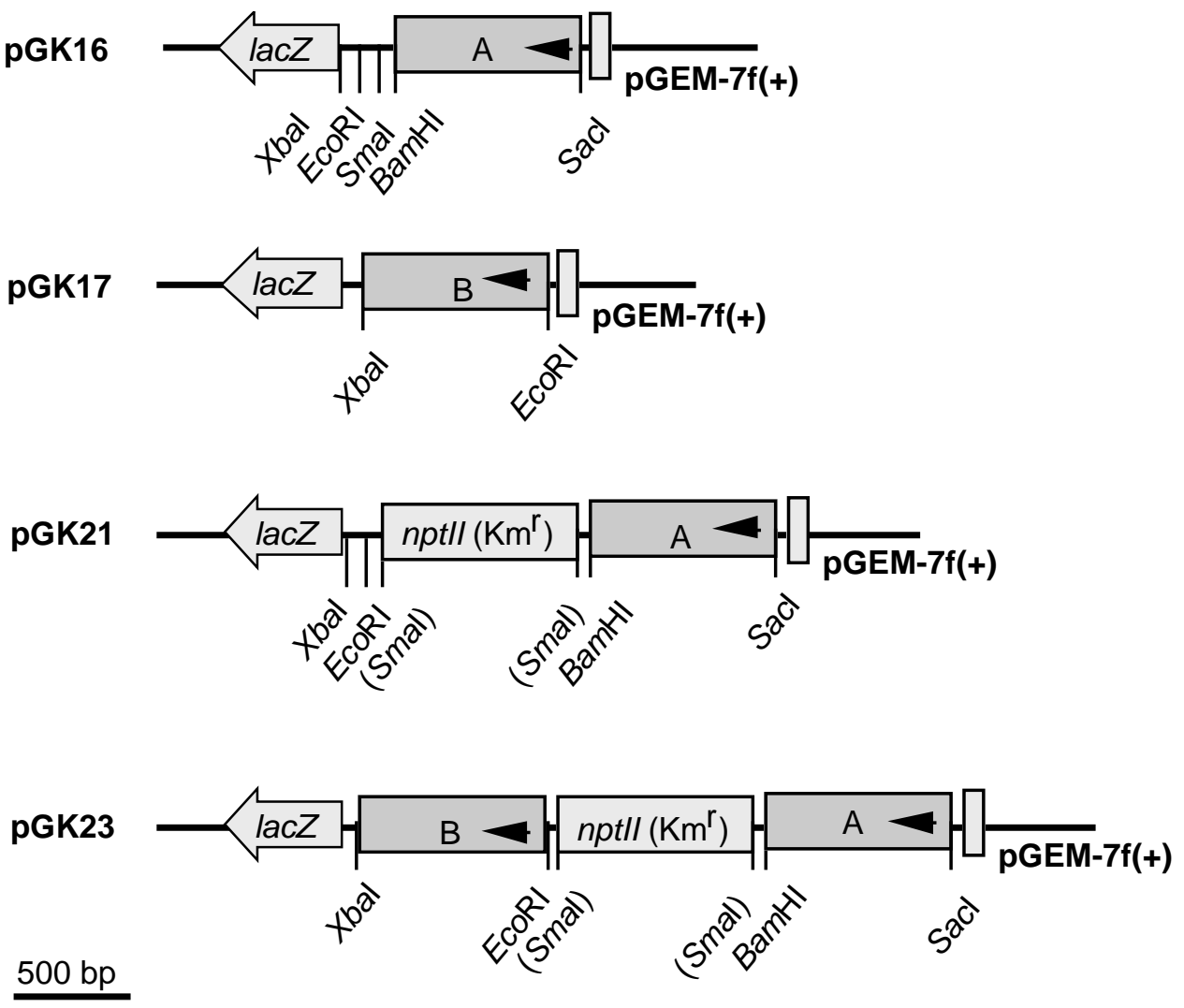

Abb. 3.42: Plasmidkonstruktionen für die Unterbrechung von orfC. Die PCR-Produkte von DNA-Bereichen stromauf- $(A)$ und stromabwärts (B) des Gens orfC wurden jeweils in pGEM-7f(+) kloniert, woraus pGK16 bzw. pGK17 resultieren. In die Smal-Schnittstelle von pGK16 wurde die Kanamycin-Kassette ligiert und daraufhin in das entstandene Plasmid pGK21 das Insert (B) aus pGK17 mit EcoRI und Xbal kloniert. Daraus resultierte pGK23, in dem die DNABereiche stromauf- und stromabwärts von orfC durch das Resistenzgen unterbrochen sind. Die Pfeile markieren die Leserichtung von orfC. Die in Klammern dargestellten Namen der Restriktionsschnittstellen können aufgrund der Ligation mit glatten DNA-Enden nicht mehr geschnitten werden. Der Kanamycin-Marker ist nicht maßstabsgetreu wiedergegeben. Dargestellt sind nur die für die Klonierung relevanten Schnittstellen. Das lacZ-Gen von pGEM-7f(+) gibt die Leserichtung des vektoreigenen Promotors an. 
Die Überprüfung auf einmalige und homologe Rekombination ins Genom des entstandenen Stamms Acinetobacter sp. K103 erfolgte über die Detektion des nptIIMarkers in einem SOUTHERN Blot. Die isolierte chromosomale DNA von $\mathrm{K} 103$ wurde mit EcoRV/Xbal und Kpnl restriktionsverdaut, elektrophoretisch aufgetrennt, geblottet und schließlich die Laufhöhe des DNA-Fragmentes, welches den Kanamycin-Marker trug, mit einer nptI-Sonde detektiert.

In der chromosomalen DNA des Wildtyps ADP239 lagen die beiden relevanten Schnittstellen EcoRV und Xbal 4,3 kb auseinander; unter Berücksichtigung der 1,1 kbDeletion des orfC und der Integration der $1,2 \mathrm{~kb}$ großen Kanamycin-Kassette ergaben sich die detektierten 4,4 kb (Abb. 3.43, A). Die relevanten Kpnl-Schnittstellen schlossen im ADP239-Chromosom 6,0 kb ein. Nach der Transformation, nachdem orfC durch den Resistenz-Marker (1,2 kb) ersetzt worden war, erfolgte eine zusätzlicher Integration von 0,1 kb, so daß im SOUTHERN-Blot eine Bande von 6,1 kb detektiert wurde (Abb. 3.43, A).

A

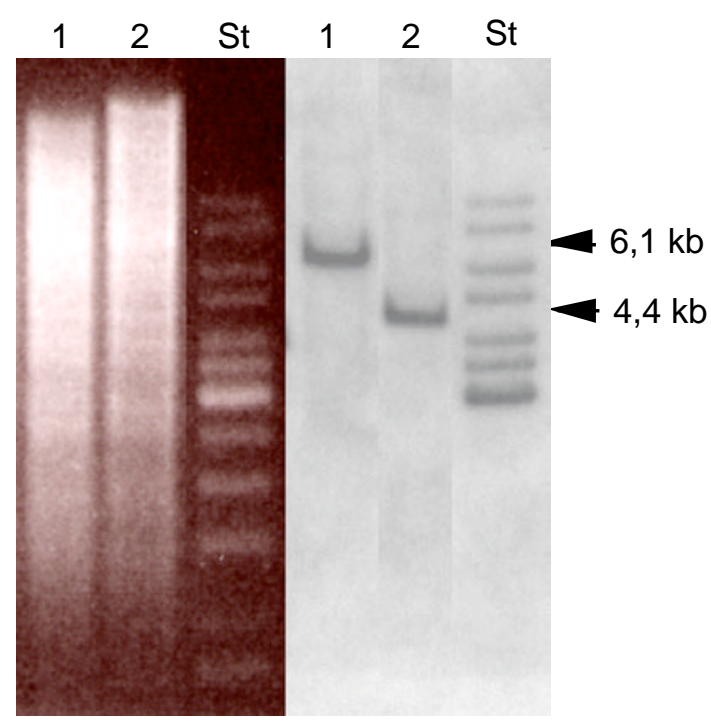

B

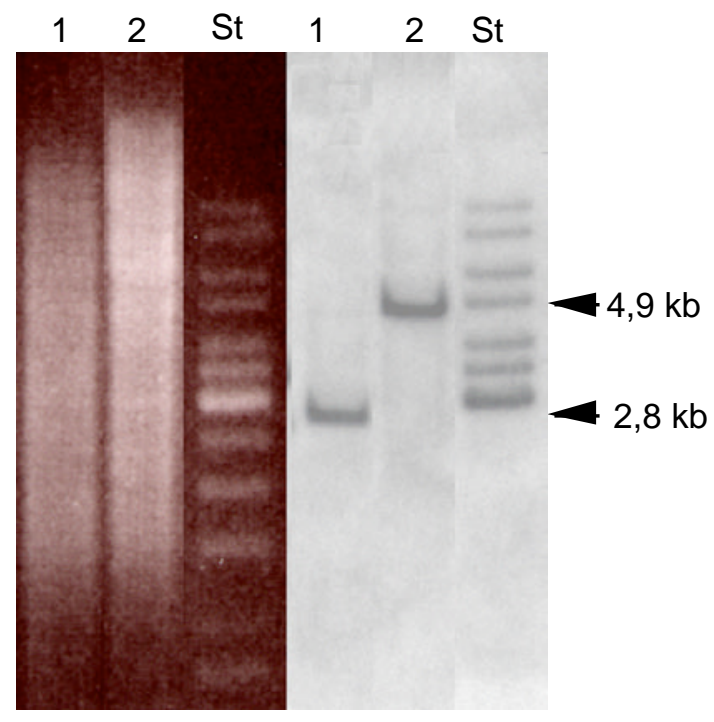

Abb. 3.43: SOUTHERN Hybridisierung restriktionsverdauter DNA gegen eine KanamycinSonde. (A) Die isolierte chromosomale DNA von Acinetobacter sp. K103 (orfC-Mutante) wurde mit Kpnl (Spur 1) und EcoR V/Xbal (Spur 2) geschnitten, im Agarosegel aufgetrennt und nach dem Blotten gegen eine Kanamycin-Sonde hybridisiert. (B) Die chromosomale DNA von Acinetobacter sp. K104 (orfD/orfE-Mutante) wurde mit EcoRV (Spur 1) und Sacl/Sall (Spur 2) geschnitten und das Kanamycin-Gen mit einer Sonde detektiert. Die Sonde markierte in unspezifischer Weise die DNA des Größenstandards $(S t)$ im Bereich von 3-10 kb. Auf der linken Seite beider Abbildungen (A/B) ist das Ethidiumbromid-gefärbte Gel und auf der rechten der SOUTHERN Blot dargestellt.

Nachdem die zu filA stromabwärts lokalisierten orfB und orfC spezifisch unterbrochen bzw. deletiert worden waren, sollte eine weitere Deletion, die orfD und orfE gemeinsam betraf, einen weiteren Hinweis über die Beteiligung der stromabwärts von filA 
lokalisierten ORFs an der Pilusbiogenese liefern. Dazu wurden die DNA-Bereiche stromaufwärts von orfD und stromabwärts von orfE mittels PCR amplifiziert. Die KIonierungsstrategie hinsichtlich der gewählten Schnittstellen erfolgte -wie bei der Deletion von orfC beschrieben - in pGEM-7f(+) (s.o.). Die Primer OMMu-Sacl-NA1 (5'CAATATTACCTTAAGGAGCTCCATTCCATTTG-3`) und OMMu-BamHI-CA1 (5`CGAATGCAACATTGGATCCCCCCGTCAAGAC-3') amplifizierten an der BD413DNA stromaufwärts von orfD einen Bereich von 730 bp, der nach dem Restriktionsverdau mit Sacl und BamHI in pGEM-7f(+) kloniert wurde, wonach das Plasmid pGK 18 entstand (Abb. 3.44).

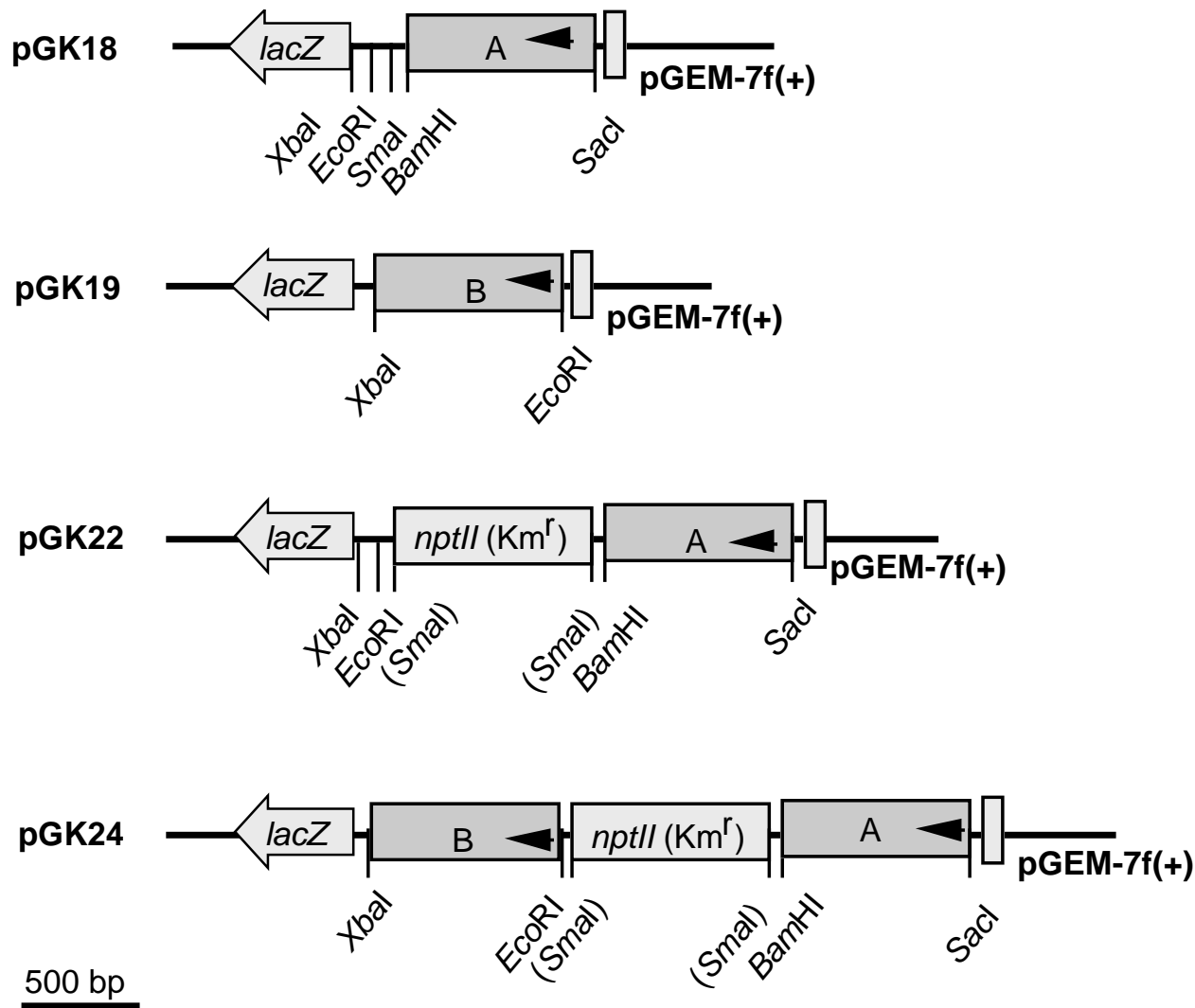

Abb. 3.44: Plasmidkonstruktionen für die gemeinsame Unterbrechung von orfD und orfC. Die PCR-P rodukte von DNA-Bereichen stromaufwärts von orfD (A) und stromabwärts von orfE (B) wurden jeweils in pGEM-7f(+) kloniert, woraus pGK18 bzw. pGK19 resultierten. In die Smal-Schnittstelle von pGK18 wurde die Kanamycin-Kassete ligiert und daraufhin in das entstandene Plasmid pGK22 das Insert (B) aus pGK19 mit EcoRI und Xbal kloniert. Daraus resultierte pGK24, in dem die DNA-Bereiche stromauf- und stromabwärts von orfD bzw. orfE durch das Resistenzgen unterbrochen sind. Die Pfeile markieren die Leserichtung von orfD bzw. orfE. Die in Klammern dargestellten Namen der Restriktionsschnittstellen können nicht mehr geschnitten werden. Der Kanamycin-Marker ist nicht maßstabsgetreu wiedergegeben. Dargestellt sind nur die für die Klonierung relevanten Schnittstellen. Das lacZ-Gen von pGEM-7f(+) gibt die Leserichtung des vektoreigenen Promotors an. 
In den mit Smal (MCS) linearisierten pGK18 wurde daraufhin der mit Hincl I geschnittene nptl I-Marker aus pUC4K ligiert. Aus dem entstandenen Plasmid pGK22 konnte das gesamte Insert (nptII-Marker und PCR-Produkt) mit Sacl und EcoRI herausgeschnitten und in den äquivalent geschnittenen pGK19 kloniert werden. pGK 19 enthielt das mit EcoRI/Xbal klonierte 680 bp PCR-Produkt, welches mit den Primern unkn5Mu-EcoRI-NB1 (5'-GTTATAAAAATCAGGAATTCGCTGCTACAG-3`) und unkn5Mu-Xbal-CB1 (5`-AAAGATGCCTGCATTCTAGAGATTCATCATG-3') zuvor amplifiziert worden war. Das Plasmid pGK24 enthielt schließlich den nptlI-Marker und angrenzend die für die spätere homologe Rekombination flankierenden DNA-Bereiche (Abb. 3.44). Für die Transformation von Acinetobacter sp. ADP239 konnte das gesamte Insert mit Sacl und Xbal herausgeschnitten werden. Die Mutante mit der Deletion von orfD und orfE wurdeals K 104 bezeichnet.

Die Überprüfung der Deletion und der homologen Rekombination des ResistenzMarkers in der generierten Mutante K104 erfolgte wiederum mittels SOUTHERN Blot. Dafür wurde die isol ierte chromosomal e DNA des Stammes K104 zum einen mit Sacl/Sall und zum anderen mit EcoRV restriktionsverdaut, elektrophoretisch aufgetrennt, geblottet und mit einer nptlI-Sonde hybridisiert. In der chromosomalen DNA des Wildtyps BD413 lagen die beiden Sacl- und Sall- Schnittstellen 6,4 kb auseinander; unter Berücksichtigung der 2,7 kb-Deletion von orfD und orfE und der Einfühgung der 1,2 kb-KanamycinKassette ergaben sich die detektierten 4,9 kb (Abb. 3.43, B). Die relevante EcoRVSchnittstelle schlossen im ADP239-Chromosom 4,3 kb ein. Die homologen Rekombination des Konstruktes führte zur Deletion von orfD und orfE durch den Resistenz-Marker (1,2 kb), so daß sich eine Netto-Deletion von 1,5 kb verzeichnen ließ und auf dem SOUTHERN Blot eine Bande von 2,8 kb detektiert wurde (Abb. 3.43, B).

Diese Untersuchungen bestätigten die einfache, homologe Rekombination des Resistenzmarkers ins Zielgen.

\subsubsection{Untersuchung auf Pilusbiogenese der Mutantenstämme K 102, K 103 und K 104}

Die Unterbrechung des Strukturgens filA führte zu einem Phänotyp, der einen Defekt in der Biosynthese der dicken Pili aufwies. Da filA das erste Gen von insgesant sechs ORFs darstellte, die in gleicher Leserichtung lagen, ließ dies die Vermutung zu, daß die ORFs zu einem neuartigen Pilus-Biosynthesecluster gehören. Die generierte Mutante K102, mit einer Unterbrechung in orfB, der Stamm K103, der eine Deletion von orfC trägt und K104, dessen orfD und orfE gemeinsam deletiert worden waren, wurden daraufhin hinsichtlich ihrer Synthese dicker Pili überprüft. 
Wie oben beschrieben und in "Material und Methoden" ausführlich behandelt, wurden die Pili der Stämme K102, K103 und K104 abgeschert und im zweistufigen Saccharosegradienten gereinigt.

Nach Auftrennung der Pilusfraktion in einem 15\%igem SDS-Gel waren in der Spur der Positivkontrolle ADP239 die Untereinheiten der dicken Pili bei $28 \mathrm{kDa}$ und die der dünnen Pili bei $16 \mathrm{kDa}$ zu erkennen, was den Wildtyp-Pilusphänotyp repräsentierte (Abb. 3.45). Den Mutanten-Stämmen K102, K103 und K104, die Unterbrechungen bzW. Deletionen in den zu filA stromabwärts lokal isierten ORFs aufwiesen, fehlte die $28 \mathrm{kDa}$ Bande im SDS-Gel. Elektronenmikroskopische Untersuchungen belegten weiterhin das Fehlen der dicken Pilusstruktur und die nicht beeinträchtigte Synthese der dünnen Pili. Dies indizierte einen Biogenesedefekt von FilA zu einer filamentösen Struktur auf der Zelloberfläche, der durch die Unterbrechungen der zu filA stromabwärts lokalisierten ORFs hervorgerufen worden sein mußte. Das Strukturgen filA wies seinerseits keine Mutation auf und stelte das erste Gen des Clusters dar, was einen polaren Effekt (ausgelöst durch die gesezzten Mutationen in den Stämmen K102, K103, und K104) ausschloß.

Die 16 kDa-Bande der Untereinheiten der dünnen Pili war dagegen imSDS-Gel aller Mutanten erkennbar, so daß bei den beiden Pilusstrukturen von Acinetobacter sp. BD413 von getrenten Biosynthesewegen ausgegangen werden kann.

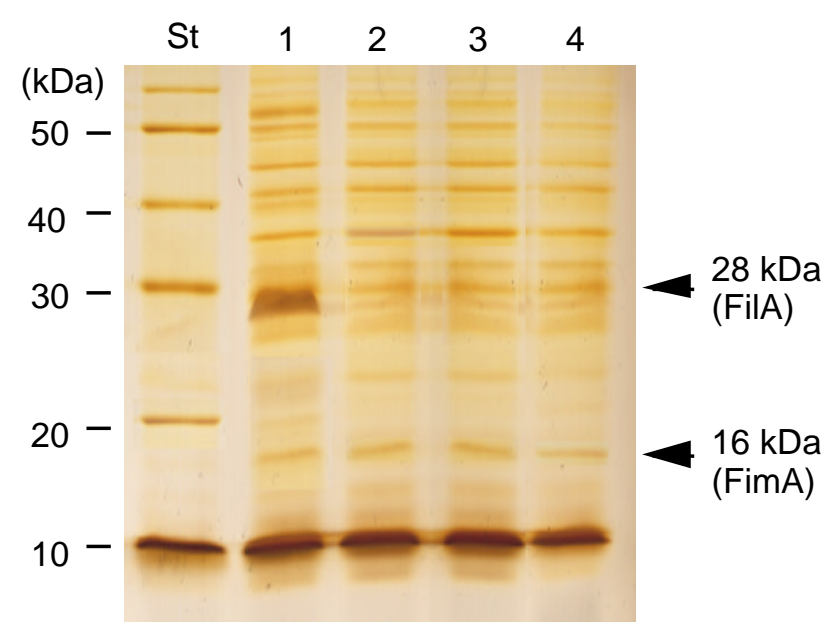

Abb. 3.45: SDS-PAGE der Scherfraktionen. Die Pilusstrukturen des Stammes ADP239 (Spur 1) sowie der Mutanten-Stämme K102 (orfB-Mutante) (Spur 2), K103 (orfC-Mutante) (Spur 3) und K104 (orfD/orfE-Mutante) (Spur 4) wurden von der Zelloberfläche abgeschert, gereinigt und in einem $15 \%$ igen SDS-G el aufgetrennt. 
Diese Untersuchungen zeigten, daß neben dem über die Aminosäure-Sequenz identifizierten Strukturgen filA ebenso die stromabwärts lokalisierten ORFs (orfB, orfC, orfD und/oder orfE) an der Biogenese des dicken Pilus von Acinetobacter sp. BD413 beteiligt sind. Da keine Ähnlichkeiten zu bereits bekannten Pilus-Biosynthesewegen bestanden, muß es sich bei dem dicken Pilus um einen neuen, nicht beschriebenen Filament-Typ unbekannter Biogenese handeln. Obwohl die gezielte Unterbrechung von orfF aussteht und der Pilus-Synthesedefekt der Mutante K103, die eine gemeinsame Deletion von orfD und orfE trägt, spezifiziert werden muß, ist es sehr wahrscheinlich, daßs hier ein Biosynthesecl uster vorliegt.

\subsubsection{K omplementation der M utantenstämme K 101 und K 102}

Gene procaryotischer Genome, die für densel ben Stoffwechsel weg codieren, liegen oft assoziiert in Genclustern vor und werden dann oft als polycistronische mRNA cotranskribiert. Das Strukturgen filA des dicken Pilus bildete das erste Gen eines Clusters, wel ches aus insgesamt sechs ORFs gleicher Leserichtung bestand. Unterbrechungen in den stromabwärts von filA lokalisierten Genen orfB bzw. orfC und die gemeinsame Deletion von orfD und orfE führten jeweils zu einem Defekt in der dicken Pilusbiogenese. Somit handelt es sich hier um ein Gencluster, das die Synthese der dicken Pilusstruktur vermittelt. Ob darüber hinaus dieses Gencluster ein Operon darstellt, sollten Komplementationsstudien zeigen. Um Hinweise auf einen Promotor außer vor filA auch vor orfB zu bekommen, wurde die Regeneration des Pilus-Phänotyps durch Komplementation von K101 und K102 mit den jeweiligen Plasmid-codierten intakten Genen untersucht.

Um das zur Komplementation intakte fil A zu erhalten, wurde in 3,6 kb-EcoRI/SaclFragment aus der chromosomalen DNA des Stammes K102 in pRK 415 kloniert (vgl. Restriktionskarte in Abb. 3.39). Das daraus resultierende Plasmid pKK32 enthielt neben filA das mit dem nptII-Marker unterbrochene orfB (Abb. 3.46). Das 3,6 kb-EcoRI/SaclFragment aus der chromosomal en DNA des Stammes K101, welches neben dem intakten orfB das durch den nptlI-Marker unterbrochene filA trug, wurde ebenso in pRK415 kloniert, so daßs das Plasmid pKK33 entstand. Um eine mögliche Promotoraktivität des nptII-Markers auf die Transkription des stromabwärts lokalisierten orfB auszuschließen, konnte durch den Restriktionsverdau mit EcoRI/Xhol und eine Ligation mit glatten DNAEnden von pKK33 der relevante DNA-Bereich entfernt werden (Abb. 3.46). Das resultierende Plasmid pKK34, welches das intakte filB enthielt, wies daraufhin keine Kanamycin-Resistenz auf. 

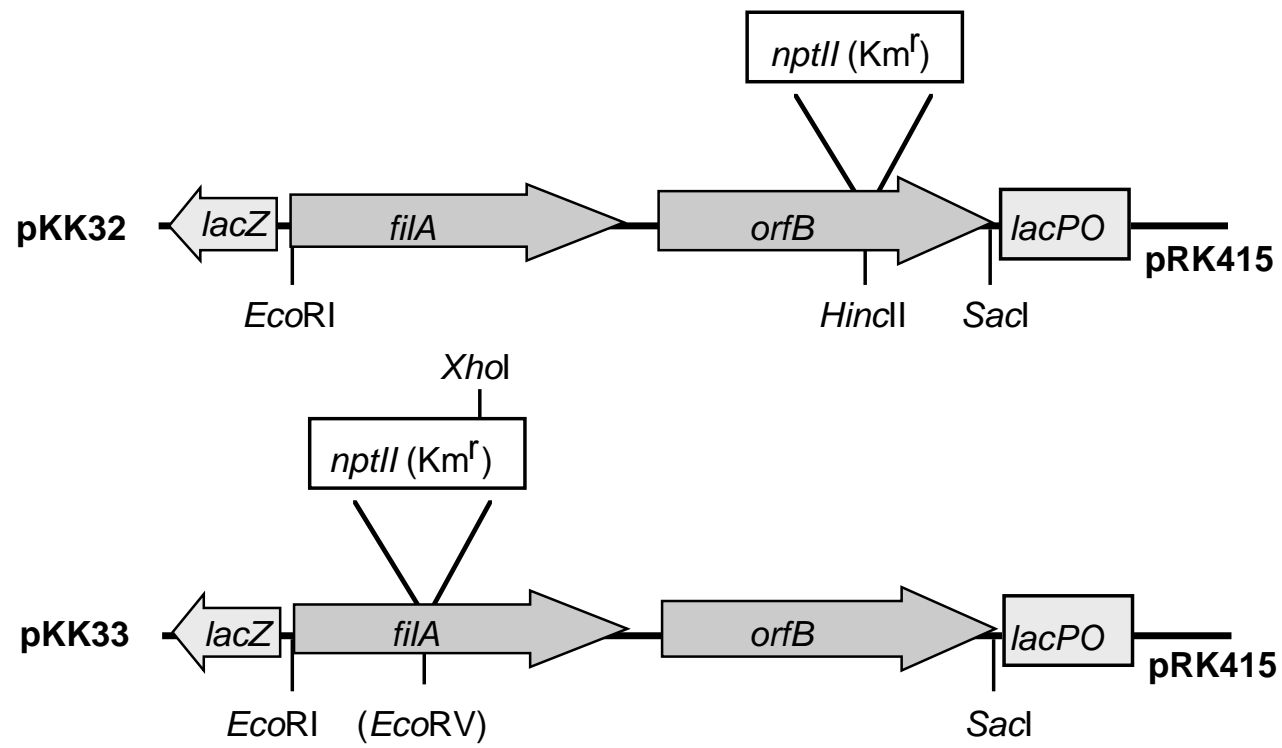

pKK34
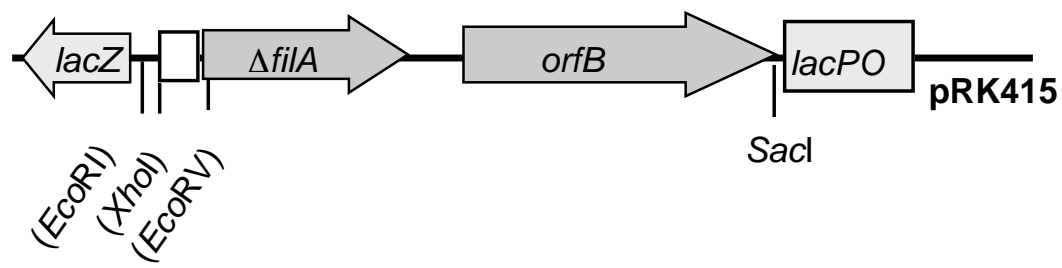

Sacl

$500 \mathrm{bp}$

Abb. 3.46: Plasmidkonstruktionen von pKK32 und pKK34. pKK32 enthält das nptII-Marker tragende DNA-Fragment aus Acinetobacter sp. K102, auf dem das intakte filA-Gen und das unterbrochene Gen orfB liegt. pKK33 besitzt das DNAFragment aus K101, welches das intakte Gen orfB und das mit dem KanamycinMarker unterbrochene filA-Gen trägt. Durch Restriktionsverdau von pKK33 mit EcoRI und Xhol, Behandlung mit Klenow-Enzym und Ligation der glatten DNAEnden, konnte der Promotorbereich des nptI-Gens eliminiert werden, woraus das Plasmid pKK34 resultierte. Die in Klammern dargestellten Namen del Restriktionsschnittstellen können nicht mehr geschnitten werden. Der KanamycinMarker ist nicht maßstabsgetreu wiedergegeben. Dargestellt sind nur die für die Klonierung relevanten Schnittstellen. Das lacZ-Gen von pRK415 gibt die Leserichtung des vektoreigenen Promotors an.

Das Plasmid pKK32, welches das intakte filA-Gen trug, wurde mittels des Helferstammes E. coli pRK2013 in den Stamm K101 konjugiert und pKK34, mit dem intakten orfB-Gen, in den Stamm K102. Die daraus resultierenden Stämme K101 pKK32 und K102 pKK34 wurden daraufhin hinsichtlich ihrer Pilusbildung untersucht, was durch dieAuftrennung der Scherfraktionen in einer SDS-PAGE erfol gte. 
Wie oben beschrieben und in "Material und Methoden" ausführlich behandelt wurden diePili der komplementierten Stämme K101 pKK 32 und K 102 pKK34 abgeschert und imzweistufigen Saccharosegradienten gereinigt.

Nach Auftrennung der Scherfraktionen in einem 15\%igem SDS-Gel waren in der Spur der Positivkontrolle ADP239 die Untereinheiten der dicken Pili bei $28 \mathrm{kDa}$ und die der dünnen Pili bei $16 \mathrm{kDa}$ sichtbar (Abb. 3.47), was die intakte Pilusbildung des Wildtyps repräsentierte. Die komplementierten Mutantenstämme K101 pKK32 und K102 pKK34 zeigten ebenso wie der Stamm ADP239 sowohl die $16 \mathrm{kDa}$ als auch die $28 \mathrm{kDa}$-Bande. Vor der konjugativen Übertragung der Plasmide, welche filA (pKK32) bzW. orfB (pKK34) tragen, wiesen die Stämme K101 und K 102 einen Defekt in der Pilusbiogenese des dicken Pilus auf, was zu einem Fehlen der $28 \mathrm{kDa}$ in der SDS-PAGE führte (Abb.3.33). Elektronenmikroskopische Untersuchungen demonstrierten darüber hinaus den Wildtypähnlichen Pilusphänotyp der komplementierten Stämme, da bei ca. 90\% der Zellen sowohl die dicken als auch die dünnen Pili erkennbar waren.

Die Plasmid-codierten Gene waren somit in der Lage den Defekt in der Synthese der dicken Pili zu komplementieren und ihre Synthese zu regenerieren.

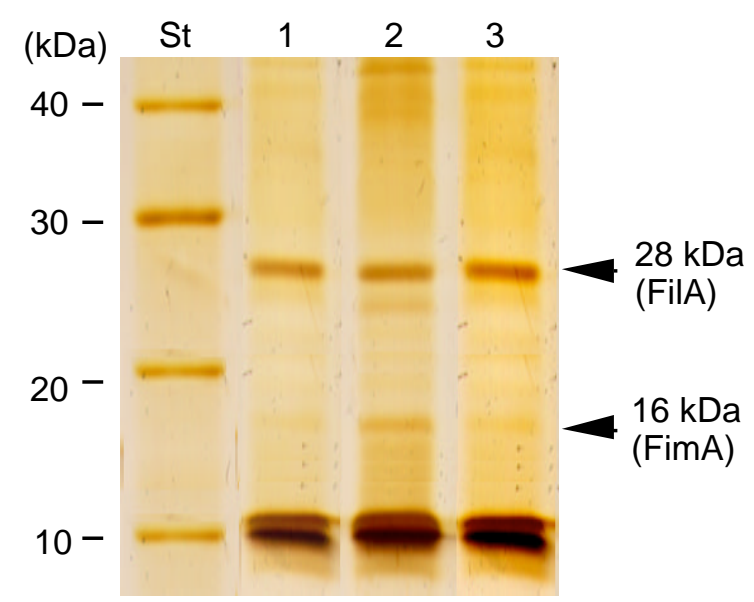

Abb. 3.47: SDS-PAGE der Scherfraktionen Die Pilusstrukturen des Stammes ADP239 (Spur $1)$, sowie der komplementierten MutantenStämme K101 pKK32 (Spur 2) und K102 pKK34 (Spur 3) wurden von der Zelloberfläch€ abgeschert, gereinigt und in einem $15 \%$ igen SDS-Gel aufgetrennt. 
Diese Ergebnisse zeigten eindeutig, daß sowohl filA als auch orfB für die Biogenese der dicken Pili essentiell sind. Weiterhin indizierten die Ergebnisse, daß vor filA und vor orfB intakte Promotorstrukturen lokalisiert sind, die die Transkription der Plasmidcodierten, isolierten Gene erlaubten. Die erfolgreiche Komplementation von K102 mit pKK34 deutet darüber hinaus auf einen Promotor vor orfC hin, da in K 102 das Gen orfB durch eine Kanamycin-Kassette unterbrochen worden war, was im Falle eines Operons vermutlich einen polaren Effekt auf orfC ausgeübt hätte. Vermutlich liegt hier ein Biosynthese-Gencluster vor, was durch weitere Mutantenstudien und Transkriptionsanalysen verifiziert werden müßte.

\subsubsection{Charakterisierung des dünnen Pilus}

Die Unterbrechung des Gens, welches für die $16 \mathrm{kDa}$ Untereinheit des dünnen Pilus codiert, führte zu der Mutante N100, die keine dünnen Pili auf der Zelloberfläche aufwies. Dieser Pilustyp ist weder an der natürlichen Transformation noch an der gleitenden Fortbewegung des Bakteriums beteiligt. Für eine weitere Charakterisierung des dünnen Pilus sollte zunächst ein Datenbankabgleich des $16 \mathrm{kDa}$-Untereinheit durchgeführt werden und die genomische Lokalisation des Strukturgens sowie die Involvierung benachbarter Gene in die Pilusbiogenese untersucht werden.

\subsubsection{Untersuchung der Untereinheit des dünnen Pilus}

Das Genprodukt des identifizierte Gens, welches für die Untereinheit des dünnen Pilus codiert, besteht aus 193 Aminosäuren und besitzt eine errechnete molekulare Masse von 19,5 kDa. Der Datenbankabgleich verwies auf eine Vielzahl von Gram-negativen Organismen, die ähnliche Proteine synthetisieren. A bbil ldung 3.48 zeigt exemplarisch einen Aminosäureabgleich mit homologen Proteinen, die in den Enterobakterien E. coli (F17-A), Proteus mirabilis (FimA) und dem pflanzenpathogenen Stamm Xylella fastidiosa (FimA) identifiziert wurden (LinTERMANs et al. 1988). Hierbei handelte es sich um Strukturproteine, die zur Klasse der Typ-I-Fimbrien gezählt werden, molekulare Massen zwischen 15 und $20 \mathrm{kDa}$ aufweisen und vorwiegend bei pathogenen Organismen untersucht sind. Am N-Terminus dieser Protein-Familie befindet sich ein basisches Signal peptid, welches beim Sec-abhängigen Transport durch die Cytoplasmamembran entfernt wird. Nach potentieller Prozessierung des Präproteins aus BD413 weist das Strukturprotein eine errechnete molekulare Masse von 16,5 kDa auf. Der zur Pilusassemblierung erforderliche Transport der Untereinheit durch die Zellmembran, der basisch-hydrophobe Charakter des N-Terminus und die in der SDS-PAGE abgeschättte Masse von 16 kDa unterstützten das Vorhandensein eines Leaderpeptids. 


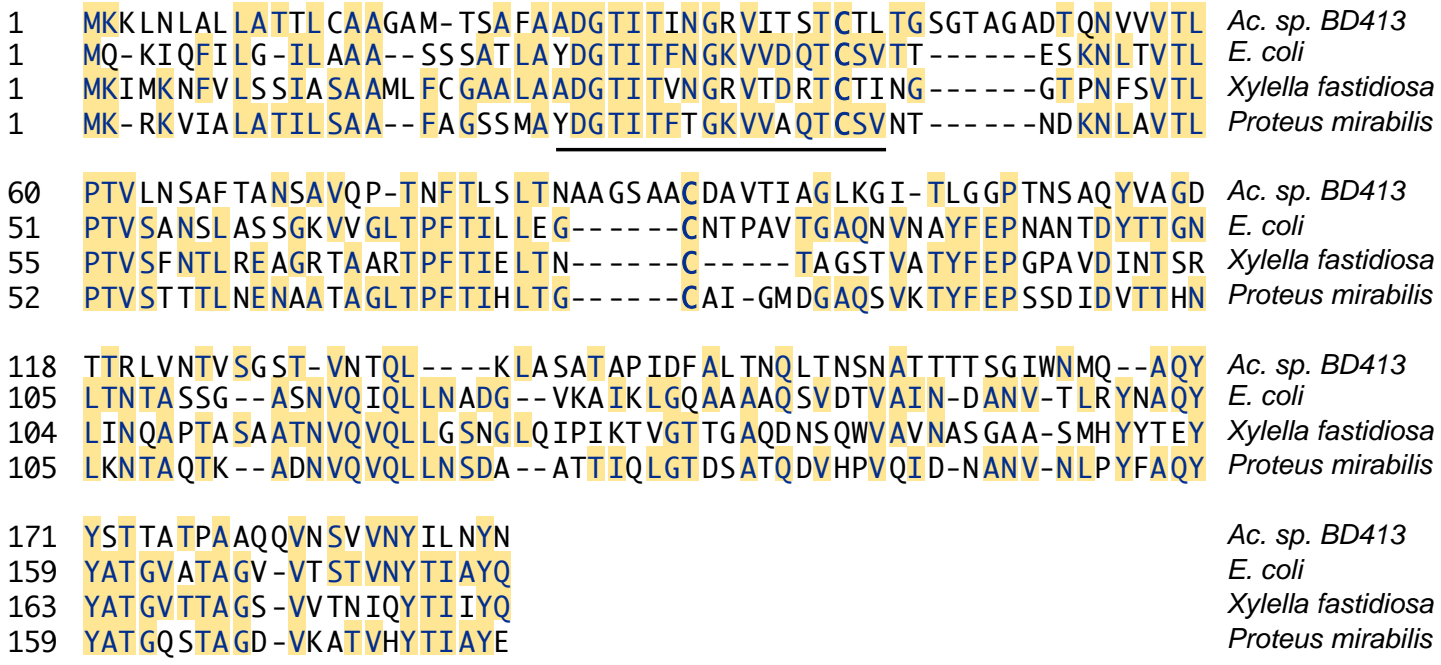

Abb. 3.48: Sequenzvergleich der Untereinheit FimA des dünnen Pilus vor Acinetobacter sp. BD413 mit Typ-I-Pilinen. Das Pilus-S trukturprotein FimA zeig Ähnlichkeiten zu den Untereinheiten der Familie der Typ-I-Pili. Dargestellt ist das F17-1-Pilin von E. coli und das FimA-Protein von Xylella fastidiosa bzw. Proteus mirabilis. Die für die Ausbildung einer Disulfidbrücke essentiellen Cysteine $(C)$ sind fett hervorgehoben Unterstrichen sind konservierte Bereiche des $\mathrm{N}$-Terminus und des $\mathrm{\square}$-Zipper-Motivs am CTerminus.

Das Strukturprotein aus Acinetobacter sp. BD413 weist die konservierten Cysteine für die Ausbildung einer Disulfidbrücke auf (Positionen 40 und 92), die für die Faltung und Assemblierung der Untereinheit in die wachsende Pilusstruktur essentiell ist (Abb. 3.48). Darüber hinaus war der hoch konservierte C-terminale Bereich vorhanden, welcher aus alternierend angeordneten hydrophoben Aminosäuren aufgebaut ist und mit der aromatischen Aminosäure Phenylalanin endete. Anstelle des konservierten Glycins zu beginn dieses $\square$-Zipper-Motivs stand bei Acinetobacter die dazu ähnliche Aminosäure Alanin. Dieser C-terminale, 15 Aminosäuren umfassende Bereich ist essentiell für die Insertion in die Cytoplasmamembran, die nachfolgende I nteraktion mit dem im Periplasma lokalisierten Chaperon und schließlich für die Polymerisation und Ausbildung der Quartärstruktur des Pilus (Holmgren et al. 1992, Hung \& HuLTGRen 1998, FernándeZ \& BeRENGUER 2000). Weiterhin weist die Sequenz des Strukturproteins aus BD413 eine zweite konservierte Region nahe des N-Terminus (A minosäuren 24-41) auf, die vermutlich mit dem peripl asmatischen Chaperon interagiert (KüHN et al. 1993).

Aufgrund der Ähnlichkeit der Untereinheit des dünnen Pilus von Acinetobacter sp. BD413 zu den strukturellen Komponenten der Typ-I Pili, wurde das codierende Gen mit fimA bezeichnet. 


\subsubsection{Untersuchung der genomischen L okalisation von fimA}

Die Gene der bisher untersuchter Typ-I-Pilus-Biogenesesysteme bilden funktionelle Gencluster, oft in Form von Operonen, wobe es erste Hinweise auf eine Prozessierung der polycistronischen mRNA gibt (LOOMIS \& MOSELEY 1998). Das Gencluster codiert für mindestens zwei Assemblierungsfaktoren: zum einen ein periplasmatisches Chaperon und zum anderen ein äußeres Membranprotein, welches eine Pore für den Durchtritt des Pilus schafft. Das Chaperon empfängt die Strukturunterinheiten nach dem Sec-abhängigen Transport an der Cytoplasmamembran, verhindert die vorzeitige Aggregation der PilusUntereinheiten und schleust das Monomer zur Öffnung in der äußeren Membran, wo es zur Pilusstruktur assembliert (KNIGHT et al. 2000). Im al lgemeinen codiert das Gencluster für ein Adhäsin, welches an der Spize des Pilus lokal isiert ist (KüHN et al. 1993, J onEs et al. 1995).

Die einfachste Pilusassemblierung, die diesem Syntheseweg folgt, ist der 'dünne flexible Pilus' (z.B. F17), der Fibrillum genannt wird und der für seine Synthese außer der strukturellen Untereinheit ein periplasmatische Chaperon, ein äußeres Membranprotein sowie ein Adhäsin erfordert (SOTO \& HULTGREN 1999).

Auf dem Chromosom von Acinetobacter sp. BD413 liegen stromabwärts von fimA drei weitere ORFs mit der gleichen Orientierung, die nach dem Datenbankabgleich Ähnlichkeiten zu den beschriebenen beiden Assemblierungfaktoren und dem Adhäsin aufwiesen. Während die Strukturproteine (Pilin und Adhäsin) AminosäuresequenzIdentitäten von $28 \%$ bzw. $23 \%$ und Ähnlichkeiten von $44 \%$ bzw. 37\% aufweisen, zeigen die Assemblierungfaktoren (Chaperon und äußeres Membranprotein) Identitäten von $41 \%$ bzw. 35\% und Ähnlichkeiten von 57\% bzw. 51\% (Tab. 3.1), was die höhere Variabilität der Strukturkomponenten indiziert. Diese vier Komponenten sind als Basisfaktoren in allen Pilusclustern der Typ-I-Biosynthesefamilien zu finden.

Tab. 3.1: Ähnlichkeiten zwischen den Fim-Proteinen aus Acinetobacter sp. BD413 und Komponenten bekannter 'Chaperon-Usher'-Synthesewegen.

\begin{tabular}{llll}
\hline $\begin{array}{l}\text { Genbezeichung } \\
\begin{array}{l}\%) \\
\text { (Acinetob. sp. BD413) }\end{array}\end{array}$ & Funktion & Organismus (Gen) & Identität / Ähnlichkeit \\
\hline fimA & strukt. Untereinheit & E. coli (F17-A) & $28 / 44$ \\
fimD & peripl. Chaperon & E. coli (F17-D) & $41 / 57$ \\
fimC & 'Usher'-Protein & E. coli (F17-C) & $35 / 51$ \\
fimH & Adhäsin & E. coli (fimH) & $23 / 37$ \\
fimH & Adhäsin & Salmonella typhi (fimH) & $23 / 37$
\end{tabular}


Ein Vergleich der Gencluster des Typ-I-Pilus und des P-Pilus von E. coli sowie des Typ-III-Pilus von Klebsiella pneumoniae (die zur Klasse der Typ-I-Pili gehören) mit dem fim-Cluster von BD413 demonstrierten den konservierten Aufbau dieser Gencluster. Das periplasmatische Chaperon, äußere Membranprotein und Adhäsin sind in ähnlicher Organisation angeordnet (Abb. 3.49). Neben demjenigen Gen, welches für die Hauptstruktur-Untereinheit codiert, finden sich im Fim und Pap-Cluster von E. coli weitere Gene, die ebenso für Pilus-Untereinheiten codieren, jedoch verglichen zur HauptStrukturkomponente in gereingerer Menge synthetisiert werden und adaptorische Funktionen ausüben (KüHN et al. 1993, JonES et al. 1995).

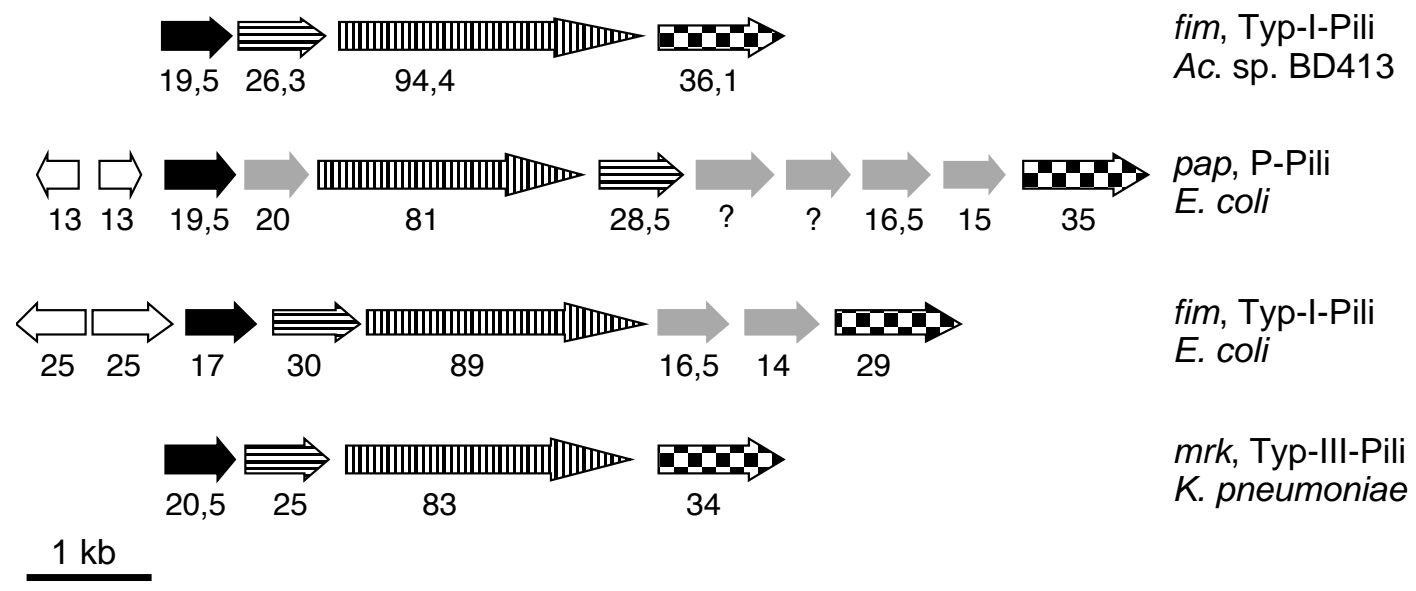

Abb. 3.49: Vergleich der Organisation des Acinetobacter fimA-Lokus mit konservierten Genclustern der Typ-I-Pili anderer Mikroorganismen. Die Gene sind durch Pfeile wiedergegeben und die molekularen Massen der Genprodukte unter den Pfeilen dargestellt. Die postulierte oder bewiesene Funktion der Genprodukte ist wie folgt markiert:

$\Rightarrow$ Hauptstrukturprotein

血岗 äußeres Membranprotein

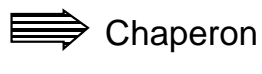

뵤 Adhäsin
Strukturprotein

Regulator

Der Vergleich der Gencluster, welche für die Familie der Typ-I-Pili codieren, zeigte, daß Acinetobacter die minimale Gen-Ausstattung für die Assemblierung der dünnen Pilusstrukturen besitzt. Zusammenfassend läßt sich sagen, daß die dünnen Pili von Acinetobacter sp. BD413 zur Familie der Typ-I-Fimbrien gehören. Neben dem Strukturgen sind stromabwärts des Genclusters konservierte Gene lokalisiert, die für seine Assemblierung und ein Adhäsin codieren. 


\subsubsection{Elektronenmikroskopische Darstellung des Untereinheitenaufbaus der dünnen Pili}

Die dünnen Pili von Acinetobacter sp. BD413 gehören zur Familie der Typ-I-Pili, die über den 'Chaperone/Usher'-Weg synthetisiert werden. Die Organellen dieser Pilus-K lasse sind i.d.R. zusammengesetzte Strukturen, wobei der Hauptteil gewöhnlich aus einem $7 \mathrm{~nm}$ dicken Pilus besteht, in dem die Untereinheiten in einer rechtsgängigen Helix angeordnet sind. Distal lokalisierte Adaptorproteine vermitteln als $3 \mathrm{~nm}$ breites Filament die Exposition des Adhäsins (JONEs et al. 1995, Russell \& ORNDORfF 1992). Hier sind mehrere untereinander ähnliche strukturelle Untereinheiten am Aufbau des Pilus beteiligt, dessen Gene in einem Cluster assoziiert vorliegen. Die dünnen Pili von Acinetobacter sp. BD413 werden aus nur einer Untereinheit aufgebaut, da im fim-Gencluster (und Genom) keine weiteren Strukturgene liegen, die Ähnlichkeiten zu Typ-I-Pilinen aufweisen (Abb. 3.49).

Für die Untersuchung der Untereinheitenstruktur der dünnen Pili von BD413 wurden diese von den Zellen abgeschert, mittels Ultrazentrifugation sedimentiert und über einen 20-70\%igen Saccharosegradienten gereinigt. Die Pilus-Fraktion des Gradienten wurde mit PBS auf eine Proteinkonzentration von $50 \square \mathrm{g} / \mathrm{ml}$ eingestelt und mit $4 \%$ Uranylacetat negativ kontrastiert.

Die hoch aufgelöste elektronenmikroskopische Abbildung 3.50 zeigt die Aneinanderreihung der Piline des dünnen Pilus von BD413 in linearer Form, wobei keine helikale Quartärstruktur ausgebildet wurde, die für die komplex aufgebauten Typ-I-Pili charakteristisch ist. Selten lagen die dünnen Pili als Einzelfilament vor, sondern aggregierten zu zweit oder mit einer Vielzahl ihresgleichen zu Bündeln, was auf eine hydrophobe Oberfläche hindeutete. Diese morphologischen Untersuchungen indizierten, daß die dünnen Pili von BD413 zur Untergruppe der als Fibrillen bezeichneten Typ-I-Pili gehören. Die Fibrillen ähneln den Adaptor-Strukturen, die bei den Pap-Pili von E. coli einen relativ langen dünnen Pilus von $3 \mathrm{~nm}$ Durchmesser bilden und als Bindemodul zwischen dem 7 nm-Pilus und dem Adhäsin fungieren (KüHN et al. 1993).

Acinetobacter sp. BD413 synthetisiert den 2-3 nm dünnen Pilus aus nur einer strukturellen Komponente, die in linearer Assemblierung möglicherweise das AdhäsinProtein exponiert. Die Komponente, die den für Typ-I-Pili charakteristischen basalen Bereich von $7 \mathrm{nmD}$ Durchmesser aufbaut, fehlt somit der Pilusstruktur von BD413. 
A

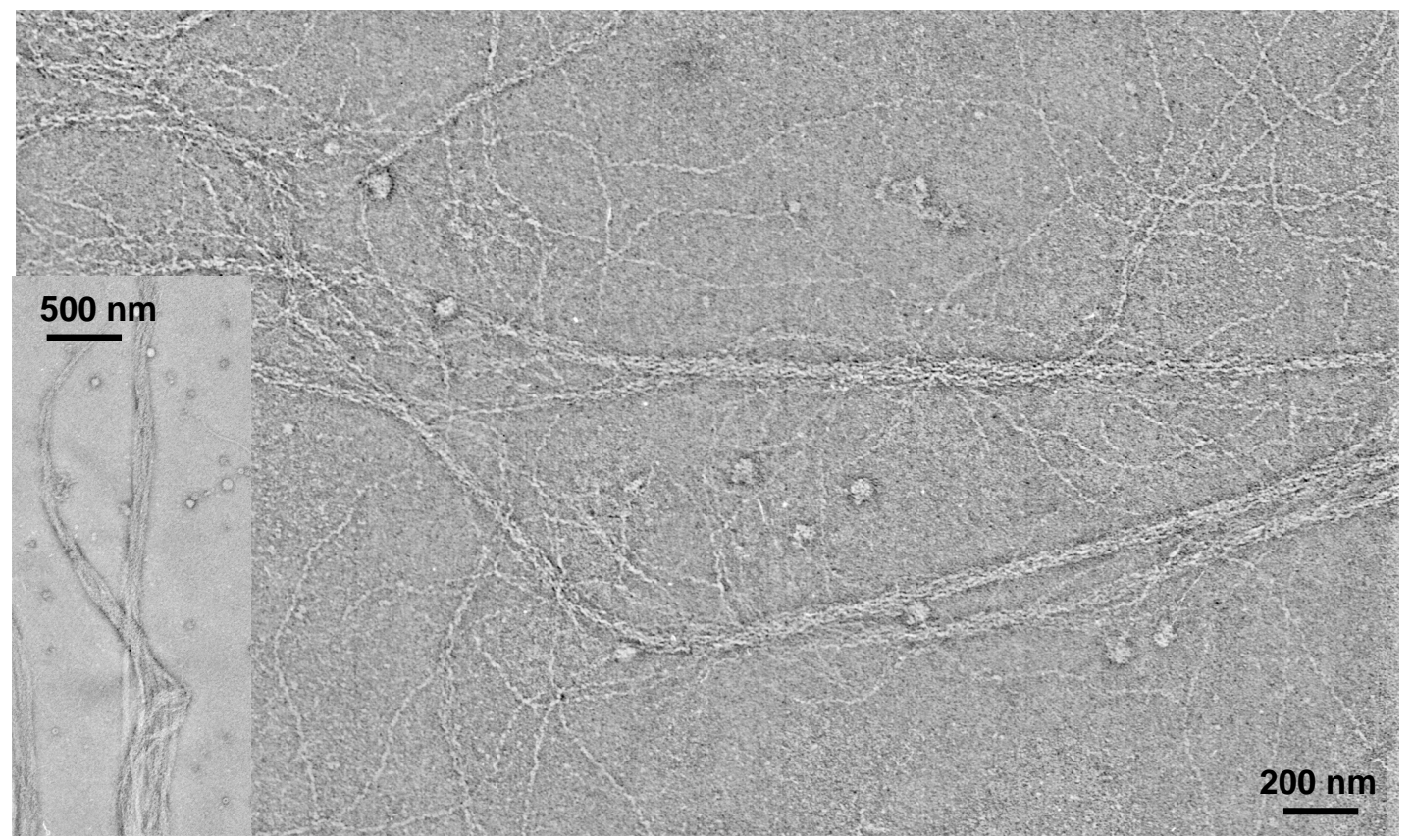

B
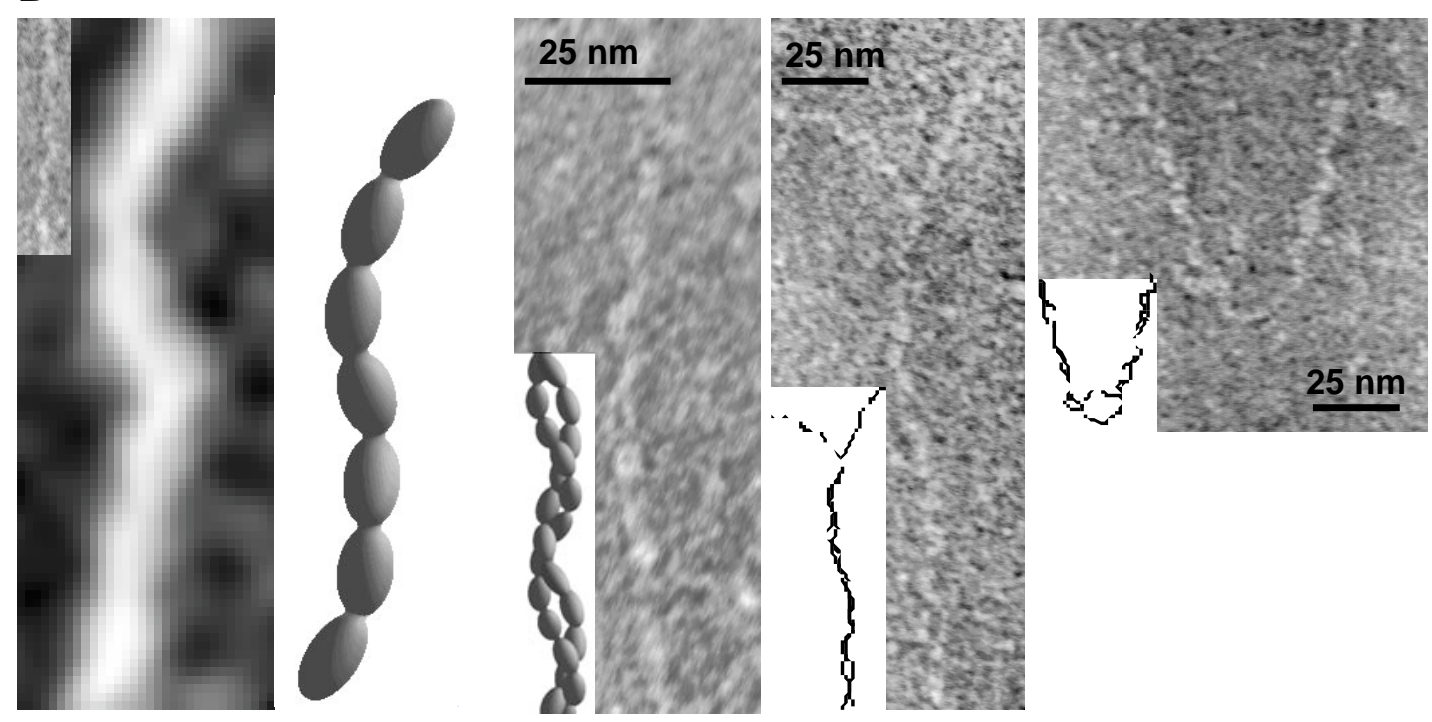

Abb. 3.50: Struktur der dünnen Pili von Acinetobacter sp. BD413. In de elektronenmikroskopischen Abbildung $(A)$ sind die bündelbildenden dünnen Pili dargestellt. Abbildung (B) zeigt Vergrößerungen einzelner und verdrillter Pilusfilamente unc schematisierte Darstellungen.

\subsubsection{Regulation der Expression der Pilusgene filA und fimA von Acinctobacter sp. B D413}

White-Ziegler et al. (2000) untersuchten die Regulation der Expression von Pilusgenen, die zu verschiedenen Klassen der Typ-I-Fimbrien gehören (pap, daa, fan). 
Niedrige Temperaturen, hohe Osmolarität, Glukose als Kohlenstoffquelle und Komplexmedien unterdrückten dieTranskription der untersuchten Operone.

Um Hinweise auf die Funktion der beiden Pilustypen von Acinetobacter sp. BD413 vor allem hinsichtlich des Selektionsvorteils am natürlichen Standort (Boden) - zu erhal ten und die Bedingungen ihrer Synthese mit denen pathogener Organismen zu vergleichen, wurden die Transkriptionsraten von filA und fimA bestimmt. Daß sich die globale Regulation mittels 'Quorum Sensing' bei Acinetobacter sp. BD413 von Mineral mediumzu Komplexmedium unterscheidet, wurde von GonZALES et al. (2001) gezeigt: Die Zahl der Signal moleküle im Kulturüberstand des Mineral mediums verdoppelte bzw. verdreifachte sich verglichen zu dejenigen Zahl im Komplexmedium

Für die Analyse der Genexpression wurden die DNA-Bereiche der potentiellen Piluspromotoren von filA bzw. fimA jeweils an das 5'-Ende eines lacZ-Gens kloniert. Das dafür eingesetzte Reporter-Gen, welches eine Ribosomen-Bindestelle aber keinen eigenen Promotor trägt, befindet sich auf dem Vektor pBK. Wird durch den stromaufwärts

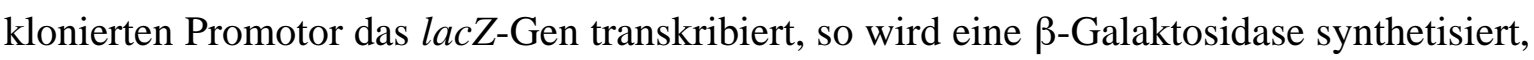
die im optisch-enzymatischen Test quantifiziert werden kann. Für das Pilusgen filA erfolgte zunächst die Amplifikation des potentiellen Promotorbereiches (390 bp) mit den Primern Di-lacZ-BamHI-N1 (5`CAAAATGTAGCAGGATCCAATCCGATAATCG-3') und DiDel2-Xbal (5`-CCAAAGCCAATCTAGAGAATATTTTCATTC-3`). Das PCRProdukt bestand aus 375 bp, die vor dem postulierten ATG-Startcodon lokalisiert sind und aus 15 bp des 5 '-Endes von filA.

290 bp der Promotorregion des Pilusgen fimA wurden mit den Primern Dü-lacZBamHI-N1.2 (5`-TTTGAGATCGGATCCATTITTTTAAAAAG-3') und Dü-lacZ-XbalC1 (5`-CAAGTACTTGTAATCTCTAGACCATTAATCG-3’) amplifiziert. Das PCRProdukt bestand aus $190 \mathrm{bp}$, die vor dem postulierten ATG-Startcodon lokalisiert sind und aus 100 bp des 5'-Endes von fimA. Für eine Überprüfung der PCR-Produkte durch Sequenzierung erfolgte die Klonierung beider PCR-Produkte zunächst jeweils über die Schnittstellen BamHI und Xbal in pUC18, so daß die Plasmide pUK25 und pUN09 entstanden (Abb. 3.51). Nach Umklonierung über Restriktionsschnittstellen EcoRI und Xbal konnten die PCR-Produkte schließlich in den EcoRI und Xbal geschnittenen Vektor pBK ligiert werden. Im Plasmid pBN10 lag daraufhin die Promotorregion des fimA-Gens stromaufwärts des lacZ-Gens und in pBK27 die Promotorregion des filA-Gens vor dem lacZ-Gen (Abb. 3.51). Nach dem konjugativen Transfer in Acinetobacter sp. ADP239 konnte die $\square$-Galaktosidaseaktivität im Verlauf des statischen Wachstums bestimmt und somit die promotorabhängige Transkriptionsrate in 'MILLER Units' abgeleitet werden. Als Kontrolle diente der Vektor pBK, welcher ebenso konjugativ in Acinetobacter übertragen wurde. Eine damit durchgeführte Nullwertbestimmung ergab keine meßbare $\square$ Galaktosidaseaktivität, so daß im folgenden Versuch die gemessene Aktivität auf die 
Promotoren von filA bzw. fimA zurückgeführt werden konnte. Aufgrund der im Vergleich zu den chromosomal lokalisierten Promotoren höheren Kopienzahlen der eingesetzten Plasmide, ließ sich die gemessene Aktivität nicht unmittelbar in eine absolute Transkriptionsrate übertragen. Nur die Relationen der Transkriptionsraten, die über die lacZ-Fusion des Promotors in pBK ermittelt werden, lassen sich miteinander vergleichen.

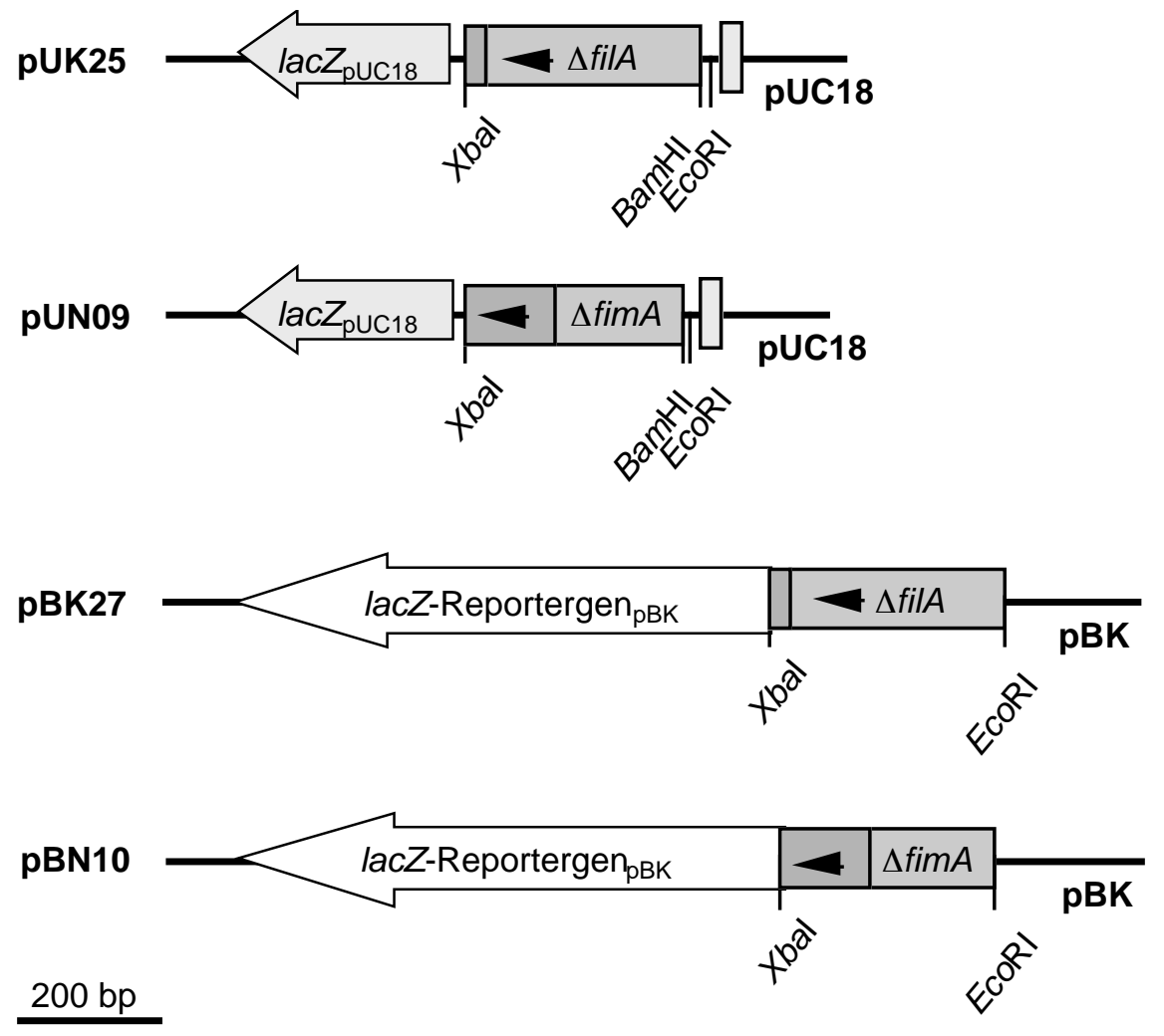

\begin{abstract}
Abb. 3.51: Plasmidkonstruktionen für die lacZ-Reportergen-Fusion von filA und fimA. Nach der Amplifikation der jeweiligen potentiellen Promotorbereiche von filA bzw. fimA erfolgte zunächst die Klonierung in pUC18 und nachfolgend in $\mathrm{pBK}$, der das promotorlose lacZ-Reportergen trägt. Vor dem filA-ATG-Startcodon liegen $375 \mathrm{bp}$ und vor dem fimAStartcodon 190 bp kloniert vor ( $\square$ filA bzw. $\square$ fimA). Die in dunkelgrauer Farbe dargestellten Bereiche symbolisieren die 15 bp bzw. 100 bp DNAFragmente nach den Startcodons. Die Pfeile geben die Richtung der Transkription an. Dargestellt sich nur die für die Klonierungen relevanten Schnittstellen. Das lacZ-Gen von pUC18 gibt die Leserichtung des vektoreigenen Promotors an.
\end{abstract}

Zur Messung der wachstumsabhängigen Transkription in statischer Kultur wurden $50 \mathrm{ml}$ Succinat-Mineral medium oder LB-Medium mit einer ausgewachsenen Vorkultur $10 \%$ ig angeimpft und bei $30^{\circ} \mathrm{C}$ oder $37^{\circ} \mathrm{C}$ schüttelnd inkubiert. Zu verschiedenen Zeitpunkten wurden Proben entnommen und sowohl das Kulturwachstum über die optische Dichte verfol gt als auch die [-Gal aktosi daseaktivität bestimmt. Diese wurde nach MILLER 
(1972) durch Umsetzung von o-Nitrophenolyl-[-D-Galaktopyronosid (ONPG) zu oNitrophenol pro Zeit und pro Zelldichte bestimmt. In diesem Versuch wurde die Zeldichte der Proben auf die $\mathrm{OD}_{600}$ von 0,1 eingestellt und die Reaktionsansätze für die gleiche Zeitdauer inkubiert, so daß als einzige Variable die von der Zelle in unterschiedlicher

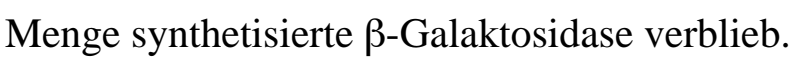
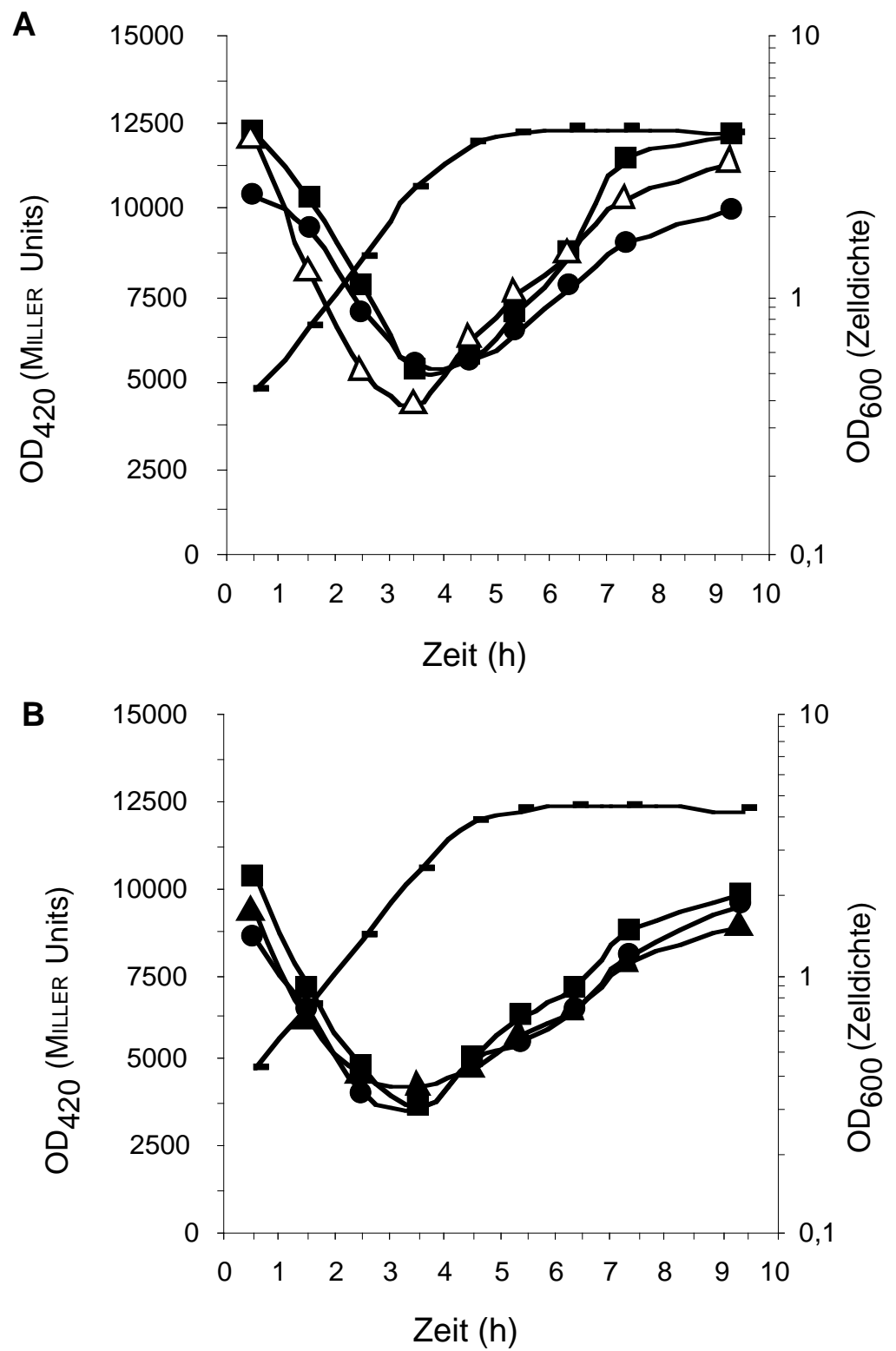

Abb. 3.52: Expression der Pilusgene filA und fimA. Di Promotoraktivität von filA (A) und fimA (B) wurden als lacZTranskriptionsfusion im Verlauf einer statischen Kultur (-) bestimmt. Die Promotorregionen wurden jeweils vor das lacZ-Gen kloniert und die $\square-$ Galaktosidaseaktivität im enzymatischen Test bestimmt. Di Wachstumsbedingungen variierten von $30^{\circ} \mathrm{C}$ in Mineralmedium ( $)$ und $37^{\circ} \mathrm{C}$ in Mineralmedium (A) sowie $30^{\circ} \mathrm{C}$ in Komplex- (LB-) Medium ( $)$. 
Die Expressionsrate der Gene beider Pilusuntereinheiten lag wie erwartet relativ hoch, da die Pilusstrukturen in großer Zahl auf der Zelloberfläche synthetisiert werden. Verglichen zur exponentiellen Wachstumsphase verdoppelte sich die Expression in der stationären Phase. Für fimA wurden in der stationären Phase 10000 MILLER Units erreicht, nach dem Überimpfen in frisches Medium fiel der Wert bis zum Ende des exponentiellen Wachstums auf 4000 MILLER Units, um mit Beginn der stationären Phase wieder anzusteigen (Abb. 3.52). filA zeigte ein ähnliches Expressionsprofil, wobei hier Werte von 5000 bis 12000 MILLER Units erreicht wurden. Der Wechsel von Mineral- zu Komplex(LB-) Medium oder der Temperaturanstieg von $30^{\circ} \mathrm{C}$ auf $37^{\circ} \mathrm{C}$ führte in beiden Fällen nicht zu einer veränderten Genexpression. Aus diesem Grund mulste hier eine Regulation vorgelegen haben, die unter den gewählten Bedingungen und Kohlenstoffquellen allein von der Wachstumsphase und/oder Zelldichte, nicht aber von der Mediumzusammensetzung und der Wachstumstemperatur abhängt.

\subsubsection{Untersuchung auf Adhäsion an hydrophobe O berflächen}

Wie unter 3.6.5.1 beschrieben war die dicke Pilusstruktur von Acinetobacter sp. BD413 mit einem Durchmesser von $6 \mathrm{~nm}$ keinem bekannten Pilustyp zuzuordnen und seine Funktion in der Physiologie des Bakteriums ist ebenso unbekannt. Der dünne Pilus mit einem Durchmesser von 2-3 nm konnte hingegen aufgrund seiner A minosäuresequenzÄhnlichkeit und seiner chromosomalen Lage innerhalb eines charakteristischen Genclusters zur Klasse der Typ-I-Pili zugeordnet werden (3.6.8.1).

ROSENBERG et al. beschrieben bereits 1980 und 1981 die pilusabhängige Adsorption des zu BD413 verwandten Stammes Acinetobacter RAG-1 an hydrophoben Oberflächen. Dieser Stamm RAG-1 synthetisiert dünne und dicke Pili, die morphologisch denen von Acinetobacter sp. BD413 gleichen. Weiterhin demonstrierten sie die Fähigkeit des Stammes BD413 zur Adsorption an hydrophobe Oberflächen, wobei die dafür verantwortliche Zelloberflächen-Strukturen hierbei nicht charakterisiert wurden. Die generierten Pilus-defekten Stämme mit Unterbrechungen in den Strukturgenen filA bzw. fimA sollte nun dazu dienen, dieZelladsorption an hydrophobe Flächen zu spezifizieren.

Der Stamm ADP239, der den Wildtyp repräsentierte, sowie die Mutanten K101 (fil $\left.A^{-}\right), N 100$ (fimA $A^{-}$) und KN100 (filA-/fimA $A^{-}$) wurden zunächst über Nacht angezogen und nach dem A bzentrifugieren mit frischem Succinat-Mineral medium auf die gleiche optische Dichte eingestellt. Als hydrophobe Oberfläche wurden leere Petrischalen aus Polystyren genutzt, auf die $2 \mathrm{ml}$ Zellsuspensionen gegeben wurden. Nach 1,5stündiger Inkubation und darauffol gendem A bwaschen der Zellen konnten die verbliebenden, adsorbierten Bakterien durch ein aufgelegtes Deckglas im Lichtmikroskop betrachtet werden. Der Stamm ADP239 und die Mutante K101, die keine dicken Pili synthetisierte, zeigten gleichmäßig 
verteilt liegende Einzelzellen und charakteristische Diplokokken, wobei dieZellen ca. 80\% der Petrischal enfläche bedeckten (Abb. 3.53, 1/2). Die Zellen der fimA-Mutante N100, die keine dünnen Pili synthetisierte, und die der Pilusdoppelmutante KN100 adhärierten dagegen signifikant in geringerer Zahl, lagen ungleichmaßig verteilt und bedeckten nur eine Fläche von ca. 5\% (Abb. 3.53, 3/4). Auf die Pilusstrukturen bezogen bedeutete dies, daß die Zellen bei der Anwesenheit beider Pilustypen oder allein der dünnen Pili an die hydrophobe Oberfläche adsorbierten; waren dagegen keine Pili oder ausschließlich die dicken Pili vorhanden, so verringerte sich die Adsorbtion unter den gewählten Bedingungen signifikant. Daraus war zu schließen, daß die dünnen Pili an der Adsorption beteiligt waren, während die dicken Pili keine fördernde oder inhibierende Wirkung diesbezüglich ausübten.
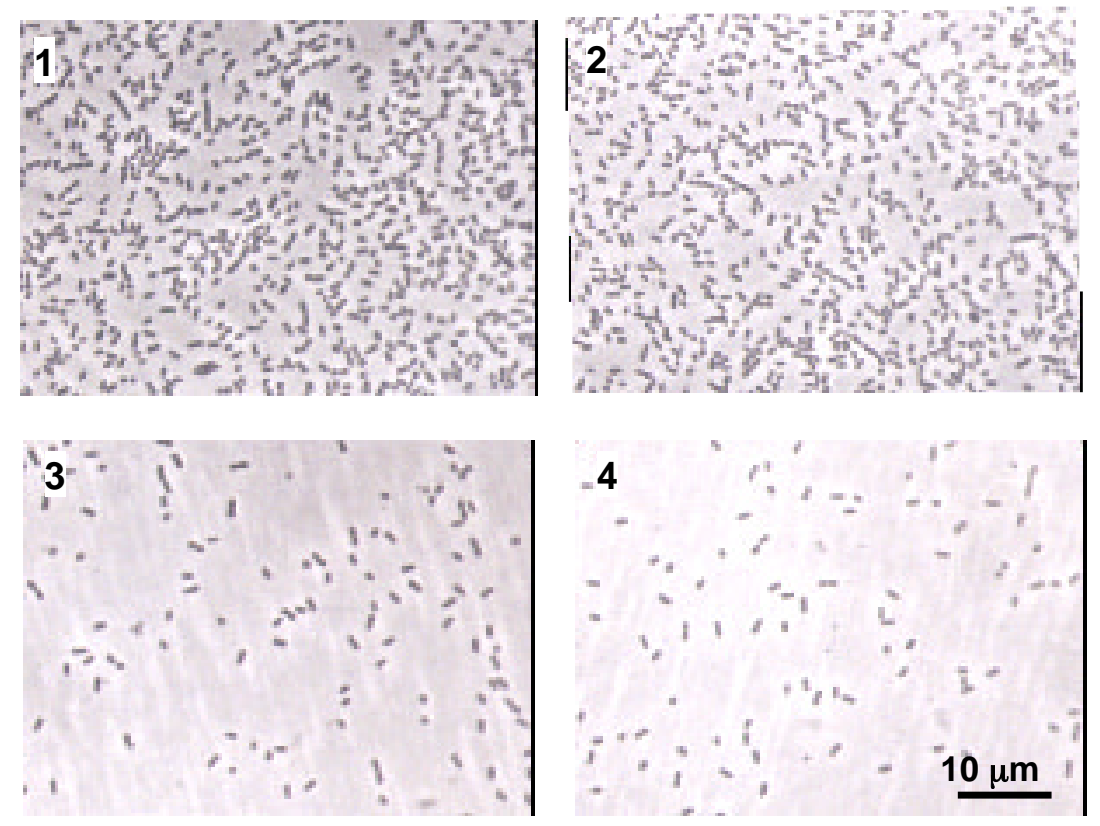

Abb. 3.53: Adhäsion an Polystyren von Acinetobacter. II Succinat-Mineralmedium über Nacht angezogene Zellen wurden nach Zentrifugation in frisches Mineralmedium resuspendiert und für $1,5 \mathrm{~h}$ in einer leeren Petrischale aus Polystyren inkubiert. Nach dem Abwaschen der nicht gebundenen Bakterien wurden die adsorbierten Zellen lichtmikroskopisch betrachtet. (1) ADP239; (2) K101 (filAMutante); (3) N100 (fimA-Mutante); (4) KN100 (filA-/fimA-Mutante)

\subsubsection{Untersuchungen zur Bindung an E rythrocyten}

Die größte Zahl der bisher untersuchten tier- und pflanzenpathogenen Bakterien synthetisieren Pili (Fimbrien) zur Exposition spezifischer Adhäsine, die als Bindungselement an die Wirtszelle dienen. Diese filamentösen Oberflächenstrukturen fungieren demnach - zusammen mit weiteren Faktoren - als erstes Auswahl organ, welches 
die Besiedel ung ausschließlich spezifischer Wirtszellen ermöglicht, die das dazu passende Sortiment an Rezeptoren aufweisen. Pili können anhand einer Zahl von Eigenschaften klassifiziert werden, wobei die wichtigste davon ihre Rezeptorspezifität darstellt. Für TypI-Fimbrien ist es i.d.R. ein grundl egendes Charakteristikum, die Fähigkeit zu vermitteln, Erythrocyten zu agglutinieren. Da der identifizierte dünne Pilus von Acinetobacter sp. BD413 Ähnlichkeiten zur Klasse der Typ-I-Fimbrien aufweist und da das Strukturgen fimA das erste Gen eines Genclusters darstellt, welches für typische Assemblierungsfaktoren und ein Adhäsin (3.6.8.2) codiert, wurde im Folgenden die Fähigkeit des Starmes BD413 an Rote Blutkörperchen zu adhärieren untersucht. Um zusätzlich zum Verhalten des dünnen Pilus dasjenige des dicken Pilus zu analysieren, wurden die Adhäsion der drei Pilusmutanten K101 (filA'), N100 (fimA) und KN100 (fil $A^{-} / f i m A^{-}$) mit der des Wildtypstammes ADP239 verglichen.

3 ml-Kulturen der Acinetobacter-Stämme wurden über Nacht in SuccinatMineral medium angezogen, mit $5 \mathrm{ml}$ PBS (Phosphat-gepufferte Saline) gewaschen und nach der Resuspendierung in 500 I I PBS zu 200 II der im Ficoll-Gradienten gereinigten humanen Erythrocyten gegeben. Nach 2 h Inkubation wurden die sich abgesetzten Blutzellen zweimal mit $1 \mathrm{ml}$ PBS gewaschen, um nicht adsorbierte Bakterien zu entfernen. Bei lichtmikroskopischer Betrachtung war daraufhin zu erkennen, daß nur der Wildtypstamm ADP239 und ebenso die filA-Mutante K101, welche nur dünne aber keine dicken Pili synthetisierte, Erythrocyten agglutinierten (Abb. 3.54, A). Diese Adsorption der Zellen wurde aufgrund der hohen Dichte der Bakterien in der Probe bestätigt; denn nicht gebundene Bakterien wären nach dem Waschschritt weitgehend entfernt worden. Die Inkubation der fimA-Mutante- defekt in der Biogenese der dünnen Pilusstruktur - oder der Doppel-Pilusmutante KN100 mit Erythrocyten führte nicht zu einer Agglutination (Abb. 3.54, A). Darüber hinaus schien die Oberfläche der Blutzellen weniger deformiert. In diesen beiden Proben wurden die Bakterien nach der gemeinsamen Inkubation mit den Erythrocyten durch den Waschschritt weitgehend entfernt. Die wenigen verbliebenen Bakterien lagen zudem frei, nicht assoziiert vor.

Um die Bindung mittels dünner Pili an der Oberfläche von Erythrocyten zu demonstrieren, wurden die Aggl utinationen el ektronenmikroskopi sch betrachtet. Da dünne, in Bündeln assoziierte Pili morphologisch von dicken Pili nur schwierig zu unterscheiden waren, erfolgte die Untersuchung nicht mit dem Wildtypstamm BD413 sondern mit der filA-Mutante K 101, die keine dicken Pili synthetisiert. Die Agglutination von Erythrocyten mit Bakterien wurde mit Phosphorwolframsäure $(\mathrm{pH} 7,4)$ kontrastiert, da der saure $\mathrm{pH}$ Wert des Uranylacetats ( $\mathrm{pH} \mathrm{4,0)}$ die Erythrocyten lysierte. Wie bereits lichtmikroskopisch erkennbar gewesen war, gruppierten sich die Bakterien um die Erythrocyten (Abb. 4.54, B). Die Deformierung der eukaryontischen Zelle war vermutlich auf die mechanischen 
Kräfte zurückzuführen, die durch die Negativkontrastierung und das nachfolgende Trocknen entstanden. In schmalen Zwischenräumen, die zwischen Bakterien und Erythrocyt erkennbar waren, zeigten dünne Pili eine starre Ausrichtung in Richtung eukaryotischer Zelloberfläche (Abb. 3.54, B). Daß die Zellen keinen direkten Kontakt zu den Blutkörperchen zeigten, sondern einen Abstand von 50-100 nm aufwiesen, war vermutlich zum einen auf das an der Spitze des Pilus Iokalisierte Adhäsin und die Abstoßungskräfte der Zelloberflächen untereinander zurückzuführen.
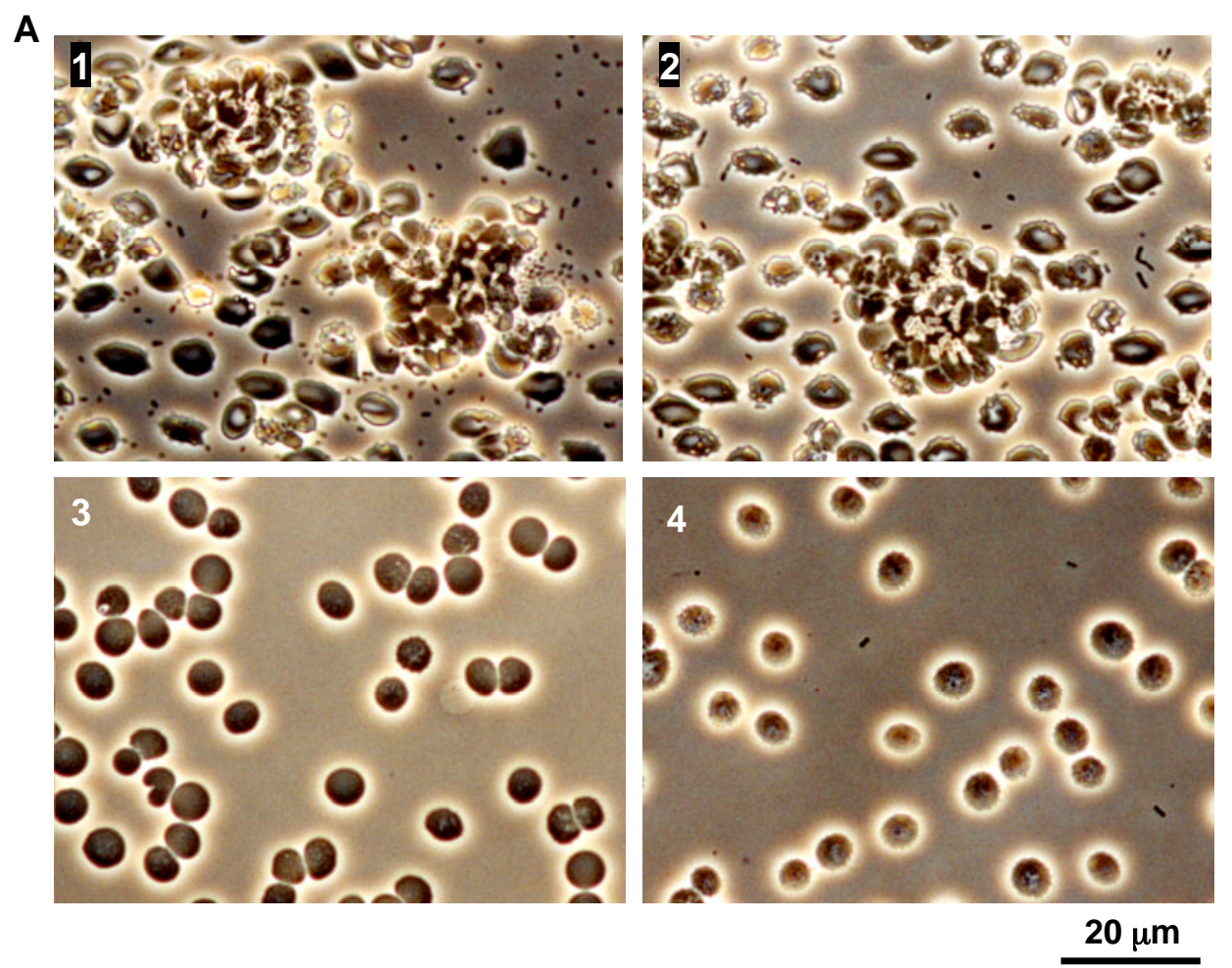

B
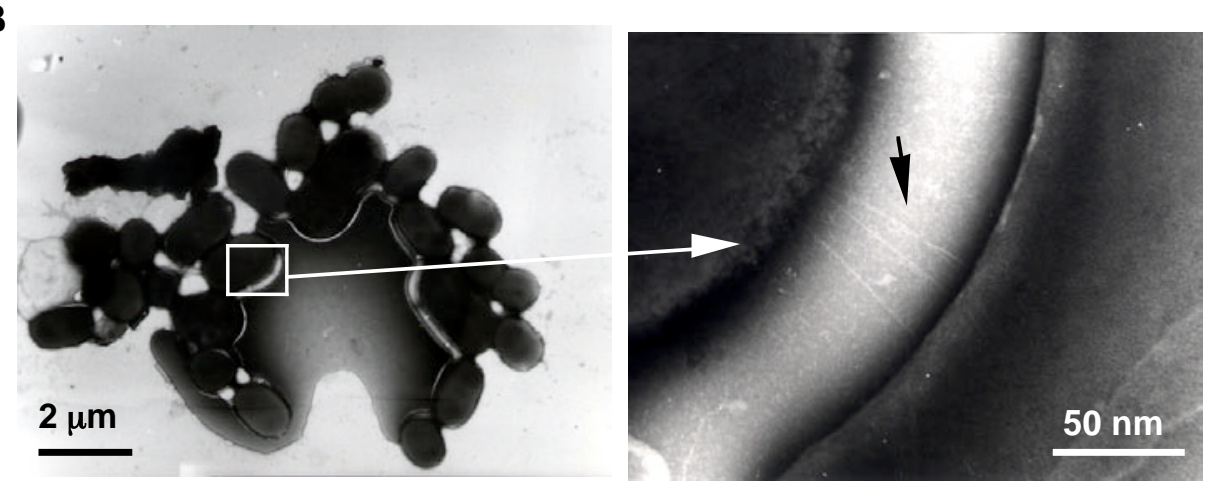

Abb. 3.54: Darstellung der Agglutination von Erythrocyten durcr Acinetobacter sp. BD413. (A) Lichtmikroskopische Abbildung der Bindung an E rythrocyten von ADP239 (1), K101 (filA-Mutante) (2), N100 (fimA-Mutante) (3) und KN100 (filA-/fimA-Mutante) (4). (B) Elektronenmikroskopische Aufnahme der Adhäsion von K101 (filA-Mutante) an ein Rotes Blutkörperchen. Der schwarze Pfeil markiert dünne Pili, die vom Bakterium zur Blutzelle orientiert sind. 
Die Agglutination Roter Blutkörperchen durch Acinetobacter sp. BD413 mittels der dünnen Pilusstrukturen demonstrierte, daß dieser Pilustyp die für Typ-I-Pili charakteristische Eigenschaft der Adhäsion an Erythrocyten besitŁt. Diese Untersuchung zeigten weiterhin, daß̧ nur die dünnen, Typ-I-ähnlichen Pili von Acinetobacter sp. BD413 Erythrocyten zu agglutinieren vermochten; die dicken Pili hingegen erwiesen sich diesbezüglich als weder förderlich noch inhibierend.

\subsection{Untersuchungen zur Synthese einer Pilusstruktur durch den DNA-A ufnahmeapparat}

Die Unterbrechungen der Gene filA und fimA, die für die Strukturuntereinheiten der dicken und dünnen Pili codieren, hatte die Generierung der Doppelmutante KN100 ermöglicht, die keine filamentösen Strukturen auf der Zelloberfläche synthetisiert. Dies bedeutete, daß Acinetobacter sp. BD413 keine Typ-IV-Pili bildet und demzufolge zu der Gruppe derjenigen Organismen gehört, dessen Typ-IV-Pilin-ähnliche Proteine des Transformationssystems zu keinen Pilusstrukturen assemblieren, die auf der Zelloberfläche sichtbar wären. Das Pilin-ähnliche Kompetenzprotein ComP aus Acinetobacter sp. BD413, welches keine Pilusstruktur ausbildet, sollte durch eine Erhöhung seiner Expression hinsichtich seinem Potential zur Filamentsynthese untersucht werden. Hierfür diente der Stamm KN100, der keine filamentösen Strukturen aufweist und das Plasmid pBK27, welches den starken filA-Piluspromotor trägt (Abb. 3.52, 3.6.7).

\subsection{1 Überexpression des Pilin-ähnlichen Proteins C omP}

Zunächst mulste das comP-Gen (mit seiner Ribosomen-Bindestelle) als 540 bp-DNAFragment amplifiziert werden, welches mit den Primern ComP-Xbal-N (5'CCAACGCGAAATAAAATCTAGACATTGGTG-3') und ComP-blunt-C (5'-AAAT ACACCAGAAACTATCGTGTAATTT-3') erfolgte. Über die N-terminale Schnittstelle Xbal und das C-terminale glatte Ende konnte das PCR-Produkt in pBK27 (Abb. 3.51) kloniert werden, welches zuvor mit Pstl geschnitten, daraufhin mit Klenow-Fragment behandelt und mit Xbal restriktionsverdaut wurde. Nach der Ligation befand sich comP stromabwärts des starken filA-Promotors (A bb. 3.55). Das resultierende Plasmid pBK 35 wurde schließlich konjugativ sowohl in Acinetobacter sp. KN100 als auch in die comPMutante T206 transferiert. 


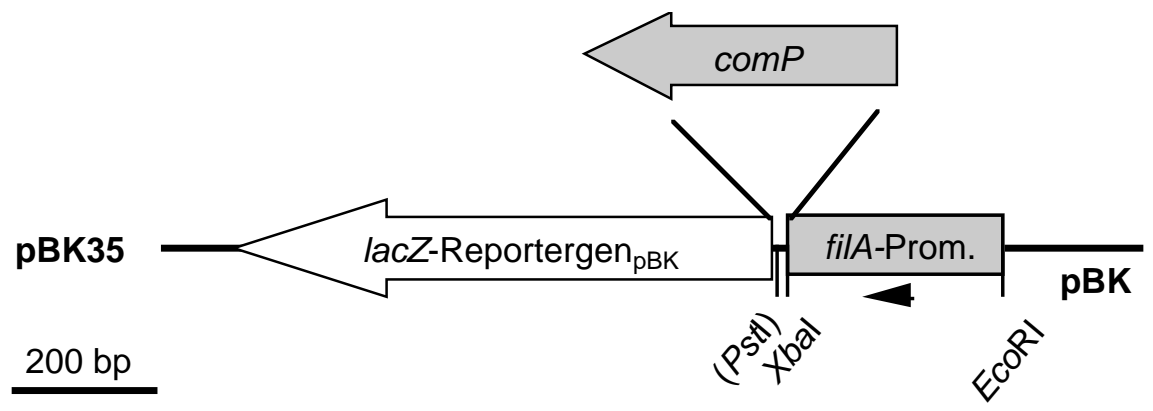

\begin{abstract}
Abb. 3.55: Plasmidkonstruktion für die Überexpression von comP durch den filA-Promotor. Nach der Amplifikation von comP erfolgte die Klonierung in pBK27 (Abb. 3.52), der den filA-Promotor (filA-Prom.) trägt. Am 5 '-Ende von comP wurde die Xbal-Schnittstelle genutzt, das $3^{\prime}$-Ende wurde hingegen nach Behandlung mit Klenow-Enzym mit glatten DNAEnden ligiert. Der Pfeil gibt die Richtung der Transkription an. Dargestellt sich nur die für die Klonierungen relevanten Schnittstellen. Da das comPGen eine Terminatorsequenz enthält, wird das lacZ-Reportergen nicht transkribiert. Nach der Integration des comP-Gens kann die PstlSchnittstelle nicht mehr restriktionsverdaut werden.
\end{abstract}

Mit Hilfe von Acinetobacter sp. T206 pBK35 konnte die Wirkung des überexprimierten Strukturproteins ComP auf die natürliche Transformation untersucht werden. Während der Stamm T206 einen vollständigen Transformationsdefekt aufweist (PoRstendöRfer et al. 1997), konnte die Komplementation dieses Defekts durch das Plasmid pBK35 in dem Transformationsschnelltest untersucht werden. Der positive Transformationstest bestätigte die Komplementation durch das Plasmid pBK35 in dem Stamm T206, da Wachstum auf p-Hydroxybenzoat erfolgte.

In Acinetobacter sp. KN100 pBK35 ließ sich das überexprimierte ComP hinsichtlich der Pilusbildung untersuchen, indem zunächst der ComP-Gehalt in den Scherfraktionen der KN100-Stämme - mit und ohne Plasmid - verglichen wurde. Ein erhöhter ComP-Gehalt in der Scherfraktion könnte auf eine Pilusbildung hindeuten. Eine 1 I-Kultur wurden in Succinat-Mineral medium über Nacht in einem Kluyverkolben angezogen, geerntet und nach der Resuspendierung in 50 m PBS zweimal durch eine Kanüle gesprittt. Nach niedertouriger Zentrifugation stel Ite der Überstand die Scherfraktion da und das Sediment, welches nochmals gewaschen wurde, die Zellfraktion.

Für die immunologische Detektion von ComP wurden jeweils 0,2 पg Protein der Zel fraktionen (nach der Scherbehandlung) und $50 \mathrm{I}$ I der Scherfraktionen in einer 15\%igen SDS-PAGE aufgetrennt und nach dem WESTERN Blotting mit Anti-ComP-Antikörper behandelt. Die Detektion lieferte Signale identischer Intensität in den Zell fraktionen der KN100-Stämme, in denen comP einerseits von seinem eigenen Promotor transkripiert und andererseits durch den starken Piluspromotor überexprimiert wurde (Abb. 3.56, 1/2). Signale unterschiedlicher Intensität waren dagegen in den Scherfraktionen zu erkennen: 
Während Acinetobacter sp. KN100, der hinsichtlich der ComP-Synthese den Wildtyp repräsentiert, nur eine schwach erscheinende Bande aufwies, lieferte der Stamm KN100, der das Plasmid pBK35 trägt, ein Signal stärkerer Intensität (Abb. 3.56, 3/4). Dies bedeutet, daß der ComP-Gehalt nach seiner verstärkten Synthese außerhalb der Zelle erhöht ist, in der Zelle dagegen verglichen zum Wildtyp in ähnlicher Konzentration vorliegt

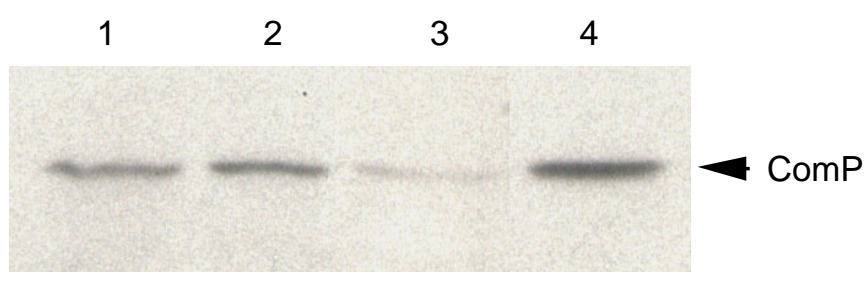

\begin{abstract}
Abb. 3.56: Detektion von ComP in Zelllysat und Scherfraktion. ComP wurde mit Hilfe des starken filAPiluspromotors in Acinetobacter KN100 überexprimiert. Die Zellen wurden über Nacht in Succinat-Mineralmedium angezogen, geerntet und die filamentösen Strukturen von der Zelle geschert. Der ComP-Gehalt im Zelllysat (Spur 2) und in der Scherfraktion (Spur 4) wurde nach der Auftrennung in einer 15\% igen SDS-PAGE in einem Immunoblot bestimmt. Als Kontrolle diente der Stamm KN100, der nur das chromosomal lokalisierte Wildtypallel trägt, und von dem ebenso das Zelllysat (Spur 1) und die Scherfraktion (Spur 3) mit AntiComP-Antikörpern detektiert wurden.
\end{abstract}

Der erhöhte Export von ComP nach Überexpression kann sowohl zu einer Pilusstruktur als auch zur Sekretion von ComP-Monomeren ins Medium geführt haben. Diese beiden Möglichkeiten sollten mittels elektronenmikroskopischer Betrachtung von Acinetobacter sp. KN100 pBK35-Zellen untersucht werden. Die Bakterien wurden in Succinat-Mineralmedium über Nacht angezogen gewaschen und mit $4 \%$ Uranylacetat kontrastiert. In mehreren unabhängigen Anzuchten konnten daraufhin bei $5-10 \%$ der Zellen ein oder zwei Pili identifiziert werden, die eine Länge von maximal $1 \square$ merreichten (A bb. 3.57). Einige Pili lagen als A bruchfragmente vor, was auf einen instabilen Charakter dieser Filamente hindeutete. Weiterhin wiesen die Strukturen einen Durchmesser von 5$6 \mathrm{~nm}$ auf. Verglichen zu den flexiblen dicken Pili von Acinetobacter, die einen Durchmesser von $6 \mathrm{~nm}$ besitzen, zeigten die hier erkennbaren Strukturen einen relativ starren und brüchigen Aufbau. Auf der Zell oberfläche von KN100, der comP vomeigenen Promotor transkribiert, waren keine filamentösen Strukturen zu erkennen (Abb. 3.33). 

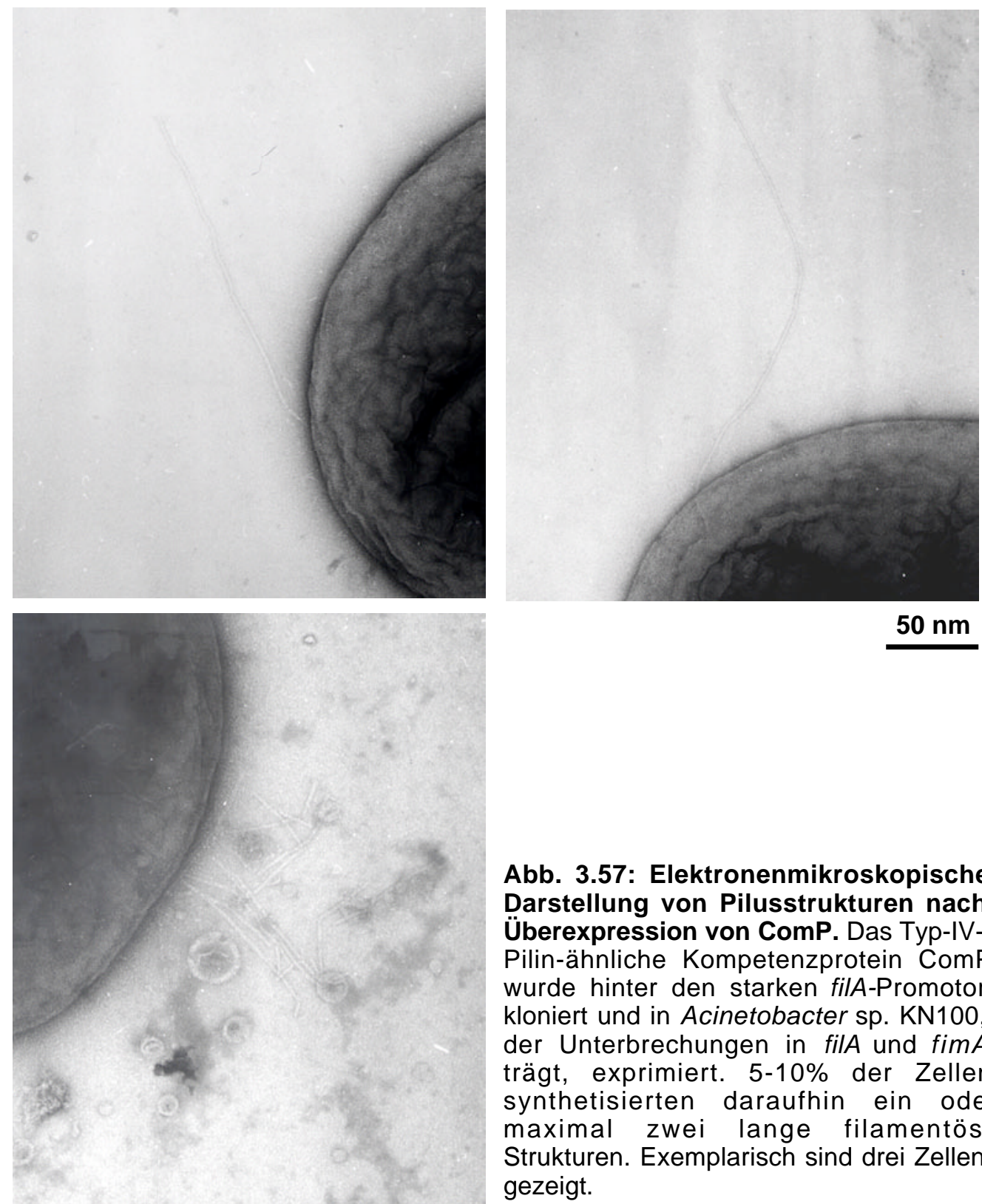

$50 \mathrm{~nm}$

Abb. 3.57: Elektronenmikroskopisch€ Darstellung von Pilusstrukturen nach Überexpression von ComP. Das Typ-IV$P$ ilin-ähnliche Kompetenzprotein ComF wurde hinter den starken filA-P romotor kloniert und in Acinetobacter sp. KN100, der Unterbrechungen in filA und fimA trägt, exprimiert. 5-10\% der Zeller synthetisierten daraufhin ein ode maximal zwei lange filamentös Strukturen. Exemplarisch sind drei Zellen gezeigt.

Die Untersuchungen demonstrierten, daß ComP nach der Expression durch den starken filA-Promotor in der Scherfraktion angereichert vorlag und daß dies auf die Assemblierung von ComP in einePilusstruktur zurückzuführen war. Diese Überexpression von ComP führte nicht zu einer Beeinträchtigung der natürlichen Transformation. 


\section{Diskussion}

\subsection{Struktur und Funktion der Pili von Acinetobacter sp. BD413}

Die physiologische und molekularbiologische Untersuchung von Transformationssystemen verschiedener natürlich kompetenter Bakterien zeigte einerseits die nahe phylogenetische Verwandtschaft der DNA-A ufnahmeapparate untereinander und führte andererseits zur Identifizierung eines hoch komplexen DNA-Transportsystems, dessen Mechanismus immer noch weitgehend unverstanden ist. Das Typ-IVPilusbiogenesesystem und der Typ-II-Transportweg stellen zum DNA-A ufnahmeapparat homologe Systeme dar, so daß bei der Interpretation des Zusammenspiels der einzel nen Proteine die Untersuchungsergebnisse al ler drei Systeme herangezogen werden können. Da Komponenten der Typ-IV-Pilusbiogenese nicht nur denjenigen des Transformationssystems ähnlich sind, sondern bei genetisch kompetenten Bakterien direkt in die Transformation involviert sind, stellte sich für Acinetobacter sp. BD413 die Frage, ob seine Pilusstrukturen zur Familie der Typ-IV-Pili gehören und ebenso an der natürlichen Transformation beteiligt sind. Vor dem Hintergrund, daß Acinetobacter sp. BD413 die Fähigkeit der gleitenden Fortbewegung besitt und Typ-IV-Pili eine spezielle Art der Bewegung vermitteln, die 'Twitching Motility' genannt wird, stelte sich weiterhin dieFrage, ob diePili von BD413 in das Gleiten involviert sind.

Acinetobacter sp. BD413 bildet zwei unterschiedliche Pilustypen, die auf der Zelloberfläche peritrich angeordnet sind. Zum einen sind dies dünne, bündel bildende Filamente, die Durchmesser von 2-3 nm aufweisen und zum anderen dicke, flexible Strukturen von ca. $6 \mathrm{~nm}$ im Durchmesser. Durch die Aufreinigung der Pilusstrukturen und die N-terminale Ansequenzierung der Untereinheiten konnten die entsprechenden Gene identifiziert und charakterisiert sowie Studien an Pilusmutanten angestellt werden.

\subsubsection{Die Pilusstrukturen sich nicht an der natürlichen Transformation beteiligt}

Die Untersuchungen dieser Arbeit indizierten, daß die dicken und dünnen Pili von Acinetobacter sp. BD413 weder in die natürliche Transformation noch in die gleitende Bewegung des Bakteriums involviert sind (3.6.6.). Die dünnen Pili konnten der Familie der Typ-I-Pili zugeordnet werden, während die dicken Pili eine neve Pilusklasse darstellen, die 
bisher nicht beschrieben ist (3.6.7/3.6.8). Da Acinetobacter sp. BD413 neben den beiden genannten Pilustypen keine weitere Filamentklasse synthetisiert, kann davon ausgegangen werden, daß das Bakterium keine auf der Zelloberfläche sichtbaren Typ-IV-Pili bildet. Diese Ergebnisse der physiologischen Untersuchungen stimmen mit den Untersuchungen überein, die zeigten, daß nur Typ-IV-Pili diegleitende Fortbewegung 'Twitching Motility' und bei bestehender genetischer Kompetenz die DNA-Aufnahme vermitteln; für einen anderer Filamenttyp dagegen konnten diese beiden Funktionen nicht nachgewiesen werden (BRAdly 1980, Merz et al. 2000, Jeffrey et al. 2001). Daß Acinetobacter sp. BD413 zwei Pilustypen synthetisiert, die nicht in Transformation und Fortbewegung involviert sind, stimmt weiterhin mit den vorangegangenen Untersuchungen transformationsdefekter BD413-Mutanten überein: Defekte in den Pilin-ähnlichen Kompetenzfaktoren ComB, -E, F und ComP sowie im ComC-Protein, welches Ähnlichkeiten zu Pilusbiogenesefaktoren aufweist, und dem Sekretin ComQ führten nicht zu einem veränderten Pilusphänotyp und nicht zu einer Beeinträchtigung der gleitenden Fortbewegung (PORSTENDÖRFER et al. 1997, LinK et al. 1998, BusCH et al. 1999, HERZBERG et al. 2000, RosenPLÄNTER pers. Mitteilung).

Da Acinetobacter sp. BD413 keine Typ-IV-Pili synthetisiert, gehört das Bakterium zu derjenigen Gruppe von Mikroorganismen, dessen Kompetenzproteine Ä hnl ichkeiten zu Komponenten der Typ-IV-Pilusbiogenese aufweisen, aber keine Typ-IV-Pili ausbildet. Zu dieser Gruppe gehören ebenso die natürlich kompetenten Gram-positiven Bakterien, wozu die gut untersuchten Organismen Bacillus subtilis und Streptococcus pneumoniae zählen, und das Gram-negative Bakterium Haemophilus influenzae (CHUNG \& DUBNAU 1998, BRIAN \& SMITH 1999).

\subsubsection{Die Pilusstrukturen von Acinetobacter sp. BD413 sind nicht an der gleitenden F ortbewegung beteiligt}

In dieser Arbeit konnte gezeigt werden, daß Acinetobacter sp. BD413 ohne Pilusstrukturen bei hoher Luftfeuchtigkeit auf festen Oberflächen gleitet (3.6.6.2). Da die Pilusstrukturen von Acinetobacter sp. BD413 nicht in die gleitende Bewegung involviert sind und da das Bakterium keine Typ-IV-Pili synthetisiert, kann das Gleiten der Zellen nicht auf Typ-IV-Pilus-vermittelter 'Twitching Motility' beruhen, sondern muß Pilusunabhängig erfolgen. Daß das 'Twitchen` an die Synthese von Typ-IV-Pilusstrukturen gebunden ist, zeigten zahl reiche Untersuchungen von BRADLY (1980), MERZ et al. (2000) und J EFFREY et al. (2001). An den Zel polen effolgt zunächst die Assemblierung der TypIV-Piline in eine bis zu mehreren Mikrometern lange filamentöse Struktur, die an festen Oberflächen, Wirtszellen oder anderen Bakterien bindet. Daraufhin führt die 
Deassemblierung der Pilinezu einer Retraktion des Pilus, was in einem Vorschub der Zelle resultiert.

Gleitende Fortbewegungen wurden bereits 1975 von HENRICHSEN und BLOM an unterschiedlichen Acinetobacter-Stämme untersucht. Sie demonstrierten bei fünf von 16 Stämmen 'Twitching Motility', was mit dem Vorhandensein polar angeordneter Pili korrelierte, die Durchmesser von 5-6 nm aufwiesen, und aufgrund des beobachteten Gleitens und der Morphologie der Pilusstrukturen der Familie der Typ-IV-Pili zugeordnet wurden. Unbewegl iche Acinetobacter-Stämme wiesen keine an den Zell polen lokal isierte Pili auf. Der Starmm BD4 unterschied sich von den genannten fünf gleitenden Stämmen in der Ausbildung von relativ weiten aus einer oder wenigen Zellschichten aufgebauten Kolonierändern, was nach HENRICHSEN und BLOM (1975) nicht auf 'Twitching' sondern 'Sliding' zurückzuführen war. 'Sliding' stellte ihrer Meinung nach eine spezielleForm der gleitenden Fortbewegung dar, in der sich die Bakterien dicht gepackt in Einzelzellagen als eine Einheit voranschieben. Es wurde postuliert, daß diese Bewegung auf die Expansionskräfte der sich teilenden Zellen zurückzuführen ist, wobei spezielle Oberflächeneigenschaften die Reibung zwischen den Bakterien und dem Substrat reduzieren (HENRICHSEN 1972, 1983). Pilus-vermitteltes Gleiten zeigt dagegen ein anderes Erscheinungsbild: Frühere Studien deuteten 'Twitching Motility' als relativ langsame, unorganisierte Art der Bewegung, wobei sich die Zellen überwiegend einzeln in ruckartiger Weise bewegen (HENRICHSEN 1972). Doch beschreiben neuere Studien das Typ-IV-Pilus-vermittelte 'Twitching' als einen schnellen, hoch organisierten Mechanismus der Fortbewegung, in dem die Zellen vorzugsweise parallel assoziiert in Richtung ihrer Längsachse gleiten (SEMMLER et al. 1999, LIU et al. 2001). Diese unterschiedliche Beschreibung der gleichen Form der Bewegung veranschaulicht die Schwierigkeit, die beim Vergleich subjektiver Betrachtung der 'Twitching Motility' resultiert. Ein weiteres wichtiges Kriterium bei der Untersuchung gleitender Bewegungen ist die Zusammensetzung und Behandl ung der Agarplatten sowie die Inkubationszeit, demnach das Alter der Kolonie, was in den verschiedenen Veröffentlichungen zahl reichen Variationen unterliegt. Aus diesem Grund erfordern die unterschiedlichen Kulturbedingungen und Betrachtungsweisen eine genetische Charakterisierung des Gleitens.

Die Untersuchungen dieser Arbeit bestätigen die frühere Beschreibung der gleitenden Bewegung von BD413 (BD4) als 'Sliding' in Form dicht gepackter Einzelzellage, die einen weiten Randbereich der wachsenden Kolonie einnimmt (HENRICHSEN \& BLOM 1975). Es zeigte sich, daß zur Mitte der Kolonie stufenförmig weitere Zellagen aufgeschichtet sind und sich daraufhin mehrere Plateaus ergeben. 
Vermutlich entsteht eine neue aufgeschichtete Zellage, wenn die durch die Zellteilung hervorgerufene Volumenzunahme die durch das Gleiten geschaffene Fläche übersteigt. Dieser Effekt nimmt zu, je weiter ein Bakterium vom Rand der Kolonie entfernt, in Richtung Zentrum liegt. Die Stufung ist demnach abhängig von Teilungsrate und Geschwindigkeit des Gleitens, was sich in der konzentrischen Anordnung der Stufen widerspiegelt.

Daß aber die Expansion der Kolonie nicht allein aufgrund von Zellteilung, Wachstum und Oberflächenbeschaffenheit zurückzuführen war, verdeutlichten Zellen, die sich vom Rand der Kolonie lösten und in kleinen Aggregaten parallel orientiert in Richtung der Längsachse bewegten. Der Ausrichtung in paralleler Längsrichtung und der Fortbewegung vom Rand der Kolonie muß einem aktiven Prozeß zugrunde liegen.

Die aktive Entfernung von Zellen vom Randbereich einer Kolonie in Form von einzellschichtigen Aggregaten auf feuchten Oberflächen scheint ein allgemeines Charakteristikum gleitender Bakterien darzustellen, und nicht auf eine bestimmte Weise der gleitenden Fortbewegung beschränkt zu sein. Unterschiede liegen vor allem in der Geschwindigkeit der gleitenden Bakterien begründet, was sich in erster Linie in der unterschiedlichen Distanz der Zellen zum Rand der Kolonie äußert. Bei Acinetobacter sp. BD413 wird der durch die sich entfernenden Zellen gelappte oder gezähnte Kolonierand schnell durch die sich teilenden Bakterien in Form einer einschichtigen Zellage ausgefültt und daraufhin begradigt, da die Expansion durch Zellwachstum die relativ langsame Bewegung von 2-3 $[\mathrm{m}$ pro Minute nahezu kompensiert. Der Randbereich von Kolonien der sich über 'Twitching Motility' fortbewegenden Organismen Pseudomonas aeruginosa und Ralstonia solanacaearum, sowie Vertreter der sich Pilus-unabhängig fortbewegenden Cytophaga-Flavobacterium-Gruppe weist neben den in floßartiger Weise gleitenden Zellaggregaten eine netzartige Struktur auf, die auf in Längsrichtung assozi ierten gleitende Zellen beruht (MCBRIDE 2000). A ufgrund der relativ schnellen Fortbewegung werden die hi erdurch entstandenen Zellzwischenräume vergl ichen zu BD413 langsamer durch die sich teilenden und wachsenden Zellen aufgefültt.

Da die Bewegung von Acinetobacter sp. BD413 nicht auf 'Twitching Motility' beruht, sondern Pilus-unabhängig erfolgt, muß eine andere Form der Fortbewegung vorliegen. Neben der 'Twitching Motility', die u.a. bei manchen einzelligen Cyanobakterien auftritt (BHAYA 2000, 1999), wurde eine weitere Form der Bewegung bei einer Gruppe von Cyanobakterien untersucht, die ausschließlich bei filamentösen Formen zu finden ist. Bei den gut untersuchten Bakterien Phormidium uncinatum und Anabaena variabilis finden sich nahe der Septen aneinandergrenzender Zellen Reihen von Poren, die Durchmesser von 14-16 nm aufweisen (HoICZYK 1998, 1995). Es wird postuliert, daß die 
Poren für die Sekretion von Polysacchariden verantwortlich sind und dadurch das Zellfilament in gleitender Weise vorantreiben (HoICZYK 2000). Bei Phormidium uncinatum wurde weiterhin das extrazelluläre Protein Oscillin identifiziert, welches helikal e faserartige Strukturen auf der Zelloberfläche ausbildet und mit der Rotation des Zellfilamentes in Verbindung steht. Beides zusammen, Polysaccharid-Sekretion und Oscillin-Fasern sprechen für eine gleitende Fortbewegung unter damit verbundener Rotation des Zellfilaments, wobei die Bakterien erstaunliche $500 \square \mathrm{m}$ in der Minute zurücklegen können (HoICZYK 1998).

Ein Vergleich dieser Pilus-unabhängigen Form der Fortbewegung mit der gleitenden Bewegung von Acinetobacter sp. BD413 zeigt keine gemeinsamen Charakteristika. So erreicht BD413 nicht die enorme Geschwindigkeit von 500 ]m in der Minute sondern vermag nur mit 2-3 $\square \mathrm{m}$ pro Minute zu gleiten, bildet keine Zell filamente und synthetisiert keine Exopolysaccharide. Aufgrund dieser grundsätzlichen Unterschiede in Morphologie und Physiologie der Bewegung von filamentösen Cyanobakterien und Acinetobacter sp. BD413, muß ein unterschiedlicher Mechanismus der gleitenden Fortbewegung vorliegen.

Eine weitere Form des Pilus-unabhängigen Gleitens wurde bei stäbchenförmigen Organismen beschrieben. Neben der Typ-IV-Pilus-abhängigen Bewegung von Myxococcus xanthus und Stigmatella aurantiaca, diezur Bildung von Fruchtkörpern führt und somit als "soziales“ Gleiten bezeichnet wird, besitzen diese Bakterien die Fähigkeit zum „abenteuerlichen“ Gleiten, welches Pilus-unabhängig erfolgt und der Bewegung der Cytophaga-Flavobacterium-Gruppe ähnelt. Untersuchungen gefriergetrockneter Zellen der Vertretern dieser Gruppe von gleitenden Bakterien wie Myxococcus xanthus, Stigmatella aurantiaca, Flexibacter filiformis und Flavobacterium johnsoniae (früher Cytophaga johnsoniae) mittels 'Scanning 'Elektronenmikroskopie führten zur Identifizierung helikal angeordneter wulstiger Strukturen auf der Zelloberfläche, die Durchmesser von 170$380 \mathrm{~nm}$ aufweisen. Hierbe handelt es sich um helikal Bänder, welche die stäbchenförmige Zelle umgeben (LüNSDORF \& SCHAIRER 2001, FREESE et al. 1997). Es scheint, daß die Bewegung dieses Oberflächenreliefs die Zelle vorantreibt. Die Geschwindigkeiten, die erreicht werden, variieren von Spezies zu Spezies. Während die Bewegung der CytophagaFlavobacterium-Gruppe mit 120-240 $\square \mathrm{m} / \mathrm{min}$ eine schnelle Ausbreitung erlaubt, erreicht Myxococcus xanthus maximal $1 \square \mathrm{m} / \mathrm{min}$.

Bisher untersuchte Mutanten-Stämme von Flexibacter johnsoniae zeigten oft neben dem Defekt in der gleitenden Bewegung eine veränderte oder inhibierte Zellteilung, was den Zusammenhang beider physiologischen Prozesse indiziert. In Übereinstimmung damit wurden Gene identifiziert, die am Zellwandaufbau sowie der gleitenden Bewegung beteiligt sind. Beispielsweise führte ein Defekt in der Synthese von Sulfonolipiden, die ein Bestandteil der äußeren Membran darstellen, zu einer beeinträchtigten Mobilität 
(ABbanat et al. 1985, Godchaux et al. 1990). Darüber hinaus wurden weitere Gene identifiziert, deren Genprodukte vermutlich in der Zellhülle lokalisiert sind. Dazu zählen Komponenten, die Ähnlichkeiten zu ABC-Transporten (GIsA, -F, -G), äußeren Membranproteinen (Gldl, - - ) oder Proteintransportern (FtsX) aufweisen (AGARWAL et al. 1997, MCBRIDE 2001, KeMPF \& MCBRIDE 2000). Die größte Zahl dieser Gene, die für die gleitende Bewegung essentiell sind, zeigen keine Homologien zu bereits charakterisierten Genen in anderen Organismen.

Diese Pilus-unabhängige Bewegung von Einzelzellen oder Zellaggregaten weist Ähnlichkeiten zum Gleiten von Acinetobacter sp. BD413 auf; im Besonderen die relativ langsame Fortbewegung von Myxococcus xanthus, der beim „abenteuerlichen“ Gleiten nur 1 $\square \mathrm{m}$ in der Minute erreicht, korreliert mit der Geschwindigkeit von 2-3 $\square \mathrm{m}$ pro Minute, die von Acinetobacter sp. BD413 erzielt werden. Interessant wären in diesem Zusammenhang elektronenmikroskopische Untersuchungen der Zelloberfläche von Acinetobacter sp. BD413 nach 'Cryo'-Präparation, die Hinweise auf Strukturen geben könnten wie sie bei Myxococcus xanthus, Stigmatella aurantiaca, Flexibacter filiformis und Flavobacteriumjohnsoniae identifiziert wurden. Die Ähnlichkeitsvergleiche der in die gleitende Bewegung involvierten Gene des gut untersuchten Organismus Flexibacter johnsoniae mit dem Genom von Acinetobacter sp. BD413 lieferten keine signifikanten Homologien, so daß eine nahe Verwandtschaft hinsichtlich des Mechanismus der gleitenden Fortbewegung zwischen diesen beiden Organismen ausgeschlossen werden kann.

Aus diesen Betrachtungen läßt sich das Gleiten von Acinetobacter sp. BD413 nicht eindeutig einem bestimmten Typ der bisher untersuchten Fortbewegungsarten zuordnen. Vor dem Hintergrund, daß die größte Zahl der Bakterien ein mehr oder weniger ausgeprägtes Gleiten zeigen, was im Zuge von Untersuchungen der Bildung von bakteriellen Biofilmen analysiert wurde (O TOOLE et al. 2000), und daß die Bedingungen, unter denen Organismen diesen Phänotyp ausbilden, wenig erforscht sind, läßt dies die Vermutung zu, daß es eine große Zahl von Fortbewegungsmechanismen gibt, die noch nicht untersucht sind. Acinetobacter sp. BD413 stelt möglicherweise einen Organismus dar, der eine noch unbekannte Form der gleitenden Bewegung ausübt.

\subsubsection{Acinetobacter 5p. B D413 bildet Biofilme}

In dieser Arbeit konnte gezeigt werden, daßs die dicken und dünnen Pili von Acinetobacter sp. BD413 nicht in die gleitende Bewegung und in die natürliche Transformation involviert sind; doch für die dünnen Pili konnte die Bindung an Polystyren demonstriert werden (3.6.10). Acinetobacter sp. BD413 besiłt somit die Fähigkeit mit 
seinen dünnen, Typ-I-Fimbrien-ähnlichen Pili an hydrophobe Oberflächen zu adsorbieren und daraufhin einen Biofilm auszubilden. In Flüssigkul tur synthetisiert BD413 die dünnen Pili in hoher Zahl, auf Agarplatten dagegen sind elektronenmikroskopisch nur vereinzelt diese filamentösen Strukturen zu sehen. Diese Beobachtung stimmt mit der Funktion der dünnen Pili als Adhäsin überein, die einen initialen Kontakt mit geeigneten Oberflächen herstellen. Befindet sich das Bakterium daraufhin auf dem festen Nährboden, so scheinen die Pili nicht mehr notwendig.

Filamentösen Strukturen der Bakterien stellen oft das erste Mittel bei der Initiation von Biofilmen dar. Beispielsweise bewirkt der Typ-IV-Pilus Tcp ('toxin co-regulated pilus') von Vibrio cholerae als wichtiger Virulenzfaktor die Besiedelung tierischer Eingeweide (HERRINGTON et al. 1988). Die Flagellen und die Typ-IV-Pili Msh ('mannosesensitive hemagglutinin') des Bakteriums sind dagegen nicht für die Pathogenität verantwortlich, sondern dienen der Besiedelung abiotischer Oberflächen wie Glas oder Plastik (THELIN \& TAYLOR 1996). Bei Pseudomonas aeruginosa sind ebenso sowohl TypIV-Pili als auch Flagellen an der Adsorption an Oberflächen beteiligt (DE WEGER et al. 1987, Dolg et al. 1988). Für E. coli K-12 konnte weiterhin gezeigt werden, daß die Flagellum-abhängige Bewegung und Typ-I-Pili den ersten Kontakt an Oberflächen vermitteln (Genevaux et al. 1996, Pratt \& Kolter 1998).

In natürlicher Umgebung leben die meisten Bakterien assoziiert an Oberflächen und bilden dabei oft komplex aufgebaute Gemeinschaften, die als Biofilme bezeichnet werden. Diese Zell-Konsortien sind ubiquitär vertreten, bedecken biotische sowie abiotische Flächen und zeichnen sich durch außergewöhnliche Resistenz gegenüber AntibiotikaBehandl ungen, gegenüber I mmunantworten von Wirtsorganismen und hydrodynamischen Scherkräften aus. Der Aufbau der Oberflächen-assoziierten Bakteriengemeinschaft stellt einen hoch organisierten Prozeß dar, dessen Regulation von zahl reichen Signalstoffen abhängt (O'TOole et al. 2000). Die dünnen Pili von Acinetobacter sp. BD413, die zur Familie der Typ-I-Pili gehören, sind in ähnlicher Weise für die Adsorption an abiotische Oberflächen verantwortich. Der hydrophobe Charakter dieser Pili vermittelt vor allem die Bindung an apolare Flächen wie Plastik (z.B. Polystyren) und langkettigen Kohlenwasserstoffen (Rosenberg 1981, Rosenberg et al. 1981). Neben der Biofilmbildung wird hier die Beteiligung der dünnen Pili an der Verwertung von CQuellen deutlich; denn bei Acinetobacter sp. RAG-1, der vermutlich ebenso Typ-IFimbrien-ähnliche Pili synthetisiert, sind diese essentiell für die Verwertung hydrophober Kohlenstoff-Quellen (RoSenBerg et al. 1981). Der erste Schritt beim Abbau von aromatischen oder aliphatischen Kohlenwasserstoffen ist der Einbau von molekularem Sauerstoff mittels zellassoziierten Enzymen (FOSTER 1962). Dies bedeutet, daß das Bakterium, welches sich in wäßriger Lösung befindet, mit dem hydrophoben Substrat 
interagieren muß. Für die Metabolisierung der hydrophoben langkettigen Kohlenwasserstoffe ist aus diesem Grund ein direkter Kontakt des Bakteriums mit dem Substrat notwendig. Es ist naheliegend, daß diese Pilus-vermittelte Eigenschaft einen Selektionsvorteil des Bodenbakteriums in seinem Habitat bewirken.

Neben der Biofilmbildung an abiotische Oberflächen sind die Typ-I-Pili bei pathogenen Organismen an der spezifischen Besiedelung von Wirtszellen beteiligt, wobei hier die Pili als Lektine fungieren und spezifische Zucker binden. Beispielsweise konnte für den F1C-Pilus von E. coli die Bindung an $\square-G a l N a c-1,4-\square-G a l$ und für den Pap-Pilus eine Affinität zu Glycolipiden, die (-D-Gal-1,4---D-Gal tragen, nachgewiesen werden (LunD et al. 1988, KHAN et al. 2000). Da stromabwärts des Gens fimA, welches für die Untereinheit des dünnen Pilus in BD413 codiert, das fimH-Gen liegt, dessen Genprodukt Ähnlichkeiten zu Adhäsinen von Typ-I-Pili aufweist, und die dünnen Pili von BD413 die Eigenschaft vermitteln Erythrocyten zu agglutinieren (3.6.11), wäre für diesen Pilustyp ebenso eine Lektineigenschaft denkbar. In Anbetracht der Tatsache, daß einige Acinetobacter-Stämme (z.B. Acinetobacter baumannii) bei immungeschwächten Menschen Biofilme auf Epithelzellen ausbilden, läßt dies die Vermutung zu, daß bei diesen pathogenen Stämmen Typ-I-Pili eine Rolle spielen, zumal neben der alleinigen Adhärenz und Persistenz keine Virulenzfaktoren synthetisiert werden, die ein eigenes Krankheitsbild verursachen. Viele pathogene Bakterien synthetisieren neben Adhäsinen wirtszellschädigende Toxine, Oberflächensubstanzen, welche die Immunantwort schwächen, sowie spezielle Eisen-A ufnahmesysteme und Invasine, die für die Persistenz im Wirtsorganismus essentiel sind (HACKER \& KAPER 2000). Bei den bisher untersuchten Stämmen der Gattung Acinetobacter konnten derartige Virulenzfaktoren nicht nachgewiesen werden.

Die Schwierigkeit bei der Bekämpfung pathogener Acinetobacter-Stämme liegt vor allem in der schnellen Resistenzbildung dieser Stämme, die somit einer Antibiotikatherapie nicht mehr zugänglich sind. Acinetobacter könnte durch seine einfache Persistenz - ohne Synthese von weiteren Virulenzfaktoren - ein Bindeglied zwischen Bodenbakterium, harmlosen Komensalen und pathogenen Organismen darstellen, so daß ein fließender Übergang zwischen den verschiedenen Lebensformen besteht.

Acinetobacter sp. BD413 wurde als typisches Bodenbakterium nicht als virulent eingestuft. Gegen die Funktion der Typ-I-Pilus-ähnlichen Filamente von Acinetobacter sp. BD413 als Virulenzfaktor spricht die Temperatur- und Medium-unabhängige Expression des Strukturgens fimA. In Flüssigkultur wurden sowohl in Mineralmedium als auch in Komplexmedium bei $30^{\circ} \mathrm{C}$ oder bei $37^{\circ} \mathrm{C}$ identische Expressionsraten ermittelt (3.6.9). Im Gegensatz dazu bilden einige Stämme von E. coli K12 und Vibrio choleraekeine Biofilme 
in Mineral medium; erst nach Zugabe von Aminosäuren zeigt sie diese Eigenschaft (PRATT \& KolTER 1998, WATNICK et al. 1999). Im allgemeinen ist bei der Synthese von Virulenzfaktoren eine Abhängigkeit von Wachstumstemperatur zu beobachten, was bereits für die Synthese des K1-Kapselantigens sowie der Adhärenzfaktoren, welche die Bindung enteropathogener E. coli-Stämme oder Salmonella typhimuriuman Wirtszellen vermitteln und was für die Expression von Invasinen bei pathogenen Shigella- und Yersiniae Stämmen demonstriert wurde (BRUBAKER 1991, DE GRAAF et al. 1980, JONES \& Richardson 1981, Bortolussi et al. 1983, MAURELli et al. 1984). Der eine Pyelonephritis hervorrufende E. coli J 96 synthetisiert Pap-Pili, die humane Erythrocyten agglutinieren (HULL et al. 1981). Untersuchungen zur Expression des Strukturgens papA der Pap-Pili mittels lacZ-Fusionen zeigten eine Thermoregulation auf der Ebene der Translation. Verglichen zum Wachstum der Bakterien bei $37^{\circ} \mathrm{C}$ führten Temperaturen von $22^{\circ} \mathrm{C}$ oder $30^{\circ} \mathrm{C}$ zur signifikanten Reduktion der Pilusbiogenese (GöRANSSON \& UHLIN 1984). Daß die Pilusbiogenese von Acinetobacter sp. BD413 keiner Thermoregulation und keiner Substratkontrolle unterliegt, spricht demnach gegen die Funktion als Virul enzfaktor

Daß die Agglutination von Erythrocyten, wie dies für die dünnen Pili von BD413 demonstriert wurde (3.6.11), nicht unbedingt ein Pathogenitätsmerkmal darstellt, veranschaulichen weiterhin die Msh-Pili von Vibrio cholerae Obwohl diese Typ-IV-Pili die Fähigkeit vermittelt Erythrocyten zu binden, ist diese Typ-IV-Pilustyp nicht an der initialen Besiedelung von Wirtszellen involviert (THELIN \& TAYLOR 1996). Für die Kolonisierung der Wirtszell-Oberflächen dient ein zweiter Typ-IV-Pilus (Tcp), der einen wichtigen Virulenzfaktor darstellt (HERRINGTON et al. 1988).

Während die dicken Pili von BD413 an der Adsorption an hydrophobe Oberflächen nicht beteiligt sind, bewirkt ein Defekt in der Synthese der dünnen Pili eine starke Reduktion des initialen Kontaktes, aber keinen vollständigen Defekt in der Adsorption (3.6.10). Demnach müssen weitere Faktoren zur Biofilmbildung beitragen, die keinen Piluscharakter aufweisen. Ein ähnliches Verhalten fanden MARKIN und BEVERIDGE (1996) bei der Untersuchung des Adsorptionsverhalten von Pseudomonas aeruginosa. Zusätzlich zu Flagellen und Pili bewirkten Variationen im Aufbau der Polysaccharide auf der Zelloberfläche ein verändertes Adsorptionsverhalten. Pseudomonas aeruginosa synthetisiert zwei verschiedene Arten von Polysacchariden, die als A-Bande und B-Bande beschrieben wurden. Bei näherer Betrachtung einer Mutante führte das Fehlen der BBande zu einer reduzierten Bindung an hydrophile Oberflächen und einem erhöhten Vermögen an hydrophobe Oberflächen zu binden. Die A-Bande hat nur geringe Auswirkung auf die Adhäsion (MARKIN \& BEVERIDGE 1996). Aus diesen Untersuchungen ist zu schließen, daß auch bei Acinetobacter sp. BD413 die Li popolysaccharide neben den dünnen Pilusstrukturen an der Adsorption beteiligt sein könnten. 
Während die dünnen Pili von Acinetobacter sp. BD413 durch ihren apolaren Charakter für die Bindung an hydrophobe Oberflächen verantwortlich sind, wie die Mutantenstudien dieser Arbeit zeigten, ist es naheliegend, daß die dicken Pili eine Affinität zu einer weiteren, andersartigen Oberfläche vermitteln, was eine Besiedelung eines definierten Standortes ermöglicht. Für die dicken Pili konnte eine Beteiligung an der Bindung an Erythrocyten oder hydrophobe Oberflächen sowie eine Beteiligung an der gleitenden Fortbewegung des Bakteriums ausgeschlossen werden. Interessant ist demnach in Zukunft die Untersuchung der Funktion dieses Pilustyps, welcher bisher nicht beschrieben wurde.

\subsection{Das T ransformationssystem von Acinetobacter sp. B D413}

Die gezielte Unterbrechung von potentiellen Kompetenzgenen lieferte neue Einblicke in den Aufbau des DNA-A ufnahmeapparats von Acinetobacter sp. BD413. In dieser Arbeit wurde PHB (D-[-]-Poly-- -Hydroxybutyrat), welches sowohl als Speichergranulum im Cytoplasma als auch als Helixstruktur in den Zellmembranen vorkommt, hinsichtich der Involvierung in die natürliche Transformation untersucht. Über Ähnlichkeitsvergleiche konnte ein DNA-bindendes Kompetenzprotein ComEA identifiziert werden, welches mit der äußeren Membran assoziiert ist. Weiterhin lieferten Proteininteraktionsstudien des Pilin-ähnlichen Proteins ComP Erkenntnisse über das Zusammenspiel der Kompetenzproteine und über den Mechanismus der DNA-Aufnahme, was die Beziehung zwischen dem natürlichen Transformationssystem und dem Typ-IVPilusbiogenesesystem verdeutlichte.

\subsubsection{Das Polymer PHB ist nicht am Transport der DNA durch die Zellmembranen beteiligt}

PHB (D-[-]-Poly-- -Hydroxybutyrat) ist ein Bestandteil der Zellmembranen und des Cytoplasmas vieler Bakterien. Während das PHB des Cytoplasmas in Form von Granula in erster Linie als Speicherstoff dient und molekulare Massen von 60-1000 kDa erreicht (DAWES \& SENIOR 1973), ist die Funktion der membranständigen PHB-Moleküle (cPHB) mit molekularen Massen von $\sim 12 \mathrm{kDa}$ weitgehend unbekannt. Untersuchungen zeigten, daß CPHB im hydrophoben Milieu helikale Strukturen ausbildet und das Potential besitzt Kanalstrukturen durch Zellmembranen zu bilden, die durchlässig für Ionen sind (MARChessault et al. 1990, Cornibert \& MARChessault et al. 1972). Reusch und SADHOFF (1983) untersuchten den Zusammenhang zwischen PHB-Synthese und DNA- 
Aufnahme bei der natürlichen Transformation, wobei sie für Azotobacter vinelandii, Bacillus subtilis und Haemophilus influenzae einen erhöhten PHB-Gehalt in den Membranen nach Kompetenzinduktion nachwiesen. Dies legte die Vermutung nahe, daß membranständiges CPHB an der DNA-Aufnahme natürlich kompetenter Bakterien beteiligt ist. Jedoch kann bei näherer Betrachtung der Anzuchtbedingungen eine zufällige Korrelation von PHB-Synthese und der Entwicklung der natürlichen Kompetenz nicht ausgeschlossen werden. So erfolgte die Kompetenzinduktion von Azotobacter vinelandii nach Überimpfen einer exponentiell wachsenden Kultur in definiertes Medium und anschließendem Wachstum für 12 bis 28 Stunden (PAGE \& VON TIGERSTROM 1978). Dabei erreichen die Bakterien die stationäre Wachstumsphase, in der imal lgemeinen ebenso eine vermehrte PHB-Synthese zur Bildung von Speicherstoffen erfolgt. Ähnliches gilt für Bacillus subtilis: Die Kultur erreicht seine höchste Transformationsfrequenz mit dem Eintritt in die stationäre Wachstumsphase (Y oung 1967). Bei Haemophilus influenzae führt ebenso die Limitierung der Nährstoffe oder des Sauerstoffs zu gesteigerten Transformationsfrequenzen (HERRIOTT et al. 1970, GOODGAL 1982).

Bei Acinetobacter sp. BD413 ist eine Induktion der Expression von Kompetenzgenen zum Ende des exponentiellen Wachstums zu beobachten, um in der stationären Phase ein Maximumzu erreichen ( Busch et al. 1999, HeRZBERG et al. 2000, PORSTENDÖRfER et al. 2000). Die höchste Transformationsrate wird daraufhin nach dem Überimpfen in frisches Medium erreicht. Inwieweit DNA bereits in der stationären Wachstumsphase gebunden und aufgenommen wird, dann aber nicht homolog ins Genom rekombiniert sondern metabolisiert wird, wurde bisher noch nicht überprüft.

Die Synthese des DNA-A ufnahmeapparates in der stationären Wachstumsphase bei Acinetobacter sp. BD413 zeigt parallelen zu der Ausbildung der natürlichen Transformation bei den oben genannten Organismen Azotobacter vinelandii, Bacillus subtilis und Haemophilus influenzae. Der Gehalt an cPHB in den Zellmembranen steigt bei den dre Bakterienspezies mit dem Eintritt in die genetisch kompetente Phase. Diese Korrelation kann jedoch kein Indiz für die Involvierung von PHB in die DNA-Aufnahme sein, da die Speicherstoffsynthese gewöhnlich am Ende des exponentiellen Wachstums und in der stationären Phase erfolgt. Durch die Unterbrechung des phaC-Gens in Acinetobacter sp. BD413, welches für die PHB-Synthase codiert, konnte gezeigt werden, daß die natürliche Transformation nicht eingeschränkt ist. Somit kann membranständiges cPHB bei Acinetobacter sp. BD413 keine essentielle Funktion in der DNA-A ufnahme ausüben. Da die in die natürliche Transformation involvierten Komponenten unter den natürlich kompetenten Organismen hoch konserviert sind, spricht dies für einen gleichen Mechanismus der DNA-Aufnahme. Aus diesem Grund scheint eine cPHB-abhängige DNA-Aufnahme auch in Azotobacter vinelandii, Bacillus subtilis und Haemophilus 
influenzae sehr fraglich. Bei Bacillus subtilis konnte zudem gezeigt werden, daß die Pilinähnlichen Proteine mit Peptidoglycan oder ihresgleichen assoziieren (CHUNG \& DUBNAU 1998, CHung et al. 1998). 'Cross-Linking' von Kompetenzproteinen an cPHB konnte dagegen nicht demonstriert werden.

Zusammenfassend läßt sich aus diesen Betrachtungen folgern, daß PHB keine essentielle Komponente bei der DNA-Aufnahme natürlich transformierbarer Bakterien darstellt.

\subsubsection{Struktur und F unktion der Pilin-ähnlichen K ompetenzfaktoren}

Durch Untersuchungen von Genen, deren Produkte Homologien zu Pilus- oder Flagellen-Biosynthese-Komponenten aufweisen, kann zum einen nicht ohne weiteres von einem Vorliegen einer filamentösen Struktur ausgegangen werden und zum anderen nicht auf eine Pilus- oder Flagellum-spezifische Funktion geschlossen werden. So bildet zum Beispie die Klasse der Typ-I-Pili einerseits Filamente und andererseits Zelloberflächenintegrale Strukturen, die beide gleichermaßen Adhäsion vermitteln (BIGLE et al. 1989, Tennent et al. 1990, HACKer 1990, Riegman et al. 1990, DeGraAf 1990). Gut untersucht sind die Flagellumbiosynthese und das dazu homologe Typ-IIISekretionssystem. Die strukturellen Untereinheiten bzw. Exoproteine beider Systeme gelangen durch den Hohlraum des Filamentes zur Spitze und werden dort zu einem Filament assembliert bzw. freigesetzt. Das 0,5-1 Dm lange Flagellum vermittelt durch seine Rotation eine schwimmende oder schwärmende Fortbewegung; im Gegensatz dazu dienen die röhrenförmigen Strukturen, die in ihrer Länge von $45 \mathrm{~nm}$ bis $700 \mathrm{~nm}$ variieren, zur Sekretion von Proteinen (TAMANo et al. 2000, SEKIY A et al. 2001).

Eine Variabilität in der Assemblierung bzw. in der Funktion struktureller Untereinheiten liegt wie bei der Typ-I-Pilus- und Flagel lenbiosynthese ebenso bei der TypIV-Pilusbiogenese vor. Zur Pilusbiogenese ähnliche Komponenten sind im DNAAufnahmeapparat der natürlichen Transformationssysteme und bei den Typ-IISekretionswegen zu finden. Bei natürlich transformierbaren Bakterien sind die Komponenten für die Assemblierung des Pilus ebenso an der DNA-A ufnahme durch die äußere Membran und den periplasmatischen Raum beteiligt. Daß die Pilusstruktur aber keine essentielles Strukturmerkmal für die DNA-Aufnahme darstellt, beweist eine Gruppe von natürlich kompetenten Organismen, wozu Acinetobacter sp. BD413, Haemophilus influenzae und natürlich transformierbare Gram-positive Bakterien gehören, die keine TypIV-Pilusstrukturen synthetisieren, aber zur DNA-A ufnahme diejenigen Komponenten besitzen, die denen der Typ-IV-Pilusbiogenese homolog sind (DuBNAU 1991, TOMB et al. 1991). Unbekannt ist, welche regulatorischen Faktoren oder strukturellen Unterschiede in 
der Aminosäuresequenz der Piline zur Synthese einerseits eines außerhalb der Zelle erscheinenden Filaments und andererseits zu Strukturen führen, die nicht über die äußere Membran hinaus assemblieren. Vorstel lbar wären regulatorische oder assemblierende, für die Pilusbiogenese spezifische Proteine, die den homologen Systemen, die keine Pili synthetisieren, fehlen. Bisher konnten jedoch derartige Komponenten nicht identifiziert werden. Die hohe Variabilität in der Aminosäuresequenz des C-Terminus der Untereinheiten diese Proteinfamilie, läßt die Vermutung zu, daß diese Domäne mit dem Potential der Filamentbildung in Zusammenhang steht. In diesem variablen Bereich könnten spezifische Aminosäurereste Interaktionen zwischen den Monomeren in der Pilusstruktur vermitteln, die den ausschließlich in den Zellmembranen und im Periplasma lokalisierten Pilin-ähnlichen Proteinen fehlen. Durch Abgleiche der A minosäuresequenzen von Pilinen und Pilin-ähnlichen Proteinen konnten jedoch keine konservierten Aminosäuren im C-Terminus identifiziert werden, die ein charakteristisches Merkmal darstellen. Daß die Stabilität des Pilus in erster Linie durch den im Zentrum des Pilus lokal isierten hydrophoben N-Terminus der Piline erlangt wird, verdeutlichten A rbeiten, die eine mehrlagige Struktur des Typ-IV-Pilus von Neisseria gonorrhoeae und Pseudomonas aeruginosa aufklärten (FOREST \& TAINER 1997, KEIZER et al. 2001). Die Piline sind in hel ikaler Ausrichtung angeordnet, wobei fünf Untereinheiten eine Umdrehung ausmachen. Im Zentrum bilden die N-terminal en Helices durch hydrophobe Interaktionen ein Gerüst, welches die Grundstabilität verleiht In Form von $\square$-Fal tblättern, die vom C-Terminus der Piline ausgebildet werden und welche die Zuckerketten tragen, wird der hydrophobe Kern umgeben. Diese Aminosäurereste bilden untereinander Wasserstoff-Brückenbindungen, was dem Pilus eine zusätzliche mechanische Stabilität verleiht (FOREST \& TAINER 1997, KEIZER et al. 2001).

Da keine signifikanten Auffälligkeiten in der Aminosäuresequenz zu beobachten sind, kann nur aufgrund der Funktion eine Unterteilung vorgenommen werden. Die eine Gruppe bilden die strukturellen Untereinheiten der Pili, die sogenannten Piline, die als langes Filament assembliert werden, welches außerhalb der Zelle sichtbar ist. Diese strukturellen Proteine liegen häufig glykosyliert vor (MARCEAU \& NASSIF 1999, J ENNINGS et al. 1998, MARCEAU et al. 1998). Zur anderen Gruppe zählen die Typ-IV-Pilin-ähnlichen Proteine, die ausschließlich in den Zellmembranen und im Periplasma lokalisiert sind und dort als Assemblierungsfaktoren bezüglich der strukturellen Untereinheiten (Piline) des Typ-IV-Pilus wirken. Während die Piline in hoher Zahl synthetisiert werden, werden die Pilin-ähnlichen Proteine in relativ geringer Menge gebildet, was den funktionalen Unterschied widerspiegelt. Beispielsweise wurden bei Pseudomonas aeruginosa zusätzlich zur strukturellen Untereinheit PilA fünf weitere Pilin-ähnliche Proteine PilE, $-\mathrm{V},-\mathrm{W},-\mathrm{X}$ und FimU identifiziert, die für die Pilusbiogenese essentiell sind und in geringer Menge in der Zellhülle lokalisiert sind (RusSEL \& DARZIN 1994, ALM \& MATTICK 1995, 1997, ALM 
et al. 1996). Unterschiede in der Syntheserate von Komponenten dieser Proteinfamilie sind nicht nur bei der Pilusbiogenese sondern ebenso bei den Typ-II-Sekretionswegen von Klebsiella oxytoca und Pseudomonas aeruginosa zu beobachten, obwohl das Sekretionssystem keine Pili ausbildet. Von den fünf Pilin-ähnlichen Proteinen PulG, $-\mathrm{H},-\mathrm{I}$, -J und PulK des Pullulanase-Sekretionssystems von Klebsiella wird PulG in größerer Menge synthetisiert (REYSS \& PUGSLEY 1990); bei Pseudomonas aeruginosa stellt XcpT die Hauptkomponente dar, wobei $\mathrm{XcpH},-\mathrm{I},-\mathrm{J}$ und $\mathrm{XcpK}$ geringer exprimiert vorliegen (FILLOUX et al. 1990). I mmunologische Detektionen der Pilin-ähnlichen Kompetenzfaktoren in Acinetobacter sp. BD413 lieferten Indizien, daß ComP verglichen zu ComB, -E und ComF in höherer Rate synthetisiert wird. Während ComP durch generierte Antikörper eindeutig detektiert werden konnte, waren die anderen Pilinähnlichen Proteine immunologisch nicht darzustellen. Darüber hinaus unterliegt ComP einer posttranslational en Glykosylierung, was ein charakteristisches Merkmal für Typ-IVPiline darstellt und Pilin-ähnlichen Proteinen, die als Assemblierungsfaktoren wirken, i.d.R. fehlt (PORSTENDÖRFER et al. 2000). Diese Beobachtungen ließen die Hypothese zu, daß nicht nur im Typ-IV-Pilusbiogenesesystem eine funktionale Differenzierung zwischen Pilinen und Pilin-ähnlichen Proteinen besteht, sondern auch in den verwandten Systemen zu finden ist (Transformations- und Typ-II-Sekretionssystem), die keine Pilusstruktur synthetisieren. Denkbar wäre die Synthese einer Pseudopilusstruktur - aufgebaut aus den am stärksten exprimierten strukturel len Komponenten -, deren Länge nicht über die äußere Membran hinausreicht.

Das Kompetenzprotein ComP aus Acinetobacter sp. BD413 stellt ein Typ-IV-Pilinähnliches Protein dar, welches in den Zellmembranen lokalisiert ist, aber zu keiner außerhal b der Zelle sichtbaren Pilusstrukturen assembliert (PORSTENDÖRFER et al. 1997, 2000). In dieser Arbeit konnte gezeigt werden, daß ComP das Potential zur Filamentbildung besitzt (3.7.1). Die Klonierung von comP hinter den starken filAPromotor führte aufgrund der Überexpression von comP zur Synthese von Filamenten, die eine Länge von bis zu 1 lm erreichten. In ähnlicher Weise wurde das Typ-IV-Pilinähnliche Protein PulG, welches die Pilin-ähnliche Hauptkomponente des Typ-IISekretionswegs aus Klebsiella oxytoca darstellt, nach seine Überexpression in E. coli K-12 als Pilusstruktur assembliert (SAuvonnet et al. 2000). Hier wurde die Überexpression durch die Lokalisation des pul-Clusters, welches für das Pullulanase-Sekretionssystem codiert, auf einem 'High Copy Plasmid erzielt.

Die Assemblierung von ComP bzw. PulG in eine Pilusstruktur unterstütt die Hypothese, daß eine Differenzierung in Strukturpilinen und Assemblierungspilinen nicht nur im Typ-IV-Pilusbiogenesesystem vorliegt, sondern auch in den verwandten Systemen, die keine eigentlichen Pilusstrukturen assemblieren, zu finden ist; denn die Assemblierung 
einer Pilusstruktur aus ComP- bzw. PulG-Proteinen indiziert den grundsätzlich ähnlichen Aufbau des Transformationssystems und des Typ-II-Sekretionswegs zum Typ-IVPilusbiogenesesystem. Erwähnenswert ist die Tatsache, daß diese Beobachtungen vermutlich nur für Gram-negative Organismen zutrifft, die eine äußere Membran synthetisieren. Die für die natürliche Transformation von Bacillus subtilis essentiellen Pilin-ähnlichen Gene (comGC, -GD -GE und comGG) sind als ein Operon organisiert und werden von einer polycistronischen mRNA translatiert (CHUNG et al. 1998), was eine einheitliche Syntheserate und äquivalente Proteinmengen indiziert. Da es für immunologische Detektionen in Bacillus subtilis erforderlich war, die Pilin-ähnlichen Genen höher zu exprimieren, belegt dies weiterhin, daß jede dieser Komponenten eher den im allgemeinen in geringer Menge synthetisierten Pilin-ähnlichen Assemblierungsproteinen als den relativ hoch exprimierten Strukturproteinen zugehörig sind. Demzufolge fehlt dem Gram-positiven Organismus Bacillus subtilis die Typ-IVPilin-ähnliche Strukturkomponente, die Pilin-Charakter aufweist. In Anbetracht der Tatsache, daß Gram-positive Organismen keine Typ-IV-Pili synthetisieren, sind die strukturellen Piline bzw. strukturellen Pilin-ähnlichen Proteine vermutlich an die Anwesenheit einer äußeren Membran gebunden.

Das Potential der Pilin-ähnlichen Proteine PulG aus Klebsiella oxytoca und ComP aus Acinetobacter sp. BD413 nach Überexpression eine Pilusstruktur auszubilden deutet darauf hin, daß die Pilusbiogenese in erster Linie vom Expressionslevel des Strukturgens abhängt, und nicht allein auf Assembl ierungsfaktoren beruhen. Dies stimmt damit überein, daß bisher keine Komponenten identifiziert wurden, die eine spezifische Funktion allein für die Assemblierung einer Pilusstruktur zeigen und in denjenigen verwandten Systemen fehlen, die keine filamentöse Struktur bilden. Die Assemblierung in eine stabile, lange Pilusstruktur kann darüber hinaus nicht auf spezifische Aminosäuren in der Primärsequenz der Piline bzw. Pilin-ähnlichen Proteine zurückzuführen sein, da ComP bzw. PulG als Untereinheit des Pilus keine Mutationen trugen. Da der hydrophobe N-Terminus unter den Pilinen und Pilin-ähnlichen Proteinen eine hoch konservierte Aminosäuresequenz aufweist, der C-terminale Bereich dagegen Variabilitäten zeigen, ist es naheliegend, daß die Grundstabilität der von PulG und ComP ausgebildeten Pilusstrukturen vom N-Terminus vermittelt wird. Die ComP-Pili weisen einen starren und brüchigen Charakter auf, was auf eine relative Instabilität der filamentösen Struktur hinweist. Diese wäre mit fehlenden Wasserstoff-Brückenbindungen zwischen ComP-Monomeren zu erklären, die bei PilE von Neisseria gonorrhoeae vom C-Terminus des Proteins ausgebildet werden und die $\square$ Fal tbl ätter untereinander verbinden und stabi lisieren.

Interessant wäre in diesem Zusammenhang die Untersuchung, inwiefern Pilinähnliche Proteine, die nicht zu den Struktur- sondern zu den Assemblierungsfaktoren 
gehören ebenso nach Überexpression filamentöse Strukturen ausbilden können. Eine Pilusbildung, z.B. von ComB, -E oder ComF aus Acinetobacter sp. BD413, würde die Hypothese bestätigen, daß eine Grundstabilität der Typ-IV-Pili in erster Linie vom konservierten, hydrophoben N-Terminus ausgeht und die Assemblierung in ein Filament ausschließlich von einer hohen Syntheserate abhängt. Bilden die Pilin-ähnlichen Proteine nach Überexpression kein Filament, so würde dies jedoch darauf hindeuten, daß Unterschiede in der A minosäuresequenz zwischen den beiden Gruppen der Proteinfamilie der Typ-IV-Piline dafür verantwortlich sind.

Bemerkenswert ist die Beobachtung, daß der erhöhte ComP-Gehalt in der Zelle nicht zur Synthese mehrerer kurzer Pili, sondern nur zur Assemblierung von einem oder maximal zwei langen Filamenten führte. Dies läßts sich damit begründen, daß entweder nur ein Assemblierungsapparat gebildet, oder daß ComP-Monomere nur zu einem Assemblierungsort geleitet wurde. Letzteres würde mit den Untersuchungen bei Neisseria gonorrhoeae übereinstimmen. Das Gen pilE, welches für die strukturelle Untereinheit der Typ-IV-Pili codiert, wurde unter die Kontrolle der regulatorischen lacl OP-Sequenz gestellt (LoNG et al. 2001). Bei niedrigstem Induktionsniveau mit 0,005 mM IPTG wies die größte Zahl der Zellen keine Pili auf; nur 5-10\% der Bakterien synthetisierten ein oder zwei lange Pili. Dieser Pilusphänotyp ist vergleichbar mit demjenigen von Acinetobacter sp. BD413, bei dem comP durch den starken Piluspromotor exprimiert wird. Nach sukzessiver Erhöhung der Induktion des laclOP-Promotors in Neisseria erhöhte sich die Zahl der Pili von zuerst mehreren einzeln liegenden Pili bis hin zu einer Vielzahl aggregierter Pilusbündel. Da die für die Assemblierung verantwortlichen Pilusbiogenese-Gene keiner artifiziellen Regulation unterlagen, sondern durch den zelleigenen Promotor transkribiert wurden, ist es anzunehmen, daß die Zahl der Assemblierungsapparate pro Zelle unter den verschiedenen I nduktionsniveaus von PilE konstant blieb. Es konnte gezeigt werden, daß das überexprimierte PilE keinen induktiven oder inhibitorischen Effekt auf die Synthese der Assemblierungsfaktoren ausübte. Dies bedeutet für die Pilusassemblierung, daßs sich Piline nacheinander an Assemblierungsapparaten sammeln, bis ein Schwellenwert an strukturellen Untereinheiten erreicht ist, so daß daraufhin diese zu einem Pilus assembliert werden. Erst dann wird möglicherweise ein weiterer Assemblierungsort mit Pilinen versorgt. Daß die Zahl der Pilusstrukturen nicht unmittelbar die Zahl der Assemblierungsapparate widerspiegelt, zeigt weiterhin die Überexpression des pulClusters aus Klebsiella oxytoca. Auf diesem Gencluster lagen alle Gene, die für die Pullulanase-Sekretion essentiell sind. Sowohl unter der Kontrolle des nativen Promotors als auch nach Überexpression des pul-Clusters blieben die Proportionen zwischen Assemblierungsfaktoren und Strukturproteinen gleich, d.h. die Sekretionssysteme wurden mit der gleichen Anzahl von PulG-Proteinen ausgestattet, nur stieg mit der erhöhten 
Expression die Zahl der Sekretionssysteme Doch werden bei niedriger Expression keine Pili und bei hoher Expression filamentöse Strukturen synthetisiert. Es wäre zu erwarten gewesen, daß die Zahl der Sekretionssysteme zunimmt und die Verteilung der Komponenten gleich bleibt. Die hohe Zahl des Pilin-ähnlichen Proteins PulG muß hier an einigen Assemblierungsapparaten das Signal zur Pilusbiogenese geliefert haben, während andere nicht durch PulG besetzt wurden.

Die 10-20fache Steigerung der comP-Expression in Acinetobacter sp. BD413 ließ ComP zu Pilusstrukturen assemblieren, wobei die natürliche Fähigkeit zur DNAAufnahme bestehen blieb. Bei Neisseria gonorrhoeae ergab die sehr geringe Expression von pilE, die zu keiner Pilussynthese führte, Transformationsraten von $10^{-5}$. Eine Steigerung war mit der Erhöhung der PilE-Synthese zu beobachten gewesen: Eine Induktion von pilE, bei dem 5-10\% der Zellen einen Pilus oder zwei Pili synthetisierten, führte zu Transformationsraten um $10^{-4}$. Mit der sukzessiven Steigerung der Expression von pilE erhöhte sich die Anzahl der Pili und damit die Transformationsrate bis zu einem Sättigungswert von $10^{-3}$. Bei dieser maximalen Transformationsrate synthetisierten die Zellen eine hohe Zahl von Pilusstrukturen. Dies läßt vermuten, daß die Synthese der Filamente für die DNA-A ufnahme nicht hinderlich, sondern im Gegenteil, eher förderlich ist. Eine weitere Steigerung der pilE-Expression führte nicht zu einer weiteren Erhöhung der Transformationsraten, sondern zu einer Stagnation der maximalen Raten von $10^{-3}$. Dies könnte damit zusammenhängen, daß bei diesem Wert alle Assemblierungsapparate bel egt sind oder andere Kompetenzproteine limitierend wirken. Interessant wäre zu untersuchen, ob die Überexpression von ComP in Acinetobacter sp. BD413 ebenso zu einer Erhöhung der Transformationsrate führt oder ob in diesem Organismus andere Faktoren die Transformationsrate bestimmen.

Die Korrelation der Zahl der Pilusstrukturen mit der Transformationsrate bei Neisseria gonorrhoeae und das Potential von ComP aus Acinetobacter sp. BD413 Pili zu bilden sind starke Indizien, daß das Typ-IV-Pilusbiogenesesystem die DNA-Aufnahme vermittelt und demzufol ge keine Trennung zwischen Transformationssystem und Typ-IVPilusbiogenesesystem herrscht. Würden zwei Systeme nebeneinander existieren, die aus den gleichen Proteinen aufgebaut werden, so wäre zu erwarten gewesen, daß durch die Erhöhung der PilE-Menge die Zahl der DNA-Aufnahmeapparate zugunsten der Pilusbildenden Systeme abnimmt. Dies hätte eine Erniedrigung der Transformationsrate bei Steigerung der pilE-Expression zur Fol ge gehabt.

Sind Typ-IV-Pilusbiogenese und DNA-Aufnahme identische Systeme, so ist es wahrscheinlich, daß zusätzliche transformationsspezifische Komponenten, die mit dem Typ-IV-Pilusbiogenesesystem interagieren, das 'Twitching Motility'-vermittel nde System 
ebenso DNA aufnehmen lassen. Da die Pilusstruktur nach ihrer Synthese durch Deassemblierung verkürzt werden kann, ist es naheliegend, daß diese Struktur dadurch zwei Funktionen übernimmt: Der außerhalb der Zelle sichtbare lange Pilus dient durch wiederholte Assemblierung und darauffolgende Deassemblierung der gleitenden Fortbewegung, wobei der verkürzte Zustand der DNA-Aufnahme dient. Der verkürzte Zustand wäre dann dem DNA-Aufnahmeapparat ähnlich, wie er in den natürlich kompetenten Organismen zu finden ist, die keine auf der Zelloberfläche erkennbaren TypIV-Pili synthetisieren. Das Kompetenzprotein ComP aus Acinetobacter sp. BD413, welches möglicherweise verglichen zu den anderen Pilin-ähnlichen Proteinen ComB, -E und ComF in größerer Menge synthetisiert wird, könnte als strukturelle Komponente (Pilin) einen sehr kurzen, stabilen Pilus bilden, der die äußere Membran und die Lipopolysaccharidschicht durchspannt. ComB, -E und ComF müßten dann gegenüber ComP als Assemblierungsfaktoren wirken. Die Überexpression von ComP läßt den Pseudopilus dann zu einem Typ-IV-Pilus assemblieren.

\subsubsection{Assemblierung des Pilin-ähnlichen Kompetenzproteins C omP in Acinetobacter sp. B D413}

Acinetobacter sp. BD413 gehört zu derjenigen Gruppe der Organismen, deren Kompetenzproteine zwar Ä hnl ichkeiten zu den Komponenten der Typ-IV-Pilusbiogenese aufweisen, aber keine Typ-IV-Pilusstruktur synthetisiert. Weitere natürlich kompetente Bakterien ohne Typ-IV-Pili sind z.B. der Gram-negative Organismus Haemophilus influenzae und Gram-positiven Bakterien, wie der gut untersuchte Bacillus subtilis und Streptococcus pneumoniae. Bei diesen Bakterien wird möglicherweise eine kurze Pseudopi lusstruktur synthetisiert, die den periplasmatischen Raum durchspannt und DNAbindende Proteine exponiert oder mit seiner Deassemblierung einen Kanal durch die Mureinschicht schafft, wodurch der DNA-Strang geleitet werden kann. Daß die Pilinähnlichen Proteine für den Transport der DNA durch die Peptidoglycanschicht verantwortlich sind, zeigte die Regeneration der DNA-Aufnahme bei Bacillus subtilis: Nach enzymatischem A bbau des Mureins zeigten transformationsdefekte Stämme, die Mutationen in Pilin-ähnlichen Kompetenzgenen aufwiesen, eine Regeneration der DNAAufnahme (Provvedi \& Dubnau 1999). Durch Protoplastierung fand die DNA Zugang zur inneren Zellmembran und konnte daraufhin ins Cytoplasma transportiert werden. Die Funktion der Pilin-ähnlichen Proteine liegt vermutlich in der Exposition des DNAbindenden Proteins auf der Zelloberfläche und im nachfolgenden Import durch die Peptidoglycanschicht. In ähnlicher Weise stellt man sich den Proteinexport des Typ-IISekretionswegs vor, nur erfolgt hier der Transport des Exoenzyms ausschließlich nach 
außen. Durch Assemblierung der Typ-IV-Pilin-ähnlichen Komponenten wird vermutlich das Exoprotein durch das Periplasma und dieäußere Membran geleitet.

Mittels Gelfiltration konnte kürzlich bei Xanthomonas campestris ein Proteinkomplex als Bestandteil des Typ-II-Sekretionswegs identifiziert werden, der eine molekulare Masse > 669 kDa aufweist und das Typ-IV-Pilin-ähnliche Protein XpsG enthält (Hu et al. 2002). Eine Abbildung der Struktur und somit die Identifizierung eines Pseudopilus steht jedoch noch aus. Durch eine Mutation in XpsG, die zu einem Defekt in der Proteinsekretion und Komplexbildung führte, die Lokalisation von XpsG verglichen zum Wildtypallel nicht änderte, wurde ausgeschlossen, daß es sich bei dem identifizierten Komplex nur um membranständiges XpsG in Form von Vesikeln handelte.

Bei Acinetobacter sp. BD413 konnte in dieser A rbeit ebenso neben dem 240 kDaComP-Komplex, der gegenüber mil den Detergenzien stabil ist, ein größerer ComP-haltiger Proteinkomplex identifiziert werden (3.5.5), dessen genaue molekulare Masse und Zusammensetzung noch nicht untersucht wurde. Charakteristisch für beide Komplexe, aus Acinetobacter sp.BD3413 und Xanthomonas campestris, ist ihre Sensitivität gegenüber milden Detergenzien wie Dodecylmaltosid oder Triton X-100. Dieses Verhalten spricht gegen eine kurze Pilus-ähnliche Struktur im DNA-Aufnahmeapparat oder Typ-IISekretionssystem, da der eigentliche Typ-IV-Pilus gegenüber diesen milden Detergenzien stabil ist.

Was die Komponenten innerhalb der Zellhülle betrifft, so bestünde jedoch ein identischer Aufbau von DNA-Aufnahme- und Pilus-Biogenesesystem, wenn der Assemblierungsgrad und damit die Stabilität des Typ-IV-Pilus im Periplasma und an der äußeren Membran Unterschiede aufwiese: Während die strukturellen Untereinheiten im Periplasma mit der in der Cytoplasmamembran lokal isierten Assembl ierungsplattform möglicherweise nur locker assoziiert werden, könnten diese beim Durchtritt durch die Pore (das Sekretin) in der äußeren Membran eine strukturelle Orientierung erfahren, die dadurch Stabilität verleiht. Diese Hypothese wird durch bisherige Untersuchungen zur Biogenese des Pilus bestätigt: Bisher konnten keine Proteininteraktionen (außer durch chemisches 'Cross-Linking') nachgewiesen werden, welche die Pilusstruktur mit Komponenten der Assemblierungsmaschinerie der Cytoplasmamembran und des Periplasmas verbindet. Die für die Pilussynthese essentiellen Pilin-ähnlichen Proteine, die in den Zellmembranen und im Periplasma lokal isiert sind, konnten bisher nicht als basal lokal isierter Bestandteil der Pilusstruktur nachgewiesen werden. Weiterhin wurde PilC bei Neisseria gonorrhoeae als ein Assemblierungsfaktor charakterisiert, welcher mit der äußeren Membran cofraktioniert und für die Pilusassemblierung essentiell ist (RYLL et al. 1997, RUDEL et al. 1995). Fehlt PilC, so wird keine Pilusstruktur synthetisiert. Die Funktion von PilC als Assemblierungsfaktor an der äußeren Membran bekräftigt die Hypothese, daß die 
endgültige Assemblierung zu einem stabilen Filament nicht an der Cytoplasmamembran oder im Periplasma, sondern an der äußeren Membran erfolgt. Daß PilC aus Neisseria erst an der äußeren Membran wirkt, zeigten erfol greiche Komplementationen eines PilCDefekts mit gereinigtem, extrazellulär zugesetztem PilC-Protein (RuDEL et al. 1995). Die Hypothese einer Assemblierung zu einer stabilen Pilusstruktur erst an der äußeren Membran wird weiterhin durch die Beobachtung erhärtet, daß sich Typ-IV-Pili sensitiv gegenüber Scherkräften verhalten, wobei die Bruchstelle direkt an der Zelloberfläche liegt (HENRICHSEN 1975). Die essentielle Funktion der äußeren Zellmembran wird bei der Betrachtung Gram-positiver Organismen deutlich, da diese Gruppe von Bakterien keine Typ-IV-Pili ausbildet, was vermutlich auf das Fehlen der äußeren Membran zurückzưühren ist. Die Typ-IV-Pilin-ähnlichen Proteine des natürlich kompetenten Grampositiven Bacillus subtilis wurden im Cytoplasma und Periplasma detektiert, wobei auch hier keine stabile Pseudopilusstruktur nachgewiesen werden konnte. Die Ähnlichkeit der Transformationssysteme beider Gram-Typen läßst die Vermutung zu, daß auch bei natürlich kompetenten Gram-positiven Bakterien ein Triton X-100-labiler Komplex - aufgebaut aus Typ-IV-Pilin-ähnlichen Komponenten - existiert, wie er bei Xanthomonas campestris und Acinetobacter sp. BD413 detektiert wurde. Eine stabile Assoziation von Pilin-ähnlichen Proteinen, wie dies für ComP als Bestandteil eines $240 \mathrm{kDa}$ Komplexes gezeigt werden konnte, scheint dagegen an die Anwesenheit einer äußeren Membran gebunden zu sein.

Wenn die Synthese des aus PilQ-Untereinheiten aufgebauten Sekretins in der äußeren Membran, wodurch der Pilus tritt, fehlt, und die Retraktion des Pilus aufgrund eines PilT-Defektes inhibiert ist, so synthetisiert Neisseria gonorrhoeae Typ-IV-Pili in den periplasmatischen Raum (WolfGANG et al. 2000). Demgegenüber werden bei Anwesenheit von PilT in der pilQ-Mutante die Piline sofort abgebaut, so daß keine Pilusstruktur erscheint. Dies verdeutlicht, daß PilT bei Neisseria für die Deassemblierung und nachfol gende Protolyse und möglicherweise für die labile Assoziation der Piline im Periplasma verantwortlich ist.

Während bei Acinetobacter sp. BD413 nach der Solubilisierung von Zellmembranen mit einem milden Detergenz nur das stabile $240 \mathrm{kDa}$ ComP-Homomultimer nachzuweisen ist, welches möglicherweise den exponierten Teil des DNA-Aufnahmeapparates an der äußeren Membran darstelt und mit den stabilisierenden Faktoren ComC und ComQ in Kontakt steht, könnte der mit dem Deassemblierungsfaktor (ComT, bei Acinetobacter noch nicht identifiziert) assoziierte und somit labile basale (Pseudo-) Pilusbereich des Periplasmas nur in Abwesenheit von milden Detergenzien dargestellt werden. Das Vorliegen einer stabilen (Pseudo-) Pilusstruktur bereits im Periplasma bei einem gemeinsamen Pil(Com)T- und Pil(Com)Q-Defekt - wie es für Neisseria gonorrhoeae gezeigt wurde (WoLfGANG et al. 2000) -, muß demzufolge auf das Fehlen 
destabilisierender Komponenten zurückgeführt werden, die stabilisierende Faktoren in der äußeren Membran entbehrlich machen. Das Zusammenspiel zwischen den genannten stabilisierenden und destabilisierenden Faktoren zeigte sich weiterhin in einem Neisseria gonorrhoeae-Stamm, in dem neben PilT auch PilC defekt sind. Obwohl eine Mutation allein in pilC die Pilusbildung inhibierte, führte ein zusätzlicher Defekt in PilT zu einer Regeneration der Pilusbiogenese (WoLfGANG et al. 1998). Wie erwartet, erwiesen sich diese Pili hinsichtlich der Vermittlung der DNA-A ufnahme und 'Twitching Motility' als funktionslos, da vermutlich die PilT-vermittelte Retraktion über eine Destabilisierung der Pilusstruktur entfiel.

Für die Assemblierung der Pilin-ähnlichen Proteine im DNA-Aufnahmeapparat von Acinetobacter sp. BD413 kann zusammenfassend ein folgender Mechanismus postuliert werden: Die Pilin-ähnlichen Proteine ComB, -E und ComF sind im Periplasma locker assoziiert und ermöglichen ComP den Durchtritt durch die Peptidoglycanschicht in Form von Monomeren oder in labiler Assoziation. An der äußeren Membran erfolgt seine Assemblierung zu einer kurzen Pilusstruktur (240 kDa-Komplex), welche die äußere Membran und die Lipopolysaccharidschicht durchspannt. Kalkuliert man 12 ComPMonomere, die den 240 kDa-Komplex aufbauen, so müßte die Länge des potentiellen Pseudopilus eine Höhe von 8 bis maximal 10 nm einnehmen, was die Durchquerung der äußeren Membran und möglicherweise die der Lipopolysaccharidschicht erlaubt.

\subsubsection{ComE A vermittelt die Bindung der DNA auf der Zelloberfläche}

Das Kompetenzprotein ComEA aus Acinetobacter sp. BD413 konnte über Ähnlichkeitsvergleiche mit bereits untersuchten DNA-bindenden Proteinen anderer natürlich kompetenter Organismen identifiziert werden (3.3.1). Dieses Protein stellt eine essentielle Komponente des DNA-A ufnahmesystems in BD413 dar, da die Unterbrechung des Gens comEA zu einem vollständigen Transformationsdefekt führte (3.3.3). Während das Protein bei den Gram-negativen Organismen Neisseria gonorrhoeae, Neisseria meningitidis und Acinetobacter sp. BD413 ausschließlich aus den charakteristischen für die DNA-Bindung essentiellen 'Helix-turn-Helix'-Motiven aufgebaut ist (CHEN \& GotSCHLICH 2001), weist ComEA bei Gram-positiven Organismen (Bacillus subtilis) zusätlich eine N-terminale hydrophobe Domäne auf (PROVVEDI \& DUBNAU 1999). Für ComEA aus Bacillus subtilis konnte gezeigt werden, daß dieser $\mathrm{N}$-Terminus die Verankerung des Proteins in der Cytoplasmamembran vermittelt, die basische DNAbindende Domäne dagegen die Bindung der DNA auf der Zelloberfläche und den anschließenden Transport in den DNase resistenten Zustand erlaubt (PROVVEDI \& DUBNAU 1999). Hierfür sind neben ComEA die Pilin-ähnlichen Kompetenzproteine ComGC, -GD, GE und ComGG erforderlich, die sowohl in der cytoplasmatischen Membran als auch in 
der Peptidoglycanschicht lokalisiert sind. Vermutlich vermitteln die Pilin-ähnlichen Proteine den Transport des C-Terminus von ComEA durch die Peptidoglycanschicht (Chung \& Dubnau 1998, Provvedi \& Dubnau 1999). Diese Hypothese, daß die Pilinähnlichen Proteine jenseits der Cytoplasmamembran agieren, stimmt mit den Untersuchungen überein, die demonstrierten, daß nach der enzymatischen Lyse des Peptidoglycangerüsts von Bacillus subtilis die Pilin-ähnlichen Proteine nicht für die Transformation erforderlich sind (CHUNG et al. 1998). Die freie DNA kann nach Protoplastierung direkt von dem in der inneren Membran verankerten ComEA-Protein gebunden werden. Eine direkte Bindung von ComEA oder der DNA mit den Pilinähnlichen Proteinen konnte bisher jedoch noch nicht nachgewiesen werden. Hier scheint somit eine sehr labile Assoziation vorzul iegen, wie diese ebenso zwischen Exoprotein und Pilin-ähnliche Proteine des Typ-II-Sekretionssystems postuliert wird (RUSSEL 1998, Possot et al. 2000). Im Sekretionssystem stellen die Pilin-ähnlichen Proteine essentielle Komponenten für den Transport der Exoproteine durch den periplasmatischen Raum und die äußere Membran dar. Der Transport von Exoproteinen erfordert keine nachweisbare Bindung mit den Pilin-ähnlichen Proteine. Aufgrund der Verschiedenartigkeit der transportierten Proteine über dassel be Typ-II-Sekretionssystem eines Bakteriums konnte bisher keine Signalstruktur oder Erkennungsdomäne identifiziert werden, welche die Spezifikation als zu exportierendes Protein erlaubt. Beispielsweise werden in Pseudomonas aeruginosa die Enzyme, wie eine Lipase, Elastase, al kalische Phosphatase und das ADP-ribosylierende Toxin A, über densel ben Sekretionsweg transportiert (LAZDUNSKI et al. 1990). Für das Exoprotein PelB aus Erwinia chrysanthemi konnte jedoch eine Bindung mit dem äußeren Membranprotein OutD, welches das Sekretin bildet, nachgewiesen werden (SHEVCHIK et al. 1997). Diese Bindung erfolgt am N-Terminus von OutD, der den variablen, ins Periplasma ragenden Teil dieser Proteinfamilie darstellt und somit für die spezifische Proteinerkennung erforderlich ist. Dies läßt vermuten, daß die Spezifikation nicht durch die Pilin-ähnlichen Proteine sondern durch andere Faktoren, wie z. B. das Sekretin, vermittelt wird.

Die zu transportierenden Proteine werden über das Sec-System durch die Cytoplasmamembran geleitet, wobei das Signal peptid entfernt wird. Mit der Freisetzung ins Periplasma erfolgt daraufhin die Passage der Peptidoglycanschicht und die äußere Membran, an der die Pilin-ähnlichen Proteine beteiligt sind. Für ComEA wäre ein zu den Exoproteinen ähnlicher Transport denkbar, da das Protein eine Signal sequenz besittt und an der äußeren Membran agieren muß. In Anlehnung an das Typ-II-Sekretionssystem wäre wahrscheinlich, daß ComEA durch die variable, ins Periplasma ragende Domäne des ComQ-Proteins erkannt und gebunden wird und mittels ComP an die Zelloberfläche gelangt. Während aber die Exoproteine ins Medium entlassen werden oder assoziiert an der Zelloberfläche wirken, ist für das Transformationssystem anzunehmen, daß die DNA- 
bindenden Proteine - assoziiert mit doppelsträngiger DNA - zurück in den periplasmatischen Raum gelangen. Es wäre weiterhin vorstellbar, daß ComEA, nach der Bindung an DNA und durch gezielte nukleolytische Fragmentierung der DNA durch eine in BD413 noch nicht identifizierte Nuklease, in diesem Zustand eine Assoziation zu den Pilin-ähnlichen Proteinen eingeht und daraufhin durch Deassemblierung der Pilinähnlichen Proteine durch das ComQ-Sekretin und daraufhin durch die Peptidoglycanschicht an die Cytoplasmamembran gelangt. Diese Hypothese würde mit den Untersuchungen an Bacillus subti lis übereinstimmen, die demonstrieren, daß eine effektive DNA-Aufnahme nur nach gezielter Nuklease-Aktivität durch NucA auf der Zelloberfläche erfolgt (ProvVEDI et al. 2001). Dieses dadurch generierte DNA-Ende - gebunden an ComEA - könnte somit die gezielte Bindung an Pilin-ähnliche Proteine vermitteln.

Daß das Pilin-ähnliche Protein ComP aus Acinetobacter sp. BD413 indirekt an der Bindung von DNA auf der Zelloberfläche beteiligt ist, belegten Studien mit der Mutante T206, in der comP unterbrochen ist. Diese Mutante zeigte neben dem Defekt in der natürlichen Transformation eine beeinträchtigte Bindung der DNA auf der Zelloberfläche (PORSTENDÖRFER et al. 1997). Dies läßst sich vermutlich darauf zurückführen, daß ComP eine essentielle Funktion bei der Exposition von ComEA ausübt. Die unveränderte Lokalisation von ComEA in der Mutante T206 (3.4.5) ist damit zu erklären, daß zunächst die Pilin-ähnlichen Proteine ComB, -E und ComF den Transport durch den periplasmatischen Raum vermitteln, so daßs das DNA-bindende Protein bis zur äußeren Membran gelangt und eventuell an der ins Periplasma ragenden Domäne von ComQ bindet. Aufgrund der der äußeren Membran aufliegenden Lipopolysaccharide läßts dies die Vermutung zu, daß erst eine ComP-abhängige Exposition von ComEA die effektive DNABindung und daraufhin den Import vermittelt.

In Übereinstimmung mit dem Typ-IV-Pilusbiogenesesystem kann vermutet werden, daßs der ComP-haltige Komplex durch ComC stabilisiert wird und durch ein PilThomologes Protein (ComT) eine Retraktion erfährt, so daß ComEA mit der gebundenen DNA ins Periplasma gelangt.

\subsubsection{Das DNA-A ufnahmesystem in Acinetobacter sp. BD413}

Die aus den Untersuchungen dieser Arbeit gewonnenen Erkenntnisse und durch die Interpretation der Ergebnisse in Bezug zu vorangegangenen Studien läßt sich für den DNA-A ufnahmeapparat von Acinetobacter sp. BD413 ein folgendes Model postulieren (Abb. 4.1): 


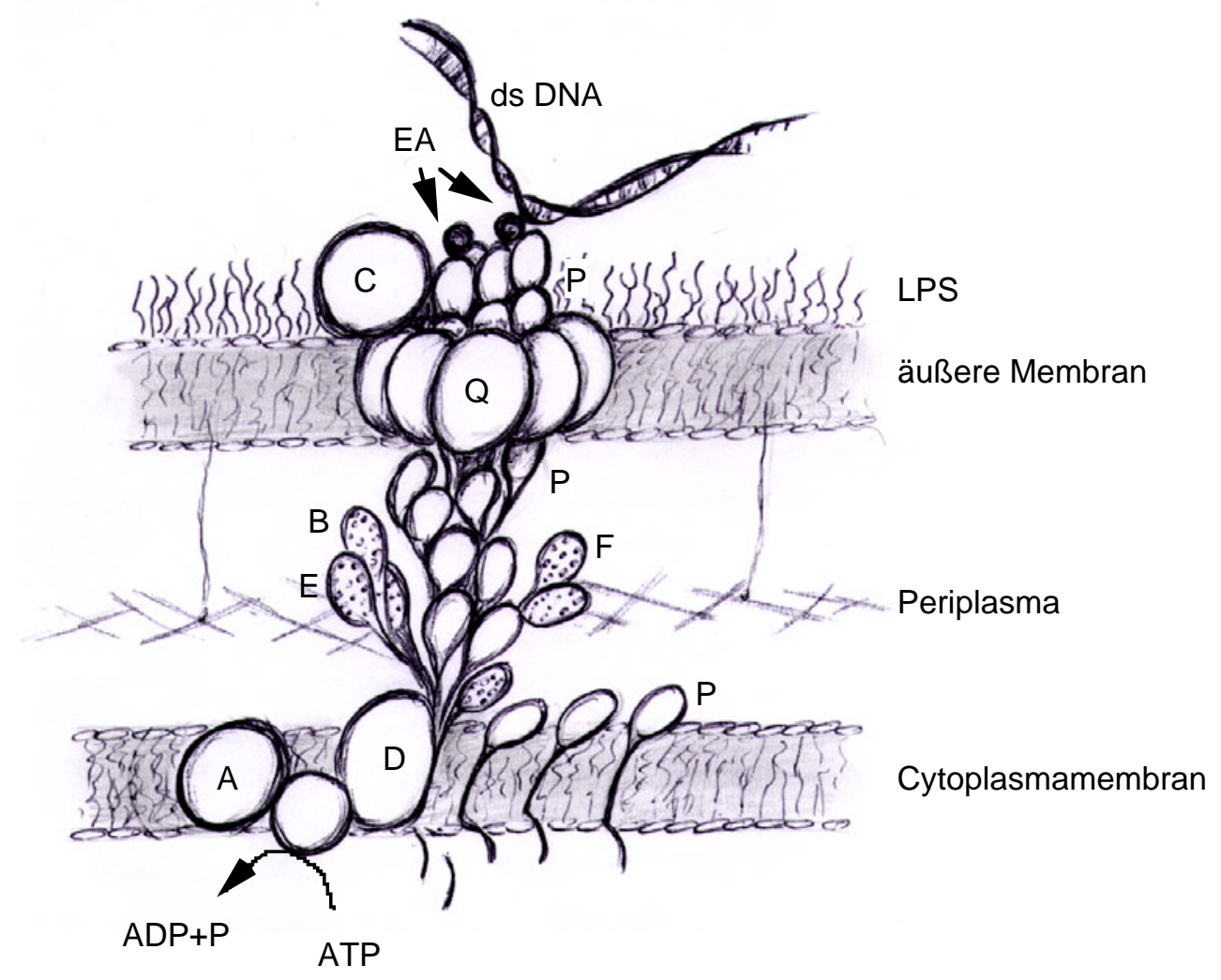

Abb. 4.1: Assemblierung des DNA-Aufnahmesystems in Acinetobacter sp. BD413. Die Pilin-ähnlichen Proteine ComB, -E, $-F$ und ComP werden durch die Präpilinpeptidase ComD an der Cytoplasmamembran prozessiert und ins Periplasma entlassen. Während ComB, -E und Comf als Assemblierungsfaktoren im Periplasma wirken, wird ComP am Sekretin ComQ mit Hilfe des Assemblierungsproteins ComC an der äußeren Membran zu einer kurzen stabilen Pilusstruktur assembliert. Hierdurch werden an der Spitze dieser Struktur die DNA-bindenden ComEA-Proteine exponiert. Über die nachfolgend $\epsilon$ Deassemblierung von ComP gelangt die gebundene DNA in den periplasmatischen Raum bis zur Cytoplasmamembran. Die mit Punkten versehenen, oval dargestellten Pilinähnlichen Proteine, dessen fädige Struktur den hydrophoben $\mathrm{N}$-Terminus symbolisiert, stellen ComB, -E und ComF dar. Die äquivalenten, nicht ausgefüllt dargestellten Komponenten symbolisieren ComP-Monomere.

Die Pilin-ähnlichen Proteine ComB, -E, -F und ComP werden zunächst durch die Präpilinpeptidase ComD (AverHoff pers. Mitteilung) an der Cytoplasmamembran prozessiert. Während ComB, -E und ComF sowie zunächst auch ComP in der inneren Membran und im Periplasma labil assoziiert agieren, erfolgt eine Assemblierung von ComP an dem aus ComQ-Untereinheiten aufgebauten Sekretin zu einer kurzen stabilen Pilusstruktur, die ca. 240 kDa aufweist, an der äußeren Membran. Der ebenso an der äußeren Membran oder an der Spitze des ComP-Pseudopilus lokalisierte Assemblierungsfaktor ComC dient der Stabilisierung dieser Struktur. In dieser Form dient ComP der Exposition des DNA-bindenden Proteins ComEA, was dazu führt, daß negative elektrostatische Wechsel wirkungen mit der Lipopolysaccharidschicht und die mechanische Barriere der Zellhülle überwunden werden und die DNA somit auf der Zelloberfläche 
gebunden werden kann. Nach endonukleolytischer Spaltung der gebundenen DNA nahe am ComEA-Protein erfolgt durch die Retraktion des ComP-Komplexes der Transport mit Hilfe der Pilin-ähnlichen Proteine durch das Periplasma. An der Cytoplasmamembran wird ein Strang der DNA hydrolysiert und der komplementäre Strang in einem ComAabhängigen Prozeß ins Cytopl asma transportiert.

\subsection{A usblick}

Im Vordergrund weiterer Arbeiten sollte die Untersuchung des Mechanismus der DNA-A ufnahme in Acinetobacter sp. BD413 stehen, indem das Zusammenspiel der Kompetenzproteine durch Interaktionsstudien weiter analysiert wird. Da sich das DNAbindende Protein ComEA erst nach erhöhter Expression mittels Antikörper detektieren ließ, so ist es naheliegend, daß auch die bisher in Zelllysaten nicht zu detektierenden Proteine ComA, $-B,-C,-E$ und ComF erst nach Klonierung der jeweiligen Genen hinter den stärkeren comP-Promotor markieren lassen. Dadurch bieten sich gute Aussichten mit den bereits generierten Antikörpern über Lokal isations- und Proteininteraktionsstudien die Funktionen der Kompetenzfaktoren aufzuklären. Wichtig erscheint hier nicht nur die Untersuchungen diesbezüglich im Wildtypstamm, sondern auch in den bisher generierten transformationsdefekten Stämmen. Durch Proteinlokal isationen in den Mutanten, die von denjenigen des Wildtypstamms abweichen, lassen sich indirekt Aussagen über interagierende Komponenten treffen.

Während Proteinwechselwirkungen über die schonende Solubilisierung der Kompetenzproteine aus den Zellmembranen verfolgt werden sollte, bieten auch molekularbiologische Techniken durch Klonierung kurzer, C-terminaler Adaptorproteine ('His-Tag' oder 'Strep-Tag'), die eine schonende Aufreinigung von Proteinen erlauben, eine weitere Möglichkeit assoziierte Faktoren nachzuweisen. Dies bietet weiterhin die Möglichkeit, neue, bisher nicht beschriebene Kompetenzproteine zu identifizieren.

Während sich die bisherigen Untersuchungen bei Acinetobacter vor allem mit der Bindung der DNA auf der Zelloberfläche und mit dem Transport durch die äußere Membran und das Periplasma beschäftigten, erlaubt die Charakterisierung des vermutlich in der Cytoplasmamembran lokal isierten Kompetenzproteins ComA die Möglichkeit, den Import durch die innere Membran zu verfolgen. Es wurde postuliert, daß ComA eine kanal artige Struktur ausbildet, welche eine Schleuse für den DNA-Import schafft. Da nur ein Einzelstrang ins Cytoplasma gel angt, muß hierbe eine Nuklease beteiligt sein, die den komplementären Strang hydrolysiert und deren Charakterisierung noch aussteht. Die Koppl ung von Einzel stranghydrolyse und DNA-Aufnahme durch die Cytoplasmamembran macht die Interaktion beider Komponenten wahrscheinlich. 
Interessante Ergebnisse versprechen darüber hinaus physiologische Studien der DNA-Bindung und -Aufnahme. So stellt sich beispielsweise die Frage, ob in Übereinstimmung mit dem Gram-positiven Organismus Bacillus subtilis auch bei Acinetobacter nach der enzymatischen Lyse der Peptidoglycanschicht die Pilin-ähnlichen Proteine für die DNA-A ufnahme entbehrlich sind. Sind daraufhin Proteoplasten in der Lage DNA zu binden und aufzunehmen? Als Positivkontrolle eines Transformationstests müßte hierbei der Wildtyp BD413 bzw. ADP239 und als Negativkontrolle die comAMutante T701 fungieren. Die unterschiedliche Verankerung des DNA-bindenden Proteins ComEA bei Gram-positiven und -negativen Bakterien, zum einen mit der Cytoplasmamembran und zum anderen mit der äußeren Membran, läßst eventuell auf einen voneinander abweichenden DNA-A ufnahmeprozeß schließen.

Während die Induktion der natürlichen Transformation mit der Synthese der Kompetenzproteine eingel eitet wird und daraufhin maximale Transformationsraten erzielt werden, erfolgen diese Prozesse bei Acinetobacter sp. BD413 bei unterschiedlichen Milieubedingungen. Die Kompetenzproteine werden zunächst in der stationären Wachstumsphase gebil det, damit das Bakterium nach dem Überimpfen in frisches Medium maximale Transformationsraten erzielen kann. Da die Messung der Transformationsraten nur die erfolgreiche homologe Rekombination der aufgenommenen DNA ins Genom widerspiegeln, ist dies kein direktes Maß für die Bindung und Aufnahme der DNA, die als von der homologen Rekombination getrennte Prozesse angesehen werden können. Somit stellt sich bei Acinetobacter sie Frage, ob die DNA erst unter den physiologischen Bedingungen der lag-Phase aufgenommen wird oder bereits in der stationären Phase, in der die Synthese der Kompetenzproteine am höchsten ist. Da in der stationären Phase eine Limitierung der Kohlenstoff- und Stickstoff-Quellen herrscht, ist es denkbar, daß die aufgenommene DNA als Energiequel le genutzt wird bevor eine homologe Rekombination erfolgen kann. Durch Untersuchung des Verbleibs der Atome der eventuell aufgenommenen DNA in der stationären Wachstumsphase könnten diese verschiedene Nutzung der DNA analysiert werden.

Die Ergebnisse aus den Untersuchungen der Pilusstrukturen von Acinetobacter sp. BD413 bieten Anknüpfungspunkte für weiterführende Arbeiten. Der neue Pilustyp des Bakteriums weist eine unter den filamentösen Strukturen einzigartige Flexibilität auf, was eine genauere Betrachtung der Untereinheitenstruktur interessant macht. Über Röntgenstrukturanalysen könnten die Wechsel wirkungen zwischen den Aminosäureresten identifiziert werden, die einerseits die Stabilität und andererseits die hohe Flexibilität verleihen. Die Untersuchung der fünf Biosynthesegene, die sich zusammen mit dem 
Strukturgen filA in einem Biosynthese-Cluster befinden, eröffnet die Charakterisierung eines neuen Biogenesewegs von Pilusstrukturen. Bisher sind mit der Flagel lum, der TypIV- und Typ-I-Pilusbiogenese erst drei Synthesewege von filamentösen Strukturen beschrieben, was die Analyse weiterer Biogenesemechanismen fordert.

Durch die Identifizierung der Pilusgene und nach Mutantenstudien stellte sich heraus, daß Acinetobacter sp. BD413 keine Typ-IV-Pili synthetisiert und sich Pilusunabhängig gleitend fortbewegt. Der Vergleich zu bereits charakterisierten Bewegungsarten von Bakteien lieferte keine Übereinstimmung. Dieses Ergebnis läßt die Vermutung zu, daß es sich beim Gleiten von Acinetobacter sp. BD413 um einen unbekannten Mechanismus handelt, dessen Charakterisierung noch aussteht. Durch Mutagenisierungen des Genoms ließen sich über generierte Mutanten, die Defekte in der gleitenden Fortbewegung aufweisen, spezifische Gene identifizieren. Da das Genom vom Stamm BD413 vollständig sequenziert vorliegt, ist ein anderer Weg die Betrachtung interessanter ORFs, die möglicherweise in die gleitende Fortbewegung involviert sind. 


\section{Z usammenfassung}

1. Acinetobacter sp. BD413 synthetisiert flexible dicke (6 nm im Durchmesser) und starre, bündelbildende dünne (2-3 nm im Durchmesser) Pilusstrukturen. Beide Pilustypen wurden isoliert und ihre strukturellen Untereinheiten gereinigt. Die Sequenzierung der N-Termini der Pilusuntereinheiten ermöglichte die Klonierung der Genemittels PCR.

2. Die Analyse des Gens filA der Untereinheit des dicken Pilus ergab keine Verwandtschaft zu bisher bekannten strukturellen Proteinen. DieCharakterisierung des Gens der Untereinheit des dünnen Pilus führte zu dem Ergebnis, daß dieser Pilustyp der Familie der Typ-I-Pili zuzuordnen ist.

3. Die dünnen Pili vermitteln die Adsorption an hydrophobe Oberflächen und vermögen Erythrocyten zu agglutinieren, eine Eigenschaft, die charakteristisch für Typ-I-Pili ist. Das Strukturgen fimA bildet das erste Gen eines aus insgesamt vier Genen aufgebauten Gencluster, dessen weitere drei Produkte Ähnlichkeiten zu periplasmatischen Chaperonen, äußeren Membranproteinen sowie zu Adhäsinen zeigen. Die FimAUntereinheiten sind in linearer Form angeordnet, dessen resultierendes Filament einen Durchmesser von 2-3 nm bildet und aufgrund seiner Hydrophobizität untereinander aggregieren, so daß Pilusbündel entstehen. Die FilA-Untereinheiten des flexiblen dicken Pilus bilden eine helikale Struktur aus, wobei die Steighöhe der Helix von 4 $5 \mathrm{~nm}$ bis hin zu $10 \mathrm{~nm}$ variiert.

4. Die Strukturgene der beiden Pilustypen von BD413 werden transkriptional reguliert, wobei das Minimum beim exponentiellen Wachstum und das Maximum in der stationären Phase erreicht wird.

5. Nach der Unterbrechung der Gene filA und fimA, die für die Untereinheit des dicken bzw. des dünnen Pilus codieren, ergaben Mutantenstudien, daß keiner der beiden Filamenttypen an der natürlichen Transformation beteiligt ist. Ebenso sind die Pili nicht essentiell für diegleitende Bewegung der Bakterien auf festen Oberflächen. 
6. Das Genom von Acinetobacter sp. BD413 codiert für eine PHB-Synthase (PhaC). Die Unterbrechung dieses Gens führte zu einer Mutante, die keine PHB-Granula synthetisiert. Durch einen Transformationstest konnte gezeigt werden, daß PHB kein essentieller Bestandteil des DNA-Aufnahmeapparates ist.

7. Die Überexpression des Typ-IV-Pilin-ähnlichen Kompetenzproteins ComP in Acinetobacter sp. BD413 führt zur Synthese einer Pilusstruktur, die den Typ-IV-Pili ähnelt.

8. Das Pilin-ähnliche Kompetenzprotein ComP liegt in den Zellmembranen als ein durch milde Detergenzien solubilisierbares $240 \mathrm{kDaHomomultimer} \mathrm{vor,} \mathrm{der} \mathrm{somit} \mathrm{einen}$ Subkomplex des DNA-A ufnahmeapparates darstellt.

9. Das Kompetenzprotein ComEA, welches im prozessierten Zustand eine molekulare Masse von 7,6 kDa aufweist und für die natürliche Transformation von Acinetobacter sp. BD413 eine essentielle Komponente darstellt, ist in der äußeren Zellmembran lokalisiert und vermittelt dort die Bindung von doppelsträngiger DNA. Die DNABindung erfol gt dabei unabhängig von der Basensequenz.

10. Hinsichtlich der Regulation auf Ebene der Transkription verhält sich comEA identisch zu den bereits untersuchten Kompetenzproteinen in Acinetobacter sp. BD413: In der stationären Wachstumsphase erreicht die Transkriptionsrate ihr Maximum, fällt nach dem Überimpfen in frisches Medium auf ein Minimum, um am Ende des exponentiellen Wachstums wieder anzusteigen. Mittels generiertem Anti-ComEAAntiserum konnte das native ComEA in BD413 erst nach der erhöhten Expression durch den comP-Promotor detektiert werden, was auf einen sehr geringen ComEAGehalt in der Zellehinweist. 


\section{L iteratur}

Abbanat DR, Godchaux W 3rd, Polychroniou G, Leadbetter ER. Biosynthesis of a sulfonolipid in gliding bacteria. Biochem. Biophys. Res. Commun. $1985 \mathrm{~J} \mathrm{ul}$ $31 ; 130(2): 873-878$

Agarwal S, Hunnicutt DW, MCBride MJ. Cloning and characterization of the Flavobacteriumjohnsoniae (Cytophaga johnsoniae) gliding motility gene, gldA. Proc. Natt. Acad. Sci. USA. 1997 Oct 28;94(22):12139-12144

Alloing G, Martin B, Granadel C, Claverys J P. Development of competence in Streptococcus pneumoniae: pheromone autoinduction and control of quorum sensing by the oligopeptide permease. Mol. Microbiol. 1998 29:75-83

Alm RA, hallinan JP, Watson AA, Mattick J S. Fimbrial biogenesis genes of Pseudomonas aeruginosa: pilW and pilX increase the similarity of type 4 fimbriae to the GSP protein-secretion systems and pilY1 encodes a gonococcal PilC homologue. Mol. Microbiol. 1996 Oct;22(1):161-173

Anderson AJ , DAwes EA. Occurrence, metabolism, metabolic role, and industrial uses of bacterial polyhydroxyalkanoates. Microbiol. Rev. 1990 Dec;54(4):450-472.

Ausubel FM, Brent R, Kingston Re, Moore DD, Seidmann J G, Smith JA, StruHL K. Current protocols in molecular biology. Green Publishing Associates and John Wiley \& Sons, Inc. 1993, New Y ork.

BaChm ANn BJ . Linkage map of Escherichia coli K12. Edition 8. Microbiol. Rev. 1990 54:130-197

Beachey EH, Giampapa C S, Abraham SN. Bacterial adherence. Adhesin receptormediated attachment of pathogenic bacteria to mucosal surfaces. Am. Rev. Respir. Dis. 1988 Dec;138(6 Pt 2):S45-48

Behn W, Arnold CG. Die Wirkung von Streptomycin und Neamin auf die Chloroplasten- und Mitochondrienstruktur von Chlamydomonas reinhardii. Protoplasma 1974 82:77-89 
Belsky I, Gutnick DL, Rosenberg E. Emulsifier of Arthrobacter RAG-1: determination of emulsifier-bound fatty acids. FEBS Letters 1979 101:175-178

Biswas GD, Sox T, Blackman E, Sparling PF. Factors affecting genetic transformation of Neisseria gonorrhoeae. J. Bacteriol. 1977 Feb;129(2):983-992

BL UM H B, G Ross HJ . Improved silver staining method of plant proteins, RNA and DNA in polyacrylamide gels. Electrophoresis 1987 8:93-99

Bortolussi R, FerRIERI P, Q UIE PG. Influence of growth temperature of Escherichia coli on $\mathrm{K} 1$ capsular antigen production and resistance to opsonization. Infect. Immun. 1983 Mar;39(3):1136-1141

B OUCHE JP. The effect of spermidine on endonuclease inhibition by agarose contaminants. Anal. Biochem 1981 J ul 15;115(1):42-45

BRADFORD M M. A rapid and sensitive method for the quantitation of microgram quantities of protein utilizing the principle of protein-dye binding. Anal. Biochem. 1976 72:248-254

BRADLEY DE. A function of Pseudomonas aeruginosa PAO polar pili: twitching motility. Can. J. Microbiol. 1980 Feb;26(2):146-154

Brubake R R R. Factors promoting acute and chronic diseases caused by yersiniae. Clin. Microbiol Rev. 1991 Jul;4(3):309-324

Busch S, R osenplanter C, Averhoff B. Identification and characterization of ComE and ComF, two novel pilin-like competence factors involved in natural transformation of Acinetobacter sp. strain BD413. Appl. Environ. Microbiol. 1999 Oct;65(10):4568-4574

Campbell EA, Chol SY, Masure HR. A competence regulon in Streptococcus pneumoniae reveal ed by genomic analysis. Mol. Microbiol. 1998 27:929-939

CHANDLER MS. The gene encoding cyclic AMP receptor protein is required for competence development in Haemophilus influenzae Rd. Proc. Natt. Acad. Sci. USA 1992 89:1626-1630 
Chen I, G отsChlich E C. ComE, a competence protein from Neisseriagonorrhoeae with DNA-binding activity. J. Bacteriol. 2001 183(10):3160-3168

Chung Y S, Breidt F, Dubnau D. Cell surface localization and processing of the ComG proteins, required for DNA binding during transformation of Bacillus subtilis. Mol Microbiol. 1998 Aug;29(3):905-913

C hUNG YS, DubnaU D. All seven comG open reading frames are required for DNA binding during transformation of competent Bacillus subtilis. J. Bacteriol. 1998 Jan;180(1):41-5

Clifton SW, McCarthy D, Roe BA. Sequence of the rec-2 locus of Haemophilus influenzae: homologies to comE-ORF3 of Bacillus subtilis and msbA of Escherichia coli. Gene 1994 Aug 19;146(1):95-100

Clos J, Brandau S. pJ C20 and pJ C40--two high-copy-number vectors for T7 RNA polymerase-dependent expression of recombinant genes in Escherichia coli. Protein Expr. Purif. 1994 Apr;5(2):133-137

Cornibert J, Marchessault RH. Physical properties of poly- $\square$-hydroxybutyrate IV. Conformational analysis and crystalline structure. J. Mol. Biol. 1972 Nov 28;71(3):735-756

DAwEs EA, SENIOR PJ. The role and regulation of energy reserve polymers in microorganisms. Adv. Microb. Physiol. 1973;10:135-266

de Graff FK, KlaAsen-Boor P, van Hees J E. Biosynthesis of the K99 surfaceantigen is repressed by alanine Infect. Immun. 1980 Oct;30(1):125-128

DE G RAAF FK. Genetics of adhesive fimbriae of intestinal Escherichia coli. Curr. Top. Microbiol. Immunol. 1990;151:29-53

De Weger LA, van der Vlugt Ci, Wijfjes Ah, Bakker Pa, Schippers B, L UGTENBeR G B. Flagella of a plant-growth-stimulating Pseudomonas fluorescens strain are required for colonization of potato roots. J. Bacteriol. 1987 Jun;169(6):2769-2773 
Deich RA, Smith H O. Mechanism of homospecific DNA uptake in Haemophilus influenzae transformation. Mol Gen Genet. 1980 Feb;177(3):369-374

Dewanti R, Wong AC. Influence of culture conditions on biofilm formation by Escherichia coli O157:H7. Int J. Food. Microbiol. 1995 J ul;26(2):147-164

Doig P, Todd T, Sastry PA, Lee KK, Hodges RS, Paranchych W, Irvin RT. Role of pili in adhesion of Pseudomonas aeruginosa to human respiratory epithelial cells. Infect. Immun. 1988 J un;56(6):1641-1646

DOUGHERTY BA, SMITH HO. I dentification of Haemophilus influenzae Rd transformation genes using cassette mutagenesis. Microbiology. 1999 Feb;145 ( Pt 2):401-409

Drake SL, Sandstedt SA, Koomey M. PilP, a pilus biogenesis lipoprotein in Neisseria gonorrhoeae, affects expression of PilQ as a high-molecular-mass multimer. Mol. Microbiol. 1997 Feb;23(4):657-668

Dubnau D, CiRigliano C. Fate of transforming deoxyribonucleic acid after uptake by competent Bacillus subtilis: nonrequirement of deoxyribonucleic acid replication for uptake and integration of transforming deoxyribonucleic acid. J. Bacteriol. 1973 Mar;113(3):1512-1514

Dubnau D, CiRigliano C. Fate of transforming DNA following uptake by competent Bacillus subtilis. VI. Non-covalent association of donor and recipient DNA. Mol. Gen. Genet. 1973 J an 24;120(2):101-106

Dubnau D, Davidoff-Abelson R, Scher B, Cirigliano C. Fate of transforming deoxyribonucleic acid after uptake by competent Bacillus subtilis: phenotypic characterization of radiation-sensitive recombination-deficient mutants. J. Bacteriol. 1973 Apr;114(1):273-286

Dubnau D. Genetic competence in Bacillus subtilis. Microbiol. Rev. 1991 Sep;55(3):395424

Dubnau D. The regulation of genetic competence in Bacillus subtilis. Mol. Microbiol. 1991 Jan;5(1):11-18 
Echenique JR, Chapuy-Regaud S, Trombe M-C. Competence regulation by oxygen in Streptococcus pneumoniae: involvement of ciaRH and comCDE. Mol. Microbiol. 2000 36(3):688-696

EChenique J R, Chapuy-Regaud S, Trombe MC. Competence regulation by oxygen in Streptococcus pneumoniae: involvement of ciaRH and comCDE. Mol. Microbiol. 2000 May;36(3):688-696

Edman P, Be GG G. A protein sequenator. Eur. J. Biochem 1967 Mar; 1(1):80-91

Facius D, Fussenegger M, Meyer TF. Sequential action of factors involved in natural competence for transformation of Neisseriagonorrhoeae. FEMS Microbiol. Lett. 1996 Apr 1;137(2-3):159-164

FACius D, Meyer TF. A novel determinant (comA) essential for natural transformation competence in Neisseria gonorrhoeae and the effect of a comA defect on pilin variation. Mol. Microbiol. 1993 Nov; 10(4):699-712

Fernandez LA, Berenguer J. Secretion and assembly of regular surface structures in Gram-negative bacteria. FEMS Microbiol. Rev. 2000 J an;24(1):21-44

Filloux A, Bally M, Ball G, Akrim M, Tommassen J, Lazdunski A. Protein secretion in gram-negative bacteria: transport across the outer membrane involves common mechanisms in different bacteria. EMBO J. 1990 Dec;9(13):4323-4329

Filloux A, Michel G, Bally M. GSP-dependent protein secretion in gram-negative bacteria: the Xcp system of Pseudomonas aeruginosa. FEMS Microbiol. Rev. 1998 Sep;22(3):177-198

Finkel SE, KolteR R. DNA as a nutrient: novel role for bacterial competence gene homologs. J. Bacteriol. 2001 Nov;183(21):6288-6293

Forest KT, TAINeR J A. Type-4 pilus-structure: outside to inside and top to bottom-a minireview. Gene. 1997 Jun 11;192(1):165-169

Freese A, Reichenbach H, Lunsdorf H. Further characterization and in situ localization of chain-like aggregates of the gliding bacteria Myxococcus fulvus and Myxococcus xanthus. J. Bacteriol. $1997 \mathrm{Feb} ; 179(4): 1246-1252$. 
Friedrich A, Hartsch T, Averhoff B. Natural transformation in mesophilic and thermophilic bacteria: identification and characterization of novel, closely related competence genes in Acinetobacter sp. strain BD413 and Thermus thermophilus HB27. Appl. Environ. Microbiol. 2001 J ul;67(7):3140-3148

Genevaux P, M uller S, Bauda P. A rapid screening procedure to identify mini-Tn10 insertion mutants of Escherichia coli K-12 with altered adhesion properties. FEMS Microbiol. Lett. 1996 Aug 15;142(1):27-30

GIAM m ARINARo P, SICARd M, Gasc AM. Genetic and physiological studies of the CiaHCiaR two-component signal-transducing system involved in cefotaxime resistence and competence of Streptococcus pneumoniae. Microbiology 1999 145:1859-1869

GODCHAUX W 3RD, GORSKI L, LeADBetTeR ER. Outer membrane polysaccharide deficiency in two nongliding mutants of Cytophaga johnsonae. J. Bacteriol. 1990 Mar;172(3):1250-1255

G оHL 0. Der DNA-Aufnahmeapparat in Acinetobacter sp. BD413: Identifizierung, Anreicherung und Untersuchung zur Membranverankerung. Diplomarbeit GeorgAugust-Universität Göttingen, 1999 unveröffentlicht

G OODGAL SH. DNA uptake in Haemophilus transformation. Annu. Rev. Genet. 1982;16:169-192

G OODMAN SD, ScocCA JJ. Identification and arrangement of the DNA sequence recognized in specific transformation of Neisseria gonorrhoeae. Proc. Natl. Acad. Sci. USA. 1988 Sep;85(18):6982-6986

G ORANSSON M, UHLIN BE. Environmental temperature regulates transcription of a virulence pili operon in E. coli. EMBO J. 1984 Dec 1;3(12):2885-2888

GREGG-J OLLY LA, ORnSt ON LN. Properties of Acinetobacter calcoaceticus recA and its contribution to intracellular gene conversion. Mol. Microbiol. 1994 J un;12(6):985992

GrinIUS L. Nucleic acid transport driven by ion gradient across cell membrane. FEBS Lett. 1980 Apr 21;113(1):1-10 
Hacker J, Bender L, Ott M, Wingender J, Lund B, Marre R, Goebel W. Deletions of chromosomal regions coding for fimbriae and hemolysins occur in vitro and in vivo in various extraintestinal Escherichia coli isolates. Microb. Pathog. 1990 Mar;8(3):213-225

H ACKe R J , K APER J B. Pathogenicity islands and the evolution of microbes. Annu. Rev. Microbiol. 2000;54:641-679

Hahn J, Inamine G, Kozlov Y, Dubnau D. Characterization of come, a late competence operon of Bacillus subtilis required for the binding and uptake of transforming DNA. Mol. Microbiol. 1993 Oct;10(1):99-111

HAHN J , K ONG L, DUBNAU D. The regulation of competence transcription factor synthesis constitutes a critical control point in the regulation of competence in Bacillus subtilis. J. Bacteriol. 1994 Sep;176(18):5753-5761

Hanah AN D. Studies on transformation of Escherichia coli with plasmids. J. Mol. Biol. 1983 J un 5;166(4):557-580

H ANC OCK RE, NıK AIDo H. Outer membranes of gram-negative bacteria. XIX. Isolation from Pseudomonas aeruginosa PAO1 and use in reconstitution and definition of the permeability barrier. J. Bacteriol. 1987 139:381-390

hartnett GB, Averhoff B, Ornston LN. Selection of Acinetobacter calcoaceticus mutants deficient in the $p$-hydroxybenzoate hydroxylase gene (pobA), a member of a supraoperonic cluster. J Bacteriol. 1990 Oct;172(10):6160-6161

Havarstein L S, Coomaraswam y G, M OrR Ison DA. An unmodified heptadecapeptide pheromone induces competence for genetic transformation in Streptococcus pneumoniae. Proc Natl Acad Sci USA. 1995 Nov 21;92(24):11140-1114

HENRICHSEN J , BLOM J . EXamination of fimbriation of some gram-negative rods with and without twitching and gliding motility. Acta. Pathol. Microbiol. Scand. [B]. 1975 Jun;83(3):161-170

Herrington Da, hall RH, Losonsky G, Mekalanos JJ, Taylor RK, Levine $\mathbf{M} \mathbf{M}$. Toxin, toxin-coregulated pili, and the toxR regulon are essential for Vibrio cholerae pathogenesis in humans. J. Exp. Med. 1988 Oct 1;168(4):1487-1492 
Herriott RM, Meyer em, Vogt M. Defined nongrowth media for stage II development of competence in Haemophilus influenzae. J. Bacteriol. 1970 Feb; 101(2):517-524

Herzberg C, Friedrich A, Averhoff B. comB, a novel competence gene required for natural transformation of Acinetobacter sp. BD413: identification, characterization, and analysis of growth-phase-dependent regulation. Arch. Microbiol. 2000 Mar;173(3):220-228

Hidaka Y, Hasegawa M, Nakahara T, Hoshino T. Theentire population of Thermus thermophilus cells is al ways competent at any growth phase. Biosci. Biotechnol. Biochem 1994 Jul;58(7):1338-1339

Hоввs M, M ATtICK J S. Common components in the assembly of type 4 fimbriae, DNA transfer systems, filamentous phage and protein-secretion apparatus: a general system for the formation of surface-associated protein complexes. Mol. Microbiol. 1993 Oct; 10(2):233-243

HofREUte R D, HAAS R. Natural transformation in Helicobacter pylori: DNA transport in an unexpected way. Trends Microbiol. 2002 A pr;10(4):162

Hofreuter D, Odenbreit S, HaAs R. Natural transformation competence in Helicobacter pylori is mediated by the basic components of a type IV secretion system. Mol. Microbiol. 2001 Jul;41(2):379-391

Holmgren A, Kuehn MJ, Branden Cl, Hultgren SJ . Conserved immunoglobulinlike features in a family of periplasmic pilus chaperones in bacteria. EMBO J. 1992 Apr;11(4):1617-1622

Hu NT, Leu WM, Lee MS, Chen A, Chen SC, Song YL, Chen LY. XpsG, the major pseudopilin in Xanthomonas campestris pv. campestris, forms a pilus-like structure between cytoplasmic and outer membranes. Biochem. J. 2002 Jul 1;365(Pt 1):205211

Hück CJ . Type III protein secretion systems in bacterial pathogens of animals and plants. Microbiol. Mol. Biol. Rev. 1998 Jun;62(2):379-433 
Hull RA, Gill RE, Hsu P, Minshew BH, Falkow S. Construction and expression of recombinant plasmids encoding type 1 or D-mannose-resistant pili from a urinary tract infection Escherichia coli isolate. Infect. Immun. 1981 Sep;33(3):933-938

H UNG DL, Hultgren SJ. Pilus biogenesis via the chaperone/usher pathway: an integration of structure and function. J. Struct. Biol. 1998 Dec 15;124(2-3):201-220

HunNiCUtT DW, MCBRIDE MJ . Cloning and characterization of the Flavobacterium johnsoniae gliding-motility genes gldB and gldC. J. Bacteriol. 2000 Feb;182(4):911918

InAm Ine G S, Dubnau D. ComEA, a Bacillus subtilis integral membrane protein required for genetic transformation, is needed for both DNA binding and transport. J Bacteriol. 1995 J un;177(11):3045-3051

Inoue H, Noj ima H, Okayama H. High efficiency transformation of Escherichia coli with plasmids. Gene 1990 Nov 30;96(1):23-28

Jennings MP, Virji M, Evans D, Foster V, Srikhanta YN, Steeghs L, van der LEY P, M OXON ER . Identification of a novel gene involved in pilin glycosylation in Neisseria meningitidis. Mol. Microbiol. 1998 Aug;29(4):975-984

Jones Ch, Pinkner J S, Roth R, Heuser J , Nicholes AV, Abraham SN, Hultgren SJ. FimH adhesin of type 1 pili is assembled into a fibrillar tip structure in the Enterobacteriaceae Proc. Natl. Acad. Sci. USA. 1995 Mar 14;92(6):2081-2085

J ONe S C H, Pink ne R J S, R отн R. FimH adhesin of type 1 pili is assembled into a fibrillar tip structure in the Enterobacteriaceae Proc. Natl. Acad. Sci. USA 1995; 92:20815

J ONES GW, RICHARDSON LA. The attachment to, and invasion of Hela cells by Salmonella typhimurium the contribution of mannose-sensitive and mannoseresistant haemagglutinating activities. J. Gen. Microbiol. 1981 Dec;127 (Pt 2):361370

J Onsson AB, Nyberg G, Normark S. Phase variation of gonococcal pili by frameshift mutation in pilC, a novel gene for pilus assembly. EMBO J . 1991 Feb;10(2):477-488 
J UNI E , J A NIK A. Transformation of Acinetobacter calcoaceticus (Bacteriumanitratum). J . Bacteriol. 1969 Apr;98(1):281-288

J UNI E. Genetics and physiology of Acinetobacter. Annu. Rev. Microbiol. 1978;32:349371

J UNI E . Interspecies transformation of Acinetobacter: genetic evidence for a ubiquitous genus. J. Bacteriol. 1972 Nov;112(2):917-931

Keen NT, Tamaki S, Kobayashi D, Trollinger D. Improved broad-host-range plasmids for DNA cloning in gram-negative bacteria. Gene. 1988 Oct 15;70(1):191197

Keizer DW, Slupsky CM, Kalisiak M, Campbell AP, Crump MP, Sastry Pa, HAZE S B, IR VIN RT, Sy Kes BD. Structure of a pilin monomer from Pseudomonas aeruginosa: implications for the assembly of pili. J. Biol. Chem. 2001 Jun 29;276(26):24186-24193

KEM PF MJ , M CBRIDE MJ . Transposon insertions in the Flavobacterium johnsoniaeftsX gene disrupt gliding motility and cell division. J . Bacteriol. 2000 Mar;182(6):16711679

KNIGHT SD, Berglund J , Choudhury D. Bacterial adhesins: structural studies reveal chaperone function and pilus biogenesis. Curr. Opin. Chem. Biol. 2000 Dec;4(6):653-660

Kubori T, Matsushima Y, Nakamura D, Uralil J, Lara-Tejero M, Sukhan A, G AL AN J E . Supramolecular structure of the Salmonella typhimuriumtype III protein secretion system. Science 1998 Apr 24;280(5363):602-605

Kühn MJ, Ogg DJ , Kihlberg J, Slonim L N, Flemmer K, Bergfors T, Hultgren SJ . Structural basis of pilus subunit recognition by the PapD chaperone. Science. 1993 Nov 19;262(5137):1234-1241

K USIAN B, BowIEN B. Operator binding of the CbbR protein, which activates the duplicate $\mathrm{cbb} \mathrm{CO}_{2}$ assimilation operons of Alcaligenes eutrophus. J. Bacteriol. 1995 Nov;177(22):6568-6574 
LAEMMLI UK. Cleavage of structural proteins during the assembly of the head of bacteriophage T4. Nature. 1970 Aug 15;227(259):680-685

LaI E M, KADo Cl. The T-pilus of Agrobacterium tumefaciens. Trends Microbiol. 2000 Aug;8(8):361-369

Lazdunski A, Guzzo J, Filloux A, Bally M, Murgier M. Secretion of extracellular proteins by Pseudomonas aeruginosa. Biochimie 1990 Feb-Mar;72(2-3):147-56

Link C, Eickernjager S, Porstendörfer D, Averhoff B. Identification and characterization of a novel competence gene, comC, required for DNA binding and uptake in Acinetobacter sp. strain BD413. J. Bacteriol. 1998 Mar; 180(6):1592-1595

L INK C. Charakterisierung von Komponenten des natürlichen Transformationssystems in Acinetobacter sp. BD413. Diplomarbeit Georg-August-Universität Göttingen, 1997 unveröffentlicht

Lintermans P, Pohl P, Deboeck F, Bertels A, Schlicker C, Vandekerckhove J, Van Damme J, Van Montagu M, De Greve H. Isolation and nucleotide sequence of the F17-A gene encoding the structural protein of the F17 fimbriae in bovine enterotoxigenic Escherichia coli. Infect. Immun. 1988 J un;56(6):1475-1484

Liu H, Kang Y, Genin S, Schell MA, Denny TP. Twitching motility of Ralstonia solanacearum requires a type IV pilus system. Microbiology. 2001 Dec;147(Pt 12):3215-3229

Long CD, hayes Sf, van Putten JP, harvey ha, Apicella Ma, Seifert hS. Modulation of gonococcal piliation by regulatable transcription of pilE. J. Bacteriol. 2001 Mar;183(5):1600-1609

L OOMIS WP, M OSELEY SL. Translational control of mRNA processing in the F1845 fimbrial operon of Escherichia coli. Mol. Microbiol. 1998 Nov;30(4):843-853

LoRenz M G, Reipschlager K, W ACKe RnAGeL W. Plasmid transformation of naturally competent Acinetobacter calcoaceticus in non-sterile soil extract and groundwater. Arch. Microbiol. 1992;157(4):355-360 
L OREnz MG, WAckernagel W. Bacterial gene transfer by natural genetic transformation in the environment. Microbiol. Rev. 1994 Sep;58(3):563-602

L ORY S. Secretion of proteins and assembly of bacterial surface organelles: shared pathways of extracellular protein targeting. Curr. Opin. Microbiol. 1998 Feb; 1(1):2735

Lund B, Marklund Bi, Stromberg N, Lindberg F, Karlsson KA, Normark S. Uropathogenic Escherichia coli can express serologically identical pili of different receptor binding specificities. Mol. Microbiol. 1988 Mar;2(2):255-263

L UNSDORF H, SCHAIRE R HU. Frozen motion of gliding bacteria outlines inherent features of the motility apparatus. Microbiology. 2001 A pr; 147(Pt 4):939-947

Macfadyen LP, Ma C, Redfield RJ . A 3',5' cyclic AMP (CAMP) phosphodiesterase modulates CAMP levels and optimizes competence in Haemphilus influenzae Rd. J . Bacteriol. 1998 Sep;180(17):4401-4405

Macfadyen LP, Ma C, Redfield RJ . A 3', 5' cyclic AMP (CAMP) phosphodiesterase modulates CAMP levels and optimizes competence in Haemphilus influenzae Rd. J . Bacteriol. 1998 180:4401-4405

Magnuson R, Solomon J , G R OSSM An AD. Biochemical and genetic characterization of a competence pheromone from Bacillus subtilis. Cell. 1994 Apr 22;77(2):207-216

Marceau M, Forest K, Berett J L, Tainer J , Nassif X. Consequences of the loss of O-linked glycosylation of meningococcal type IV pilin on piliation and pilusmediated adhesion. Mol. Microbiol. 1998 Feb;27(4):705-715

M AR CEAU M, NASSIF X. Role of glycosylation at Ser63 in production of soluble pilin in pathogenic Neisseria. J . Bacteriol. 1999 Jan; 181(2):656-661

Marchessault RH, Monasterios CJ, Morin FG, Sundararajan PR. Chiral poly(beta-hydroxyalkanoates): an adaptable helix influenced by the alkane sidechain. Int J . Biol. Macromol. 1990 Apr;12(2):158-165

Martoglio B, Dobberstein B. Signal sequences: more than just greasy peptides. Trends Cell. Biol. 1998 Oct;8(10):410-415 
Maurelli AT, Blackm On B, CuRtiss R 3RD. Temperature dependent expression of virulence genes in Shigella species. Infect. Immun. 1984 J an;43(1):195-201

MCBRIDE MJ . Bacterial gliding motility: multiple mechanisms for cell movement over surfaces. Annu. Rev. Microbiol. 2001;55:49-75

Merz AJ, So M, Sheetz MP. Pilus retraction powers bacterial twitching motility. Nature 2000 Sep 7;407(6800):98-102

MESSING J, VIEIRA J. A new pair of M13 vectors for selecting either DNA strand of doubledigest restriction fragments. 1982. Biotechnology. 1992;24:202-209

Miller J H. Assay of G-galactosidase. In: PlatT T, Miller-Hill B, Miller JH (Hrsg.): Experiments in molecular genetics, S. 319-353. 1972 Cold Spring Harbor Laboratory, Cold Spring Harbor, N.Y ., USA

Morand PC, Tattevin P, Eugene E, Beretti J L, Nassif X. The adhesive property of the type IV pilus-associated component PilC1 of pathogenic Neisseria is supported by the conformational structure of the $\mathrm{N}$-terminal part of the molecule. Mol. Microbiol. 2001 May;40(4):846-856

Nassif X, Beretti J L, Lowy J, Stenberg P, O'Gaora P, Pfeifer J, Normark S, So M. Roles of pilin and PilC in adhesion of Neisseriamenigitidis to human epithelial and endothelial cells. Proc. Natl. Acad. Sci. USA. 1994 A pr 26;91(9):3769-3773

Nowicki B, Svanborg-E den C, Hull R, Hull S. Molecular analysis and epidemiology of the Dr hemagglutinin of uropathogenic Escherichia coli. Infect. Immun. 1989 Feb;57(2):446-451

Ornston L N, Stanier RY. The conversion of catechol and protocatechuate to betaketoadi pate by Pseudomonas putida. J. Biol. Chem. 1966 Aug 25;241(16):3776-3786

O'Toole G, Kaplan HB, Kolter R. Biofilm formation as microbial development. Annu. Rev. Microbiol. 2000;54:49-79

Ott M, Schmoll T, Goebel W, Van Die I, Hacker J. Comparison of the genetic determinant coding for the S-fimbrial adhesin (sfa) of Escherichia coli to other 
chromosomally encoded fimbrial determinants. Infect. Immun. 1987 Aug;55(8):1940-1943

PAGE WJ, VON TIGERSTROM M. Induction of transformation competence in Azotobacter vinelandii iron-limited cultures. Can. J. Microbiol. 1978 Dec;24(12):1590-1594

Palmen R, Hellingwerf KJ . Uptake and processing of DNA by Acinetobacter calcoaceticus-a review. Gene. 1997 J un 11;192(1):179-190

Palmen R, Vosman B, Buijsman P, Breek CK, Hellingwerf KJ. Physiological characterization of natural transformation in Acinetobacter calcoaceticus. J. Gen. Microbiol. 1993 Feb;139 ( Pt 2):295-305

Parge he, forest KT, Hickey MJ, Christensen DA, Getzoff Ed, tainer JA. Structure of the fibreforming protein pilin at 2.6 A resolution. Nature. $1995 \mathrm{Nov}$ 2;378(6552):32-38

PatTe R SON SD. From electrophoretical ly separated protein to identification: strategies for sequence and mass analysis. Anal. Biochem 1994 Aug 15;221(1):1-15

Peferoen M, Huybrechts R, De Loof A. Vacuum blotting: a new simpleand efficient transfer of proteins from sodium dodecylsul fate polyacrylamid gels to nitrocellulose FEBS Lett. 1982 145:369-372

Pestova EV, havarstein LS, Morrison DA. Regulation of competence for genetic transformation in Streptococcus pneumoniae by an auto-induced peptide pheromone and a two-component regulatory system Mol. Microbiol. 1996 Aug;21(4):853-862

Pestova E V, Morrison DA. Isolation and characterization of three Streptococcus pneumniae transformation-specific loci by use of a lac Z reporter insertion vector. J . Bacteriol. 1998 May;180(10):2701-2710

Porstendörfer D, Gohl 0, Mayer F, Averhoff B. ComP, a pilin-like protein essential for natural competence in Acinetobacter sp. Strain BD413: regulation, modification, and cellular localization. J. Bacteriol. 2000 J ul;182(13):3673-3680 
Por Ste ndöRFER D. Isolierung, Charakterisierung und Funktionsanalyse von ComP, einer essentiellen Komponente des natürlichen Transformationssystems in Acinetobacter sp. BD413. Dissertation Georg-August-Universität Göttingen, 1998 unveröffentlicht

Possot OM, Vignon G, Bomchil N, Ebel F, Pugsley AP. Multiple interactions between pullulanase secreton components involved in stabilization and cytoplasmic membrane association of PulE. J. Bacteriol. 2000 A pr; 182(8):2142-2152

Pratt LA, Kolter R. Genetic analysis of Escherichia coli biofilm formation: roles of flagella, motility, chemotaxis and type I pili. Mol. Microbiol. 1998 Oct;30(2):285293

Provvedi R, Chen I, Dubnau D. NucA is required for DNA cleavage during transformation of Bacillus subtilis. Mol. Microbiol. 2001 May;40(3):634-644

Provvedi R, Dubnau D. ComEA is a DNA receptor for transformation of competent Bacillus subtilis. Mol. Microbiol. 1999 Jan;31(1):271-280

Puyet A, Greenberg B, Lacks SA. Genetic and structural characterization of endA. A membrane-bound nuclease required for transformation of Streptococcus pneumniae. J. Mol. Biol. 1990 J un 20;213(4):727-738

Rahman M, Kallstrom H, Normark S, J onsson AB. PilC of pathogenic Neisseriais associated with the bacterial cell surface. Mol. Microbiol. 1997 J ul;25(1):11-25

Reusch R N, Huang H, Bramble LL. Poly-ß-hydroxybutyrate/Polyphosphate complexes form voltage-activated $\mathrm{Ca}^{2+}$ channels in the plasma membranes of Escherichia coli. Biophys. J. 1995 69:754-766

Re USCH R N, Hiske T, SAdoff H. Poly-ß-hydroxybutyrate membrane structure and its relationship to genetic transformability in Escherichia coli. J. Bacteriol. 1986 168:553-562

REUSCH RN, SAdOFF HL. D-(-)-poly-ß-hydroxybutyrate in membranes of genetically competent bacteria. J. Bacteriol. 1983 Nov;156(2):778-788

REUSCH RN, SADOFF HL, D-(-)-poly-ß-hydroxybutyrate in membranes of genetically competent bacteria. J. Bacteriol. 1983 156:778-788 
REUSCH RN, SAdoff HL. Putative structure and function of a poly-ßhydroxybutyrate/calcium polyphosphate channel in bacterial plasma membranes. Proc. Natt. Acad. Sci. 1988 USA. 85:4176-4180

Riegman N, Kusters R, Van Veggel H, Bergmans H, Van Bergen en Henegoumen P, Hacker J, Van Die I. FIC fimbriae of a uropathogenic Escherichia coli strain: genetic and functional organization of the foc gene cluster and identification of minor subunits. J. Bacteriol. 1990 Feb;172(2):1114-1120

Rosenberg E, Zuckerberg A, Rubinowitz h Gutnick DL. Emulsifier of Arthrobacter RAG-1: isolation and emulsifying properties. Appl. Env. Microbiol. 1979 37:402-408

Rosenberg E, Zuckerberg A, Rubinowitz H, Gutnick DL. Emulsifier of Arthrobacter RAG-1: isolation and emulsifying properties. Appl. Env. Microbiol. 1979 37:402-408

Rosenberg M, Perry A, Bayer EA, Gutnick DL, Rosenberg E, Ofek I. Adherence of Acinetobacter cal coaceticus RAG-1 to human epithelial cells and to hexadecane. Infect Immun. 1981 Jul;33(1):29-33

R OSENBER G M. Bacterial adherence to polystyrene: a replica method of screening for bacterial hydrophobicity. Appl. Environ. Microbiol. 1981 Aug;42(2):375-377

Rudel T, Boxberger HJ, Meyer TF. Pilus biogenesis and epithelial cell adherence of Neisseria gonorrhoeae pilC double knock-out mutants. Mol. Microbiol. 1995 Sep;17(6):1057-1071

Rudel T, Facius D, Barten R, Scheuerpflug I, Nonnenmacher E, Meyer tF. Role of pili and the phase-variable PilC protein in natural competence for transformation of Neisseria gonorrhoeae. Proc. Natl. Acad. Sci. USA. 1995a Aug 15;92(17): 7986-7990

Rudel T, Scheurerpflug I, Meyer Tf. Neisseria PilC protein identified as type-4 pilus tip-located adhesin. Nature. 1995b J an 26;373(6512):357-359 
R USSE L M. Macromolecular assembly and secretion across the bacterial cell envelope: type II protein secretion systems. J. Mol. Biol. 1998 J un 12;279(3):485-499

R ussell PW, Orndorf PE . Lesions in two Escherichia coli type 1 pilus genes alter pilus number and length without affecting receptor binding. J. Bacteriol. 1992 Sep;174(18):5923-5935

Ryll RR, Rudel T, Scheuerpflug I, Barten R, Meyer Tf. PilC of Neisseria meningitidis is involved in class II pilus formation and restores pilus assembly, natural transformation competence and adherence to epithelial cells in PilC-deficient gonococci. Mol. Microbiol. 1997 Mar;23(5):879-892

SAMBR OOK J , FritsCh EF, MANIATIS T. Molecular cloning: a laboratory manual (2nd ed.) 1989. Cold Spring Harbor, New Y ork

SAndKVISt M, Bagdasarian M, How ARd SP, DiR ITA VJ. Interaction between the autokinase EpsE and EpsL in the cytoplasmic membrane is required for extracellular secretion in Vibrio cholerae EMBO J . 1995 Apr 18;14(8):1664-1673

Sauvonnet N, Vignon G, Pugsley AP, Gounon P. Pilus formation and protein secretion by the same machinery in Escherichia coli. EMBO J. 2000 May 15;19(10):2221-2228

SCHÄGGER H, VON JAGOW G. Blue native electrophoresis for isolation of membrane protein complexes in enzymatically active form Anal. Biochem 1991 199:223-231

SChembri MA, Bayly RC, DAVies JK. Cloning and analysis of the polyhydroxyalkanoic acid synthase gene from an Acinetobacter sp.: evidence that the gene is both plasmid and chromosomal ly located. FEMS Microbiol. Lett. 1994 May 1;118(1-2):145-152

SChembri MA, BAyLy R C, DAvies J K. Phosphate concentration regulates transcription of the Acinetobacter polyhydroxyalkanoic acid biosynthetic genes. J. Bacteriol. 1995a Aug;177(15):4501-4507

SCHEMbri MA, WOOdS AA, BAyLY RC, DAVIES J K. Identification of a 13-kDa protein associated with the polyhydroxyalkanoic acid granules from Acinetobacter spp. FEMS Microbiol. Lett. 1995 Nov 15;133(3):277-283 
Scheuerplug I, Rudel T, Ryll R, Pandit J, Meyer Tf. Roles of PilC and Pile proteins in pilus-mediated adherence of Neisseria gonorrhoeae and Neisseria menigitidis to human erythrocytes and endothelial and epithelial cells. Infect. I mmun. 1999 Feb;67(2):834-843

Sekiya K, Ohishi M, Ogino T, Tamano K, Sasakawa C, Abe A. Supermolecular structure of the enteropathogenic Escherichia coli type III secretion system and its direct interaction with the EspA-sheath-like structure. Proc. Natl. Acad. Sci. USA 2001 Sep 25;98(20):11638-11643

Semmler AB, Whitchurch CB, Mattick J S. A reexamination of twitching motility in Pseudomonas aeruginosa. Microbiology. 1999 Oct; 145 ( Pt 10):2863-2873

Shevchik Ve, Robert-Baudouy J, Condem ine G. Specific interaction between OutD, an Erwinia chrysanthemi outer membrane protein of the general secretory pathway, and secreted proteins. EMBO J. 1997 J un 2;16(11):3007-3016

Soto GE, Hultgren SJ . Bacterial adhesins: common themes and variations in architecture and assembly. J. Bacteriol. 1999 Feb;181(4):1059-1071

SOUTHE RN E M. Detection of specific sequences among DNA fragments separated by gel electrophoresis. J. Mol. Biol. 1975 Nov 5;98(3):503-517

SPURR A. A low-viscosity epoxy resin embedding medium for electron microscopy. J. Ultrastruct. Res. 1969 26:31-43

Strom MS, Lory S. Structurefunction and biogenesis of the type IV pili. Annu. Rev. Microbiol. 1993;47:565-596

Strom M S, Nunn DN, Lory S. A single bifunctional enzyme, PilD, catalyzes cleavage and $\mathrm{N}$-methylation of proteins belonging to the type IV pilin family. Proc. Natl. Acad. Sci. USA. 1993 Mar 15;90(6):2404-2408

StUdie R FW, M OfFatt BA. Use of bacteriophageT7 RNA polymerase to direct selective high-level expression of cloned genes. J. Mol. Biol. 1986 May 5;189(1):113-130 
Tamano K, Aizawa S, Katayama E, Nonaka T, Imajoh-Ohmi S, Kuwae A, Nagai S, Sasakawa C. Supramolecular structure of the Shigella type III secretion machinery: the needle part is changeable in length and essential for delivery of effectors. EMBO J . 2000 Aug 1; 19(15):3876-3887

Taylor R, Shaw C, Peterson K, Spears P, Mekalanos J . Safe, live Vibrio cholerae vaccines? Vaccine. 1988 A pr;6(2):151-154

Tennent J M, Lindberg F, Normark S. Integrity of Escherichia coli P pili during biogenesis: properties and role of PapJ . Mol. Microbiol. 1990 May;4(5):747-758

Thelin KH, Taylor RK. Toxin-coregulated pilus, but not mannose-sensitive hemagglutinin, is required for colonization by Vibrio cholerae O1 El Tor biotype and O139 strains. Infect. Immun. 1996 J ul;64(7):2853-2856

Tom Asz A. Model for the mechanism controlling the expression of competent state in Pneumococcus cultures. J. Bacteriol. 1966 Mar;91(3):1050-1061

Tом в J F, EL-HaJJ H, Sм iтн HO. Nucleotide sequence of a cluster of genes involved in the transformation of Haemophilus influenzae Rd. Gene. 1991 J ul 31;104(1):1-10

T о м в J F . A periplasmic protein disulfide oxidoreductase is required for transformation of Haemophilus influenzae Rd. Proc. Natl. Acad. Sci. USA. 1992 Nov 1;89(21):1025210256

Trombe MC, Clave C, M anias J M. Calcium regulation of growth and differentiation in Streptococcus pneumoniae. J. Gen. Microbiol. 1992 J an;138 (Pt 1):77-84

Trom BE M C. Characterization of a calcium porter of Streptococcus pneumoniae involved in calcium regulation of growth and competence. J. Gen. Microbiol. 1993 Mar;139 (Pt 3):433-439

Tschech A, Pfennig N. Growth yield increase linked to caffeate reduction in Acetobacteriumwoodii. Arch. Microbiol. 1984 137:163-167

Turner LR, LARA J C, Nunn DN, Lory S. Mutations in the consensus ATP-binding sites of $\mathrm{XcpR}$ and PilB eliminate extracellular protein secretion and pilus biogenesis in Pseudomonas aeruginosa. J. Bacteriol. 1993 Aug;175(16):4962-4969 
Vallet I, Olson JW, Lory S, Lazdunski A, Filloux A. The chaperon/usher pathways of Pseudomonas aeruginosa: Identification of fimbrial gene cluster (cup) and their invol vement in biofilm formation. PANS 2001 98(12):6911-6916

Vosman B, Hellingwerf KJ. Molecular cloning and functional characterization of a recA analog from Pseudomonas stutzeri and construction of a $\mathrm{P}$. stutzeri recA mutant. Antonie Van Leeuwenhoek. 1991 Feb;59(2):115-123

V OSMAN B, K OK R, HellingwerF KJ. Random insertional mutagenesis in Acinetobacter. In: Towner KJ, Bergogne-BérézIN E, Fewson CA (eds.). The Biology of Acinetobacter. Taxonomy, Clinical Importance, Molecular Biology, Physiology, Industrial Relevance 1991 New Y ork: PlenumPress

Watnick PI, Fullner KJ, Kolter R. A rolefor the mannose-sensitive hemagglutinin in biofilm formation by Vibrio cholerae El Tor. J. Bacteriol. 1999 J un;181(11):36063609

Weber K, Osborn M. The reliability of molecular weight determinations by dodecyl sulfate-polyacrylamide gel electrophoresis. J. Biol. Chem. 1969 Aug 25;244(16):4406-4412

White-Ziegler CA, Villapakkam A, Ronaszeki K, Young S. H-NS controls pap and daa fimbrial transcription in Escherichia coli in response to multiple environmental cues. J. Bacteriol. 2000 Nov;182(22):6391-6400

Wise e M J R, Alexander SP, Powers M. Adenosine 3':5'-cyclic monophosphate as a regulator of bacterial transformation. Proc. Natl. Acad. Sci. USA. 1973 Feb; 70(2):471-474

Wolfgang M, Lauer P, Park hS, Brossay L, Hebert J, Koomey M. PilT mutations lead to simultaneous defects in competence for natural transformation and twitching motility in piliated Neisseriagonorrhoeae. Mol. Microbiol. 1998a Jul;29(1):321-330

Wolfgang M, Park HS, Hayes SF, van Putten J P, Koomey M. Suppression of an absolute defect in type IV pilus biogenesis by loss-of-function mutations in pilT, a twitching motility gene in Neisseria gonorrhoeae. Proc. Natl. Acad. Sci. USA. 1998 Dec 8;95(25):14973-14978 
Wolfgang M, van Putten JP, Hayes SF, Dorward D, Koomey M. Components and dynamics of fiber formation define a ubiquitous biogenesis pathway for bacterial pili. EMBO J. 2000 Dec 1;19(23):6408-6418. 


\section{Danksagung}

Besonderer Dank gilt Frau Priv.Doz. Dr. BeateA verhoff für die Überlassung des Themas, die stetige Hilfs- und Diskussionsbereitschaft, den motivierenden Optimismus, für die Möglichkeit der Teilnahme an zahl reichen Tagungen und besonders für die Bereitschaft der Betreuung aus München zum Ende meiner Arbeit.

Herm Prof. Dr. Gottschalk möchte ich herzlich für die Ermöglichung eines sel bständigen wissenschaftlichen Arbeitens und für sein Interesse am Fortgang der Arbeit sowie für die Mögl ichkeit zur Fertigstel lung meiner Arbeit in Göttingen danken.

Allen ehemaligen und derzeitigen Mitgliedern im Labor 255 möchte ich für das hervorragende Arbeitsklima danken. Besonders erwähnt seien hierbei Christina Herzberg mit ihrer Hilfsbereitschaft und ihrem Fachwissen, meine Transformations-Mitstreiter Alexandra Friedrich mit den täglichen erheiternden Erlebnisberichten und der Organi sation schöner Aufenthalte in München sowie Christine Rosenplänter, die immer ein offenes Ohr für meine Proteine hatte. Besonders möchte ich Christiane Scherp für ihr soziales Engagement danken, womit sie immer mit Rat und Tat zur Seite stand.

Danken möchte ich weiterhin Birgit Veith, Doris Schmidt und Volker Held, die das Labor 255 zum Ende meiner Arbeit mit neuem Leben füllten, und besonders Dr. Armin Ehrenreich für die erleichternde Gewi Sheit, daß jedes Computerproblem zu bewältigen ist.

Besonderer Dank gilt ebenfalls der elektronenmikroskopischen A bteilung von Prof. Dr. F. Mayer und den immer hilfsbereiten Mitarbeitern Dr. Michael Hoppert, Carolin Wichmann, Jan Hegermann und Inge Kornrumpf; ohne sie wäre ein Großteil dieser Arbeit nicht möglich gewesen.

Herrn M. Hellwig danke ich für die Bereitstellung verschiedenster Utensilien (KluyverKolben !), seinen Hilfestellungen bei der Praktikumsbetreuung und den immer guten Tee (mit oder ohne Verdünnung).

Dank gilt auch dem Werkstatt-Team aus dem Keller, Gerd Birke, 'Charlie` Bertram und J ürgen Steckel, für die Bewältigung nicht-biologischer Probleme, wobei sie vor keiner Reparaturmaßsnahme oder technischen Neukonstruktionen zurückschreckten. 
Besonders danken möchte ich Carsten Raasch, der mir während der gesamten Zeit immer mit Rat und Tat zur Seite stand, für die lustigen KAZ-A bende, die Gesel Ischschaft bei so manchem Mensa-Essen und für die entspannenden sonnigen Tage am Baggersee sowie für das Korrekturlesen.

Allen Institutsangehörigen, die mir mit Tips oder sonstiger Unterstützung zum Gelingen dieser Arbeit beigetragen haben, sei hiermit ebenfalls gedankt.

Meinen Eltern möchte ich herzlichst für die Ermöglichung des Studiums und für die Fürsorge und Unterstützung danken, sowie meinem Bruder für die Fahrdienste zwischen Goslar und Göttingen.

Ebenso herzlich danke ich Dirk Porstendörfer für sein Verständnis, den Ratschlägen und seinem Interesse an der Arbeit und für die gesamte schöne Zeit. 


\section{Lebenslauf}

14. Dezember 1971

August 1978

September 1982

September 1984

Juni 1991

August 1991-J uni 1994

Juni 1994

Oktober 1994

Oktober 1996

Juli 1998

August 1998-September 1999

Oktober 1999
Geboren in Goslar

Einschul ung in die Grundschule Sudmerberg

Beginn der Orientierungsstufe an der Schule „Bei der Eiche“ in Oker

Wechsel an das Ratsgymnasiumin Goslar

Abitur

Lehre zur Damenschneiderin (im Handwerk) an der Beruffachschule Textil und Kehmstedtstiftung in Goslar

Gesel lenprüfung zur Damenschneiderin

Immatrikulation an der Georg-August-Universität Göttingen für das Studienfach Biologie (Diplom)

Vordiplom in den Fächern Mikrobiologie, Botanik, Anorganische Chemie und Physikal ische Chemie

Mündliche Diplomprüfung in den Fächern Mikrobiologie, Biochemie und Organische Chemie

Experimentelle Diplomarbeit unter der Leitung von Prof. Dr. G. Gottschalk am Institut für Mikrobiologie der Universität Göttingen mit dem Thema „Der DNAAufnahmeapparat in Acinetobacter sp. BD413: Identifizierung, Anreicherung und Untersuchung zur Membranverankerung."

Beginn der experimentel len Arbeiten zur vorliegenden Dissertation 